ORNL/Sub--87-SA581/1

DE92 041382

\title{
DEVELOPMENT OF WEAR-RESISTANT CERAMIC COATINGS FOR DIESEL ENGINE COMPONENTS
}

\section{VOLUME 1: COATING DEVELOPMENT AND TRIBOLOGICAL TESTING}

\author{
M. G. S. Naylor
}

Date Published: June 1992

\section{FINALREPORT}

Prepared by

Cummins Engine Company, Inc.

P.O. Box 3005

Columbus, Indiana 47202

Under Subcontract 86X-SA581C

Prepared for the

U.S. Department of Energy

Assistant Secretary for Conservation and Renewable Energy

Office of Transportation Materials

Office of Transportation Technologies

EE 5101000

Prepared by the

OAK RIDGE NATIONAL LABORATORY

Oak Ridge, Tennessee 37831-6285

managed by

MARTIN MARIETTA ENERGY SYSTEMS, INC.

for the

US. DEPARTMENT OF ENERGY

under contract DE-AC05-84OR21400 
Table of Contents

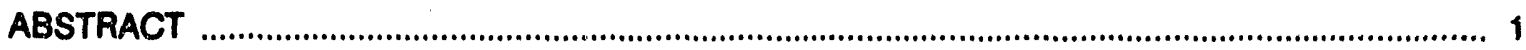

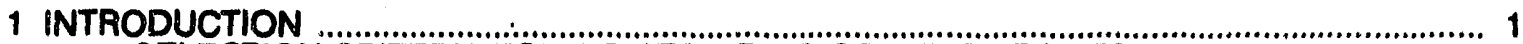

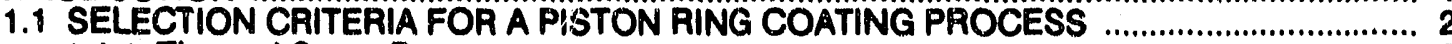

1.1.1 Thermal Spray Processes ............................................................................................... 3

1.1.1.1 Plasma Arc Coating …….................................................................................... 3

1.1.1.2 High Velocity Oxy-Fuel Coating ........................................................................ 5

1.1.2 Diffusion Alloying ..................................................................................................... 6

1.1.3 Physical Vapor Depostion (PVD) ……................................................................... 7

1.1.4 The Kaman Sclence Slurry-Dipped Silica-Chromia-Alumina Process ......................... 9

1.1.5 Dlamond-Like Coatings ................................................................................................. 9

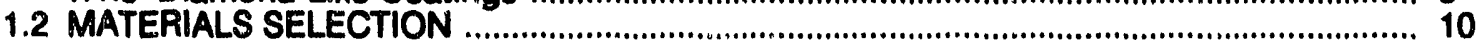

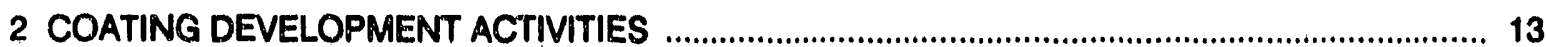

2.1 COATING DEVELOPMENT AT APS MATERIALS INCORPORATED ……........................ 15

2.1.1 Chromium Oxide-Based Coatings .................................................................... 15

2.1.2 Tungsten Carbide - Cobalt Coatings …............................................................................. 22

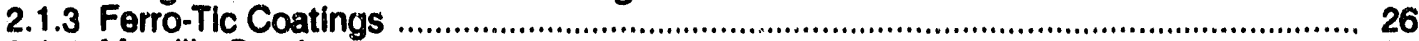

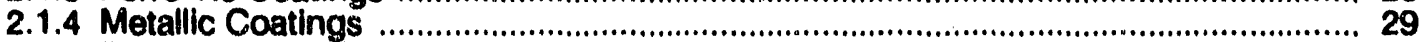

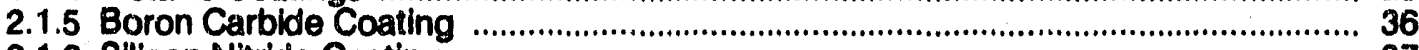

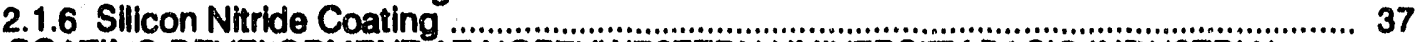

2.2 COATING DEVELOPMENT AT NORTHWESTERN UNIVERSITY BASIC INDUSTRIAL

RESEARCH LABORATORY

2.2.2 Chromium Oxide and Chromium Oxide-Aluminum Oxide Coating

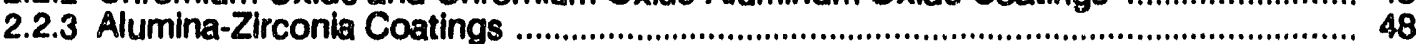

2.2.4 Laser Processed Alumina-Zirconla Coatings …................................................ 55

2.3 COATING DEVELOPMENT AT BOYD MACHINE AND REPAIR CÖMPANY, INC. ............ 59

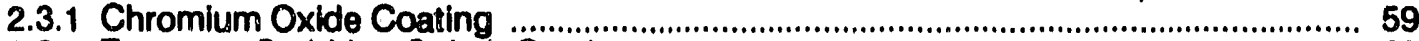

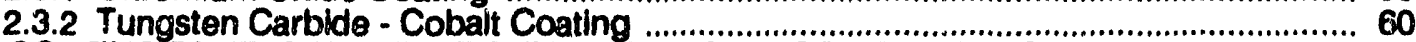

2.4 COATING DEVEL.OPMENT AT CUMMINS ENGINE COMPANY, INC ............................... 61

2.5 COATING DEVELOPMENT AT IMPLANT SCIENCES CORPORATION ……......................6...6. 63

2.6 COATING DEVELOPMENT AT TURBINE METAL TECHNOLOGY INCORPORATED ........ 65

2.6.1 Chromium Carblde - Nichrome Coating …............................................................6. 65

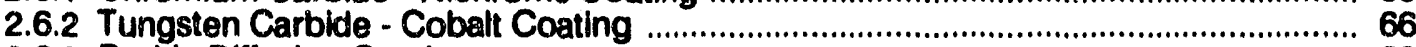

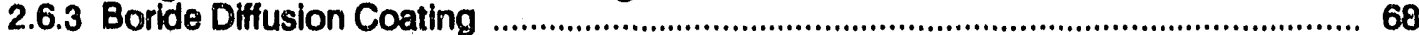

2.7 COATING DEVELOPMENT AT UNITED TECHNOLOGIES RESEARCH CENTER (UTRC)

2.7.1 Chromium Carbide - Nichrome Coating

2.7.2 Zlrconia-Titania-Yttrla Coating .................................................................................. 72

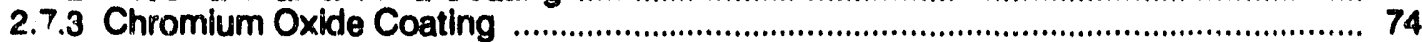

2.7.4 Nicket-Chromium-Boron-Silicon Coating ............................................................... 75

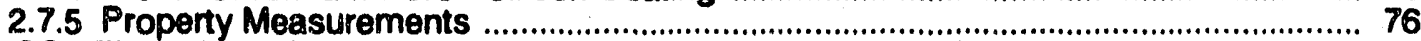

2.8 COATING DEVELOPMENT AT VAPOA TECHNOLLOGIES INCOORPORATED ................... 83

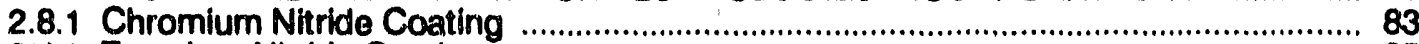

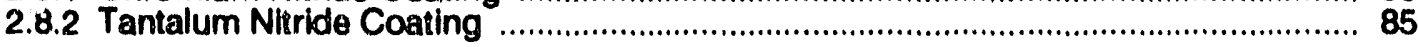

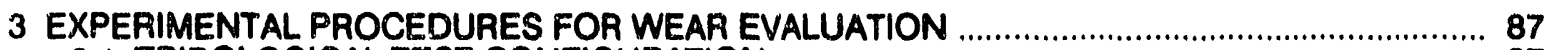

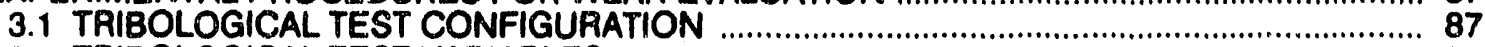

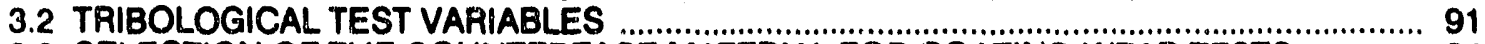

3.3 SELECTION OF THE COUNTERFACE MATERIAL FOR COOATING WEAR TESTS ............. 94

3.4 WEAR MEASUREMENT ERRORS AND TEST REPEATABILITY …................................... 96

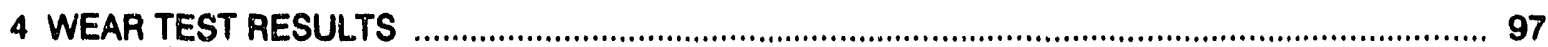

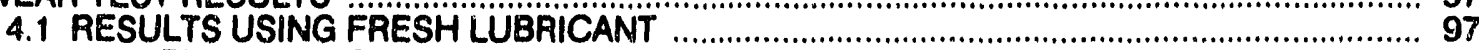

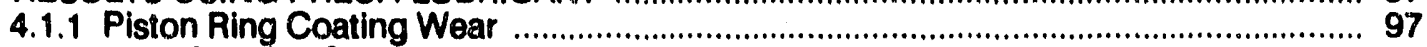

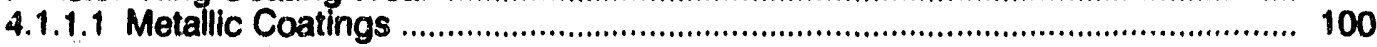




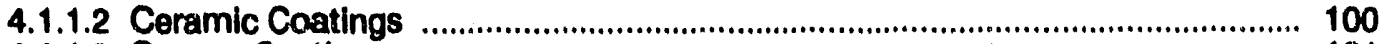

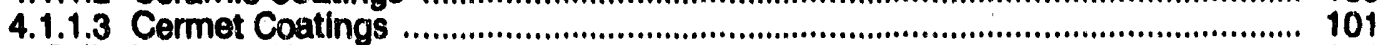

4.1.2 Gylinder Liner Wear .................................................................................. 101

4.1.3 Friction Coefficients .................................................................................. 104

4.1.4 High Temperature Wear Tests With A Synthetic Lubricant ......................................... 106

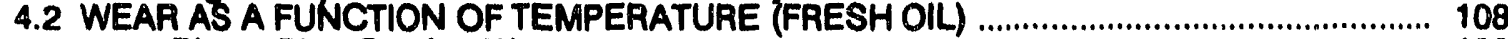

4.2.1 Piston Ring Coating Woar ........................................................................... 108

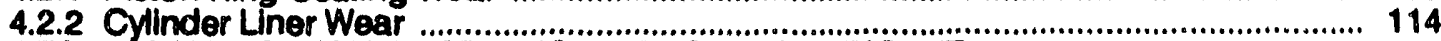

4.3 RESULFS USING HIGH-SOOT, ENGINE-TESTED LUBRICANT ................................ 116

4.3.1 Plston Ring Coating Wear ............................................................................. 116

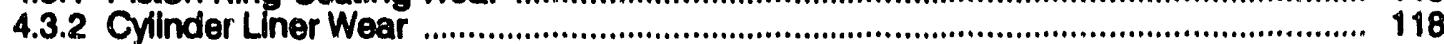

4.3.3 Friction Coefficients .................................................................................. 119

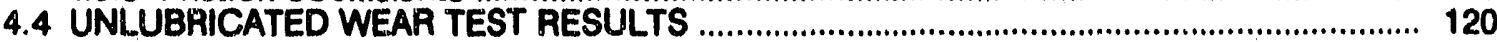

4.4.1 Piston Ring Coating Wear ................................................................................... 120

4.4.2 Cylinder Liner Wear ......................................................................................... 122

4.4.3 Friction Coefficients ................................................................................... 123

4.5 MICROSTRUCTURAL EFFECTS ON FRICTION AND WEAR .................................. 12.4

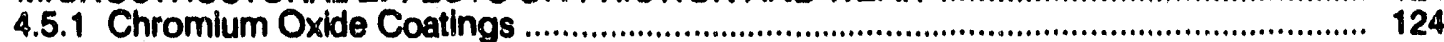

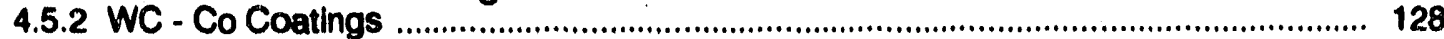

4.5.3 Chromium Carbide - Nichrome Coatings .......................................................... 132

4.5.4 Ferro-Tic Coatings ................................................................................... 135

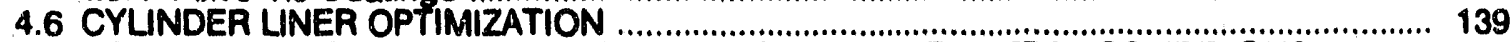

4.7 CORRELATIONS BETWEEN WEAR DATA FOR DIFFERENT TEST CONDITIONS .......... 142

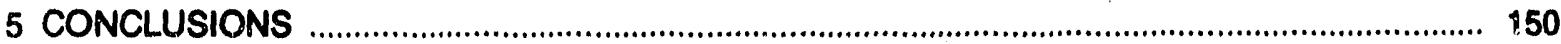

6 ACKNOWLEDGEMENTS ............................................................................................ 151

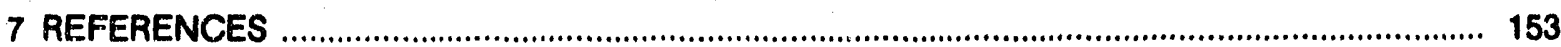

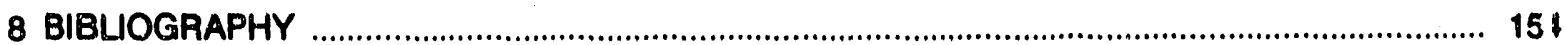


Table of Figures

Figure 1. Schematic of the plasma arc spraying process .......................................................... 4

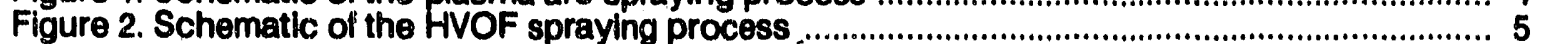

Figure 3. Hardness and wear for various coatings ........................................................................ 11

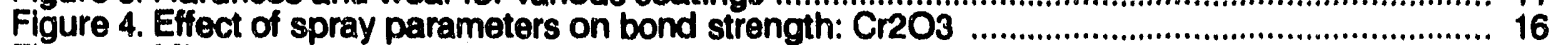

Figure 5. Microstructure of APS UCAR chromlum oxide coating ................................................. 19

Figure 6. Microstructure of APS Metco 136 Cr2O3 coating .............................................................. 19

Figure 7. Microstructure of APS Metco $136+3 \%$ SiO2 coating …............................................ 20

Figure 8. Microstructure of APS Metco 136+15\% A12O3 coating …............................................. 20

Figure 9. Microstructure of Metco $136+33 \%$ Stellte 6 coating ……..................................................... 21

Figure 10. Microstructure of APS WC - 12\% Co coating ............................................................ 24

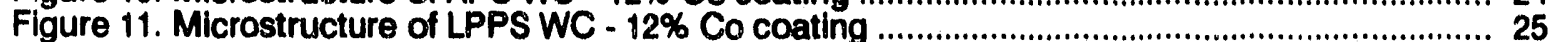

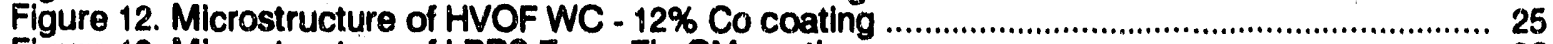

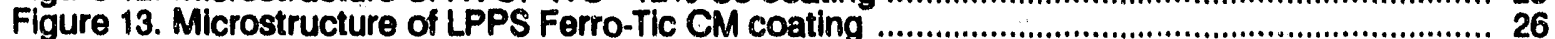

Figure 14. Microstructure of LPPS Ferro-Tic CS-40 coating ...................................................... 27

Figure 15. Microstructure of LPPS Ferro-Tic HT-6A coating ……..................................................... 28

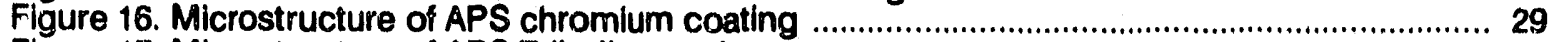

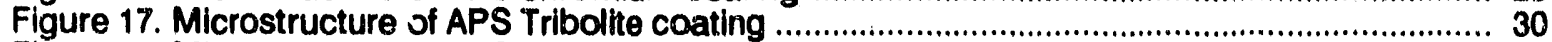

Figure 18. Microstructure of APS Armacor M coating .......................................................................... 31

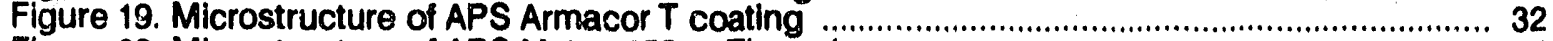

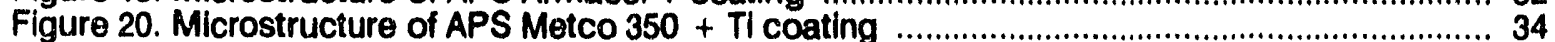

Figure 21. Microstructure of APS Metco 350 + B coating …................................................... 34

Figure 22. Microstructure of Metco $350+50 \%$ TiB2 coating ……................................................... 35

Figure 23. Microstructure of APS Metco $350+25 \%$ B4C coating ……..................................... 35

Figure 24. Microstructure of LPPS boron carbide coating ……....................................................... 37

Figure 25. Microstructure of LPPS sllicon nitride costing ........................................................... 38

Figure 26. X-ray diffraction pattern from LPPS SI3N4 coating ........................................................ 38

Figure 27. SEM micrograph of GTE SA-901 Mo - 25\% NI powder ............................................. 40

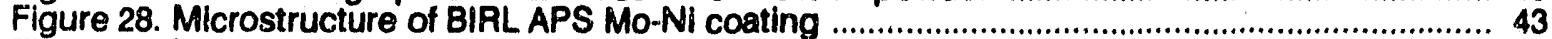

Figure 29. Microstructure of BIRL HVOF Mo-Ni coating …............................................................ 43

Figure 30. SEM micrograph of GTE SA-110 Mo-MoO2 powder .............................................. 44

Figure 31. Microstructure of BIRL APS MO-MOO2 coating …….......................................................... 44

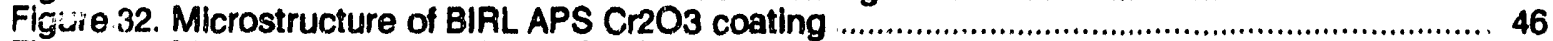

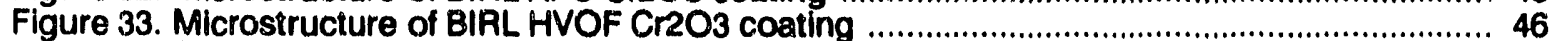

Figure 34. SEM micrograph of Cr2O3 - 50\% Al2O3 powder …….......................................... 47

Figure 35. Microstrurture of BIRL Cr2O3 - 50\% Al2O3 coating ……....................................................4 47

Figure 36. SEM micrograph of PA-AZ Al2O3 - 25.7\% ZrO2 powder …….......................................... 49

Figure 37. SEM micrograph of PC-AZE Al2O3 - 41\% ZrO2 powder ..................................................... 49

Figure 38. Microstructure of BIRL Al2O3 - 26\% ZrO2 coating …....................................................... 50

Figure 39. Microstructure of BIRL Al2O3 - 41\% ZrO2 coating …............................................... 50

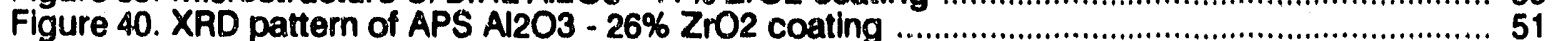

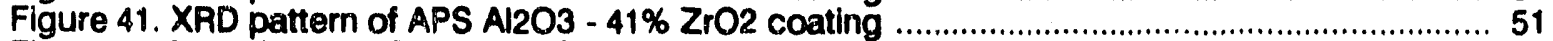

Figure 42. XRD data: Al2O3-26\% ZrO2: as-sprayed \& 400C, $1 \mathrm{hr}$. ..................................................... 52

Figure 43. XRD data: Al2O3-41\% ZrO2: as-sprayed \& 400C, 1hr. .................................................. 53

Figure 44. XRD data: $\mathrm{Al2O}-26 \% \mathrm{ZrO} 2$ and $\mathrm{Al} 2 \mathrm{O} 3-41 \% \mathrm{ZrO} 2$

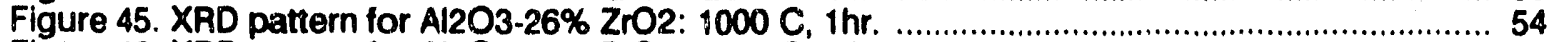

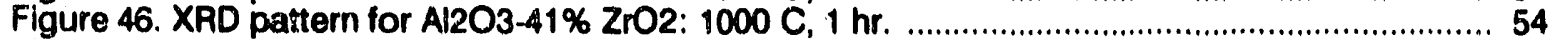

Figure 47. XRD pattern of laser-processed Al2O3 - 26\% ZrO2

Figure 48. XRD pattern of laser-processed Al2O3 - 41\% ZrO2 …......................................... 56

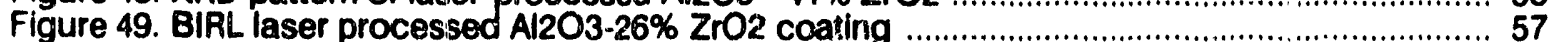

Figure 50. Surface of BIRL laser processed Al2O3 - 26\% ZrO2 ……............................................ 57

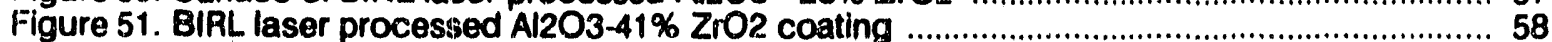

Figure 52. Surface of BIRL laser processed Al2O3 - 41\% $2 \mathrm{rOO}_{2}$ …................................................. 58

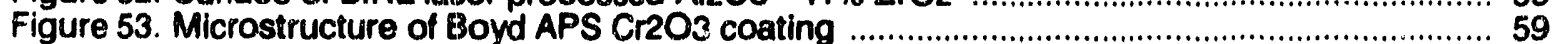

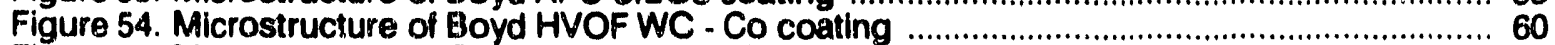

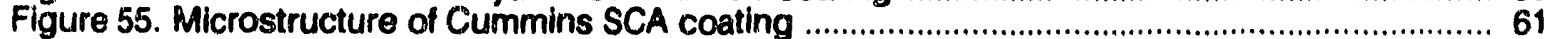

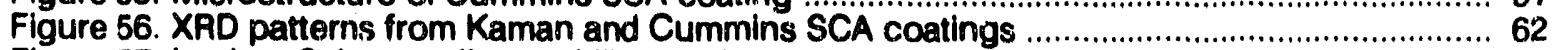

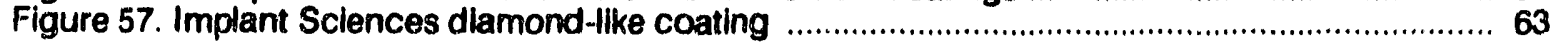


Figure 58. As-coated surface of diarnond-llke coating

Figure 59. As-coated surface of diamond-like coating

FIGure 60. SEM micrograph of TMT HVOF Cr3C2-NiC

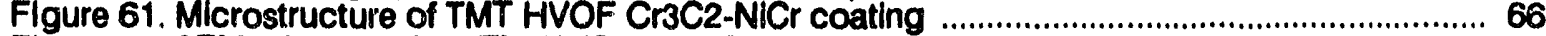

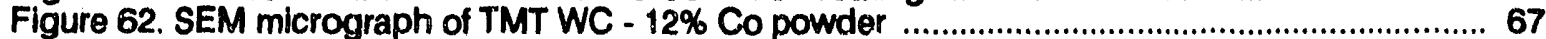

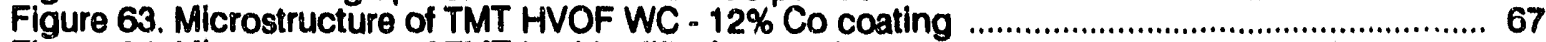

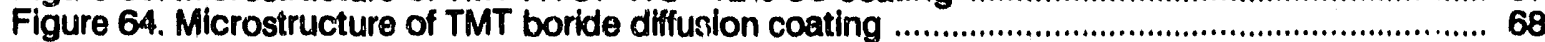

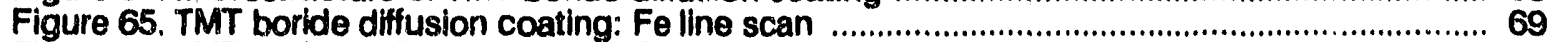

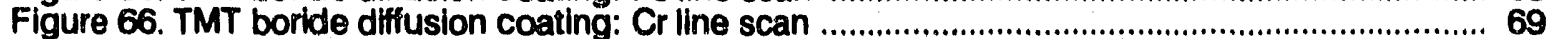

Figure 67. TMT boride diffusion coating: $\mathrm{C}$ line scan ................................................................. 70

Figure 68. TMT boride diffusion coating: B line scan .................................................................... 70

Figure 69. Microstructure of UTRC HVOF Cr3C2-NiCr coating ................................................. 71

Figure 70. Microstructure of UTRC plasma sprayed ZTY coating ….............................................. 72

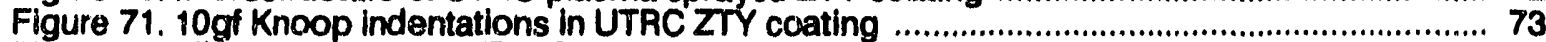

Figure 72. Microstructure of UTRC $\mathrm{Cr} 2 \mathrm{O} 3$ coating ..................................................................... 74

Figure 73. Microstructure of UTRC HVOF NICrBSI coating .............................................................. 75

Figure 74. Bend strength vs temperature for UTRC coatings …............................................... 77

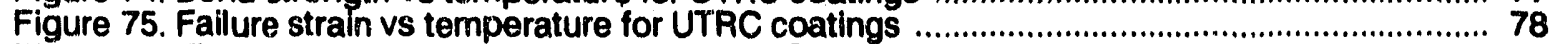

Figure 76. Elastic modulus vs temperature for UTRC coatings .................................................... 79

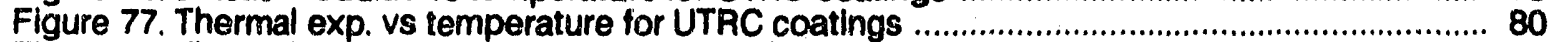

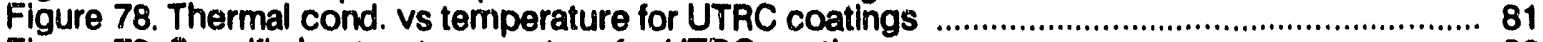

Figure 79. Specific heat vs temperature for UTRC coatings …............................................ 82

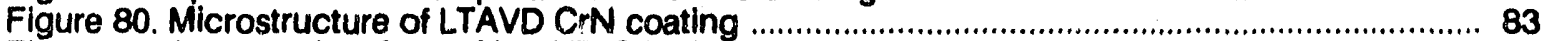

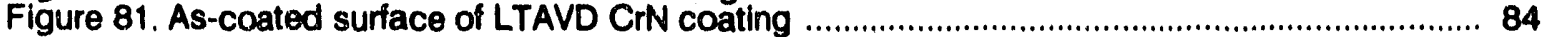

Figure 82. As-coated surface of LTAVD CrN coating ........................................................... 84

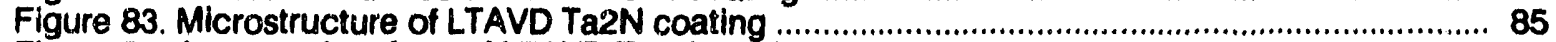

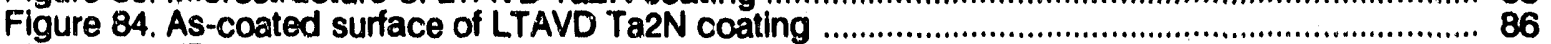

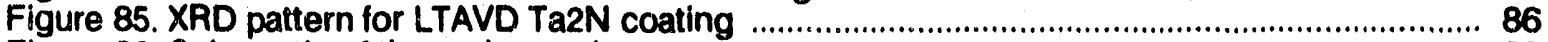

Figure 86. Schematic of the reciprocating wear tests .................................................................... 88

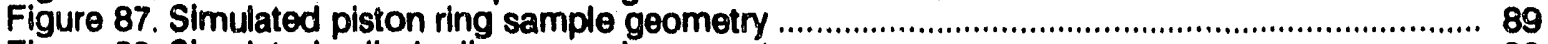

Figure 88. Simulated cylinder liner sample geometry ...................................................................... 90

Figure 89. Coating wear coefficients at $200 \mathrm{C}$ with fresh oll ..................................................... 98

Figure 90. Coating wear coefficients at $350 \mathrm{C}$ with fresh oil ........................................................ 99

Figure 91. Liner wear coefficients at $200 \mathrm{C}$ with fresh oil .................................................................... 102

Figure 92. Liner wear coefficients at $350 \mathrm{C}$ with fresh oll .......................................................... 103

Figure 93. Friction coefficients for $200 \mathrm{C}$ fresh oil tests …................................................................ 104

Figure 94. Friction coefficients for $350 \mathrm{C}$ fresh oil tests .......................................................... 105

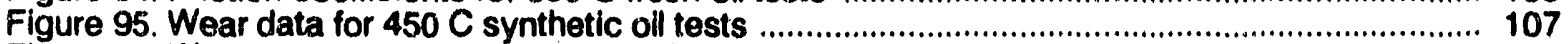

Figure 96. Wear vs temperature for conventional materials ........................................................ 109

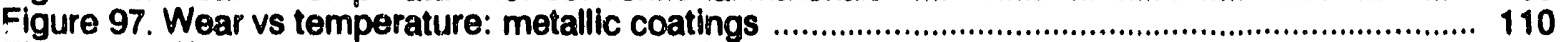

Figure 98. Wear vs temperature: ceramic coatings ................................................................... 111

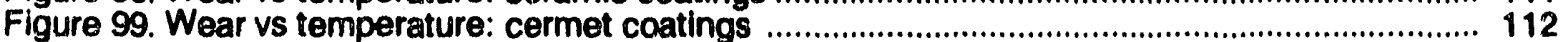

Figure 100. Wear vs temperature: chromium oxide vs SCA liner .............................................. 113

Figure 101. Liner wear vs temperature: metallic/cermet rings .................................................... 114

Figure 102. Liner wear vs temperature: ceramic coatings ....................................................... 115

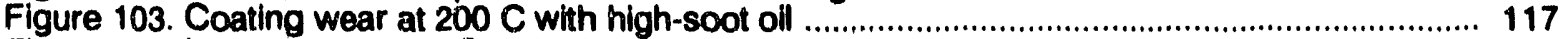

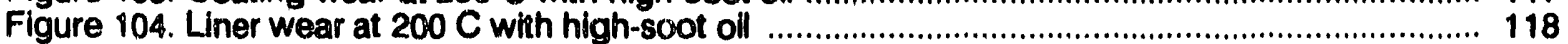

Figure 105. Friction coefficients for high-soot oll tests ......................................................... 119

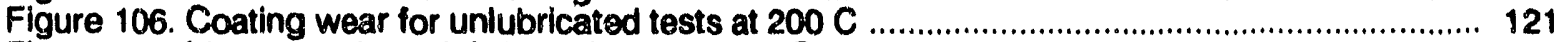

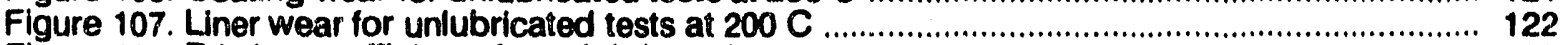

Figure 108. Friction coefficients for unlubricated tests ....................................................................... 123

Figure 109. Wear of chromium oxide ring coatings ............................................................. 125

Figure 110. Liner wear for chromium oxide coating tests ........................................................ 126

Figure 111. Friction coefficients for chromium oxide tests ...................................................... 127

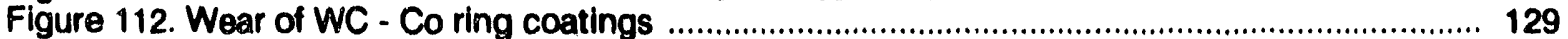

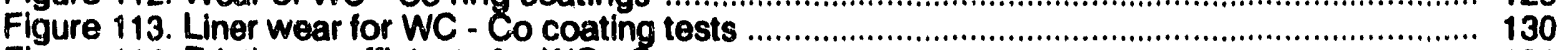

Figure 114. Friction coefficients for WC - Co tests ............................................................. 131

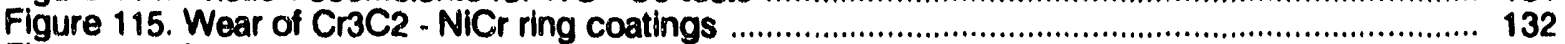

Figure 116. Liner wear for $\mathrm{Cr} 3 \mathrm{C} 2$ - NiCr coating tests ............................................................. 133 
Figure 117. Friction coefficients for $\mathrm{Cr} 3 \mathrm{C} 2$ - NiCr tests ........................................................... 134

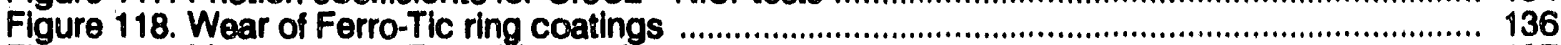

Figure 119. Liner wear for Ferro-fic coating tests ................................................................... 137

Figure 120. Friction coefficients for Ferro-ric tests ............................................................. 138

Figure 121. Results of lirer optimization tests (lubricated) ..................................................... 140

Figure 122. Results of liner optimization tests (dry) ................................................................ 141

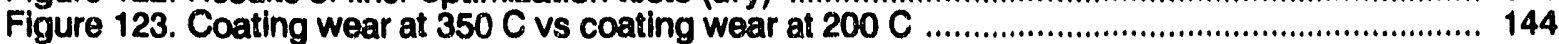

Figure 124. 200 and $350 \mathrm{C}$ wear results (fresh oil) .............................................................. 145

Figure 125. Coating wear with $3.3 \%$ soot oll vs fresh oil ............................................................. 146

Figure 126. Fresh and high-soot oll wear results .................................................................. 147

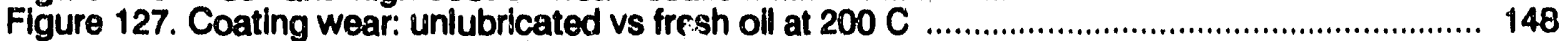

Figure 128. Lubricated and unlubricated wear results ...................................................................... 149 


\section{Table of Tables}

Table 1. Metallic ring coating materials investigated ...............................................................

Table 2. Ceramic ring coating materials investigated .............................................................. 14

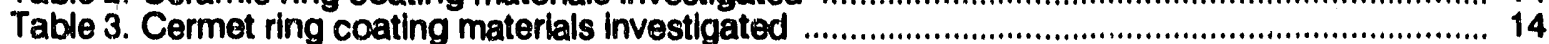

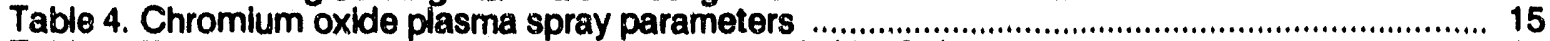

Table 5. Effect of spray parameters on bond strength (Cr2O3) ............................................... 17

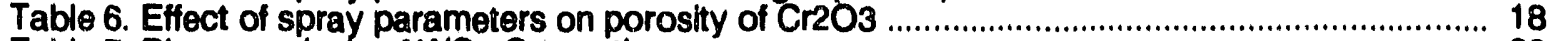

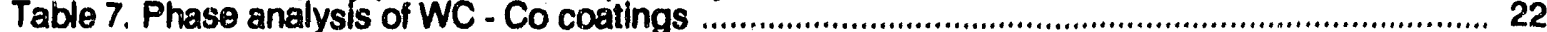

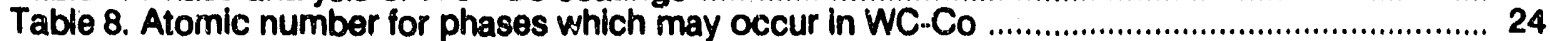

Table 9. Hardness of LPPS Fe-Mo-C with various additions ................................................... 33

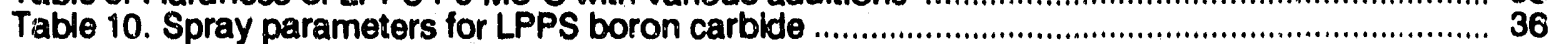

Table 11. Specifications for GTE SA-901 Mo - 25\% Ni powder ................................................. 39

Table 12. Speclfications for GTE SA-1 10 Mo-MoO2 powder ........................................................ 39

Table 13. Spray trial parameters for BIRL Mo-based coatings ................................................. 41

Table 14. Optimized parameters for BIRL Mo-based coatings .................................................... 42

Table 15. An example of Top Gun HVOF deposition parameters ......................................... 42

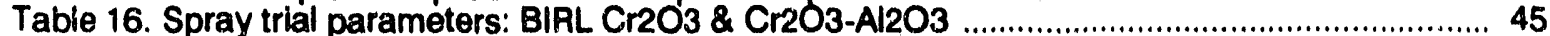

Table 17. Optimized parameters for BIRL Cr2O3 \& Cr2O3-Al2O3 ….................................................. 45

Table 18. Optimized spray parameters for Al2O3-Z1O2 coatings .............................................. 48

Table 19. JCPDS files used for analyzing Al2O3-ZrO2 coatings …........................................ 52

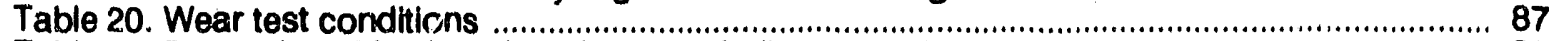

Table 21. Properties of fresh and engine-tested olls ............................................................... 92

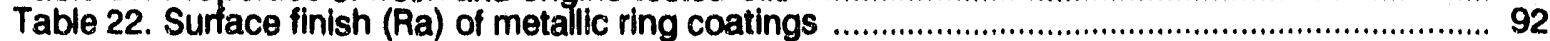

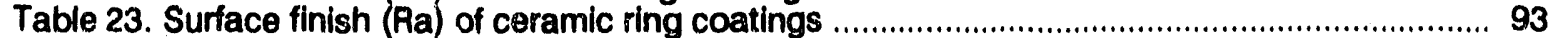

Table 24. Surface finish (Ra) of cermet ring coatings ................................................................. 94

Table 25. Compositions of cylinder liner materials evaluated ................................................. 95

Table 26. Friction and wear coefficients for 4 repeat tests ............................................................. 96

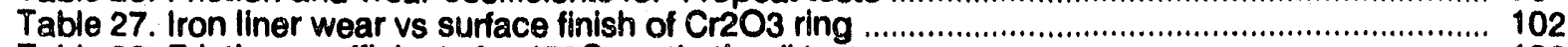

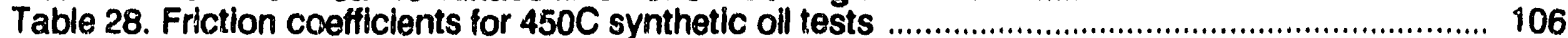

Table 29. Phase analysis of WC - Co coatings .............................................................................. 128

Table 30. Correlation coeff: coating wear: 4 test conditions ................................................... 143

Table 31. Correlation coeff: liner wear: 4 test conditions ……............................................................. 143

Table 32. Correlation coeff: ring wear - liner wear ................................................................. 143

Table 33. Correlation coeff: ring wear - micronardness ........................................................ 143 


\title{
DEVELOPMENT OF WEAR-PESISTANT CERAMIC COATINGS FOR DIESEL ENGINE COMPONENTS
}

\section{VOLUME 1: COATING DEVELOPMENT AND TRIBOLOGICAL TESTING}

\author{
M.G.S. Naylor
}

\begin{abstract}
The tribological properties of a variety of advanced coating materials have been evaluated under conditions which simulate the piston ring - cylinder liner environment near top ring reversal in a heavy duty diesel engine. Coated "ring" samples were tested against a conventional pearlitic grey cast iron liner material using a high temperature reciprocating wear test rig. Tests were run with a fresh $\mathrm{CE} / \mathrm{SF}, 5 \mathrm{~W} 40$ lubricant at 200 and $350^{\circ} \mathrm{C}$, with a high-soot, engine-tested oil at $200^{\circ} \mathrm{C}$ and with no lubrication $\varepsilon^{*}: 200^{\circ} \mathrm{C}$.

For lowest wear under bound ary lubricated conditions, the most promising candidates to emerge from this study were high velocity oxy-fuel (HVOF) $\mathrm{Cr}_{3} \mathrm{C}_{2}-20 \% \mathrm{NiCr}$ and WC - $12 \%$ Co cermets, low temperature arc vapor deposited (LTAVD) CrN and plasma sprayed chromium oxides. Also, plasma sprayed $\mathrm{Cr}_{2} \mathrm{O}_{3}$ and $\mathrm{Al}_{2} \mathrm{O}_{3}-\mathrm{ZrO}_{2}$ materials were found to give excellent wear resistance in unlubricated tests and at extremely high temperatures $\left(450^{\circ} \mathrm{C}\right)$ with a synthetic oil. All of these materials would offer substantial wear reductions compared to the conventional electroplated hard chromilum ring facing and thermally sprayed metaltic coatings, especially at high temperatures and with high-soot oils subjected to degradation in diesel environments. The LTAVD CrN coating provided the lowest lubricated wear rates of all the materials evaluated, but may be too thin $(4 \mu \mathrm{m})$ for use as a top ring facing.

Most of the coatings evaluated showed higher wear rates with high-soot, engine-tested oil than with fresh oil, with increases of more than a factor of ten in some cases. Generally, metallic materials were found to be much more sensitive to soot/oil degradation than ceramic and cermet coatings. Thus, decreased "soot sensitivity" is a significant driving force for utilizing ceramic or cermet coatings in diesel engine wear applications.
\end{abstract}

\section{INTRODUCTION}

This report describes the results of a three year program to develop and evaluate wear-resistant coatings for in-cylinder components for future, advanced diesel engines. The following goals were set for piston ring and cylinder liner coating: and substrates:

1. low wear (as measured in laboratory rig tests at 200 and $3500^{\circ} \mathrm{C}$ ), with target wear coefficients (for $350^{\circ} \mathrm{C}$ tests) of $10^{-12} \mathrm{~mm}^{3} / \mathrm{mm} / \mathrm{N}$ for piston ring coatings and $10^{-10}$ $\mathrm{mm}^{3} / \mathrm{mm} / \mathrm{N}$ for cylinder liner materials.

2. low friction coefficients when tested under boundary lubricated conditions (target 0.1 ) and unlubricated conditions (target 0.2 ) at ambient temperature and $350^{\circ} \mathrm{C}$. 
3. good thermal shock resistance.

4. high adherence and compatiblity with substrate materlals up to $650^{\circ} \mathrm{C}$.

5. high uniformity and reproducibility.

This volume of the report describes the coating development activities (section 2.0), experimental procedures (section 3.0), results of tribological testing (section 4.0) and conclusions (section 5.0). Volume 2 contains the appendices and documents the wear surfaces of each of the coatings tested. In the remainder of section 1, the background to the project is described, including the motivation for developing improved wear-resistant piston ring facings, and the selection criteria for coating procosses and inaterials.

The requirement for improved wear performance of advanced diesel engine components, especially for the piston ring-cylinder liner interface, is driven by several needs:

1. improved fuel economy/emissions tradeoffs, requiring improvements to the combustion system which typically result in higher mechanical and thermal stresses on in-cylinder components.

2. improved control of oil consumption (for low particulate emissions), which requires that critical component dimensions and surface finishes be maintained for longer periods of time, with reductions in oll supply to in-cylinder components.

3. in proved engine performance for the same displacement, resulting in higher in-cylinder temperatures.

4. overall increased engine durability, hence lower component wear rates.

5. increased maintenance (e.g. oll change) intervals, requiring greater tolerance to soot, abrasive contaminants and oil degradation products.

\subsection{SELECTION CRITERIA FOR A PISTON RING COATING PROCESS}

In the U.S., the industry-standard ring coating for heavy duty diesel engines is currently electroplated hard chromium. Moderately thick $(150-250,1 \mathrm{~m})$ coatings are used because piston rings for on-highway trucks are typically required to last for upwards of 500,000 miles prior to being replaced at ti ie first major overhaul. This durability/thickness requirement has a major impact on the selection of a coating process. For example, a $10 \mathrm{\mu m}$ thick coating would require a wear coefficient 15 - 25 times lower than electroplated hard chromium for the material to be useful, which is a difficult goal for this environment. Many otherwise promising coating technologies are unsultable for piston ring applications because sufficient thicknesses cannot be achieved.

Another important requirement of the coating process is that it should not subject the piston ring substrate to excessive temperatures. Thermally induced distortions of the ring would potentially change the radial pressure distribution with the cylinder liner, which is critical in controlling oil consumption and blowby in the engine [e.g. 1]. In fact, a common method of producing the optimum ring shape is to form the ring over a heated mandrel. Thus, the coating temperature should generally not exceed the heat forming temperature, which is typically $500-600^{\circ} \mathrm{C}$ for conventional materials, although selection of ring substrate materials with better high temperature properties may ralse this limit. For piston rings shaped by cam turning processes rather than heat forming, the coating temperature limit is set by the stress relief temperature of the ring substrate material.

Additional process requirements include adequate adherence of the coating to the substrate, with low residual stresses. In particular, the process must not compromise the fatigue properties of the ring substrate material. Adequate process control must be available with the capability to produce highly reproducible coatings with uniform microstructures and properties. Finally, the combination of coating process, material and finishing operation should have maximum cost effectiveness.

The following sections give briet descriptions of the coating processes evaluated during this program. In particular, the relative advantages and disadvantages of each system for piston ring face coatings is discussed. 


\subsubsection{Thermal Spray Processes}

Thermal spraying is a generic category of processes which involve applying a consumable in the form of a spray of finely divided molten or semimolten droplets to produce a coating. The consumable can be introduced into the heat scurce in the form of powder, rod or wire. For this program, all coatings were sprayed from powders. There are two basic methods of heating the consumable: gas combustion and electric arc. Within these two categories, there are a variety of basic processes, including flame spray, "wire gun", detonation gun and high velocity combustion jet spray (combustion processes) and wire/arc and arc plasma (electric arc processes). The different techniques are reviowed in more detall in reference [2], for example.

Thermal spray processes are generally sultable for applying any material which melts or becomes plastic in the heating cycle and does not degrade in heating. Thus, a wide variety of metals, ceramics, cermets and polymers are sultable for thermal spraying. The deposit does not fuse with the substrate, and so does not form a "metallurgical" bond. Although this can be a disadvantage from an adherence standpoint, issues of metallurgical compatibility (e.g. abillty to form solkd solutions with the substrate) are avoided. Further, substrate temperatures are typlcally low $\left(100-200^{\circ} \mathrm{C}\right)$, so the cholce of substrate materials is almost unlimited, giving thermal spray processes great versatility. Coating thickness limitations are generally specific to the process and material, but typical coating thicknesses are in the range $50-500 \mu \mathrm{m}$, which is ideal for piston ring applications. Piston ring fatigue tests at Cummins have shown lower fatigue debits for thermal spray coatings than for conventional electroplated hard chromium.

Recent advances in thermal spray technology, coupled with advances in powder processing, have resulted in the potential for producing extremely high quality coatings with low porosity and excellent adherence. An important objective of this program was to evaluate the potential of those new processes and powder materlals for diesel engine applications. The two thermal spray processes used for development work in this prograin were plasma arc and high velocity oxy-fuel. These processes are described briefly below.

\subsubsection{Plasma Arc Coating}

Plasma arc spraying is the process of applying a material by melting and atomizing it in powder form in a plasma which is obtained by passing a gas through an electric arc between nonconsumable electrodes within the torch. A schematic of a plasma torch is shown in Figure 1. Powder is delivered by a powder feeder that usually consists of a hopper pressurized with an inert gas, a vibrator to keep the powder from clumping and a gear pump to meter the powder into the carrier gas. Powder sizes are normally in the range $30-100 \mu \mathrm{m}$. The gas used to form the plasma is a process variable, argon or helium being commonly used. The plasma temperature is typically in excess of $28,000^{\circ} \mathrm{C}$, well above the temperatures attained in gas combustion processes. The velocity of the plasma/droplet stream that exits the nozzle is usually subsonic, although high-velocity plasma torches with constricted nozzle designs are avallable.

The final stage in the spray process is for the molten or semi-molten droplets to impinge on the target as "splats" of material. Splat cooling rates are extremely high, sometimes high enough to produce amorphol is deposits. Coatings normally contain porosity (typically 5 - 15\%) and oxide inclusions caused by exposure of the molten droplets to oxygen prior to hitting the target. With carbides, a certain amount of decarburization may also occur. A number of methods are avallable to minimize this effect:

1. use of inert or reducing carrier and arc gases.

2. shrouding the spray emerging from the nozzle with an inert or reducing gas envelope.

3. spraying inside a chamber evacuated to low pressure or containing an inert atmosphere. in this program, the low pressure plasma spray process is designated "LPPS", as distinct from "APS" for air plasma spray. 


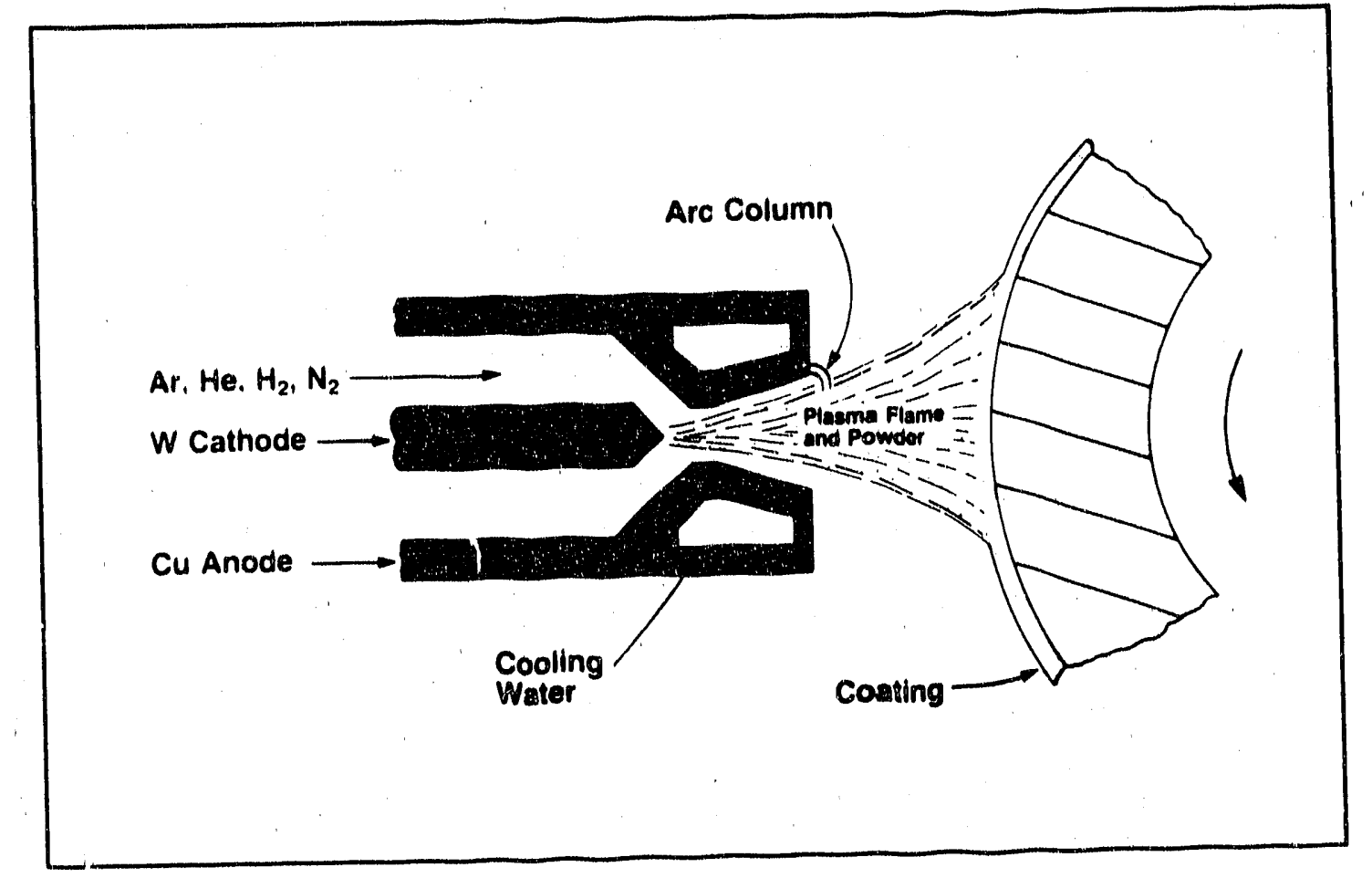

Figure 1. Schematic of the plasma aro spraying process.

A number of parameters must be controlled to obtain high-quality, consistent coatings. These include nozzle-to-work distance, powder size and type, point of powder introduction, arc current and voltage, type of plasma gas, particle carrier gas and powder fluence.

Since bonding of the coating to the substrate occurs largely by mechanical interlocking rather than by metallurgical bonding, surface preparation is important for thermal spray coatings. Surfaces to be coated are roughened, typically by grit blasting. Often, improved mechanical bonding can be achieved by using an intermediate or "bond" coat.

Although plasma spray processes produce high quality coatings and provide great versatility compared to many other thermal spray techniques, there are some dlsadvantages. The biggest drawback is probably the high cost of the equipment. Also, due to the large number of spray parameters, process control is more difficult than for gas combustion processes. As with all thermal spray processes, coating is line-of-sight, and thus unsuitable for components such as small internal diameters and complex shapes with re-entrant angles. Generally, coating adherence is not as high for thermal spray coatings as for coating systems such as $C V D$, electroplating and PVD, and coating "break-out" is recognized as an important issue for piston ring face coatings [3].

Plasma sprayed piston ring coatings have been available commercially for a number of years, although in limited production quantities in the U.S. In Europe, wire sprayed and plasma sprayed molybdenum-based coatings have gained increasing popularity due to improved scuffing/seizure resistance compared to electroplated chromium, althciugh this is achieved at the expense of slightly higher wear rates under well-lubricated conditions [4].

During this project, advanced plasma spray coatings were obtained from APS Materials, Inc. (Dayton, OH), Northwestern University Basic Industrial Research Laboratory (Evanston, IL), Boyd Machine and Repair Company, Inc. (Kimmell, IN) and United Technologies Research Center (East Hartford, CT). 


\subsubsection{High Velocity Oxy-Fuel Coating}

High velocity oxy-fuel (HVOF) processes are relatively new, having been introduced commercially in 1981. Several systems are now avallable, Including "Jet-Kote" (a reglstered trademark of Stoody/Deloro Stellite, Inc.), "Top Gun" (a registered trademark of Miller Thermal Technologles) and "Dlamond Jet" (a registered trademark of Metco Division of Perkin Elmer).

The HVOF process is illustrated schematically in Figure 2. The heat source and carrier for the powder is a continuous gas combustion jet emanating from a combustion chamber within the torch. The fuel gas, typically hydrogen, propylene or acetylene, is mixed with oxygen and ignited. The consumable to be sprayed is introduced into the center of the jet stream from a powder feeder using a carrier gas that is compatible with the fuel gas mixture. The flame temperature at the point of powder introduction is typically about $2,800^{\circ} \mathrm{C}$. Gas exhaust velocities approach $1370 \mathrm{~ms}^{-1}$ (approximately four times the speed of sound in air). Powder particles melt or become plastic as in other thermal spray processes, and the bond strength and porosity levels are controlled by the particle velocity and temperature.

Advantages of HVOF processes compared to plasma spraying include:

1. greater bond strength, arising from the higher impingement velocity. Often, the need for a bond coat may be eliminated. However, bond strengths are still generally low compared to coating systems which give metallurgical bonding.

2. porosity levels are typically lower for HVOF than for plasma sprayed coatings.

3. HVOF processes are inherently simpler, resulting in improved process control and greater uniformity and reproducibility of coatings. In particular, coating quality is less sensitive to the nozzle-to-work distance.

4. equipment cost is often lower for HVOF processes. Offsetting this is higher operating costs due to increased usage of oxygen and combustion gases.

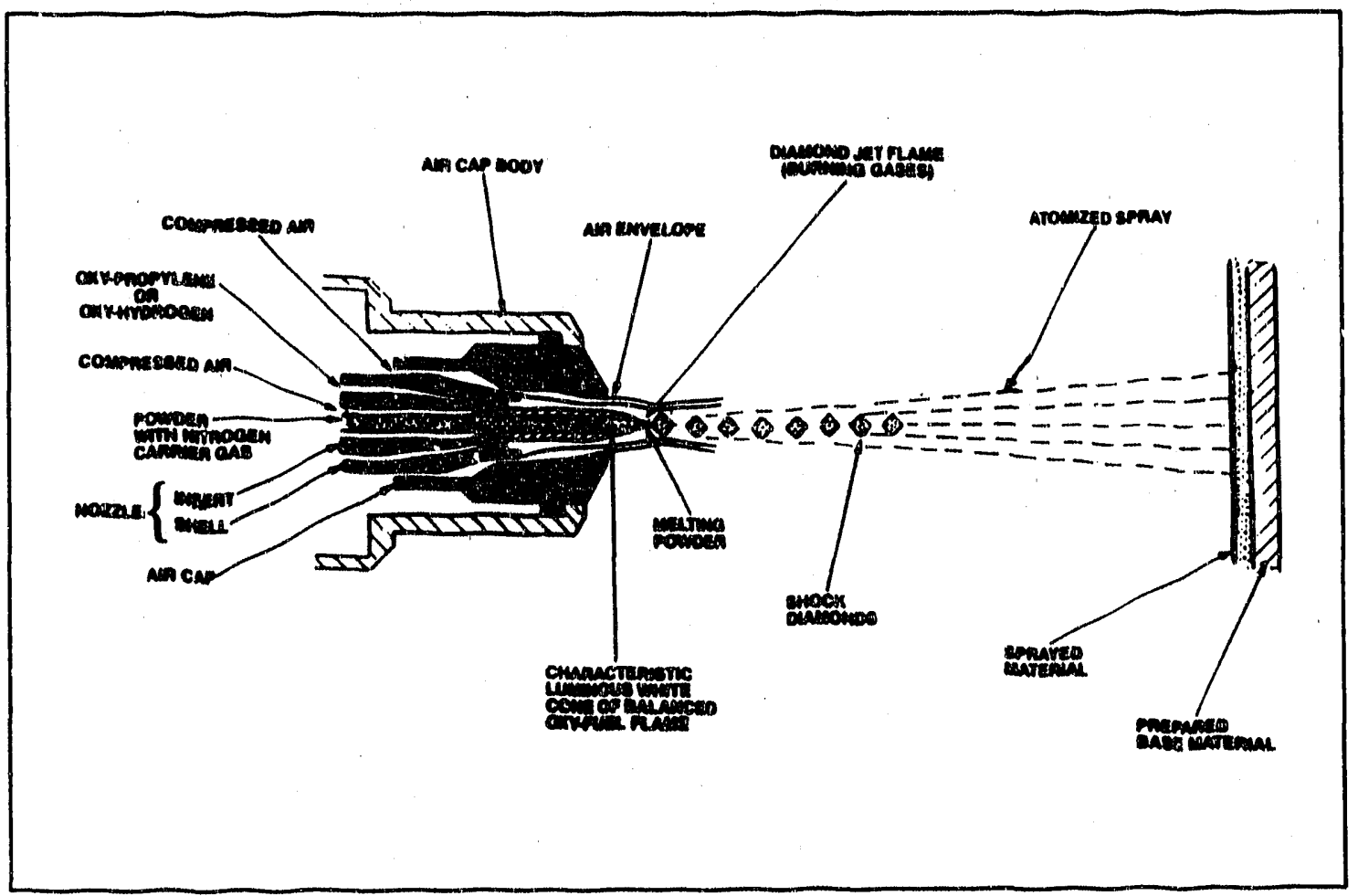

Figure 2. Schematic of the high velocity oxy-fuel spraying process (Metco Diamond Jet). 
A disadvantage of HVOF processes is the requirement for powders with closely controlled size distributions. Since the process is failly new, the availability of sultable powders is somew/nat limited compared to plasma spray materials. A second disadvantage is the high level of sound ennitted by the process, requiring sound-proof spray booths and remote operation. Also, flame temperatures are lower for HVOF processes than for plasma spraying, which makes these systems less sultable for spraying coramic coatings (although considerable success was achieved with HVOF chromium oxide coatings in this program). Even though fiame temperatures are lower than for plasma spraying, the combustion process results in a long flame front which can give rise to greater teat input into the substrate, which is an issue for ring coating. As for all thermal spray techniques, the HVOF process is ine-of-sight.

During this project, HVOF coatings were obtained from APS Materials, Inc. (Dayton, $O H$ ), Northwestern University Basic Industrial Research Laboratory (Evanston, IL), Boyd Machlne and Repair Company, Inc. (Kimmell, IN), Turbine Metal Technology, Inc. (Tujunga, CA) and United Teichnologies Research Center (East Hartiord, CT).

\subsection{Diffusion Alloxing}

Diffusion alloying is a process in which a part to be coated is heated in a closed, protective atmosphere and, at the appropriate temperature (typically in the range $800-1100^{\circ} \mathrm{C}$ ), gaseous sipecies of the elements desired are introduced. Examples of the reactant gases include $\mathrm{BCl}_{3}$ for bcride coatings, $\mathrm{AlCl}_{3}$ for aluminides and $\mathrm{TiCl}_{4}+\mathrm{CH}_{4}$ for TiC coatings. The gases decompose on contacting the helated part, and atoms of the desired element are avallable for diffusion into the substrate. In this respect, the process is similar to chemical vapor depesition (CVD), except that the deposition rates and the rate of diffusion into the substrate are balanced to limit the buildup of unreacted material on the surface. Both alloys and intermetallic compounds can be formed by this method. It is important to realize thall the process is essentially a surface conversion rather than a true "coating", since the composition of the processed surface is derived from a combination of elements from the original metal part with ellements derived from the reactant gas. Thus, the bonding of the surface layer to the substrate is metallurgical, and the process requires no special preparation techniques to enhance bonding, as do therinal spray (and other) processes.

Advantages of diffusion alloying processes for producing piston ring coatings would include:

1. Excellent bond strengths, far exceeding those for electroplated, thermal spray and PVD coatings.

2. Ceramic surface layers (e.g. borides and carbides) and intermetallic compounds (18.g. aluminides) can be formed with high hardness levels (>1500 Knoop) arid excellent tribological properties.

3. Surface layers are very uniform and contain low levels of porosity.

4. The process is not line-of-sight, which reduces the complexity of fixturing large numbers of parts within a reactor.

Disadvantages the diffusion alloying process include:

1. The high process temperatures (typically in the range $800-1100{ }^{\circ} \mathrm{C}$ ) would cause distortion problems with most potential ing substrates. Substrate selection is limitted to hot work tool steels, stainless steels and superalloys. With spocial precautions, hardenable materials can be heat treated after coating.

2. Coating thicknesses are typically limited to less than $10-50 \mu \mathrm{m}$.

3. Diffusion alloying processes normally require long cycle times (typically 10 - 20 hours).

During this project, a boride diffusion alloy was obtained from Turbine Metal Technology, Inc. 


\subsubsection{Physical Vapor Depposition (PVD)}

Physical vapor deposition (PVD) processes involve the creation of a vapor (often in partially ionized form) from a source contained within a vacuum system and the subsequent deposition of atoms or lons from this vapor onto a substrate. There are three generic types of PVD process, according to the method of producing the vapor:

1. thermal evaporazion: the source is heated to produce a non-lonized vapor, which subsequently condenses on any material exposed within the vacuum chamber. The kinetic energy of incident atoms is typically low (a few tenths of an electron volt (eV)) for this type of process.

2. sputtering:

Ions from a gas-generated plasma are used to dislodge ("sputter") atoms or molecules from a target made from the coating material. The plasma is established between the negatively blased target (cathode) and the substrate (anode) by the application of a DC potential or a radio frequency (RF) power sourse. An inert gas such as argon is introduced into the vacuum chamber to form a glow discharge between the electrodes. Positively charged argon ions are accelerated towards the target, where lonic bombardment results in a sputtered fiux of target atoms/molecules, lons and electrons. As electrons are accelerated towards the anode, collisions occur with neutral argon atoms, causing dissociation, excitation and lonization, thus sustaining the glow discharge. A portion of the flux of target atoms/molecules and ions reaches the substrate and is deposited to form a coating. The kinetic energy of incident atoms/lons is typically $6-10 \mathrm{eV}$ for sputtered PVD coatings.

3. ion plating:

ion plating is a hybrid process in which a vapor of the materlal to be coated is directed into a DC or RF glow discharge around the negatively biased (cathodic) substrates. There are various mathods of introducing the vapor, the simplest method being to evaporate the coating material such that vaporized atoms enter the plasma, where some are ionized and accelerated towards the substrate. At the substrate, a combination of deposition (from lons and thermally evaporated atoms) and sputtering processes takes place. The rate of evaporation from the source is controlled such that the deposition rate is higher than the rate of sputtering. Deposition of the coating in partially lonized form, coupled with sputter cleaning of the surfaces, is claimed to improve coating adhesion. Although the percentage of lonized target species is often very low $(<1 \%)$, conventional lon plating processes give incident ion energies of around $10 \mathrm{eV}$.

One important modification of the above coating techniques is "reactive deposition", in which reactive gases (e.g. $\mathrm{N}_{2}, \mathrm{NH}_{3}, \mathrm{CH}_{4}$ ) are mixed with the plasma gas (usually argon), causing a reaction with the target species to form a compound coating. By this method, ceramic coatings such as TiN and TiC can be formed using metallic titanium targets and appropriate reactive gases.

The PVD process selected for piston ring coating development in this program was cathodic arc PVD (CAPVD), which is essentially a variant of the ion plating process in which the vapor source is one or more electric arcs contained within the vacuum chamber. Arcing is initiated by applying a high-voltage pulse to an electrode placed near a cathode (composed of the source material) or by mechanical ignition. Evaporation occurs as a result of cathodic arc spots that move rapidly across the cathode surface, either in a random fashion or magnetically guided. Arc spots are typlcally 1 to $3 \mu \mathrm{m}$ in diameter and carry current densities as high as $10^{13} \mathrm{Am}^{-2}$. This high current density causes flash ivaporation of the source material in the form of electrons, ions, neutral vapor atoms and microdroplets. Thie high degree of lonization in the arc plasma (typically $30-90 \%$ ), coupled with the high energles imparted to each ion (60-100 eV), result in high deposition rates and high energy efficiency compared with other PVD processes, including conventional ion plating. CAPVD coatings are often more adherent, less columnar and less porous than PVD coatings produced by other methods.

With all PVD processes, substrates are normally heated to moderate temperatures in order to improve coating adhesion and reduce residual stress levels within the coating. Process temperatures are typically in the range $150-550^{\circ} \mathrm{C}$, depending on the substrate material, ine level of coating adhesion required for the application, the coating thickness, etc. Due to the high kinetic energy of incident ions/atoms in the CAPVD process, adhesion is inherently greater than for other PVD processes, which can allow the use of lower process temperatures. 
The success of all PVD coating systems depends strongly on substrate preparation, particularly in the cleaning processes used to remove olls and other residues. Typically, ultrasonic solvent cleaning and/or vapor degreasing procedures are used prior to inserting parts into the vacuum system. Often, a sputter cleaning cycle is used in the vacuum chamber prior to initiating the coating process.

Advantages of the PVD processes for producing piston ring coatings would include:

1. Reacthe sputtering techniques can produce veiy hard ( $22000 \mathrm{Knoop}$ ) ceramic coatings with excellent tribological properties.

2. PVD coatings are very uniform and contain low lovels of porosity.

3. Coating bond strengths are typlcally in the same range as for electroplated coatings (> $70 \mathrm{MPa}$ ). Although lower than for CVD processes, borid strengths are adequate for piston ring applications, and are generally higher then for thermal spray coatings.

4. PVD coating processes, often maintain tha surface finish of the substrate to a large degree, potentially eliminating the need for machining after coating.

Disadvantages of PVD processes inciuve:

1. The rate of deposition for reacthe sputtering processes is limited by the rate of reaction between the vaporized metal and the plasma gas, and is generally much less than for metallic deposition. This imposes a severe cost premium on thick (>5 $\mu \mathrm{m}$ ) cerarnic coatings. In addition, other factors, such as the development of a columnar grain structure with undesirable mechanical properties or the build-up of residual stresses in the coating, limit the maximum thickness of a ceramic coating to less than $15 \mu \mathrm{m}$ with current technology.

2. All PVD processes require vacuum chambers, typically requiring pressures as low as $10^{-6}$ torr $\left(1.3 \times 10^{-3} \mathrm{~Pa}\right)$. This results in high equipment and maintenance costs. The cleanliness of the parts to be coatrod is a very important feature, often requiring additional purpose-built equipment integrated with the coating units.

3. Although process temperatures are lower than for CVD processes, distortion problems may be a factor for conventional piston ring substrate materials.

4. Most PVD processes are largely line-of-sight, which restricts the component geometries that can be coaied. Whille this is not a blg factor for piston rings, care must be taken in fixturing large numbers of parts in the vacuum chamber to achieve uniform coating rates across the whole surface.

5. Ceramic coatings formed by PVO processes are often found to contain nodules or "macroparticles". In the case of TiN, these macroparticles are Ti-rich and occur due to the formation of microdroplets in the vaporization of the metal or to flaking of material from the chamber walls. Microdroplet problems can be particularly severe for CAPVD coatings, unless the process is optimized, for example by magnetically steering the arc across the target. Excessive concentrations of macroparticles can compromise the surface finish of the coating and, for tightly toleranced parts, may result in the need to finish machine the coating, since macroparticles can be as large as $10 \mu \mathrm{m}$ (greater than the coating thickness). Also, if the macroparticles are deeply embedded, their removal may cause fracture and spallation of the coating.

During this project, PVD coatings were obtained from Vapor Technologies, Inc. (Boulder, CO). 


\subsubsection{Tra Kaman Science Slurny-Dioped Sllica-Chromia-Alumina Process}

This patented process starts with the formation of a sillca - chromla - alumina (SCA) skeletal structure formed on the metal surface by dipping or spraying the part with a slurry of ceramic powders in chromic acid $\left(\mathrm{CrO}_{3}\right)$. The skeletel structure is densified by a series of $\mathrm{CrO}_{3}$ solution impregnation - heat treatment cycles. The heat treatment results in conversion of $\mathrm{CrO}_{3}$ to $\mathrm{Cr}_{2} \mathrm{O}_{3}$.

The advantages of this technique are that relatively high bond strengths can be obtained by the formation of Iron - chromium spinels at the interface whth the substrate and high hardnesses can be obtained through multiplo processing cycles.

Disadvantages include the toxicity of hexavalent chromium used in the process, and attendant waste disposal issues, and the requirement for multiple processing steps which add cost.

SCA contings were prepared at Cummins Engine Company under license from Kaman Sciences, Inc. (Boulder, CO).

\section{1 .5 Diamond-Llke Coatings}

Considerable excitement has recently been generated by the discovery that crystalline dlamond films can be produced using low-pressure gases rather than the high pressures and temperatures previously considered essential [e.g. 5, 6]. These developments offer such potential applications as wear resistant coatings, bearings and cutting tools, free standing windows, lens coatings for visible and infrared transmission and high-temperature, high-power semiconductor devices.

One of the diamond coating processes which has generated recent interest is a chemical vapor deposition (CVD) process based on the reaction

$$
\mathrm{CH}_{4(\sigma)} \underset{\text { activalion }}{\rightarrow} \mathrm{C}_{\text {(diamond: }}+2 \mathrm{H}_{2(\theta)}
$$

In addition to methane, a wide variety of carbon-containing reactant gases can be used. The typical process uses a reactant gas at less than atmospheric pressure and containing $>95 \%$ hydrogen, which is activated by passing it through a plasma or past a heated filament (at approximately $2000^{\circ} \mathrm{C}$ ) before contacting a heated substrate (at $800-1000^{\circ} \mathrm{C}$ ). The purpose of the hydrogen is to continually etch out any graphite formed in the deposit. Thus, kinetic factors allow the formation of diamond even though graphite is clearly the stable form of carbon at the temperature and pressure coriditions used.

Several other processes have been developed for producing "diamond-like" carbon coatings, in which the diamond phase is created and stabilized by bombardment of the flim by energetic species. The term "diamond-like carbon" (DLC) is used to describe a variety of noncrystalline carbon materials ranging from amorphous to microcrystalline, and typically containing anywhere from 0 to 50 atomic percent hydrogen. DLC coatings may be classified according to the method of preparation [7]. One group of methods uses solid carbon as a source of carbon-vapor atoms and molecules. High-energy particle bombardment ( $>40 \mathrm{eV}$ and up to several $\mathrm{MeV}$ ) is used during growth of the film, ether from energetic carbon primary ions or inert gas secondary ions. The second group of methods uses hydrocarbon gases as a source of carbon atoms, with some kind of electrical discharge to produce ionized and excited gas phase species. In these cases, the bombardment occurs due to floating potential differences between the substrate and the plasma.

The primary advantage of diamond or DLC films for wear resistant applications is obviously the extremely high hardness attainable. Asso, very low susceptibitity to adhesive wear (transfer of material) would be anticipated for diamond, due to the strong $\mathrm{sp}^{3}$ covalent bonding between carbon atoms. In addition, the high thermal conductivity should provlde excellent thermal shock resistance.

Processing temperatures for CVD diamond films would be much too high for piston rings, limiting the selection of processes to lower temperature ion-assisted methods, which tend to give higher contents of amorphous carbon and hydrogen. As with many ion-assisted processes, coating thicknesses are generally sinall $(e . g$. $<1 \mu \mathrm{m})$, which would require extreme wear resistance to be us(sful for piston ring applications. Due to the high elastic modulus of diamond, such coatings are anticipe ted to contain very high levels of residual stress, and adhesion to ferrous substrates would be an issue. For high temperature use, two factors may prove to be limiting: (1) graphitization and oxidation (the maxinium use temperature for natural diamond in air is approximately $600^{\circ} \mathrm{C}$, depending on impurity content) and (2) the high 
solubility and diffusivity of all forms of carbon in ferrous materials (thus, the coating may dissolve in the substrate or the wear courterface). Howevei, nelther of these should be limling factors for plston ring applications.

Since the processes for manufacturing dlamond or DLC films are so new, it is unclear how the morphology of the films may be controlled to optimize tribological properties. For example, the presence of large, facetted crystallites of diamond may cause abrasion of the sliding counterface, which would be desirable for a cutting tool, but highly undesirable for a sliding machine element (such as a piston ring) where low counterface wear is also important.

One dlamond-like coating, obtained from Implant Sclences Corporation (Danvers, MS), was evaluated during this program.

\subsection{MATERIALS SELECTION}

Requirements for a piston ring face coating material include:

1. extremely low wear rates under oil-starved boundary lubrication conditions (especially at top ring reversal, where temperatures and pressures are highest and sliding speeds are low).

?. compatiblity with the in-cylinder tribo-chemical environment (high soot content, sulphur-contaminated, acidic, oxidized lubricant flims, high relative humidity and oxidizing conditions).

3. good "scuff resistance" is desirable in case of temporary loss of oll fitm in the engine (under short duration conditions of extreme hot running or on start-up, for example). The term "scuff resistance" is not well-defined but, in the context of piston ring coatings, an important factor is the resistance to adhesive wear (transfer of material to the counterface). In the piston ring industry, the need for improved scuffing properties has been a driving force for selecting plasma sprayed and wire sprayed molybdenum-based coatings in place of electroplated hard chromium $[4,8]$.

4. the coating must not cause excessive wear of the cylinder liner material (typlcally pearlitic or hardened grey cast iron). Extensive engine testing of alternathe coatings by one ring manufacturer established a general trend of increasing liner wear as the wear resistance of the ring was improved [4]. Thus, the selection of a tribological system involves a trade-off between ring and liner wear.

5. Low friction coefficients in the mid-stroke of the piston (hydrodynamic lubrication), requiring excellent control of surface finish and low coating porosity. Engine friction studies by one ring manufacturer have shown that coatings with high porosity, such as wire-sprayed molybdenum, caused high friction compared to denser coatings [9].

6. high adherence and compatibility with piston ring substrate materials. Residual stresses arising from differential thermal expanslon of the coating and substrate can result in "break-out" of the coating during operation [3]

7. acceptable fatigue propenties. Propagation of fatigue cracks from the coating to the ring substrate would lead to ring breakage. Also, residual tensile stresses in the coating or substrate would be undesirable.

8. good thermal shock resistance.

Given the diversity of processes suitable for coating piston rings and cylinder liners, the range of materials which could be applied is virtually unlimited. The selection criteria place a premium on good tribological properties, however a major problem in materials selection for wear resistant applications is that there are no simple predictive tools. For example, the lack of correlation between coating microhardness values and wear coefficients is illustrated graphically in Figure 3 (using data generated during this program). For this reason, Cummins has taken an experimental approach, developing laboratory wear test procedures to screen candidate materials under conditions simulating the top ring reversal environment. Engine testing to validate the screening tests and, if necessary, refine the test procedures is in progress. 


\section{WEAR - HARDNESS RELATIONSHIP \\ Various Coatings Sliding ve Grey Iron \\ Fresh Oll Lubricated, $200^{\circ} \mathrm{C}$}

Boride Diffusion APS ZTY

HVOF NICrBSi

APS Armacor M

APS MO-MOO2

APS $\mathrm{Cr}$

APS A1203-26\%ZrO2

APS Cr203-50\%A1203

APS Tribolite

APS MO-Ni

APS Armacor T

EP Cr

APS A1203-41\%ZrO2

APS $\mathrm{Cr} 2 \mathrm{O3}$ (BIRL)

HVOF WC-12\%Co (TMT)

LPPS Ferrotic CS40

HVOF Cr3C2-20\%NICr

LTAVD CrN

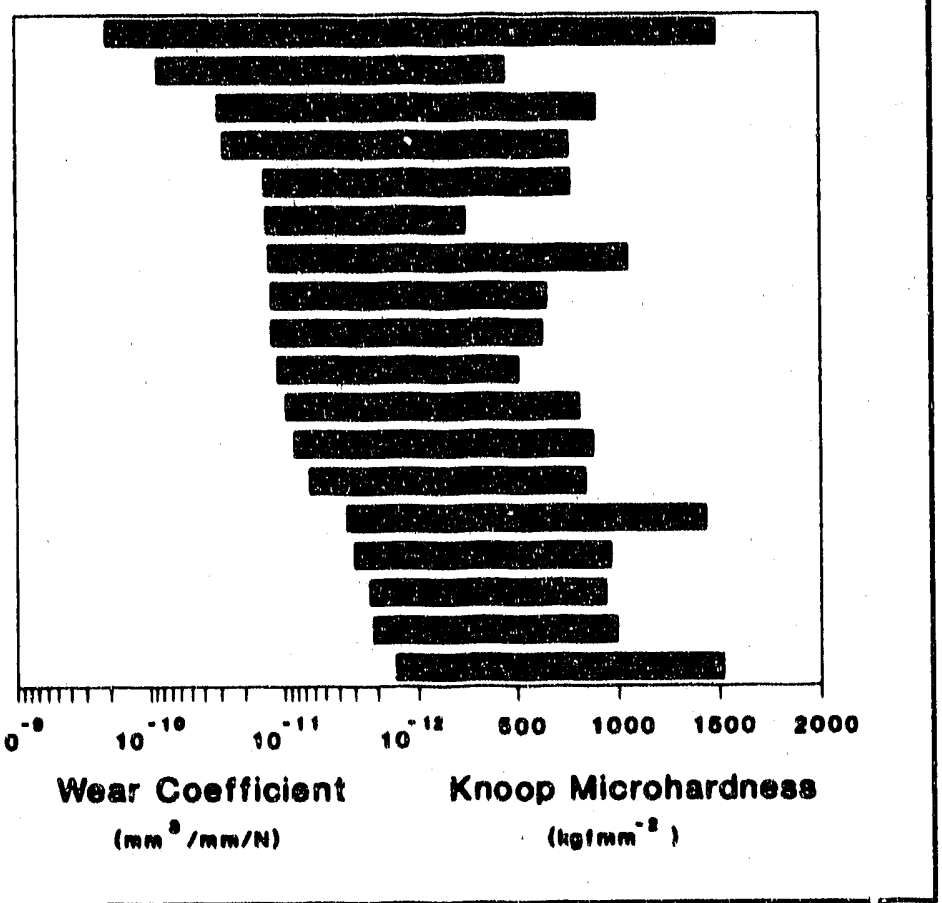

Figure 3. Microhardness values and lubricated sliding wear coefficients (fresh oll, 2000 C) for a range of coatings tested in this program. 
Selection of the Initial candidate coatings for evaluation in this program was made largely on the basis of recommendations from suppliers based on successful applications (often not in diesel engines), and also on the basis of some limited engine testing of thermal sprayed coatings during TACOM-funded "Adiabatic Dlesel Engine" programs at Cummins in the early 1980's. In view of the lack of objective selection criterla, it was decided to include as broad a range of materlals and acrva. Iced coating processes as possible. During the program, further coatings were selected, and work on other systems was discontinued on the basis of the test results obtained.

Due to the large number of coatings evaluated and the multiplicity of test conditions, screening of ring coating materials was performed using one liner material as the countertace. The decision to test coated rings rather than coated liners was made primarily because current high speed diesel engines normally use a hard ring facing (typically electroplated hard chromium) sliding against a softer cylinder liner, although in some automotive, motorcycle and medlum/low speed diesel engines, the reverse combination (coated liners and uncoated grey lron rings) is used. In onder to maintain low oll consumpition of the engine over a long service life (commonly greater than 500,000 milles to first major overhaul), it is essential to maintain certain critical dimensions of the ring proflle. Liner wear depths are typically low enough with current materlals that geometry and surface finishes (at least in the mid-stroke reglon) are not changed to the point of affecting oil consumption. For these reasons, the approach taken was to develop a highly wear resistant ring facing which would not cause increased liner wear compared to traditional ring materials. A conventional liner material (pearlitic grey cast iron) was selected as the sliding counterface for this program because it is likely that any new ring coating would have to be compatible with existing cylinder liner materials. Alternathe liner materials and coatings were also evaluated for one ring coating: a HVOF $\mathrm{Cr}_{3} \mathrm{C}_{2}-20 \%$ NiCr ldenifiled as providing the best combination of low ring and liner wear in the first round of testing with conventional liners. 


\section{COATING DEVE! OPMENT ACTIVITIES}

This section contains detalled descriptions of the coating development actitiles and characterization of coating microstructures. Wear-resistant coatings evaluated during this program are listed in Table 1 (metallic coatings), Table 2 (ceramic coatings) and Table 3 (cermet materials). Coatings were developed and supplied by various organizations, as summarized in Tables 1 - 3 . The coating subcontractors were:

APS Materials, Inc., Dayton, Ohio

Basic Industrial Research Laboratory (BIRL), Northwestern University, Evanston, Illinois

Boyd Machine \& Repair Company, Inc., Kimmell, Indiana

Implant Sciences Corporation, Danvers, Massachusetts

Turbine Metal Technology, Inc., Tujunga, Calfornla

United Technologies Research Center, East Hartiord, Connecticut

Vapor Technologies, Inc., Boulder, Colorado

Coating development actwities at each subcontractor are described in the following section. The coatings evaluated are listed in Tables 1 (metallic), 2 (ceramic) and 3 (cermet). Microhardness values were determined for each coating, where possible (Tables 1 - 3). For these tests, a Tukon microhardness tester equipped with a Knoop indenter was used. The applied load was normally 100 gf. Indentations were aligned such that the long diagonal was parallet to the suisstrate interface, 1.e. With the indentations parallel to the splat boundaries for thermal sprayed coatings.

Table 1. Metallic ring coating materials investigated.

\begin{tabular}{|l|l|l|c|}
\hline \multicolumn{1}{|c|}{ Coating } & \multicolumn{1}{|c|}{ Substrate } & \multicolumn{1}{c|}{ Supplier } & $H_{100}$ \\
\hline Electroplated Chromium & Ductile Iron & Cummins & 880 \\
APS Chromium & 422 Stainless & APS Materials & 250 \\
HVOF2 NiCrBSI & 422 Stainless & UTRC & 900 \\
APS MO $-25 \% \mathrm{NI}$ & 422 Stainless & BIRL & 510 \\
HVOF Mo $-25 \% \mathrm{Ni}$ & 422 Stainless & BIRL & 540 \\
APS MO-MoO & 422 Stainless & BIRL & 770 \\
APS Tribolite & 422 Stainless & APS Materials & 630 \\
APS Armacor M & HK40 Stainless & APS Materials & 760 \\
APS Armacor T & HK40 Stainless & APS Materials & 810 \\
\hline
\end{tabular}

1 APS = Air Plasma Spray

2 HVOF = High Velocity Oxy-Fued 
Table 2. Ceramic ring coating materlals investigated.

\begin{tabular}{|c|c|c|c|}
\hline Coating & Substrate & Supplier & $H K_{100}$ \\
\hline 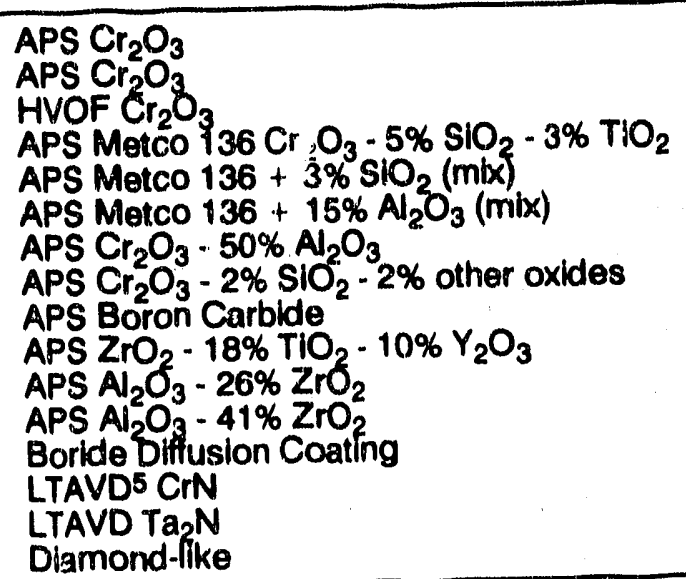 & $\begin{array}{l}\text { HK40 Stainless } \\
422 \text { Stainless } \\
422 \text { Stainless } \\
\text { HK40 Stainless } \\
\text { HK40 Stainless } \\
\text { HK40 Stainless } \\
422 \text { Stainless } \\
422 \text { Stainless } \\
422 \text { Stainless } \\
422 \text { Stainless } \\
422 \text { Stainless } \\
422 \text { Stainless } \\
422 \text { Stainless } \\
\text { H13 tool steol } \\
\text { H13 tool steel } \\
\text { H13 tool steel }\end{array}$ & $\begin{array}{l}\text { APS Materials } \\
\text { BIRL } \\
\text { BIRL } \\
\text { APS Materials } \\
\text { APS Materials } \\
\text { APS Materials } \\
\text { BIRL } \\
\text { UTRC } \\
\text { APS Materials } \\
\text { UTRC } \\
\text { BIRL } \\
\text { BIRL } \\
\text { TMT } \\
\text { Vapor Tech } \\
\text { Vapor Tech } \\
\text { Implant Sci }\end{array}$ & \begin{tabular}{r}
770 \\
1440 \\
1320 \\
960 \\
1020 \\
1260 \\
650 \\
850 \\
\multicolumn{2}{|c|}{} \\
450 \\
1050 \\
840 \\
14904 \\
$1520^{6}$ \\
.7 \\
.8
\end{tabular} \\
\hline
\end{tabular}

Table 3. Cermet ring coating materials investigated.

\begin{tabular}{|c|c|c|c|}
\hline Coating & Substrate & Supplier & $H K_{100}$ \\
\hline 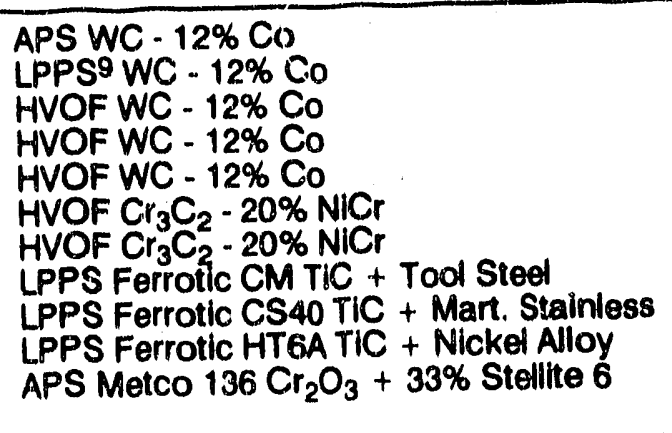 & $\begin{array}{l}\text { HK40 Stainless } \\
\text { HK40 Stainless } \\
\text { HK40 Stainless } \\
\text { HK40 Stainless } \\
422 \text { Stainless } \\
422 \text { Stainless } \\
422 \text { Stainless } \\
422 \text { Stainless } \\
422 \text { Stainless } \\
422 \text { Stainless } \\
\text { HK40 Stainless }\end{array}$ & $\begin{array}{l}\text { APS Materials } \\
\text { APS Materials } \\
\text { APS Materials } \\
\text { Boyd Machine } \\
\text { TMT } \\
\text { TMT } \\
\text { UTRC } \\
\text { APS Materials } \\
\text { APS Materials } \\
\text { APS Materials } \\
\text { APS Materials }\end{array}$ & $\begin{array}{c}1240 \\
1130 \\
880 \\
1120 \\
960 \\
500^{10} \\
990 \\
990 \\
940 \\
620 \\
1250^{11} \\
440^{12}\end{array}$ \\
\hline
\end{tabular}

3 Coating was too porous for microhardness test

$425 \mathrm{gfl}$ load

5 LTAVD = Low Temperature Arc Vapor Deposition

6 logf load.

7 too thin to measure.

8 too thin to measure.

9 LPPS = Low Pressure Plasma Spray

$1050 \mathrm{gf} \mathrm{load}$

11 Matrix $\mathrm{Cr}_{2} \mathrm{O}_{3}$ phase $\left(\mathrm{HK}_{10}\right)$

12 Stellite 6 phase $\left(H K_{10}\right)$ 


\subsection{COATING DEVELOPMENT AT APS MATERIALS INCORPORATED}

\subsection{Chromium Oxide-Based Coatings}

Chromium oxide was selected as a promising candidate for piston ring coatings on the basis of previous successful performance during uncooled engine tests at Cummins [10].

A study of the effect of plasm a spray process variables on coating adhesion and microstructure was conducted for air plasma sprayed (APS) chromium oxide $\left(\mathrm{Cr}_{2} \mathrm{O}_{3}\right)$. Two powders wero used: a commercial $\mathrm{Cr}_{2} \mathrm{O}_{3}-5 \% \mathrm{TIO}_{2}-3 \% \mathrm{SiO}_{2}$ (Metco 136) and a pure $\mathrm{Cr}_{2} \mathrm{O}_{3}$ materal (UCAA). In all cases, a Metco 447 bond coat was used. "The test parameters are listed in Table 4, key variables being powder composition, powder feed gas (argon or oxygen), powder feed rate and spray velocity (arc gas flow rate). Two guns were used: an Avco gun for lower velocities, and a Plasmadyne SG-100 gun with various nozzles for higher velocities (tests 9, 10, 13 and 14 produced Mach 1 spray velocitles). In addition, test 15 used an inert argon shroud around the plasma spray.

Table 4. Chromium oxide plasma spray parameters.

Test 15 used an inert argon shroud with nitrogen coolers.

\begin{tabular}{|c|c|c|c|c|c|c|c|c|c|}
\hline Test & Amps & Volts & $\begin{array}{c}\text { Arc Gas } \\
\text { Feod }\end{array}$ & Mix Gas & $\begin{array}{c}\text { Pwdr } \\
\text { Gas } \\
\text { Feod }\end{array}$ & $\begin{array}{l}\text { Hopper } \\
\text { Speed }\end{array}$ & Gun & Nozzle & Powder \\
\hline 1 & 600 & & 40 & $12-\mathrm{He}$ & & $40 \%$ & Avco & 065 & M-136 \\
\hline 2 & 500 & & 40 & $12-\mathrm{He}$ & & $40 \%$ & Avco & 065 & M-136 \\
\hline 3 & 500 & & 60 & $3-\mathrm{Hyd}$ & 10 & $30 \%$ & Avco & 315 & M-136 \\
\hline 4 & 500 & & 60 & $3-\mathrm{Hyd}$ & 10 & $30 \%$ & Avco & 315 & UCAR \\
\hline 5 & 600 & & 40 & $12-\mathrm{He}$ & $20-\mathrm{Oxy}$ & $1 \%$ & Avco & 315 & M-136 \\
\hline 6 & 600 & & 40 & $12-\mathrm{He}$ & $20-\mathrm{Oxy}$ & $1 \%$ & Avco & 315 & UCAR \\
\hline 7 & 900 & 35 & 50 & $60-\mathrm{He}$ & 12 & $1 \%$ & SG-1130 & 165 & M-136 \\
\hline 8 & 900 & 35 & 50 & $60-\mathrm{He}$ & 12 & $1 \%$ & SG-100 & 165 & UCAR \\
\hline $8-\mathrm{A}$ & 700 & 34 & 50 & $60-\mathrm{He}$ & 15 & $1 \%$ & SG-100 & 165 & UCAR \\
\hline $8-\mathrm{B}$ & 700 & 34 & 50 & $60-\mathrm{He}$ & 15 & $1 \%$ & SG-100 & 165 & M-136 \\
\hline 9 & 700 & 52 & 270 & $45-\mathrm{Ar}, \mathrm{N}$ & 18 & $3 \mathrm{rpm}$ & SG-100 & 360 & M-136 \\
\hline 10 & 700 & 52 & 270 & $45-\mathrm{Ar}, \mathrm{N}$ & 18 & $3 \mathrm{rpm}$ & SG-100 & 360 & UCAR \\
\hline 11 & 700 & 34 & 50 & $60-\mathrm{He}$ & 15 & $1 \%$ & SG-100 & 165 & M-136 \\
\hline 12 & 700 & 34 & 50 & $60-\mathrm{He}$ & 15 & $1 \%$ & SG-100 & 165 & UCAR \\
\hline 13 & 1000 & 45 & 115 & $45-\mathrm{Ar}, \mathrm{N}$ & 10 & $1.4 \mathrm{rpm}$ & SG-100 & 360 & M-136 \\
\hline 14 & 1000 & 45 & 115 & $45-\mathrm{Ar}, \mathrm{N}$ & 10 & $1.4 \mathrm{rpm}$ & SG-100 & 360 & UCAR \\
\hline 15 & 900 & 51 & 116 & $83-\mathrm{He}$ & 6 & $1.4 \mathrm{rpm}$ & SG-100 & 165 & M-136 \\
\hline
\end{tabular}




\section{TENSILE BOND STRENGTH OF CHROMIUM OXIDES APS Materials}

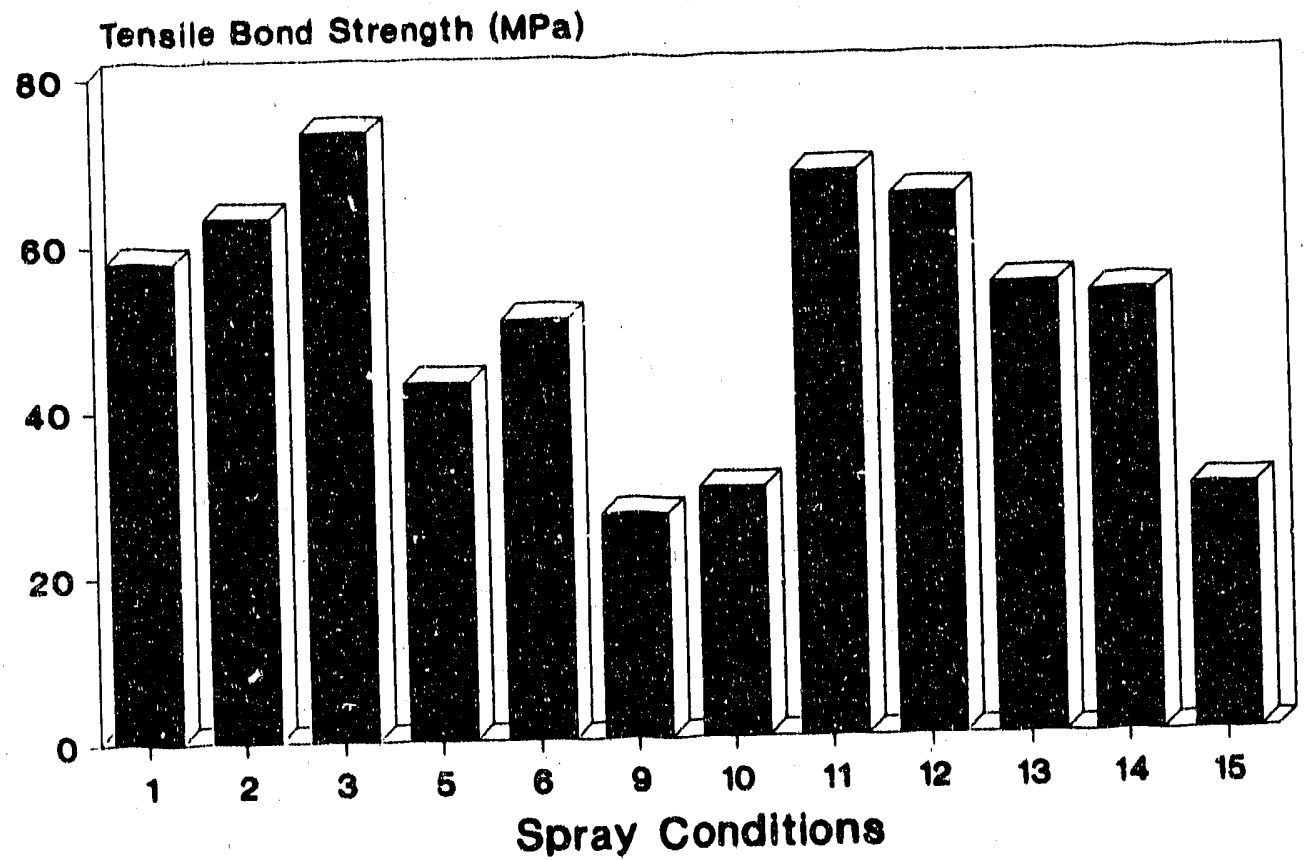

Figure 4. Tensile bond strength data for APS chromium oxide coatings produced by various spray conditions (listed in Table 4).

The bond strengths of coatings sprayed onto steel test coupons were measured by tenslle pull tests (using fixtures bonded to the coating with epoxy cement). Bond strength data are presented in Figure 4 and Table 5 . Light microscopy was used to determine the relative porostity levels of the coatings on these sample coupons (Table 6).

The following conclusions were drawn from the above study:

1. The pure $\mathrm{Cr}_{2} \mathrm{O}_{3}$ had slightly greater adherence than the Metco 136 (disregarding fallures in the epoxy), but there was no significant effect on density.

2. The oxygen powder feed gas produced higher densitles but lower bond strengths than with argon. The lower bond strength may have resulted from oxidation of the bond coat.

3. Reducing the powder feed rate resulted in slightly higher bond strength, but had no effect on density.

4. Higher velocity coatings generally had lower bond strengths. There was no consistent effect of velocity on density for these conditions.

5. The argon shroud with inert cooling produced a coating with failly low bond strength and average density. 
Table 5. Tensile bond test data for APS chromium oxide coatings produced by varlous spray conditions (listed in Table 4).

\begin{tabular}{|c|c|c|c|c|c|c|}
\hline Test & $\begin{array}{l}\text { Force } \\
\text { (kN) }\end{array}$ & $\begin{array}{l}\text { Tensile } \\
\text { Bond } \\
\text { Strength } \\
\text { (MPa) }\end{array}$ & $\begin{array}{l}\text { Mean } \\
\text { Bond } \\
\text { Strength } \\
\text { (MPa) }\end{array}$ & $\begin{array}{c}\text { Std. } \\
\text { Devlation } \\
\text { (MPa) }\end{array}$ & Powder & Failure Mode \\
\hline 1 & $\begin{array}{l}29.4 \\
25.8 \\
32.9\end{array}$ & $\begin{array}{l}57.9 \\
50.9 \\
64.9\end{array}$ & 57.9 & 5.7 & Metco 136 & $\begin{array}{l}\text { Bond } / 25 \% \text { Cer } \\
\text { Bond } \\
\text { Ceramic }\end{array}$ \\
\hline 2 & $\begin{array}{l}34.7 \\
31.6 \\
29.6\end{array}$ & $\begin{array}{l}68.5 \\
62.3 \\
58.4\end{array}$ & 63.1 & 4.2 & Metco 136 & $\begin{array}{l}\text { Bond/Epoxy } \\
\text { Bond/Epoxy } \\
\text { Epoxy }\end{array}$ \\
\hline 3 & $\begin{array}{l}39.1 \\
37.8 \\
34.3 \\
\end{array}$ & $\begin{array}{l}77.3 \\
74.6 \\
67.6 \\
\end{array}$ & 73.2 & 4.1 & Metco 136 & $\begin{array}{l}\text { Epoxy } \\
\text { Epoxy } \\
\text { Epoxy }\end{array}$ \\
\hline 5 & $\begin{array}{l}17.8 \\
24.5 \\
23.1\end{array}$ & $\begin{array}{l}35.1 \\
48.3 \\
45.7\end{array}$ & 43.0 & 5.7 & Metco 136 & $\begin{array}{l}\text { Bond/Cer Int } \\
\text { Bond/Cer Int } \\
\text { Bund/Cer Int }\end{array}$ \\
\hline 6 & $\begin{array}{l}22.4 \\
25.4 \\
28.0 \\
\end{array}$ & $\begin{array}{l}46.1 \\
50.0 \\
55.3 \\
\end{array}$ & 50.5 & 3.8 & UCAR & $\begin{array}{l}\text { Bond/Cer Int } \\
\text { Bond/Cer Int } \\
\text { Int/Cer }\end{array}$ \\
\hline 9 & $\begin{array}{l}13.1 \\
15.1 \\
12.5 \\
\end{array}$ & $\begin{array}{l}25.9 \\
29.8 \\
24.6\end{array}$ & 26.8 & 2.2 & Metco 136 & $\begin{array}{l}\text { Bond/Cer Int } \\
\text { Bond/Cer Int } \\
\text { Int/Band }\end{array}$ \\
\hline 10 & $\begin{array}{l}16.2 \\
14.7 \\
14.5 \\
\end{array}$ & $\begin{array}{l}32.0 \\
29.0 \\
28.5 \\
\end{array}$ & 29.8 & 1.6 & UCAR & $\begin{array}{l}\text { Bond/Cer Int } \\
\text { Bond/Cer Int } \\
\text { Int/Bnd }\end{array}$ \\
\hline 11 & $\begin{array}{l}35.6 \\
32.0 \\
35.6 \\
35.1 \\
31.4 \\
36.4 \\
\end{array}$ & $\begin{array}{l}70.2 \\
63.2 \\
70.2 \\
69.4 \\
61.9 \\
71.8 \\
\end{array}$ & 67.8 & 3.8 & Metco 136 & $\begin{array}{l}\text { Epoxy } \\
\text { Epoxy } \\
\text { Epoxy } \\
\text { Epoxy } \\
\text { Epoxy } \\
\text { Epoxy }\end{array}$ \\
\hline 12 & $\begin{array}{l}32.9 \\
34.3 \\
31.7 \\
\end{array}$ & $\begin{array}{l}65.0 \\
67.6 \\
62.6 \\
\end{array}$ & 65.0 & 2.1 & UCAR & $\begin{array}{l}\text { Epoxy } \\
\text { Epoxy } \\
\text { Epoxy }\end{array}$ \\
\hline 13 & $\begin{array}{l}23.0 \\
28.2 \\
30.9 \\
\end{array}$ & $\begin{array}{l}45.4 \\
55.7 \\
61.0 \\
\end{array}$ & 54.1 & 6.5 & Metco 136 & $\begin{array}{l}\text { Ceramic } \\
\text { Ceramic } \\
\text { Ceramic }\end{array}$ \\
\hline 14 & $\begin{array}{l}25.1 \\
22.4 \\
33.1 \\
\end{array}$ & $\begin{array}{l}49.6 \\
44.1 \\
65.4 \\
\end{array}$ & 53.0 & 9.0 & UCAR & $\begin{array}{l}\text { Epoxy } \\
\text { Epoxy } \\
\text { Epoxy }\end{array}$ \\
\hline 15 & $\begin{array}{l}14.9 \\
13.3 \\
16.2\end{array}$ & $\begin{array}{l}29.4 \\
26.3 \\
32.0\end{array}$ & 29.3 & 2.3 & Metco 136 & $\begin{array}{l}\text { Bond/Cer int } \\
\text { Bond/Cer Int } \\
\text { Bond/Cer Int }\end{array}$ \\
\hline
\end{tabular}


Table 6. Relative levels of porosity/microcracking of chromium oxide coatings assessed by light microscopy. $1=$ LOWEST, $\tilde{E}=$ HIGHEST.

\begin{tabular}{|l|c|c|c|c|c|c|c|c|c|c|c|c|c|c|c|c|c|}
\hline Test & 1 & 2 & 3 & 4 & 5 & 6 & 7 & 8 & $8 \mathrm{~A}$ & $8 \mathrm{~B}$ & 9 & 10 & 11 & 12 & 13 & 14 & 15 \\
\hline Porosity & 2 & 3 & 2 & 2 & 1 & & 1 & & 3 & 1 & 3 & 3 & 5 & 4 & 1 & & 2 \\
\hline
\end{tabular}

Wear test samples were prepared using the conditions of tests 3 and 4 (the optimum combination of bond strength and density), for all types of powder. The coatings were applied to an HK40 austenitic stainless sieel substrate (100 $\mathrm{mm}$ diameter).

The microstructure of the coating sprayed from UCAR powder is shown in Figure 5 (SEM, backscattered electron mode). Bonding between the coating, the bond coat and the substrate was generally good. The soating contains ines of microcracks/volds running parallel to the interface, which are more prevalent near the surface. These features are evidence of incomplete adhesion between splats of molten material. Regions of large-scale porosity and pull-out were observed throughout this coating, especially in areas adjacent to the bond coat. These large prores were possibly caused by interconnected crack/void networks which gave rise to weak regions in the coating which were then removed during metallographic polishing.

The Metco 136 coating showed much lower porosity and inter-splat microcrack/vold formation than the above coating (Figure 6). Pores were much smaller and were equiaxed rather than elongated parallel to the interface. Again, bonding between the coating, bond coat and substrate was good.

A $3 \%$ SIO addition was made to the Metco 136 powder in order to try to increase coating density and splat adherei se by forming increased amounts of glassy binder phase. The microstructure of this coating was inter lediate between the UCAR and Metco 136 materials (Figure 7 ) in terms of porosity and microcracking. I fferences in grey scales between splats are probably due to elemental contrast between $\mathrm{SiO}_{2}$ (lower meal atornic number, hence darker imaging) and $\mathrm{Cr}_{2} \mathrm{O}_{3}$. This indicates that the mixed powder particles melt an , solidify separately, with little mixing in the plasma. Bonding between the $\mathrm{SIO}_{2}$ and $\mathrm{Cr}_{2} \mathrm{O}_{3}$ splats was good. Equlaxed reglons containing porosity and a very fine-scale microstructure are evidence of unmelted particles being entrapped within this coating (Figure 7). The tensile bond strength was $54.1 \mathrm{MPa}$ (mean of three tests).

In order to investigate the effects of coating composition on wear, a coating was sprayed from a Metco 136 powder mixed with $15 \% \mathrm{Al}_{2} \mathrm{O}_{3}$ by weight. The microstructure shows darker imaging $\mathrm{Al}_{2} \mathrm{O}_{3}$ which is clearly differentiated from the lighter $\mathrm{Cr}_{2} \mathrm{O}_{3}$-rich matrix material (Figure 8). Both phases were melted in the plasma and solidified without mixing, and with no apparent cracking or debonding at the $\mathrm{Cr}_{2} \mathrm{O}_{3}-\mathrm{Al}_{2} \mathrm{O}_{3}$ interfaces. The content and morphology of pores and microcracks were approximately the same for this coating as for the Metco 136 coating.

Attempts were made to spray a $\mathrm{Cr}_{2} \mathrm{O}_{3}-33 \%$ Stellite 6 cermet material by mixing Metco 136 and Stellite 6 powders. The microstructure showed discrete splats of $\mathrm{Cr}_{2} \mathrm{O}_{3}$ and Stellite 6 , both phases having been melted in the plasma. Bonding between the two phases appeared to be good, with very little inter-splat cracking/voiding in this material (Figure 9). The levels of porosity and microcracking were very low for this coating. The tensile bond strength was $56.2 \mathrm{MPa}$ (mean of three tests). 


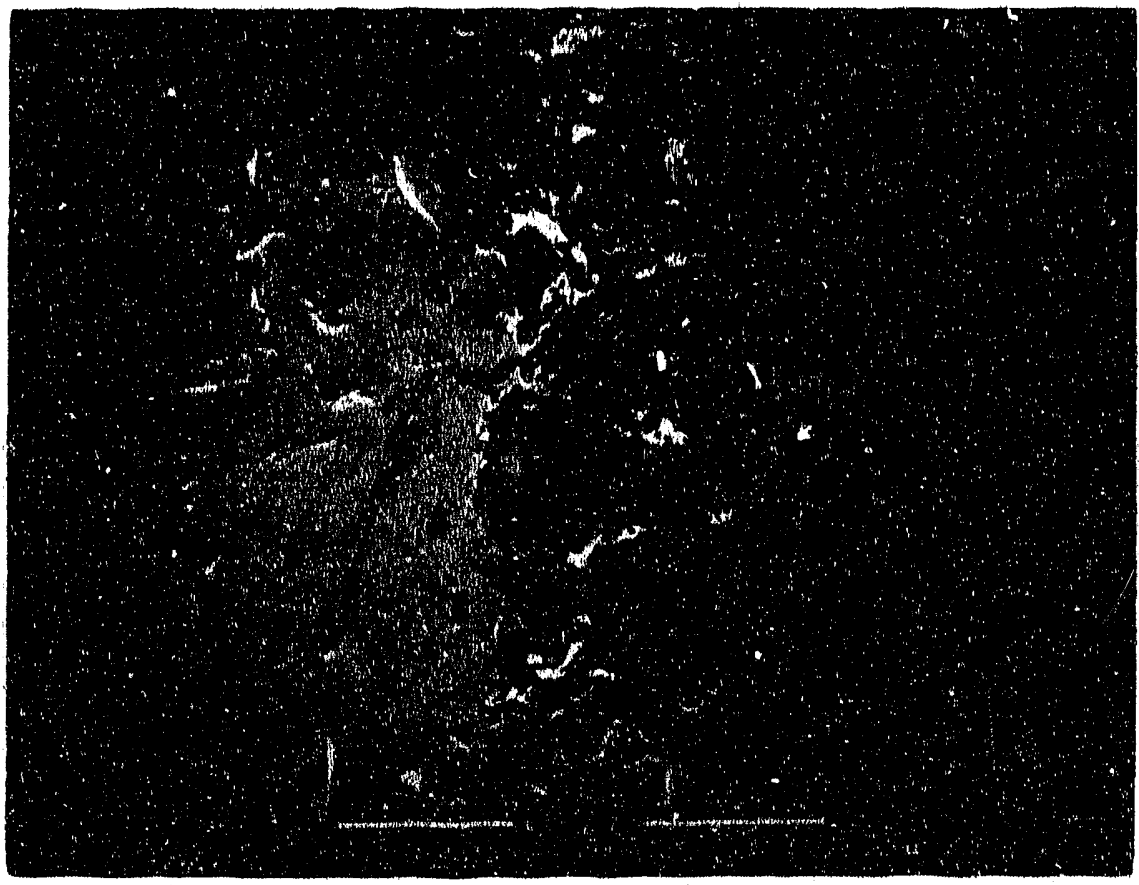

Figure 5. Microstructure of APS UCAR chromium oxide coating (SEM, backscattered electron). High levels of inter-splat microcracking and porosity/pull-out are visible.

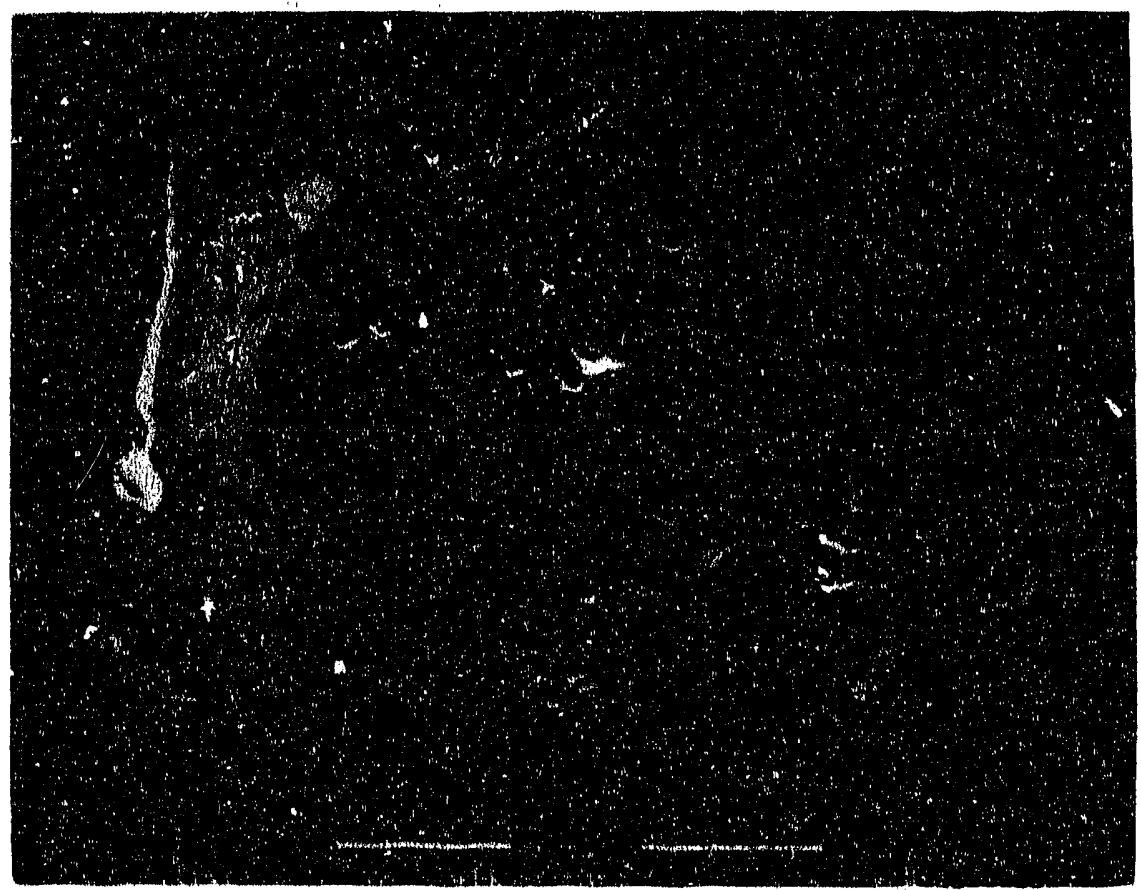

Figure 6. Microstructure of APS Metco 136 chromium oxide (SEM, backscattered electron). Low levels of porosity and inter-splat microcracking are visible. 


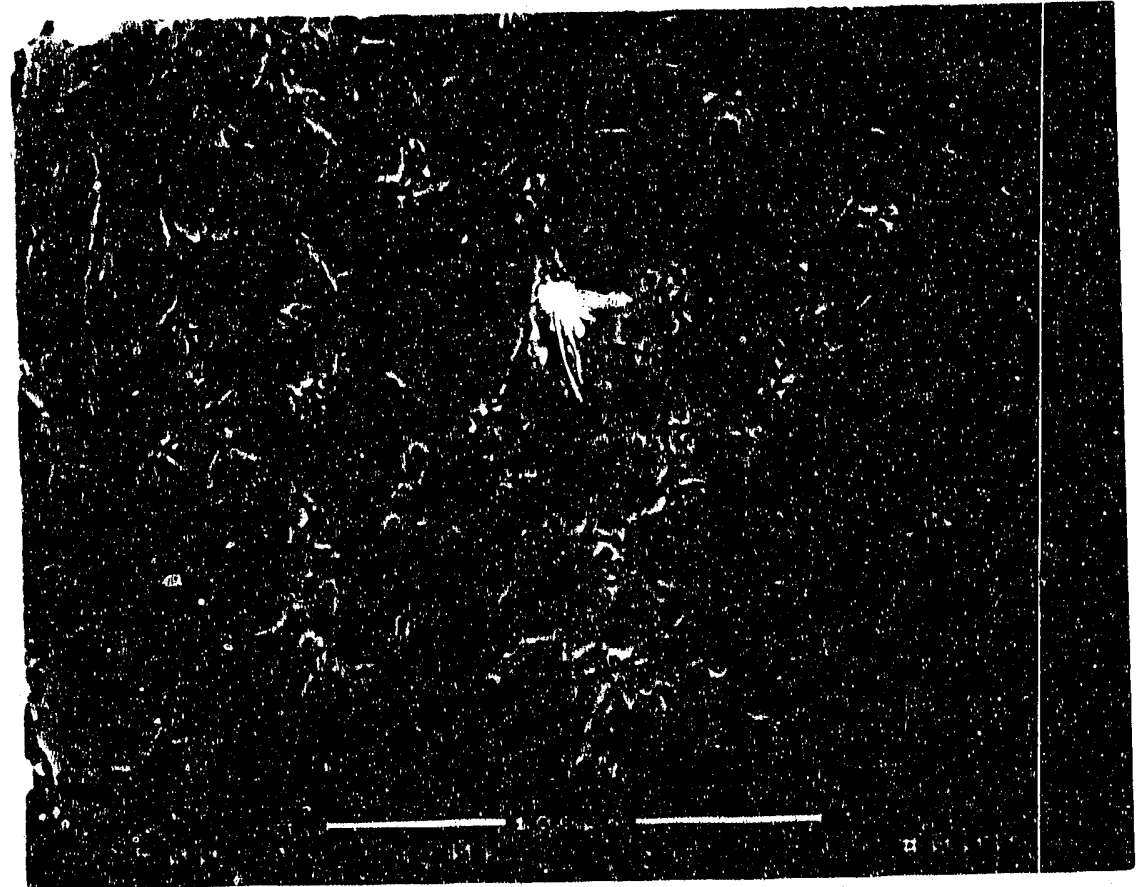

Figure 7. Microstructure of APS Metco $136+3 \%$ sllica (SEM, backscattered electron).
Darker phase is $\mathrm{SH}_{2}$ Intermediate levols of poroshy/microcrackingl are visible:

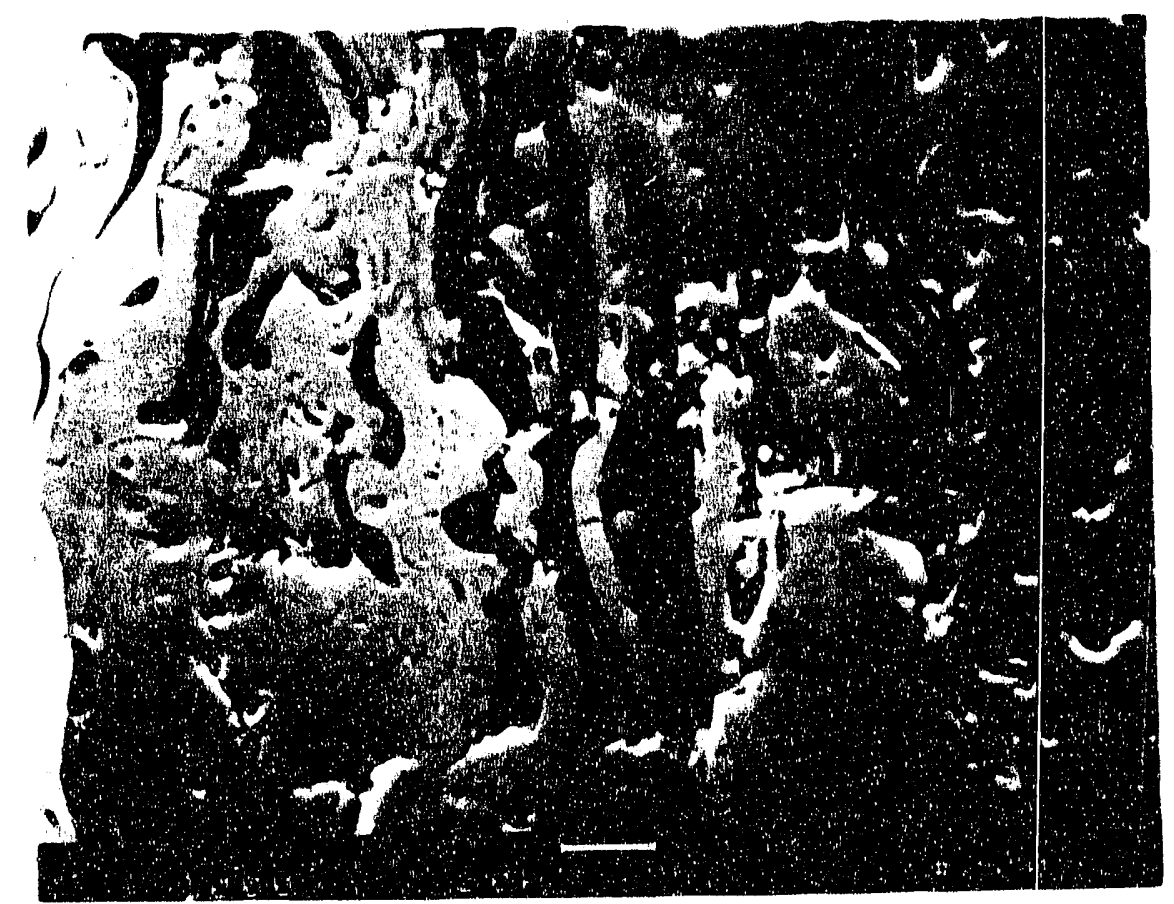

Figure 8. Microstructure of APS Metco $136+15 \%$ alumina (SEM, backscattired electinon). Darker phase is $\mathrm{A}_{2} \mathrm{O}_{3}$. Porosity leveis are low, with good interphase bonding. 


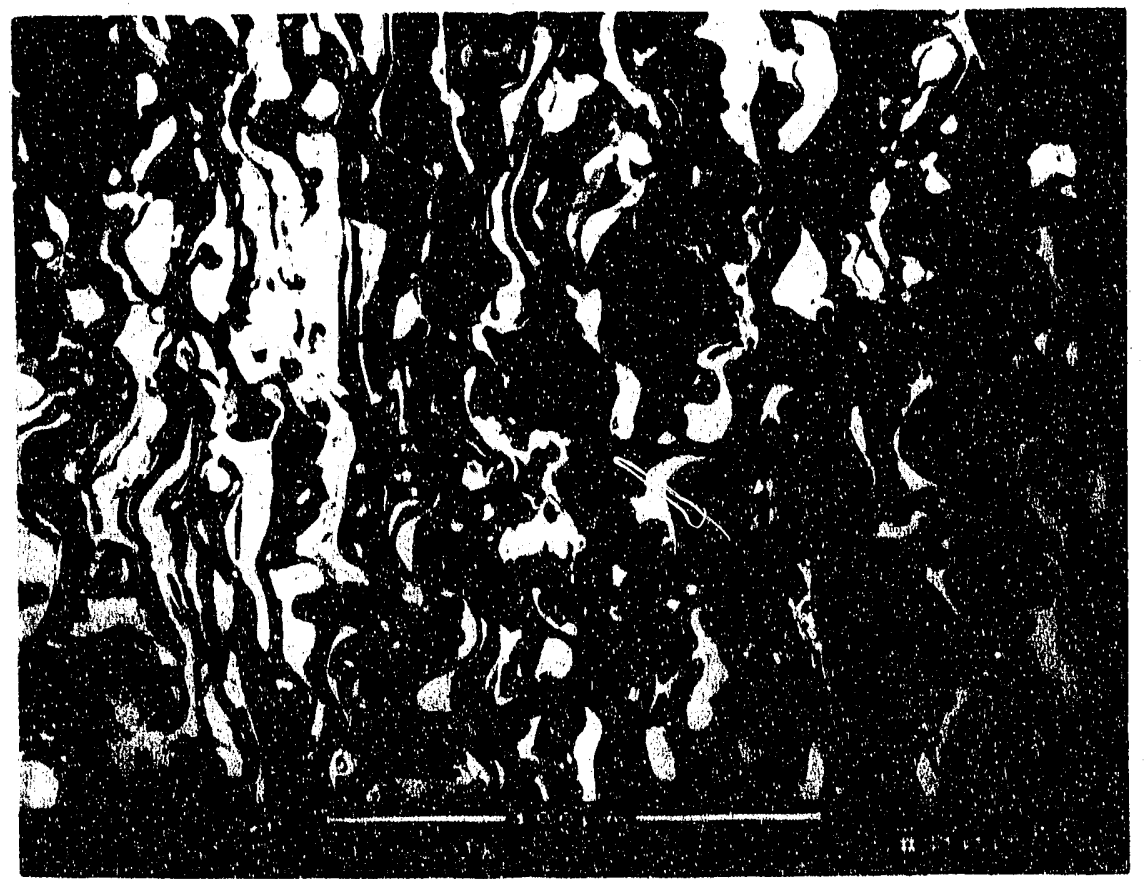

Figure 9. Microstructure of APS Metco $136+33 \%$ Stellite 6 (SEM, backscattered electron). Light phase is Stellite 6. Both phases were mehed in the plasma. Interphase bonding is good, with low porosity and inter-splat microcracking. 


\subsection{Iungsten Carbide - Cobatt Coatings}

Tungsten carbidp - cobalt coatings are widely used for wear-reckstant applications, especlally those involving abrashe or orostve wear conditions, and pouders sultable for all forms of themal spray process are readiy avatable. On this basis, tungsten cartolde materials were ovaluated as potentil ing coatings. The emphasis was to evaluate coatings produced by the most etate-of-tho-art thermal spray processes, including low pressure plasma spray (LPPS) and hlgh velochy oxy-tual (HVOF) in addhion to more conventional air plasma spray (APS) mothods.

Two important factors for themally sprayed WC - Co coatings are (a) the degree of solutionizing of the carbides in the matrx phase and (b) the amount of decarburtzation in the plasma or combustion gas. Varlous phases can be formed by combinations of dissolution and decarburization, including (in addition to WC and Co): $W_{6} \mathrm{C}, \mathrm{Co}_{6} W_{6} \mathrm{C}, \mathrm{Co}_{2} W_{4} \mathrm{C}_{1} \mathrm{Co}_{3} \mathrm{~W}_{9} \mathrm{C}_{4}, \mathrm{Co}_{3} W_{3} \mathrm{C}$ and non-stolchlometric phases generally described as $W_{1} C_{1 \times}$. Ai WC - Co coatings tested in this program were sent to BIRL for detalled X-ray difiraction (XRD) analysis (Table 7). In addition, microstructures were characterized using backscattered electron SEM micrographs, using a quadrupole detector swiched for $100 \%$ atomic number (elementail) contrast. In these images, contrast varies in proportion to the mean atomic number of the matertal (mean atomic numbers for soveral phases are listed in fable 8). Note that pure Co ls ahays the darkede imaging of the possible phases. Qualitatively, the volume fraction of the darkest phase (remaining Co) ghes a measure of the degree of solutionizing, and the volume fraction of phases brighter than wC of this can be identlifed) gives a measure of the amount of combined decarburization and solutionizing.

APS Materials produced WC - 12\% Co coatings by three difierent spray methods: alr plasma spray, low pressure plasma spray and high veloclty oxy-fuel using a "Jetkote ll" system. The stanting powder was the same (Miller Thermal 1172) for all coatings, in onder to compare the effects of the differen procesees on microstructure and wear properties. It should be appreciated that optimizing the powder for each process would porhaps have given different results.

The XRD data in Table 7 clearly show that all the themally sprayed WC - Co coatings exhlblted some degree of solutionizing, although this is not easy to quantfy, in view of the range of phases identiled. The percentage values shown in brackets I I represent the peak Irtensity of the strongest peak from the minor phase divided by the strongest WC peak intensity. These numbers do not indicate that the minor phase exists in that abundance.

Table 7. Phase anatysis of WC - Co coatings used in this program. X-ray diffraction anahysis and phase identification was pertormed at BIRL. important: Percentage values in brackets [ ] represent the peak intensity of the strongest peak trom the minor phase divided by the strongest WC peak intensity. These numbers do not indicate that the minor phase exists in that abundance.

\begin{tabular}{|c|c|c|}
\hline Coating Process & Supplier & Analysis \\
\hline Air Plasma & APS Materials & $\begin{array}{l}\mathrm{WC}+\mathrm{Co}_{2} \mathrm{~W}_{2} \mathrm{C}_{4}[12 \%]+ \\
\mathrm{Co}_{3} \mathrm{~W}_{3} \mathrm{C}[10 \%]\end{array}$ \\
\hline Low Pressure Plasma & APS Materials & $\begin{array}{l}W C+\mathrm{Co}_{2} W_{4} \mathrm{C}[16 \%]+ \\
\mathrm{Co}_{3} \mathrm{~W}_{0} \mathrm{C}_{4}[14 \%]\end{array}$ \\
\hline HVOF (Jetkote II) & APS Materials & $\begin{array}{l}\mathrm{WC}+\mathrm{CO}_{2} \mathrm{~W}_{4} \mathrm{C}[24 \%]+ \\
\mathrm{CO}_{3} \mathrm{~W}_{0} \mathrm{C}_{4}[10 \%]\end{array}$ \\
\hline HVOF ( Jetkote II) & Boyd Machine \& Repair & $w C+a-w_{2} C[13 \%]$ \\
\hline $\begin{array}{l}\text { HVOF (proprietary } \\
\text { gun) }\end{array}$ & Turbine Metal Technolocy & $\begin{array}{l}W C+W C_{1-x}[7 \%]+C_{6} W_{6} C \\
{[6 \%]}\end{array}$ \\
\hline
\end{tabular}


Backscattered electron SEM images of the APS material (Flgure 10) revealed "blocky" carbide particles with a bimodal size distribution. At least five levels of grey scale are visible, indicating the presence of several phases. The pure Co phase is present only in small concentrations, and the "marrb" phase is actually a W-CO-C phaso in most reglons. XRD phase analysis (Table 7) showed the presence of $\mathrm{Co}_{3} \mathrm{~W}_{9} \mathrm{C}_{4}$ and $\mathrm{CO}_{3} \mathrm{~W}_{3} \mathrm{C}$ phases in addition to WC. The costing also contained porosity, ranging from small, equiaxed pores within the matrix phase to large-scale porosity and pull-out extending acrose one or more carbide gralns.

The microstructure of the LPPS WC - 12\% Co coating (Figure 11) appeared qualitatively simllar to that of the APS material described above. XRD anaisis revealed a different phase mbxture, however, the LPPS material containing $\mathrm{CO}_{2} \mathrm{~W}_{4} \mathrm{C}$ and $\mathrm{CO}_{3} \mathrm{~W}_{8} \mathrm{C}_{4}$ phases. Porosity levels were simllar to those for the APS material.

One dificulty encountered with the LPPS process was that thick coatings (greater than approximately $150 \mu \mathrm{m}$ ) tended to shatter on cooling after spraying, indlcating high substrate temperatures and/or high rosidual stress in the costing. In this case, the substrate was a castable austeniltic stainless steal (HK40), which would have a greater thermal expansion mismatch with the crating than 422 martensitic stainless steel. Adherence to the substrate was found to be excellent for the LPPS matertal, however, eince tenslle bond strengths in excess of $65 \mathrm{MPa}$ were measured for coatings which survived the cool-down process.

The HVOF WC - 12\% Co coating (Figure 12) showed varbus difierences in microstructure from the APS and LPPS materials. For example, it is difilcult to differentiate the original WC grains from the matrix phases in the HVOF material. The matrix phase showed evidence of a fine-scale microstructure developing in some areas (perhaps due to preclpitation of solid phases), and some of the carbldes or W-Co-C phases appeared to be fractured (perhaps due to high residual stresses). XRD analysis showed the presence of $\mathrm{CO}_{2} W_{4} \mathrm{C}$ and $\mathrm{CO}_{3} \mathrm{~W}_{0} \mathrm{C}$ phases, as for the LPPS materlal, but the $\mathrm{CO}_{2} \mathrm{~W}_{4} \mathrm{C}$ peak was stronger (24 v8 $16 \%$ relattve intensity) and the $\mathrm{CO}_{3} \mathrm{~W}_{9} \mathrm{C}_{4}$ peak silghty weaker (10 vs $14 \%$ relative intensity). Overall, the level of solutionizing appeared to be greater for the HVOF than for the APS and LPPS coatings. This is somewhat unexpected, since the flame temperature for HVOF processes is generally much lower than for alr plasma spray.

Microhardness values for the APS, LPPS and HVOF coatings were, respectively, 1240, 1130 and $880 \mathrm{kgfmm}^{2}\left(\mathrm{KHN}_{100}\right)$, although there was considerable scatter from one location to ancther for each coating. The differences are probably caused by different amounts of decarburtzation and carbide solutionizing, as discussed above. 
Table 8. Mean atomic number for several phases which may occur in WC - Co coatings.

\begin{tabular}{|l|c|}
\hline \multicolumn{1}{|c|}{ Phase } & Mean Atomic Number \\
\hline $\mathrm{W}_{2} \mathrm{C}$ & 51.3 \\
\hline $\mathrm{Co}_{2} \mathrm{~W}_{4} \mathrm{C}$ & 50.9 \\
\hline $\mathrm{Co}_{3} \mathrm{~W}_{8} \mathrm{C}_{4}$ & 48.2 \\
\hline $\mathrm{Co}_{6} \mathrm{~W}_{6} \mathrm{C}$ & 47.1 \\
\hline $\mathrm{Co}_{3} \mathrm{~W}_{3} \mathrm{C}$ & 44.1 \\
\hline $\mathrm{WC}_{1-x}$ & $\frac{74 \cdot 6(1-x)}{(2-x)}$ \\
\hline$W C$ & 40.0 \\
\hline $\mathrm{Co}$ & 27.0 \\
\hline
\end{tabular}

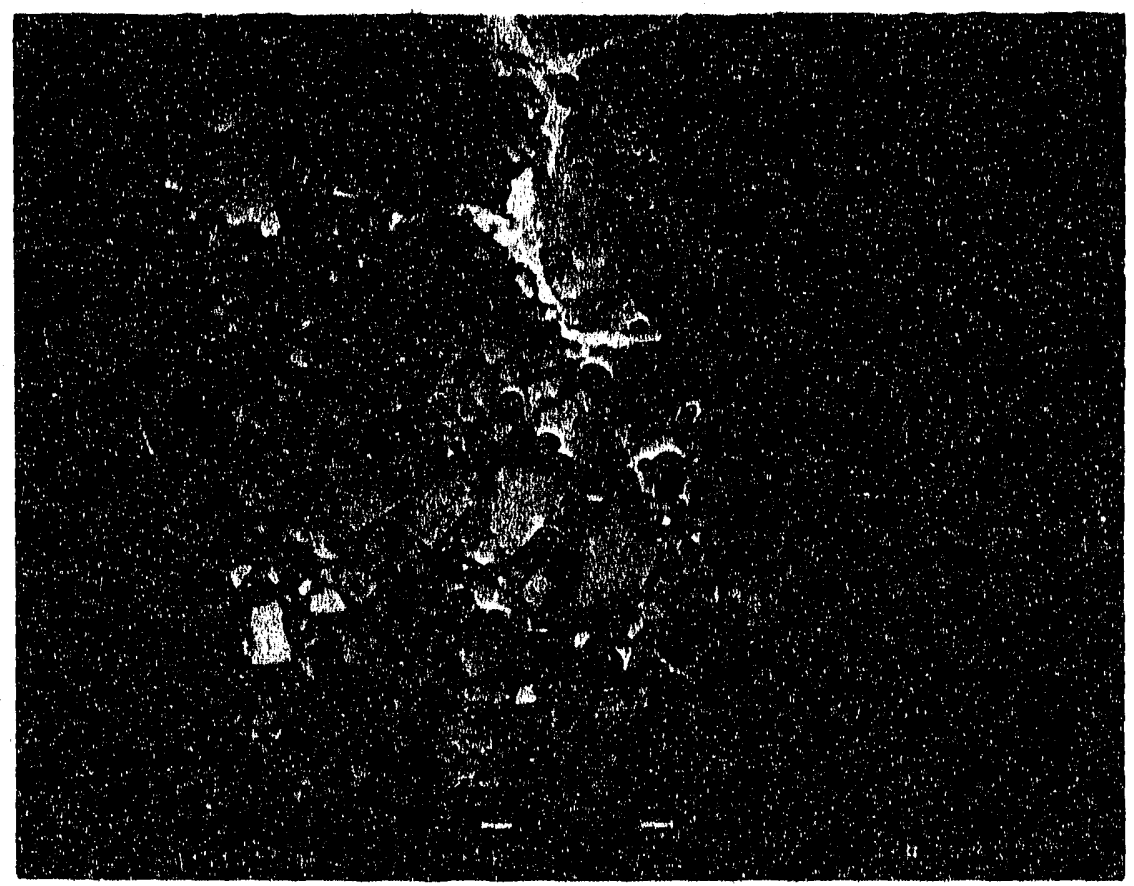

Figure 10. Microstructure of APS WC - 12\% Co coating (SEM, backscattered electron image). Coating shows blocky carbides, with evidence of several phases formed by solutionizing, re-precipitation and decarburization. The "matrix" phase is actually a $W$-Co-C phase in most regions. 


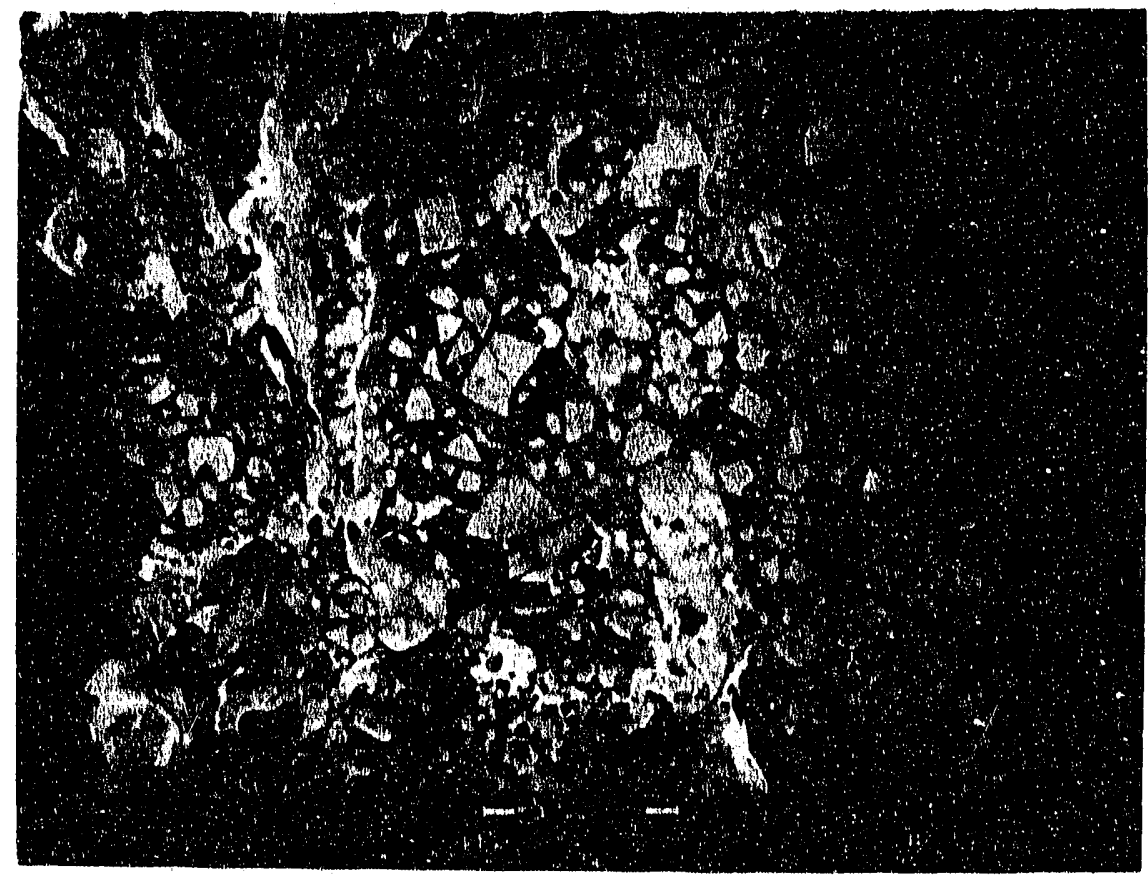

Figure 11. Microstructure of LPPS WC - 12\% Co coating (SEM, backscattered electron image). The microstructure appears to be similar to that of the APS material (Figure 10).

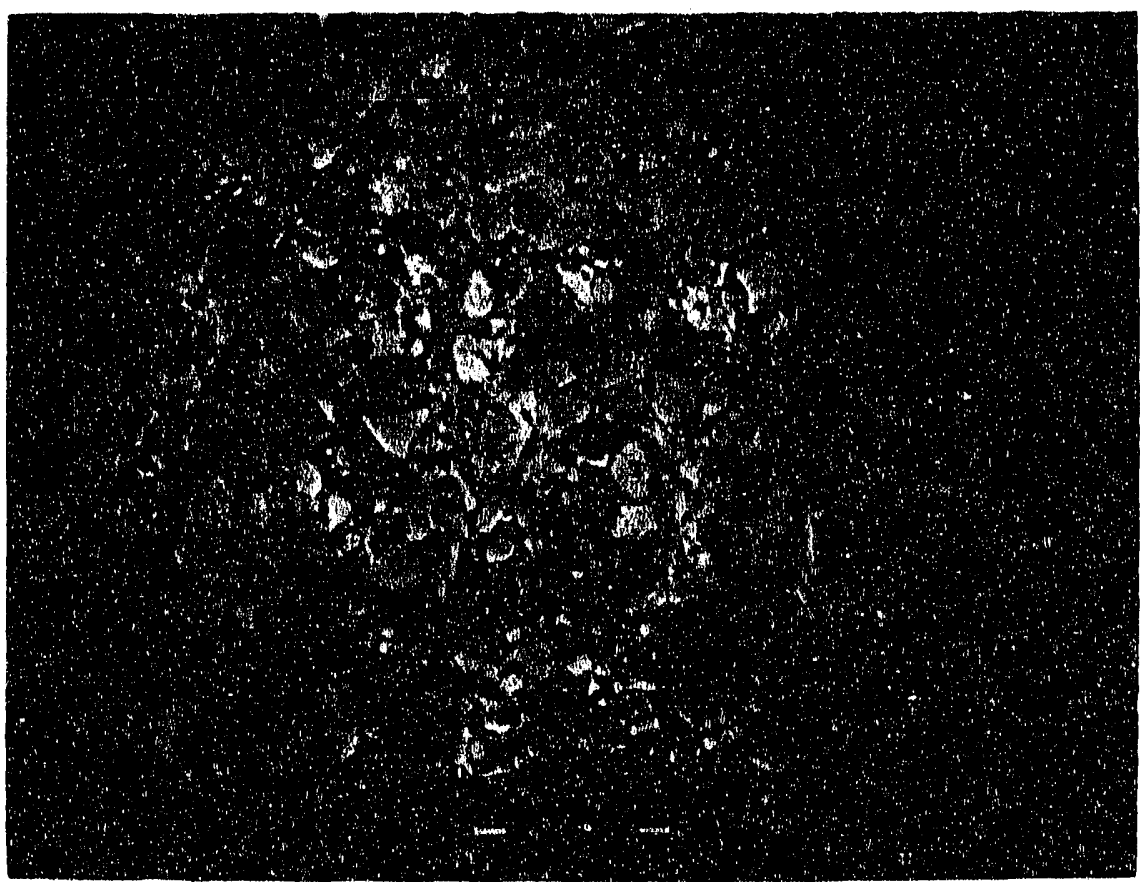

Figure 12. Microstructure of HVOF (Jet-Kote) WC - 12\% Co (SEM, backscattered electron). Microstructure as in Figures 10 and 11, but showing a higher degree of solutionizing. 


\title{
2.1.3 Ferro-Tic Coatings
}

Ferro-Tic ${ }^{13}$ materials (steel- or nickel alloy-bonded TIC) were investigated in order to broaden the range of cermet compositions studied, since WC-Co and $\mathrm{Cr}_{3} \mathrm{C}_{2}$-NiCr coatings had been found to give excellent wear properties. Product literature from Alloy Technology, Inc. claims that an important advantage of Ferro-Tic materials is that the carbide particles are rounded in shape and consequently the materials are very "lubricious". For this program, it was hoped that smooth, rounded carbldes would be less abrasive to soft pearlitic iron cylinder liner counterfaces.

Three grades of Ferro-Tic powder were evaluated. Coatings were sprayed using a LPPS system, in order to minimize decarburization effects and retain the highest possible hardness levels. The materials investigated were:
1. Ferro-Tic CM
2. Ferro-TiC CS-40
3. Ferro-Tic HT-6A

\begin{abstract}
$45 \%$ TiC in a high chrome tool steel matrix
45\% TIC in a martensitic stainless steel matrix

$35 \%$ TIC in an age hardenable nickel base matrix.
\end{abstract}

The microstructure of the CM grade material comprised $5 \mu \mathrm{m}$ sized TIC particles in a metallic matrix, with some porosity/pu"l-out and inter-splat microcracking (Figure 13). The carbide morphology was found to be equiaxed, but is best described as "blocky" rather than rounded. A fine dispersion of sub-micron sized carbides is also evident in Figure 13. It is not known whether this was due to a birnodal carbide size distribution in the starting powder or to solutionizing and re-precipitation of carbides in the matrix phase during the spray process. The steel matrix phases are assumed to have contained carbides in addition to the TiC hard phase.

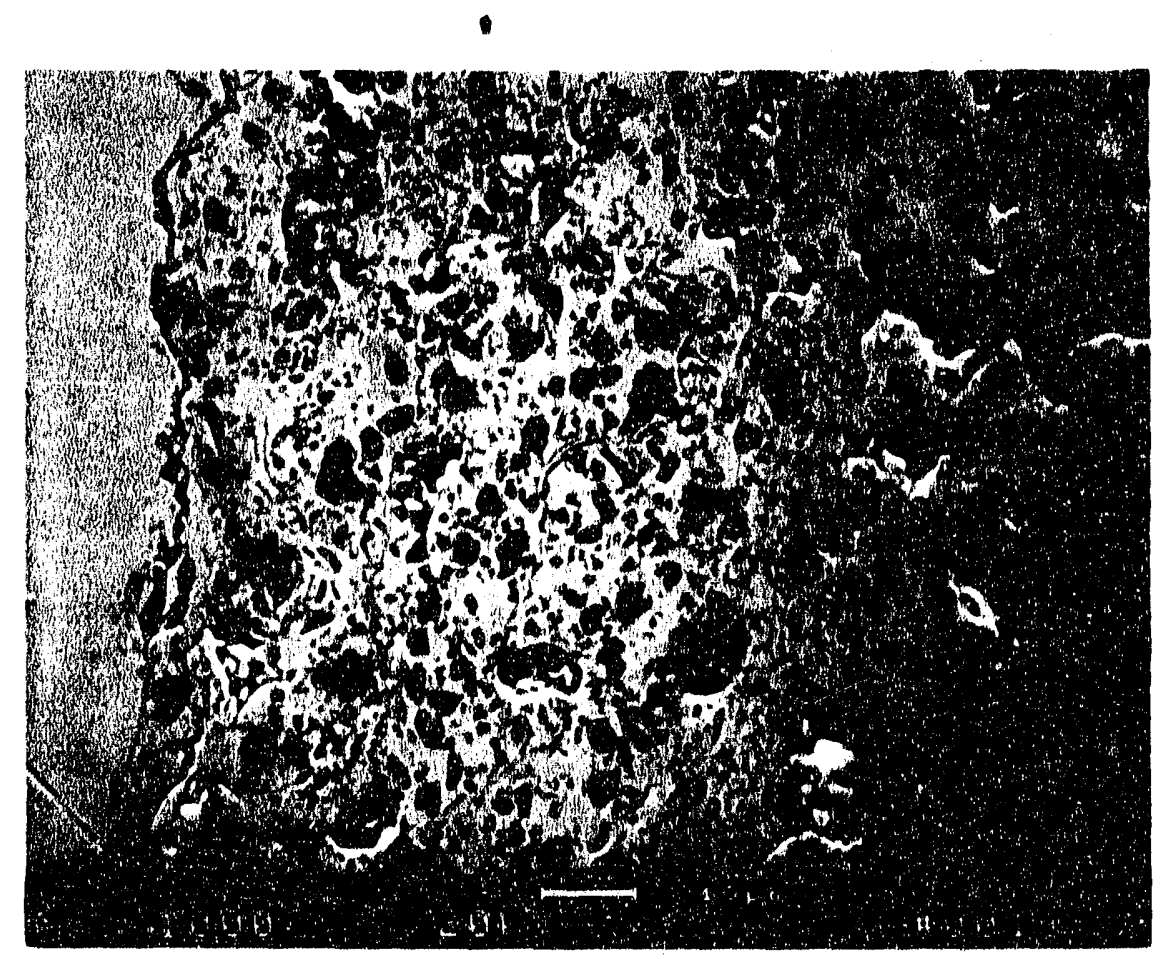

Figure 13. Microstructure of LPPS Ferro-Tic CM coating (SEM, backscattered electron image). Microstructure comprises blocky carbides (darker phase) in a steel matrix. Finer carbides may be evidence of solutionizing and re-precipitation.

13 "Ferro-Tir" is a registered trademark of Alloy Technology, Inc., Nyack, NY 


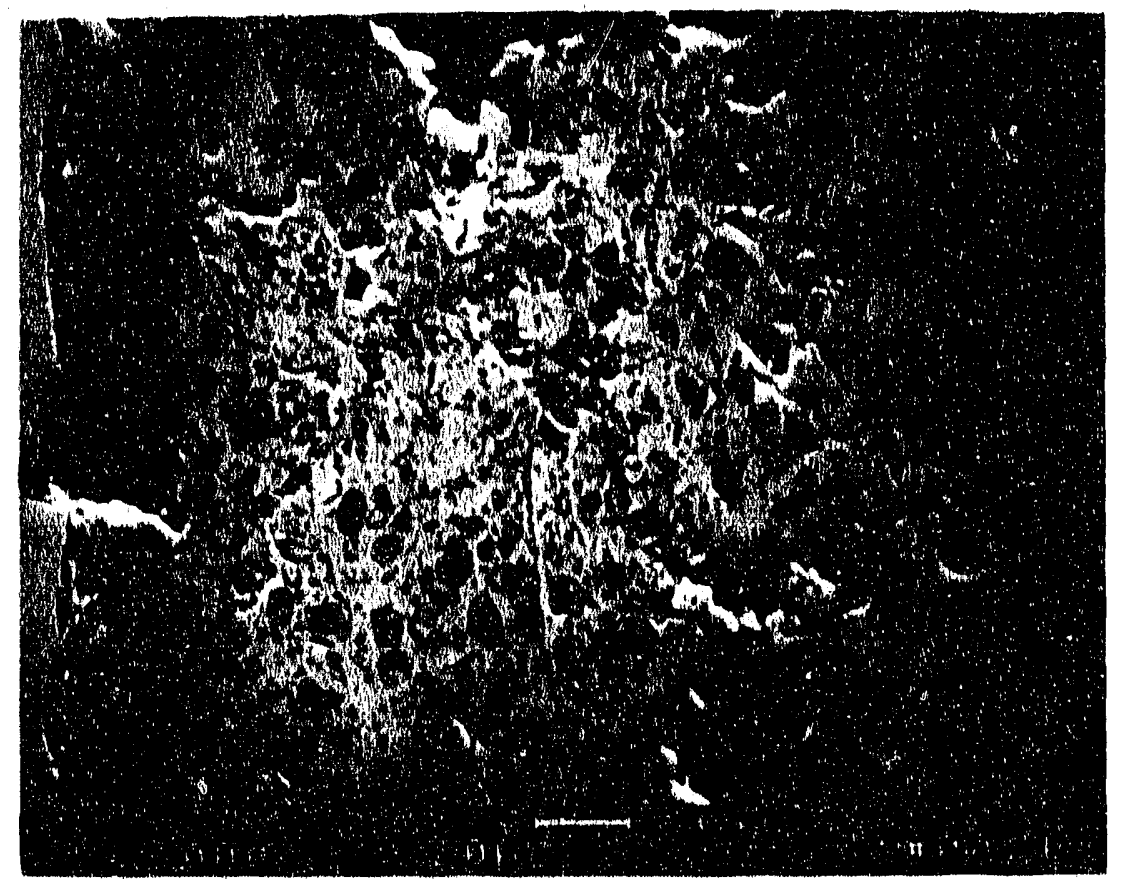

Figure 14. Microstructure of LPPS Ferro-Tic CS-40 coating (SEM, backscattered electron image). The microstructure appears to be similar to that for the CM grade (Figure 13).

Th.9 microstructure of the CS-40 grade material (Figure 14) was essentially similar to that of the CM grade, the inajor difference being the chemical composition of the matrix phase.

The $\mathrm{H}) 6 \mathrm{~A}$ material (Figure 15) contained fewer $5 \mu \mathrm{m}$ sized TiC particles than the CM and CS-40 grades, consistent with the lower carbide content of the stanting powder. The fine dispersion of carbides observed for the steel matrix grades was also observed for this material. The HT-6A coating was significantly softer ( $520 \mathrm{kgfmm}^{-2}, H K_{100}$ ) than the CM and CS-40 grades (990 and $940 \mathrm{kgfmm}^{-2}, \mathrm{HK}_{100}$ respectively).

It is important to note that, compared to the microstructures observed for the WC - Co coatings, all the Ferro-Tic materials showed less evidence of carbide solutlonizing. From the microstructural evaluation, coating adherence was identified as a concern for the Ferro-Tic materials, since all three grades showed. evidence of debonding at the substrate interface (Figures 13-15). However, tensile bond strengths measured for the three coatings were high: $70.9 \mathrm{MPa}$ for the $\mathrm{CM}$ grade, $73.0 \mathrm{MPa}$ for the CS-40 and 68.0 MPa for the HT-6A, all tests giving fracture in the epoxy. 


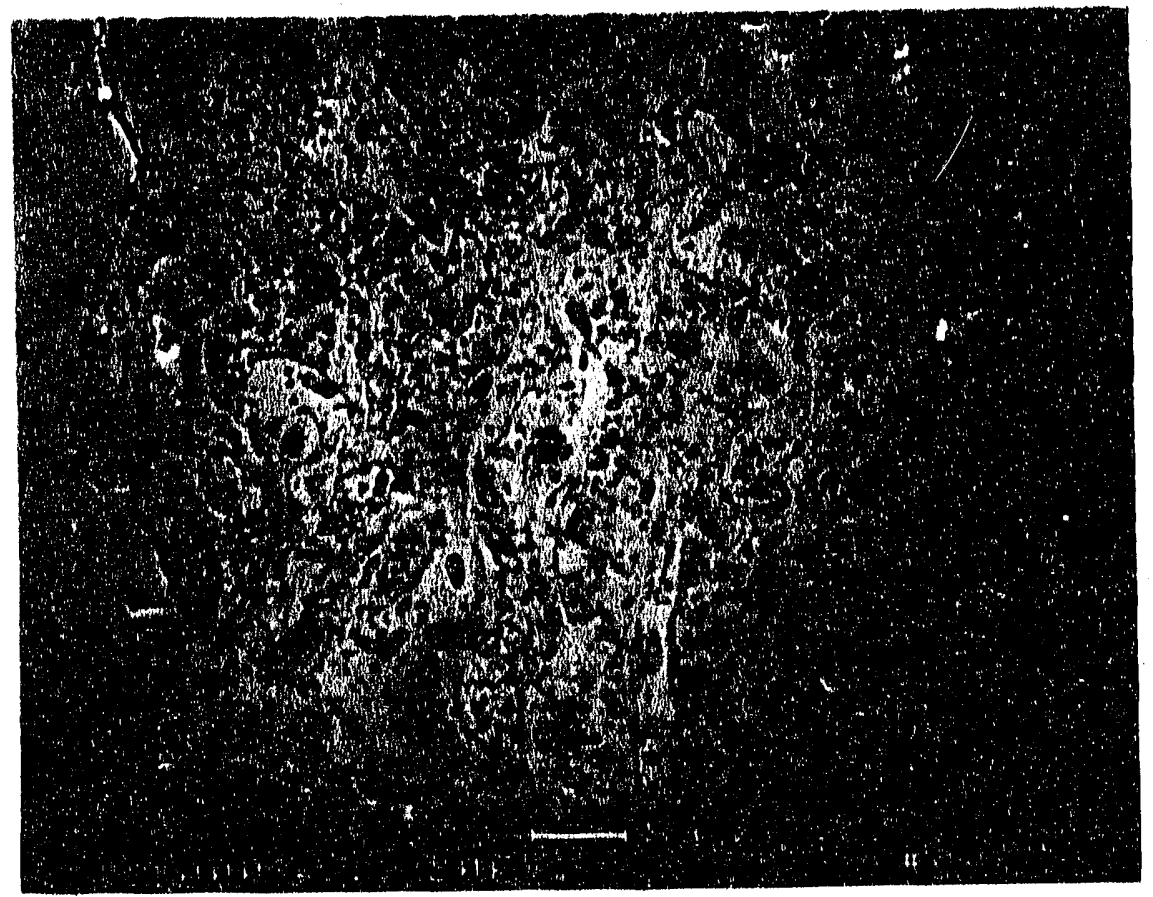

Figure 15. Microstructure of LPPS Ferro-TiC HT-6A coating (SEM, backscattered electron image). The carbide content of this coating is lower than for the CM and CS-40 grades. 


\subsubsection{Matallic Coatings}

Although the primary objective of this program was to develop ceramic and cermet coatings, a limited amount of effort was devoted to evaluating alternative metallic coatings which might show greater wear resistance than the baseline electroplated hard chromium.

Plasma sprayed chromium samples were obtained for comparison with electroplated hard chromium. The microstructure of the plasma sprayed material showed a disperslon of dark-Imaging, lamellar features, presumed to be chromlum oxlde, with excellent inter-splat bonding and adherence to the substrate (Flgure 16). The microhardness of this coating was low $\left(250 \mathrm{kgfmm}^{-2} \mathrm{HK}_{100}\right)$ compared to electroplated hard chromlum $\left(880 \mathrm{~kg} f \mathrm{~mm}^{-2}\right)$.

Figure 16. Microstructure of APS chromium coating (SEM, backscattered electron image). Darker imaging lamellar features are thought to be oxides. The coating shows excellent inter-splat bonding and adhesion to the substrate. 


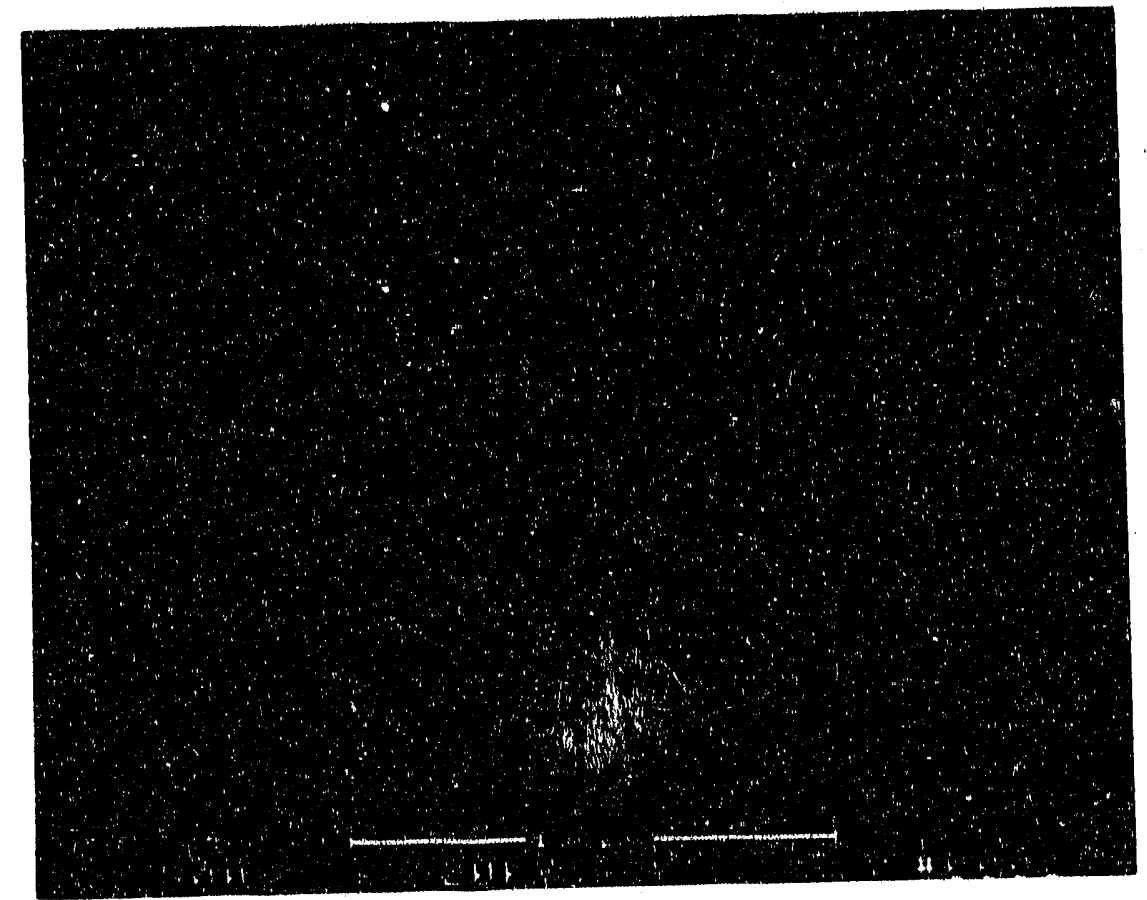

Figure 17. Microstructure of APS Tribolite coating (SEM, backscattered electron image).

Etched with Marbles reagent.

The coating comprises an extremely fine dispersion of boron carbide in an austenitic steel matrix. Porosity is very low, with excellent inter-splat bonding and adherence to the substrate.

Coatings were sprayed with a "Tribolite" powder, which is a proprietany material of Wear Management Services, Inc. Wear Management Services product ilterature describes the material as a very fine boron carbide dispersion in an austenitic steel matrix. The microstructure of the coating sprayed from this powder by APS Materials was found to contain a mixture of light imaging and dark-imaging phases, with very low porosity levels and excellent inter-splat bonding and adherence to the substrate (Figure 17). Energy dispersive $X$-ray analysis in the SEM gave a bulk coating composition of $68 \% \mathrm{Fe}, 28 \% \mathrm{NI}, 2 \% \mathrm{SI}$ and $2 \% \mathrm{Cr}$. Boron and carbon would not have been detected by this analysis technique. 


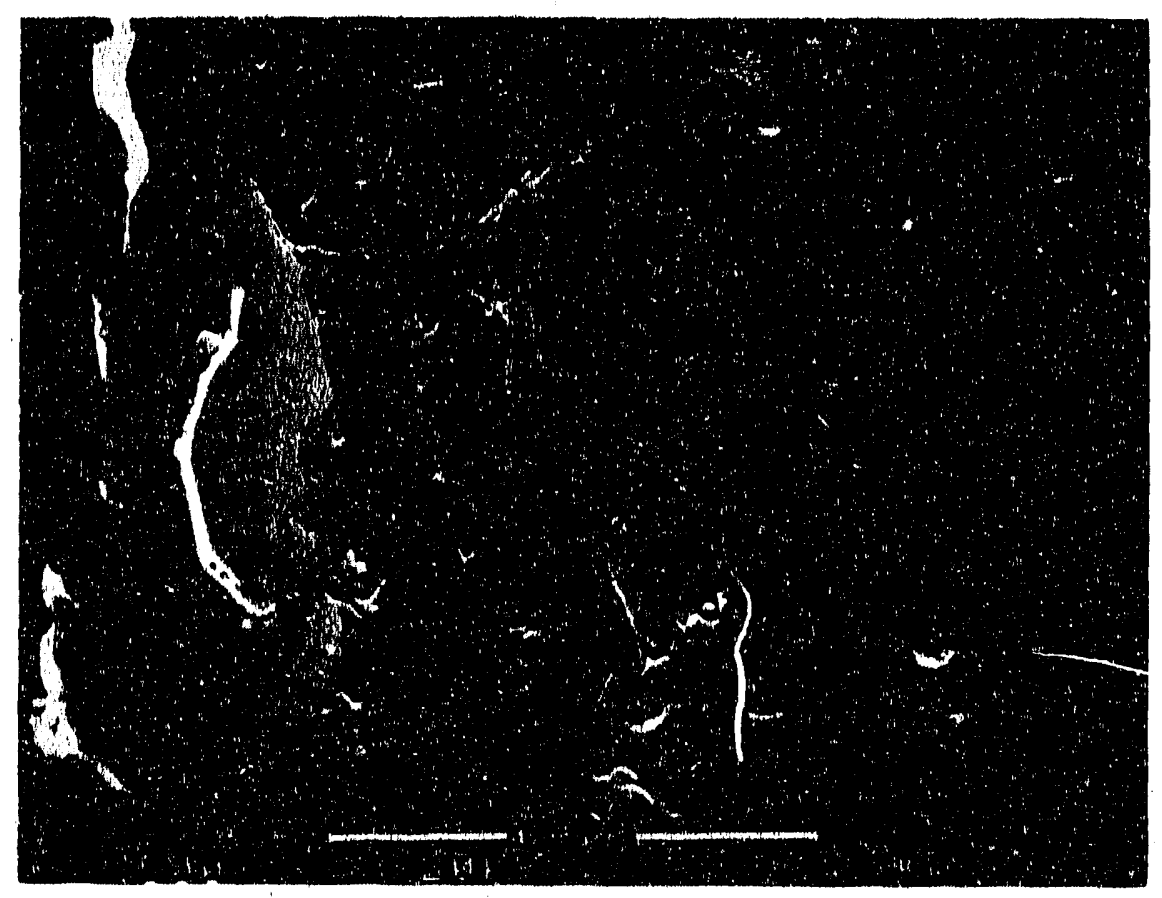

Figure 18. Microstructure of APS Armacor M coating (SEM, backscattered electron image). The coating shows a fine dispersion of carbides/borides in a metallic matrix. Porosity levels are high, and inter-splat oxidation and microcracking is visible.

Two proprietary powders, "Armacor M" and "Armacor T", were obtained from Amorphous Metals Technologles, Inc. (Irvine, CA). Armacor $M$ is an iron-based material which is claimed to produce an amorphous surface layer during grinding and abrasion processes. Product literature shows dry sand abrasive wear propertles which are comparable to WC - Co hard facings. Information about the "T" grade was not avallable.

The microstructure of the Armacor $M$ coating sprayed by APS Materlals, using conventional air plasma spray methods, is shown in Figure 18. Splat sizes were relatively large for this coating, indicating a fairly coarse starting powder. Porosity levels were relathely high, perhaps due to poor powder feeding due to the coarser paricle size. Oxide films and microcracks were observed between splats, indicating poor inter-splat adhesion. Bonding between the coating, bond coat and substrate was, however, good. Within the splats, a fine dispersion of a slightly darker imaging phase is visible in some regions (Figure 18). EDS analysis of the Armacor $\mathrm{M}$ coating revealed high levels of $\mathrm{Cr}(47 \mathrm{wt} \%$ ) and $\mathrm{Fe}(44 \mathrm{wt} \%)$ with some $\mathrm{Ni}$ $(2 w \%)$ and SI (6 wt\%). WDS light element analysis was not performed for this coating. 


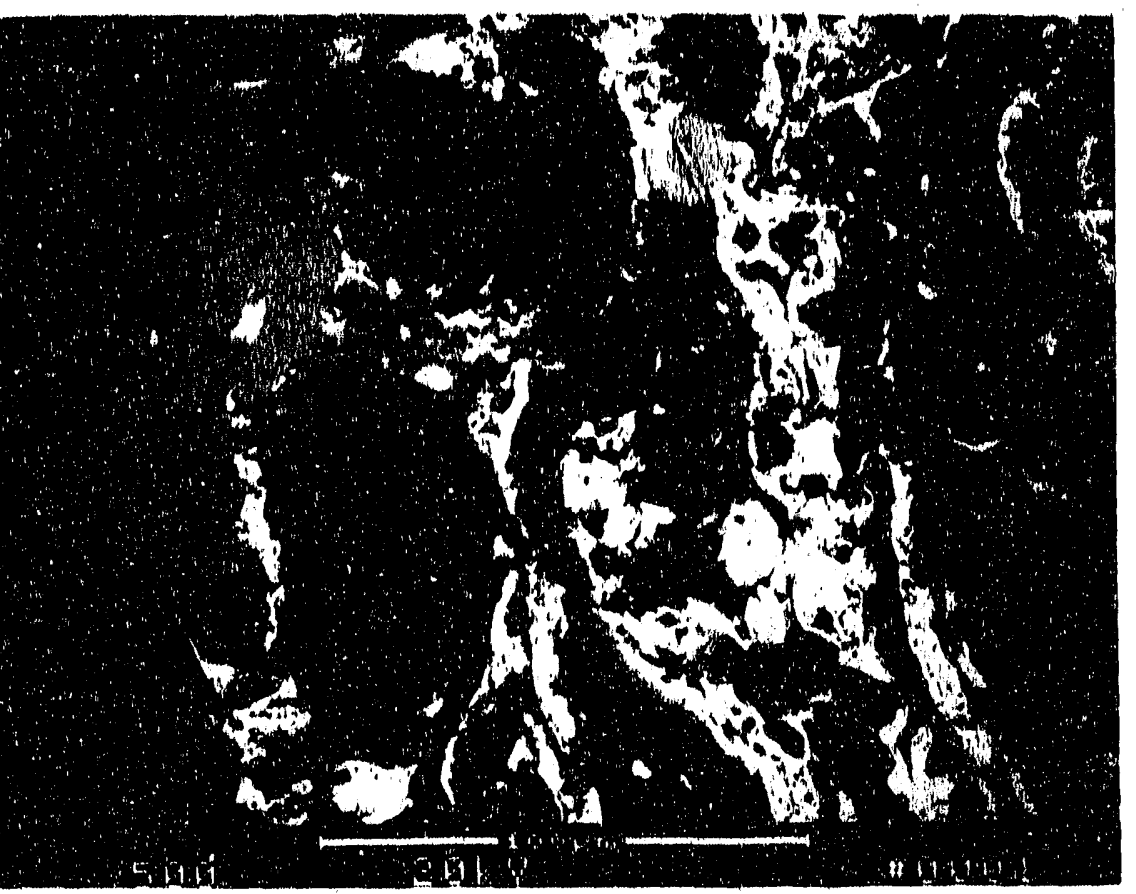

Figure 19. Microstructure of APS Armacor T coating (SEM, backscattered electron image). Dark phase: as Armacor M. Light phase: tungsten. The tungsten phase shows evidence of incomplete melting. Inter-splat bonding was better than for the Armacor M material.

The Almacor T coating (Figure 19) showed a mixture of two distinct powders, the darker imaging phase having a similar composition to Armacor $M$, the lighter imaging phase being essentially pure tungstern metal (by EDS analysis). The tungsten phase contained a high level of porosity and pull-out, suggesting incomplete melting. Inter-splat oxidation and microcracking was less than for the Armacor M coating. Bonding between the coating, bond coat and substrate was good. 
Table 9. Miorohardness values for LPPS Metco 350 Fe - 15\% Mo - 3\% C coatings with varlous additions.

\begin{tabular}{|l|l|}
\hline \multicolumn{1}{|c|}{ Coating } & $H_{K_{100}}$ \\
\hline Metco 350 with 25\% titanium & 588 \\
\hline Metco 350 with 25\% boron & 738 \\
\hline Metco 350 with 50\% TiB & 623 \\
\hline Metco 350 with 25\% B B & 662 \\
\hline
\end{tabular}

A series of test coupons were sprayed with a Metco $350 \mathrm{Fe}-15 \%$ Mo - 3\% C powder blended with various metallic and ceramic additions, in an attempt to create microstructures comprising a relatively hard metallic matrlx phase with a hard carbide or borkde dispersion. Additions of (a) thanlum and (b) boron were made to investigate whether the high processing temperatures inherent with the plasma spray process would cause significant reaction of the added element with carbon in the matrix phase. In addition, coatings. Were sprayed with (c) $\mathrm{TiB}_{2}$ and (d) $\mathrm{B}_{4} \mathrm{C}$ additions to form more conventional cermet microstructures. The powders were sprayed with a LPPS system in order to retain the highest carbon content possible in the matrix phase. The coating mixtures sprayed were:
(a) Metco 350 with $25 \%$ titanium
Reactive system
(b) Metco 350 with 25\% boron
Reactive system
(c) Metco 350 with $50 \% \mathrm{TIB}_{2}$
Non-reactive system
(d) Metco 350 with $25 \% \mathrm{~B}_{4} \mathrm{C}$
Non-reactive system

The first two materials essentially formed mbxtures of the two components, with no apparent carbide formation (Figures 20 and 21). It is concluded that more intimately mixed powders would be required to achieve sufficient reaction of the carbon with the reactlve metal phase. The boride/carbide additlons resulted in typical cermet microstructures, but with low hard phase contents (Figures 22 and 23).

Microhardness values were similar (in the range $590-740 \mathrm{kgimm}^{-2} \mathrm{HK}_{400}$ ) for all four coatings (Table 9). On the basis of the microstructural evaluation, it was decided not to undertake further development or testing of these systems. 


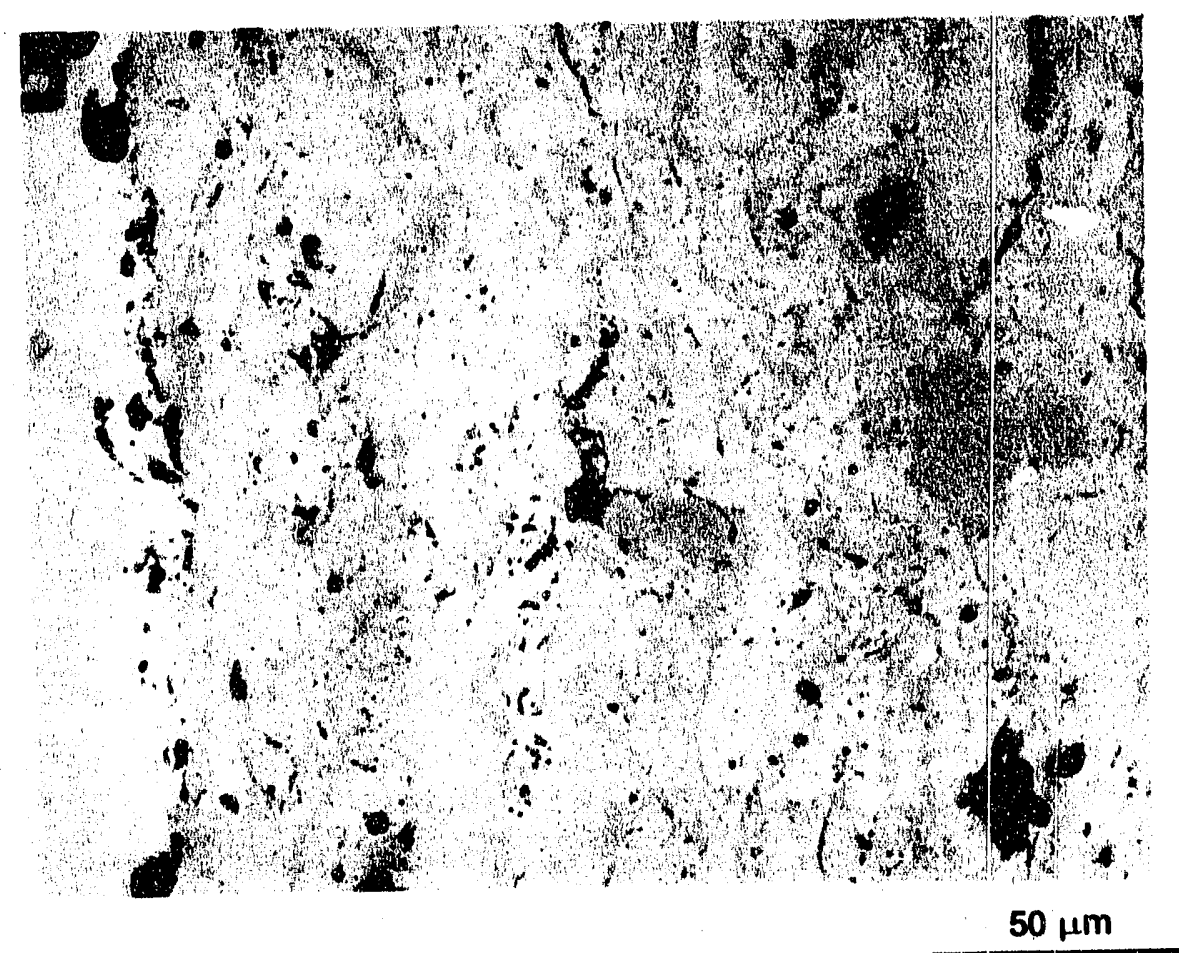

Figure 20. Microstructure of APS Metco $350+25 \%$ Ti coating (light micragraph).
Darker phase is titanium metal. There is no evidence of reaction to form TiC.

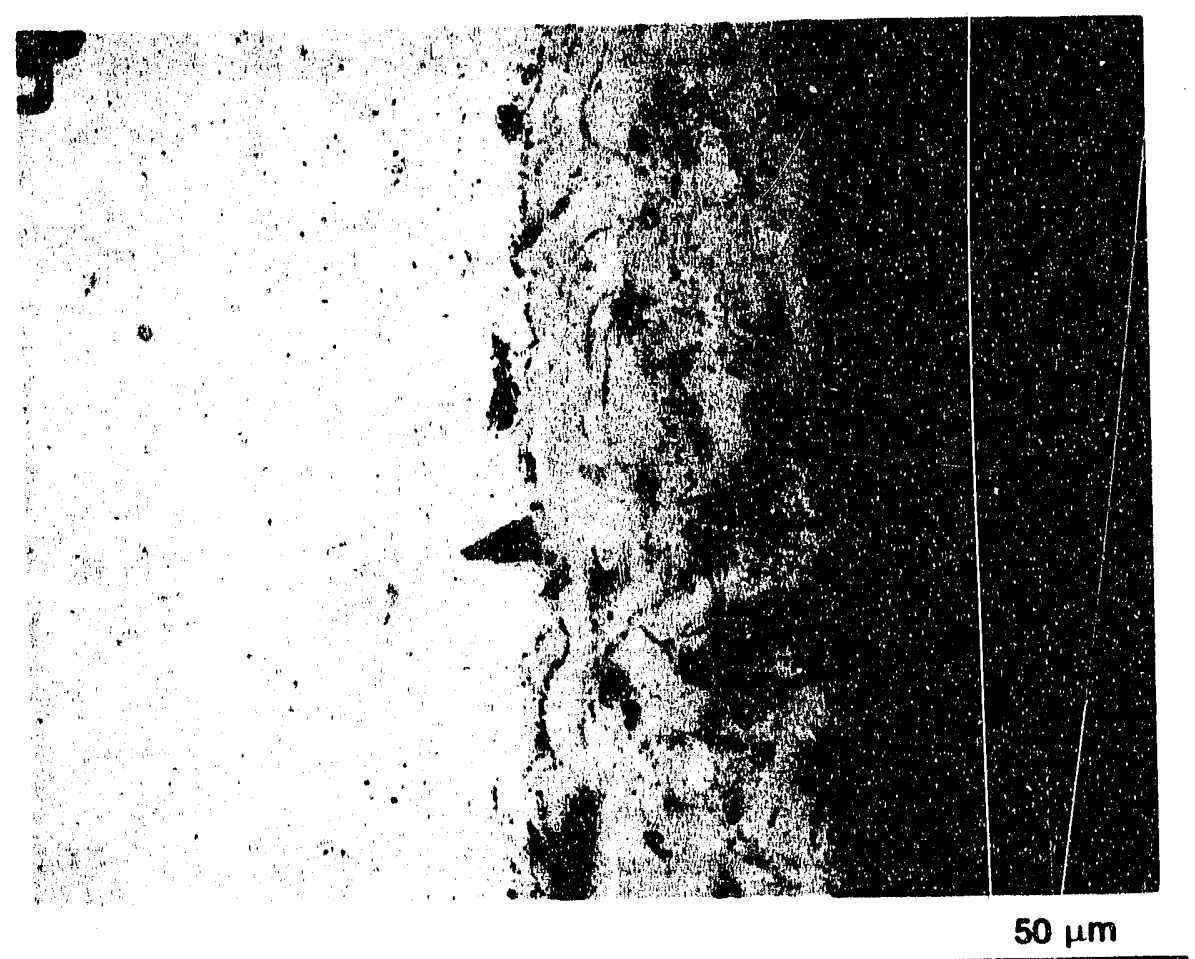

Figure 21. Microstructure of APS Meico $350+25 \%$ B costing (light microgrraph). Darker phase is boron. There is no evidence of reaction to form $B_{4} C$. 


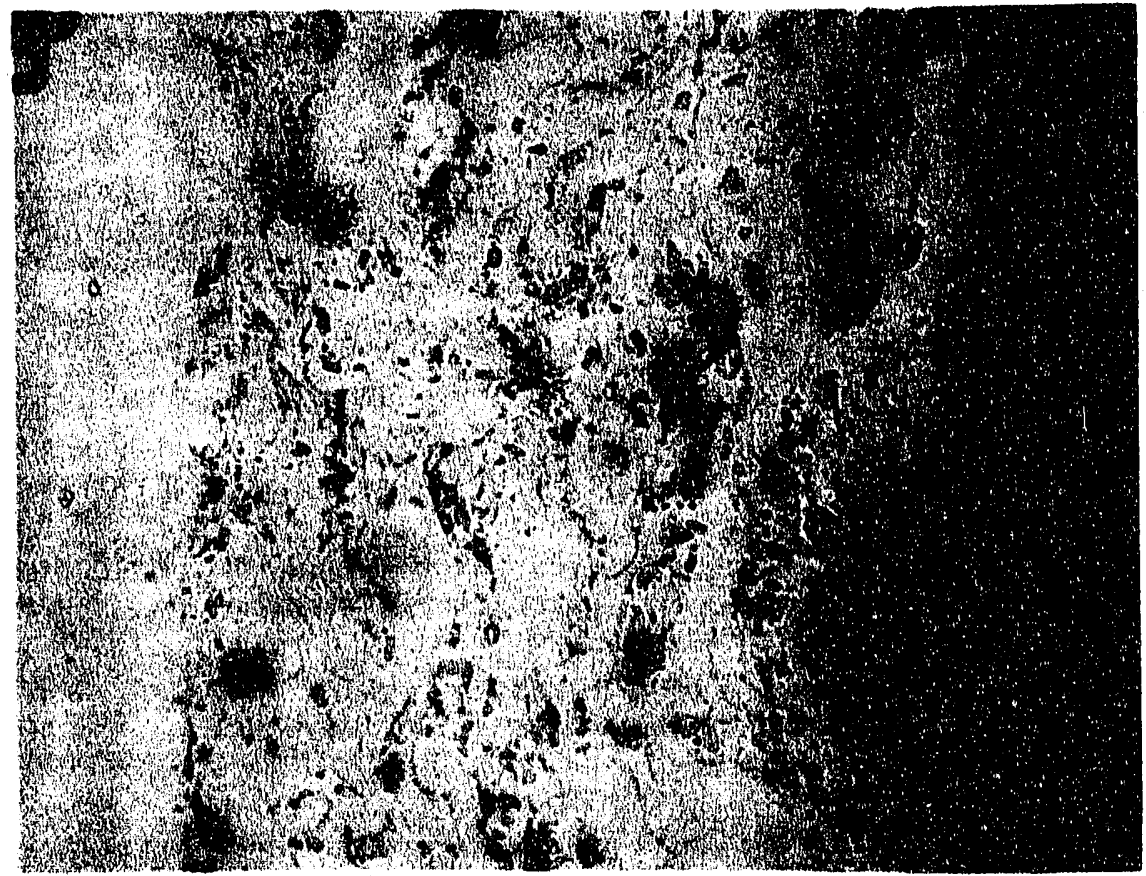

$50 \mu \mathrm{m}$

Figure 22. Microstructure of APS Metco $350+50 \%$ TiB 2 costing (light micrograph). The image shows a low concentration of blocky $T I B_{2}$ particles in a metallic matrix.

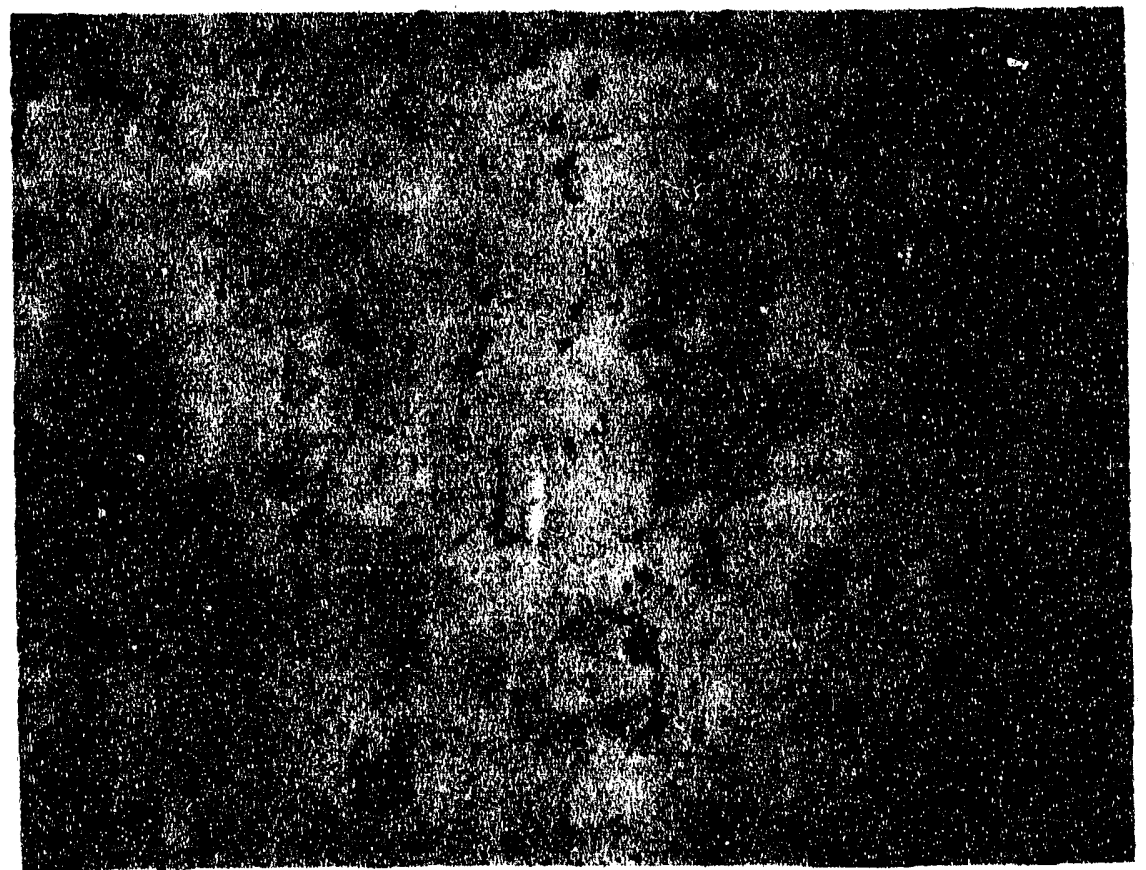

$50 \mu \mathrm{m}$

Figure 23. Microstructure of APS Motco $350+25 \% B_{4} C$ coating (light micrograph). $A$ low concentration of large, angular $B_{4} C$ particles (darker imaging) is visible. 


\section{1 .5 Boron Carbide Coating}

Ceramic materials with extremely high hardness levels generally have low wear coefficients, but "ultra-hard" materials (microhardness values greater than $2000 \mathrm{~kg}^{\mathrm{mmm}}-\mathrm{-2}$ ) are not generally avallable as thermally sprayed coatings. Ceramic materials cornmonly used include a wide range of oxides (e.g. aluminum oxide, zirconium oxide, chromlum oxide and various mixed or alloyed compositions such as alumina-thania, alumina-zirconia, etc.) with microhardness values ranging to about $1500 \mathrm{kgfmm}^{-2}$, but relatively few carbides, borides or nitrides (except as cermet coatings). Various factors contribute to the difficulty in spraying ultra-hard ceramic materials, including:

1. extremely high melting points of most covalently bonded hard materials.

2. some compounds (e.g. silicon nitride) do not melt, but rather sublimate or dissociate.

3. high residual stresses on cooling molten splat droplets from extremely high temperatures, especially for a material which has high elastic modulus. This results in low coating cohesion due to inter-splat cracking.

In this program, attempts were made to produce boron cartulde coatings using thermal spray processes (low pressure plasma spray and inert gas shrouded air plasma spray). Boron carbide was selected on the basis of prior development efforts at APS Materials, Inc.

An initial series of spray trials was made using low pressure plasma spray methods, utilizing a wide variety of test conditions (Table 10), but no deposition occurred. A disadvantage of LPPS processes is that the rate of heat transfer to the powder particles is much lower than for air plasma spray processes, so melting of refractory materials is more difficult.

Following these attempts, a much finer Starck powder (selected by BIRL), was sprayed using nitrogen shrouded air plasma spray techniques developed at APS Materials. Although a coating could be formed from this powder, porosity levels were extremely high (Figure 24).

Further attempts to develop a process for spraying boron carbide were discontinued after reviewing the results of an internal Cummins project to evaluate wear properties of monolithic ceramics. A series of Falex 1 block-on-ring wear tests were conducted with various ceramic materials sliding against 52100 steel. One conclusion of this study was that monolithic sintered boron carbide had relatively poor wear properties compared to other ceramic materials such as alumina, zirconia, silicon carblde and silicon nitride, especially when lubricated with a high-soot oll obtained from a diesel engine [11].

Table 10. Plasma spray parameters for the first series of boron carbide tests. For each test, 4 coupons were placed at distances of 10, 19, 28 and 34 inches. No deposition occurred at any setting. The 115 and 093 anodes are $20^{\circ}$ rear injection; 114 is a straight injection anode.

\begin{tabular}{|c|c|c|c|c|c|c|c|c|}
\hline Test & $\begin{array}{c}\text { Pressure } \\
\text { Torr }\end{array}$ & Arc CFH & Mix CFH & $\begin{array}{c}\text { Powder } \\
\text { CFH }\end{array}$ & $\begin{array}{c}\text { Hopper } \\
\text { RPM }\end{array}$ & Volts & Amps & Anode \\
\hline 1 & 20 & 140 & $80-\mathrm{ne}$ & 25 & 6 & 48 & 1550 & 115 \\
\hline 2 & 20 & 120 & $12-\mathrm{H} 2$ & 25 & 2 & 51 & 1475 & 115 \\
\hline 3 & 280 & 120 & $80-\mathrm{He}$ & 25 & 2 & 44 & 1600 & 115 \\
\hline 4 & 10 & 120 & $60-\mathrm{He}$ & 25 & 2 & 44 & 1600 & 115 \\
\hline 5 & 10 & 120 & $80-\mathrm{He}$ & 20 & 2 & 46 & 1625 & 114 \\
\hline 6 & 20 & 120 & $15-\mathrm{H} 2$ & 20 & 4.6 & 48 & 1500 & 114 \\
\hline 7 & 50 & 120 & $15-\mathrm{H} 2$ & 25 & 3 & 46 & 1525 & 093 \\
\hline 8 & 20 & 120 & $\begin{array}{c}80-\mathrm{He} \\
15-\mathrm{H} 2\end{array}$ & 25 & 2 & 52 & 1525 & 093 \\
\hline
\end{tabular}




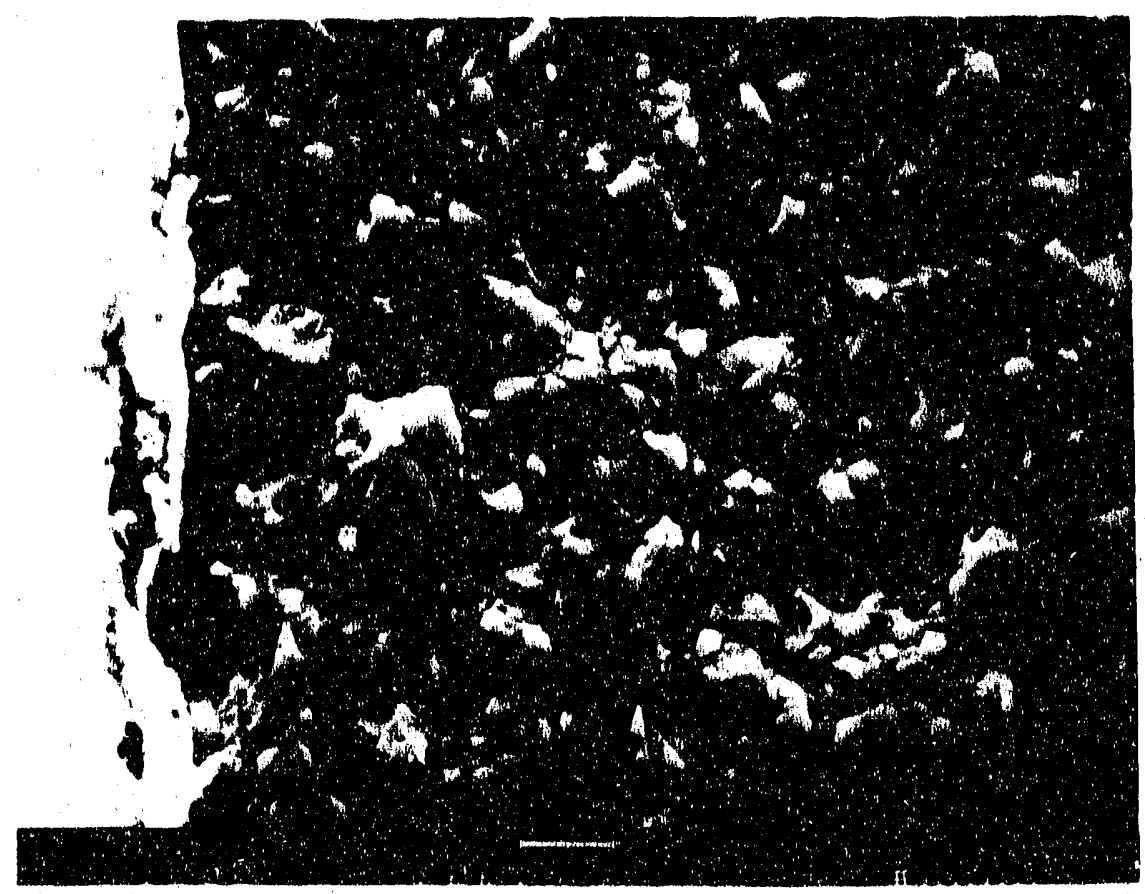

Figure 24. Microstructure of LPPS boron carbide coating (SEM, backscattered electron image). The coating is extremely porous, with little inter-splat bonding.

\subsubsection{Sllicon Nitride Coating}

From a variety of laboratory bench tests and engine component testing, Cummins has previously established that monolithic silicon nitride is a highly wear-resistant materlal. Pure sillicon nitride coatings cannot be formed by conventional thermal spray methods, however, because the material does not melt, but rather sublimates in the temperature range $1700-1900^{\circ} \mathrm{C}$. Desplte this, silicon nitride powders are available in size distribution ranges that would be suitable for thermal spraying, intended for mixing or cladding with metallic components to form cermet coatings. As an experiment, attempts were made to spray a Starck silicon nitride powder (selected by BIRL) with no metallic binder phase using LPPS processes. The substrates were flat steol test plates.

The LPPS process was found to essentlally sublimate the silicon nitride powder, some of which condensed on the substrates as a thin deposit (essentlally an evaporathe physical vapor deposition process). The deposit adhered to the substrates as a $15 \mu \mathrm{m}$ thick, dense, fine-grained coating containing large cracks parallel to the surface within the coating and at the interface with the substrate (Figure 25). Arrested cracks running perpendicular to the surface were also observed. The high crack content suggests high residual stress levels within the coating. X-ray diffraction verified that the coating was composed of predominantly $\alpha-\mathrm{Si}_{3} \mathrm{~N}_{4}$ (Figure 26), as was the starting powder.

Although these preliminary efforts to produce a silicon nitride coating showed promise, it was thought that the low adherence and high residual stress levels would be unsultable for piston ring applications, and further development was not undertaken. Wear tests were not conducted with this material. 


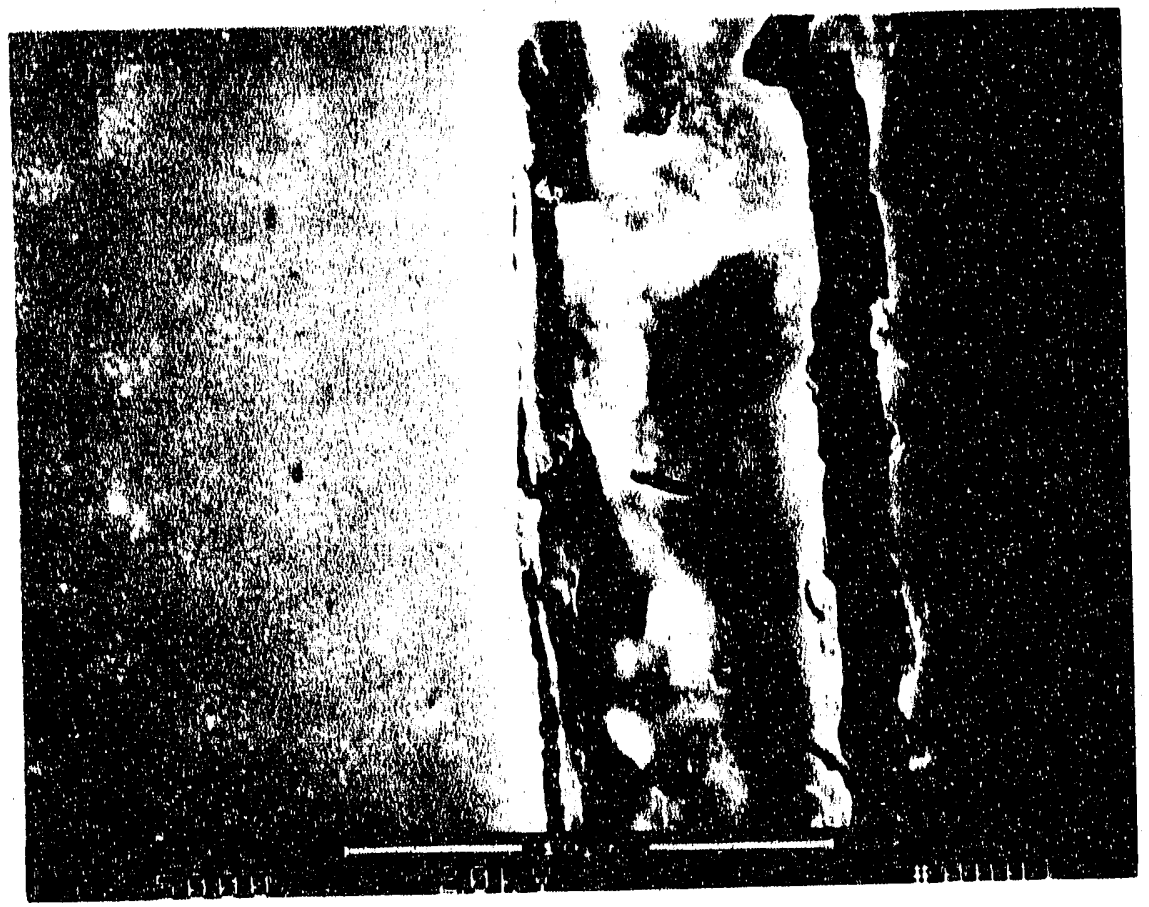

Figure 25. Microstructure of LPPS silicon nitride coating (SEM, backscattered electron image).
Cracking parallel to and perpendicular to the surface indicate high residual stresses.

Figure 26. X-ray diffraction pattorn from LPPS Si, $N_{4}$ coating, showing $\alpha-S I_{3} N_{4}$ poaks. 


\subsection{COATING DEVELOPMENT AT NORTHWESTERN UNIVERSITY BASIC INDUSTRIAL RESEARCH LABORATORY}

\subsection{Molybdenum-Based Coatings}

Combustion wire sprayed and air plasma sprayed molybdenum-based piston ring coatings have been avallable commercially for a number of years, aithough in limited production quantities in the U.S. In Europe, such coatings have gained increasing popularity due to improved scuffing/selzure resistance compared to electroplated chromium, although this is achleved at the expense of silghtly higher wear rates under well-lubricated conditions [4]. Recently, GTE Products Corporation have made significant advances in developing molybdenum-based powders for plasma sprayed piston ring applications [12]. Two of the more recently avallable powders were obtained from GTE for spray process development at BIRL. The first powder was a blend of $75 \%$ Mo with $25 \% \mathrm{NI}$, designated SA-901. Specifications for this powder are listed in Table 11. The second powder was a molybdenum - molybdenum dioxide composite powder containing $10.07 \%$ oxygen and designated SA-110 (speclfications in Table 12).

The Mo - 25\% NI powder was analyzed by scanning electron microscopy (Figure 27). The molybdenum powder particles were agglomerations of smaller particles with a "spongy" texture. The nickel phase was found to contain $14 \% \mathrm{Cr}, 5 \% \mathrm{SI}$ and $5 \% \mathrm{Fe}$ by welght (balance $\mathrm{Ni}$ ). This powder was sprayed by two methods: air plasma spray and high velocity oxy-fuet (Top Gun"). Plasma spray parameters were established by a series of spray trials, detalled in Table 13, followed by microstructural characterization of the coatings and SEM analysis of the as-sprayed surfaces. The final spray parameters are listed in

Table 14. HVOF spray parameters were determined in the same way, an example being shown in Table 15.

Table 11. Speciflcations for GTE SA-901 Mo - 25\% NI powder.

\begin{tabular}{|c|c|c|c|}
\hline $\begin{array}{l}\text { MOLYBDENUM: } \\
\text { Lot No. } \\
\text { Bulk Density } \\
\text { Hall Flow } \\
\mathrm{O}_{2} \\
\mathrm{Mo}\end{array}$ & $\begin{array}{l}90 \mathrm{~A}-026 \\
2.16 \mathrm{gcm}^{-3} \\
28 \mathrm{~s} / 50 \mathrm{~g} \\
620 \mathrm{ppm} \\
99.5 \%+\end{array}$ & $\begin{array}{l}\text { Screen Analysis: } \\
+170 \\
-170+200 \\
-200+270 \\
-270+325 \\
-325\end{array}$ & $\begin{array}{l}1.4 \% \\
21.6 \% \\
35.3 \% \\
23.0 \% \\
18.7 \%\end{array}$ \\
\hline $\begin{array}{l}\text { NICKEL: } \\
\text { Lot No. } \\
\text { Alloy }\end{array}$ & $\begin{array}{l}90 A-022 \\
\text { AP-575 Type "A" }\end{array}$ & $\begin{array}{l}\text { Screan Analysis: } \\
+270 \\
-270+325 \\
-325\end{array}$ & $\begin{array}{l}6.1 \% \\
14.7 \% \\
79.2 \%\end{array}$ \\
\hline $\begin{array}{l}\text { FINAL BLEND: } \\
\text { Lot No. } \\
\text { Hall Flow } \\
\text { Bulk Density }\end{array}$ & $\begin{array}{l}90 \mathrm{~A}-029 \\
22 \mathrm{~s} / 50 \mathrm{~g} \\
2.57 \mathrm{gcm}^{-3}\end{array}$ & & \\
\hline
\end{tabular}

Table 12. Specifications for GTE SA-110 MO $-\mathrm{MOO}_{2}$ powder.

\begin{tabular}{|llll|}
\hline Lot No. & K-188S & Screen Analysis: & \\
Hall Flow & $32 \mathrm{~s} / 50 \mathrm{~g}$ & +270 & $1.5 \%$ \\
Bulk Density & $2.32 \mathrm{gcm}$ & $-270+325$ & $18.6 \%$ \\
$\mathrm{O}_{2}$ & $10.07 \%$ & -325 & $79.9 \%$ \\
\hline
\end{tabular}




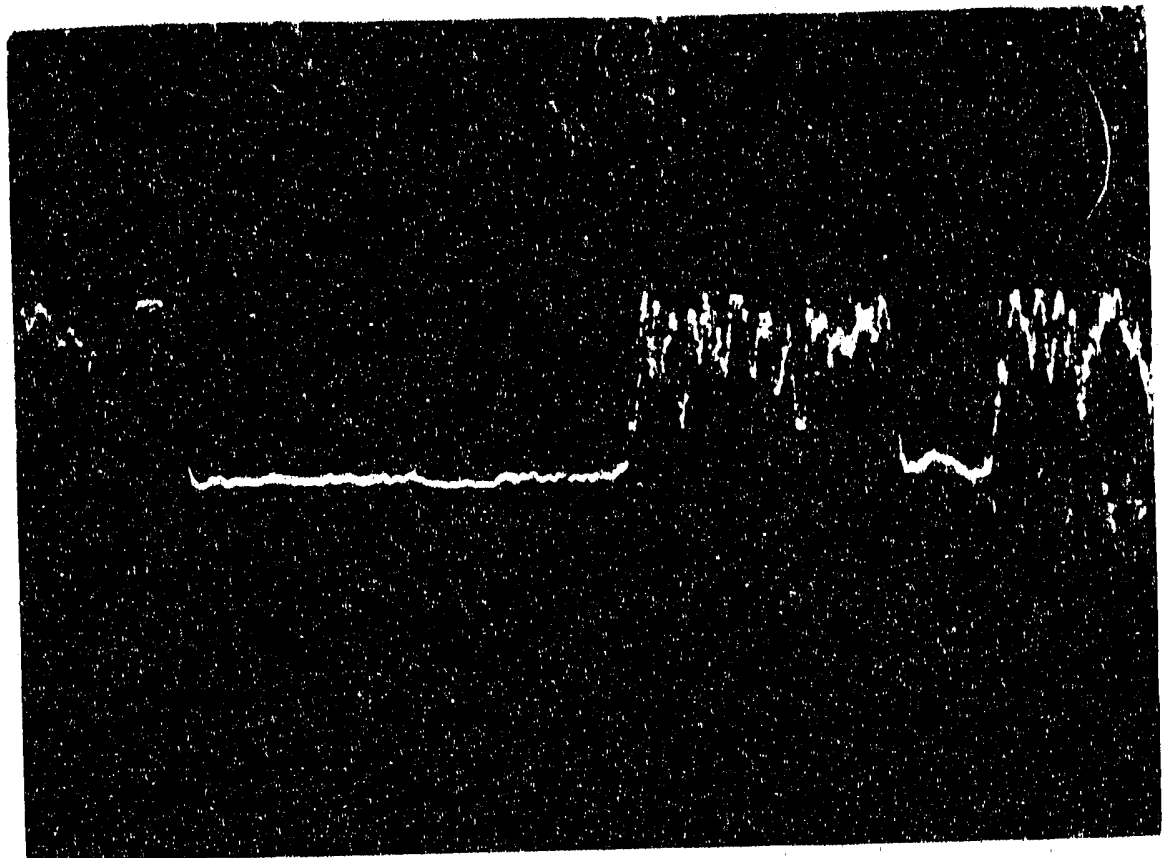

Figure 27. SEM micrograph of GTE SA-901 Mo - 25\% Ni powder, showing Mo line scan across the center of the image. The powder is a mixture of Mo particles ("spongy" agglomerations) with Ni particles containing $\mathrm{Cr}$, Si and $\mathrm{Fe}$.

The microstructure of the air plasma sprayed MO-NI coating is shown in Figure 28. The coating was clearly two phase (lighter phase: Mo), with intle or no mixing of the two metallic components. The coating contained some coarse porosity/pull-out, but little unmetted matertal. Inter-splat and inter-phase bonding was excellent. X-ray diffraction of the coating showed only the cublc phases of Mo and Ni. The microhardness of the coating was $510 \mathrm{kgfmm}^{-2}$, which was low compared to many of the other coatings evaluated.

Figure 29 shows the same powder sprayed by HVOF (Top Gun). The "spongy" character of the Mo powder was retained to a much greater degree in thls coating, indicating that the powder was not melted as completely as in the plasma spray process. However, porosity levels, inter-splat bonding and bonding to the substrate were approximately the same as for the plasma sprayed coating. X-ray diffraction again

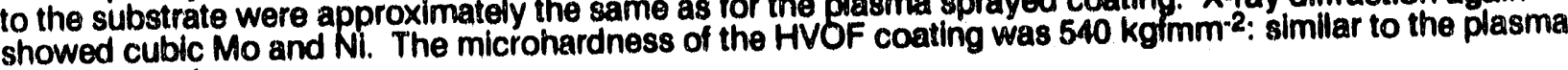
sprayed coating.

Early commerclal processes for wire spraying molybdenum coatings with an oxy-fuel torch tended to produce oxidation, resulting in the incorporation of $\mathrm{MOO}_{2}$ in the coating, giving increased wear resistance compared to pure molybdenum. Plasma spray processes, although allowing much greater flexibility in powder selection and improved coating density, tend not to produce as much oxidation. Thus, $\mathrm{Mo}-\mathrm{MOO}_{2}$ composite powders were developed to produce plasma sprayed coatings with wear propertles similar to wire sprayed materials. For this program, a MO - $\mathrm{MOO}_{2}$ powder containing $10.07 \%$ oxygen (GTE SA-110) was obtained, and coatings were sprayed by air plasma spray (parameters listed in Table 14).

The SA-110 $\mathrm{Mo}-\mathrm{MOO}_{2}$ powder was found to comprise agglomerations of smaller particles (Figure 30). The alr plasma sprayed coating (Figure 31) showed evidence of some unmelted material and arge pores. Inter-splat adhesion was not as good as for the Mo - Ni materials, as evidenced by a pronounced degree of inter-splat microcracking and volding. Faint differences in image grey scales within the coating are indicathe of varying oxygen content: the more oxygen, the darker the image. $X$-ray diffraction of the coating showed a mixture of cubic $\mathrm{Mo}$ and monoclinic $\mathrm{MOO}_{2}$. The $\mathrm{Mo} \cdot \mathrm{MOO}_{2}$ coating was considerably harder ( $\left.770 \mathrm{~kg}^{\prime} \mathrm{mm}^{-2}\right)$ than the MO - Ni coatings. 
Table 13. Spray trial parameters for APS MO-NI and $\mathrm{MO}_{-} \mathrm{MOO}_{2}$ coatings.

Miller Thermal SG 100 plasma gun

Gun configuration $145 / 129 / 113$

Powder gas: 25 - 30

Arc gas: 50

Helium: 50

\begin{tabular}{|c|c|c|c|}
\hline Test & Feod Rate & Amps & Spray Distance (ln.) \\
\hline 1 & 1,5 & 800 & 2.6 \\
\hline 2 & 2.0 & 800 & 2.5 \\
\hline 3 & 2.5 & 500 & 2.5 \\
\hline 4 & 1.5 & 550 & 2.5 \\
\hline 5 & 2.0 & 550 & 2.5 \\
\hline 6 & 2.5 & 550 & 2.5 \\
\hline 7 & 1.5 & 600 & 2.5 \\
\hline 8 & 2.0 & 600 & 2.5 \\
\hline 9 & 2.5 & 600 & 2.5 \\
\hline 10 & 1.5 & 500 & 3.0 \\
\hline 11 & 2.0 & 500 & 3.0 \\
\hline 12 & 2.5 & 500 & 3.0 \\
\hline 13 & 1.5 & 550 & 3.0 \\
\hline 14 & 2.0 & 550 & 3.0 \\
\hline 15 & 2.5 & 550 & 3,0 \\
\hline 16 & 1.5 & 600 & 3.0 \\
\hline 17 & 2.0 & 600 & 3.0 \\
\hline 18 & 2.5 & 600 & 3.0 \\
\hline 19 & 1.5 & 500 & 3.5 \\
\hline 20 & 2.0 & 500 & 3.5 \\
\hline 21 & 2.5 & 500 & 3.5 \\
\hline 22 & 1.5 & 550 & 3.5 \\
\hline 23 & 2.0 & 550 & 3.6 \\
\hline 24 & 2.5 & 550 & 3.5 \\
\hline 25 & 1.5 & 600 & 3.5 \\
\hline 26 & 2.0 & 600 & 3.5 \\
\hline 27 & 2.5 & 600 & 3.5 \\
\hline 28 & 1.5 & 500 & 4.0 \\
\hline 29 & 2.0 & 500 & 4.0 \\
\hline 30 & 2,5 & 500 & 4.0 \\
\hline 31 & 1.5 & 550 & 4.0 \\
\hline 32 & 2.0 & 550 & 4,0 \\
\hline 33 & 2.5 & 550 & 4.0 \\
\hline 34 & 1.5 & 600 & 4.0 \\
\hline 35 & 2.0 & 600 & 4.0 \\
\hline 36 & 2.5 & 600 & 4.0 \\
\hline
\end{tabular}


Table 14. Optirnized spray parameters for APS Mo-NI and Mo-MOO 2 coatings.

Miller Thermal SG 100 plasma gun

Gun configuration 145/129/113

Powder gas: 25 - 30

Aro gas: 50

Helium: 50

\begin{tabular}{|c|c|c|c|c|c|}
\hline Arc Current & Arc Voltage & Plasma Gas & \multicolumn{2}{|c|}{ Hopper } & \multirow{2}{\text{SpM}}{} \\
\cline { 3 - 6 } & & $\begin{array}{c}\text { Pressure } \\
\text { (psi) } \\
(\text { intance }\end{array}$ \\
\hline 650 & 37 & Ar/He & 2.0 & 30 & 3.0 \\
\hline
\end{tabular}

Table 15. An example of Top Gun HVOF deposition parameters.

\begin{tabular}{|c|c|c|c|}
\hline Material: & Molybdenum & Timer 3 oxygen to ramp fuel & 1.00 \\
\hline Particle size: & $-325+15$ & Timer 4 ramp fuel to main fuel & 1.50 \\
\hline Spray distance: & $6^{\prime \prime}$ & Timer 10 oxygen to ramp fuel & 0.10 \\
\hline Traverse speed: & $1200 \mathrm{lpm}$ & Timer 5 main fuel to main carrier & 0.30 \\
\hline Increment: & .100 & $\begin{array}{l}\text { Timer } 6 \text { water delay after shut-down } \\
\text { in auto }\end{array}$ & 20.0 \\
\hline Number of passes: & 22 & $\begin{array}{l}\text { Timer } 34 \text { oxygen delay atter } \\
\text { shut-down in auto }\end{array}$ & 2.00 \\
\hline Powder feed rate: & $\begin{array}{l}20 \mathrm{~g} / \mathrm{m} \\
1.30 \mathrm{rpm}\end{array}$ & & \\
\hline Coating thickness: & .012 & Deposit efficiency: & $40 \%$ \\
\hline
\end{tabular}

\begin{tabular}{|l|l|l|l|l|l|l|l|}
\hline & Oxygen & Propylene & Hydrogen & Acetylene & Carrier & Water & $\begin{array}{l}\text { Temperature } \\
\text { ( } F \text { F })\end{array}$ \\
\hline $\begin{array}{l}\text { Gun back } \\
\text { pressure }\end{array}$ & 96 & 0 & 0 & 10 & 27 & 150 & IN 72 \\
\hline Flow & 500 \\
SCFH & 0 SCFH & 0 SCFH & $\begin{array}{l}95 \\
\text { SCFH }\end{array}$ & $\begin{array}{l}35 \\
\text { SCFH }\end{array}$ & $\begin{array}{l}7 \\
\text { GPM }\end{array}$ & OUT 86 \\
\hline Ignition flow: & 30 & N/A & 110 & N/A & $\begin{array}{l}30 \\
\text { SCFH } \\
9 \mathrm{psi}\end{array}$ & N/A & N/A \\
\hline Ramp flow & 200 & 0 & 0 & 60 & N/A & N/A & N/A \\
\hline Supply pressure & 150 & 0 & 150 & 15 & 100 & & 68 \\
\hline
\end{tabular}




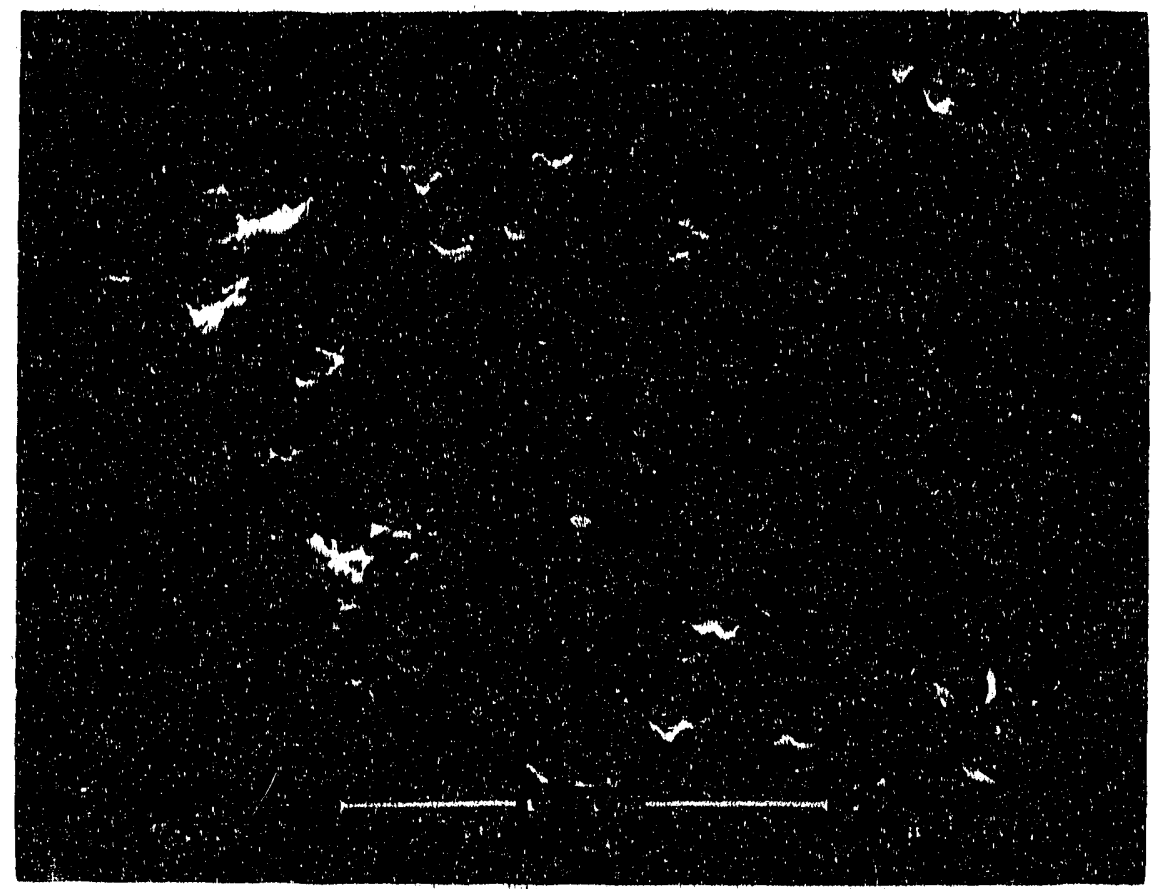

Figure 28. Microstructure of BIRL APS Mo - 25\% NI coating (SEM, backscattered electron). The coating is two-phase (lighter phase Mo), with some coarse porosity/pull-out.

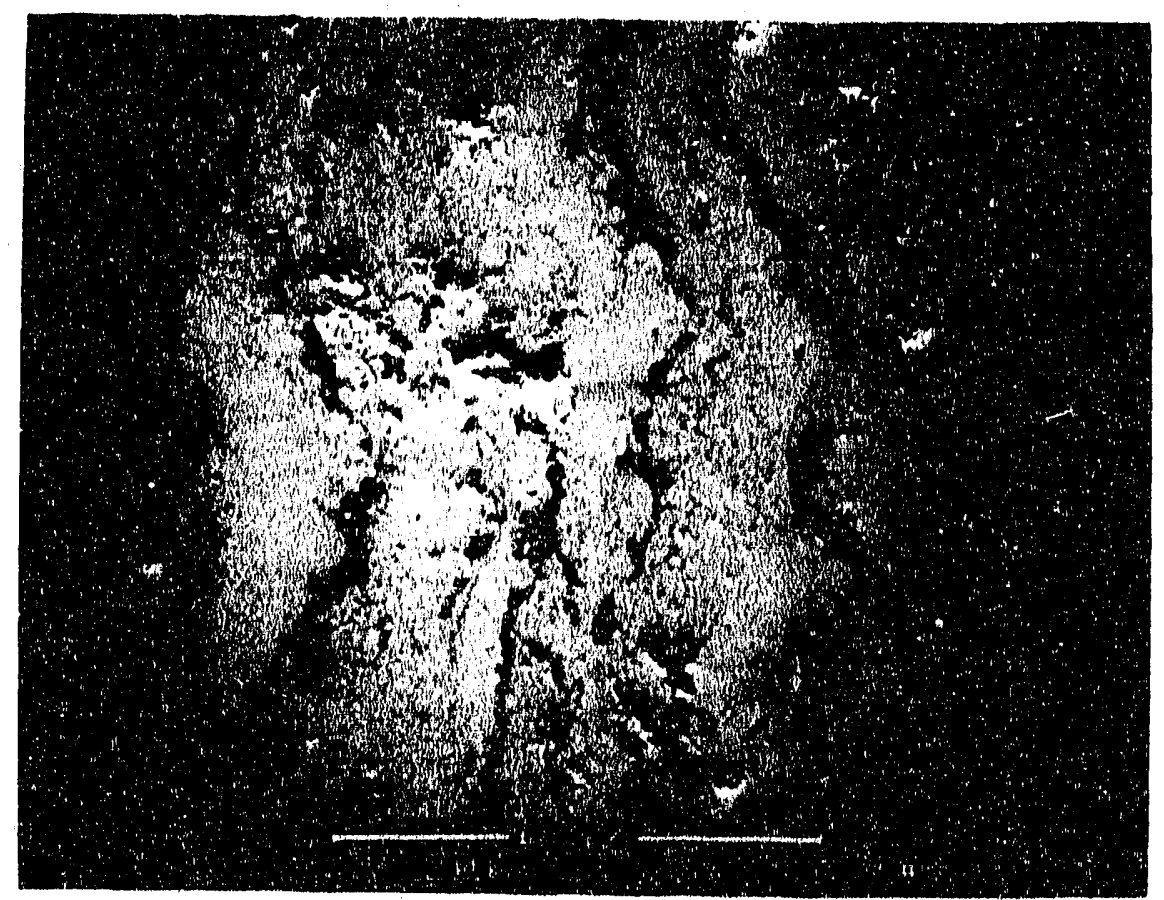

Figure 29. Microstructure of BIRL HVOF (Top Gun) Mo - 25\% NI (SEM, backscattered electron). Microstructure similar to Figure 28, the Mo phase retaining more of the powder texture. 


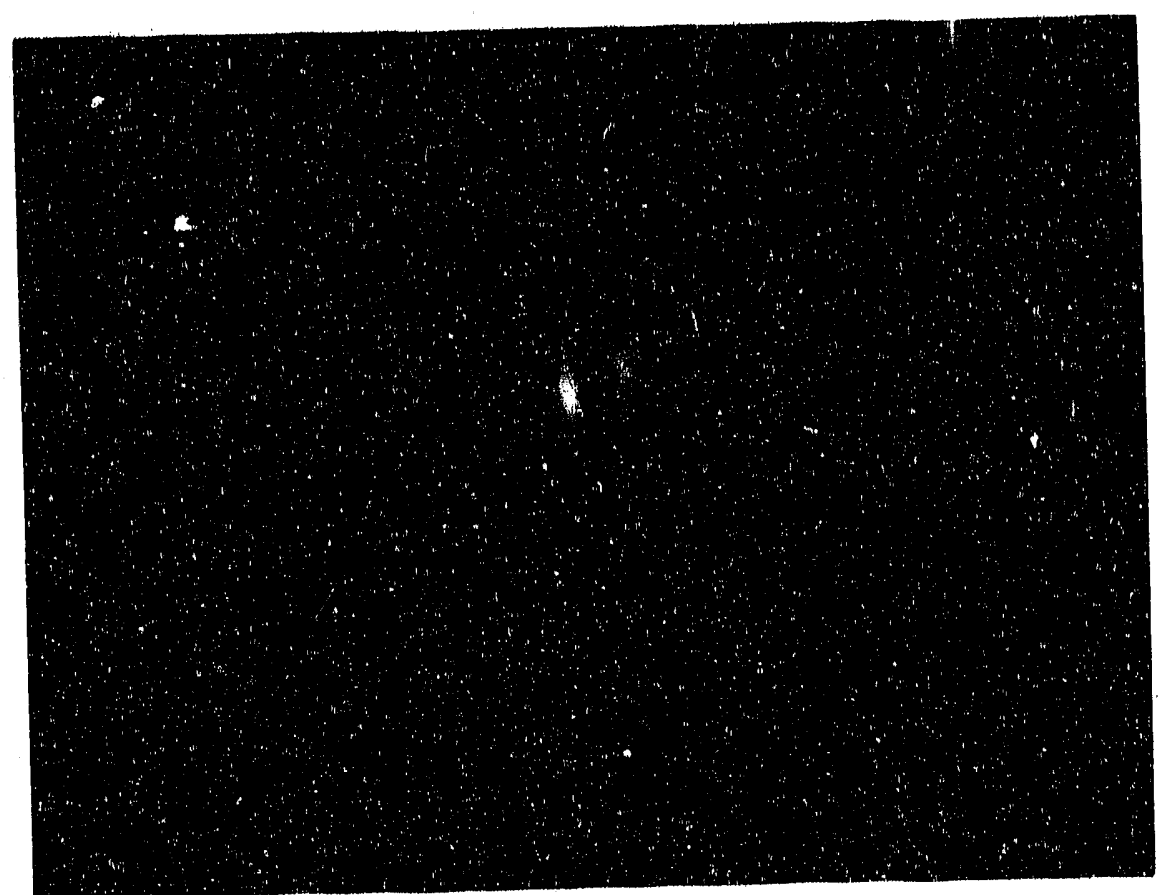

Figure 30. SEM micrograph of agglomerated GTE SA-110 Mo - MoO 2 powder.

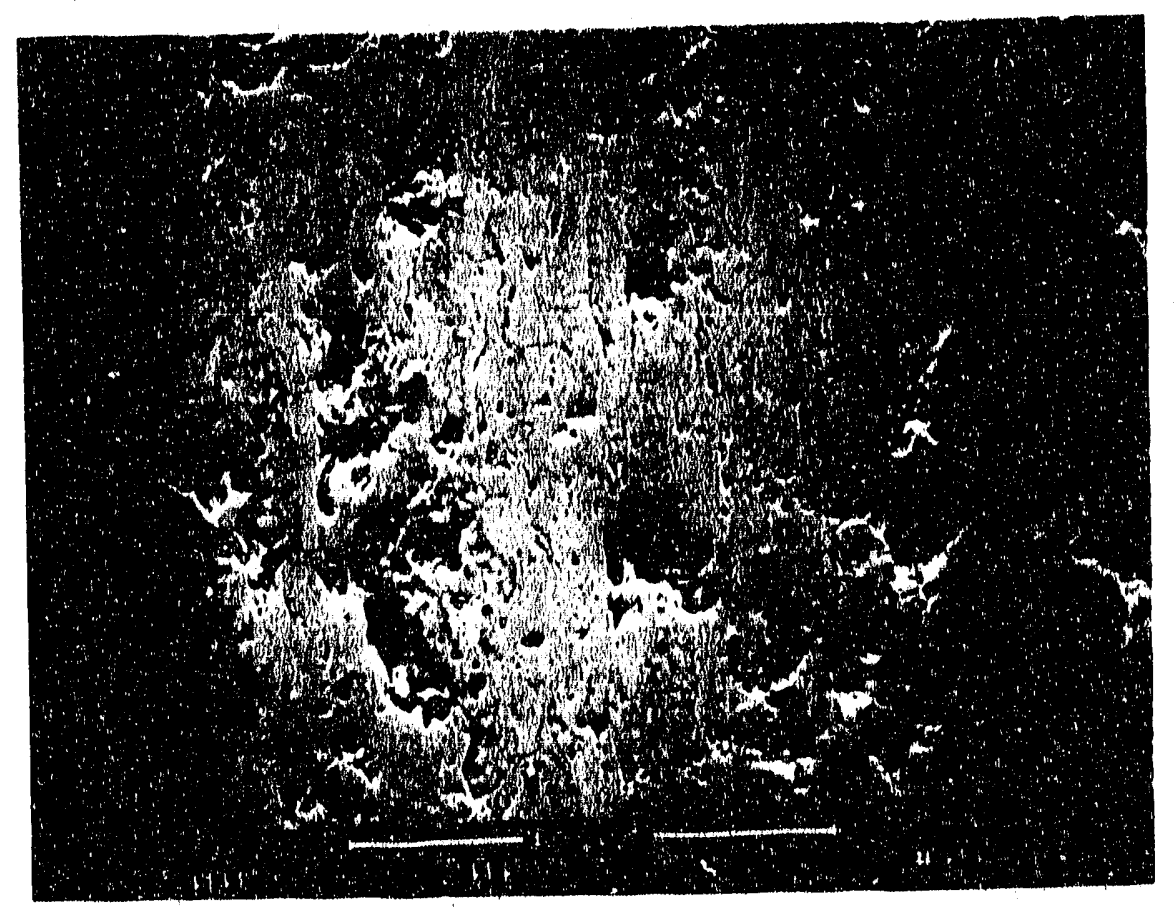

Figure 31. Microstructure of BIRL. APS Mo-MoO 2 coating (SEM, backscattered electron image). Unmelted particles, large pores and inter-splat cracks are visible. The higher the oxygen content, the darker the image. 


\subsubsection{Chromilum Oxide and Chromlum Oxide-Aluminum Oxide Coatings}

Chromium oxide coatings were sprayed by air plasma and HVOF (Top Gun), using a powder of high purity and closely-controlled, fine grain size. Plasma spray parametere are detalled in Tables 16 and 17.

The plasma sprayed chromium oxide is shown in Flgure 32. The coating was found to be extremely dense compared to other chromium oxldes evaluated. Porostity was rounded in character, rather than elongated parallel to the splats, and was evenly distributed. Inter-splat bonding was excellent in this coating. X-ray diffraction showed the dominant phase to be $\alpha-\mathrm{Cr}_{2} \mathrm{O}_{3}$. The miorohardness of this coating (1440 kgimm-2) was high compared to other chromlum oxides (Table 2), probably due to the high denslty.

The HVOF coating (Flgure 33) was similar to the plasma sprayed coating, the porosity' being a little finer and the microhardness a little lower (1320 kgfmm-2). In all other respects, the coatings were ldentical.

A pre-alloyed (fused and orushed) $\mathrm{Cr}_{2} \mathrm{O}_{3}-50 \% \mathrm{Al}_{2} \mathrm{O}_{3}$ powder was obtained to investigate the effects of solld solution alloying. Although the powder appeared uniform in composition (Figure 34), the plasma sprayed coating showed varlations in grey scales suggesting that some segregation had occurred (Figure 35), etther in the powder processing or in the plasma spray process. This powder proved to be very difficult to plasma spray, and impossible to spray by HVOF, possibly due to poor flow properties of the powder through the feeder. The plasma sprayed $\mathrm{Cr}_{2} \mathrm{O}_{3}-50 \% \mathrm{Al}_{2} \mathrm{O}_{3}$ showed a large amount of porosity and inter-splat volds/microcracks (Figure 35 ). The X-ray diffraction pattern from this coating was consistent with a solld solution based on $\alpha-\mathrm{Cr}_{2} \mathrm{O}_{3}$ and $\alpha \cdot \mathrm{Al}_{2} \mathrm{O}_{3}$. The low microhardness $\left(650 \mathrm{kgfmm}^{-2}\right)$ probably reflects the high porosity rather than inherent softness of the $\mathrm{Cr}_{2} \mathrm{O}_{3}-50 \% \mathrm{Al}_{2} \mathrm{O}_{3}$ material.

Table 16. Spray trial parameters for APS $\mathrm{Cr}_{2} \mathrm{O}_{3}$ and $\mathrm{Cr}_{2} \mathrm{O}_{3}-50 \% \mathrm{Al}_{2} \mathrm{O}_{3}$ coatings. Miller Thermal SG 100 plasma gun, gun coniliguration 165/129/113. Powder gas: 40, Arc gas: 50, Helium: 50

\begin{tabular}{|c|c|c|c|}
\hline Test & Foed Rato & Amps & Spray Distanco (nn.) \\
\hline 1 & 1.5 & 800 & 2.5 \\
\hline 2 & 2.0 & 800 & 2.5 \\
\hline 3 & 2.5 & 800 & 2.5 \\
\hline 4 & 1.5 & 800 & 3.0 \\
\hline 5 & 2.0 & 800 & 3.0 \\
\hline 6 & 2.5 & 800 & 3.0 \\
\hline 7 & 1.5 & 800 & 3.5 \\
\hline 8 & 2.0 & 800 & 3.5 \\
\hline 9 & 2.5 & 800 & 3.5 \\
\hline 10 & 1.5 & 800 & 4.0 \\
\hline 11 & 2.0 & 800 & 4.0 \\
\hline 12 & 2.5 & 800 & 4.0 \\
\hline
\end{tabular}

Table 17. Optimized spray parameters for APS $\mathrm{Cr}_{2} \mathrm{O}_{3}$ and $\mathrm{Cr}_{2} \mathrm{O}_{3}-50 \% \mathrm{Al}_{2} \mathrm{O}_{3}$ coatings. Gun configuration 165/129/113. Powoer gas: 40, Arc gas: 50, Hellum: 50

\begin{tabular}{|c|c|c|c|c|c|c|}
\hline Powder & Arc Current & Arc Voltage & Plasma Gas & RPM & $\begin{array}{c}\text { Pressure } \\
\text { (psi) }\end{array}$ & $\begin{array}{c}\text { Hoppray } \\
\text { Distance } \\
\text { (in.) }\end{array}$ \\
\hline $\mathrm{Cr}_{2} \mathrm{O}_{3}$ & 800 & 38 & $\mathrm{Ar} / \mathrm{He}$ & 1.2 & 30 & 2.5 \\
\hline $\mathrm{Cr}_{2} \mathrm{O}_{3}-\mathrm{Al}_{2} \mathrm{O}_{3}$ & 800 & 38 & $\mathrm{Ar} / \mathrm{He}$ & 1.5 & 30 & 3.0 \\
\hline
\end{tabular}




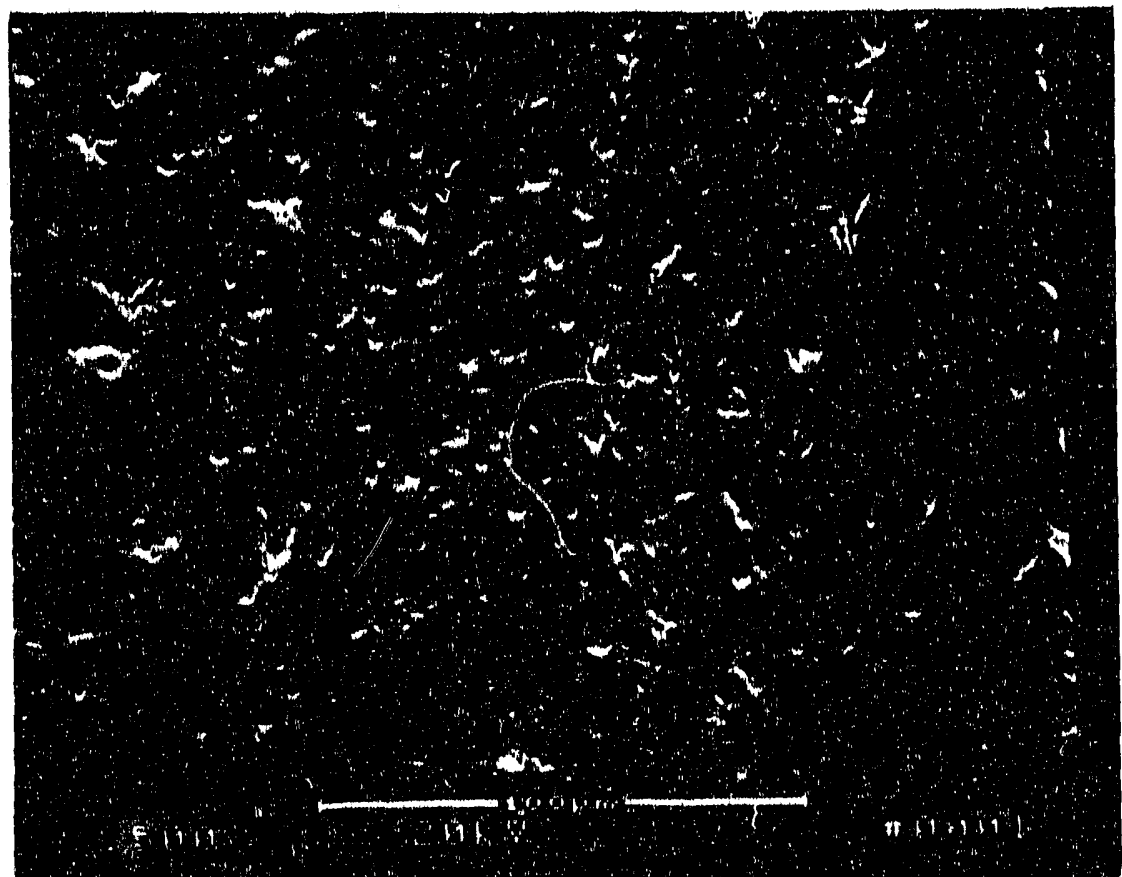

Figure 32. Microstructure of BIRL APS $\mathrm{Cr}_{2} \mathrm{O}_{3}$ coating (SEM, backscaftered electron). The coating is extremely dense, with excellent inter-splat bonding.

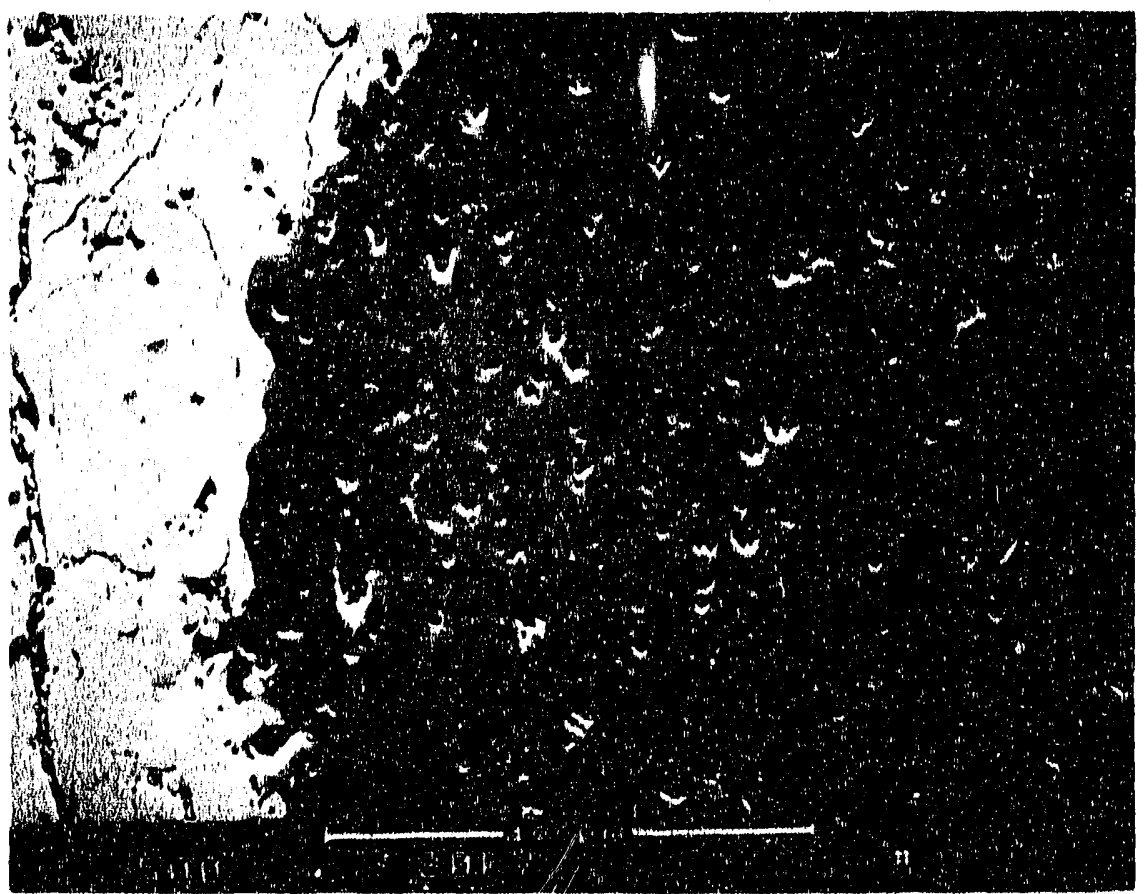

Figure 33. Microstructure of BIAL HVOF (Top Gun) $\mathrm{Cr}_{2} \mathrm{O}_{3}$ (SEM, backscattered electron). Microstructure similar to that of the plasma sprayed coating (Figure 32). 


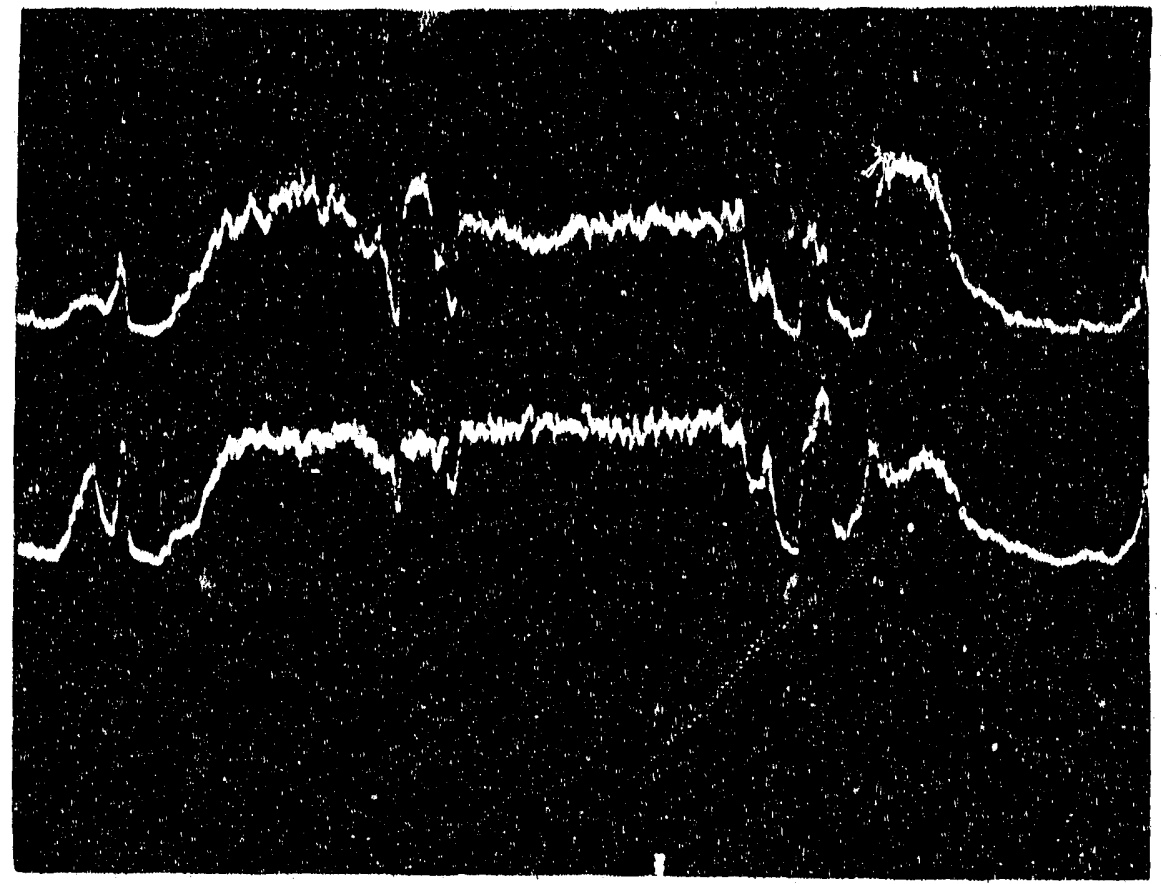

Figure 34. SEM micrograph of $\mathrm{Cr}_{2} \mathrm{O}_{3}-50 \% \mathrm{Al}_{2} \mathrm{O}_{3}$ powder with X-ray line scans for $\mathrm{Al}$ (top) and $\mathrm{Cr}$ (bottom). The angular particles appear foirty unilorm in composition.

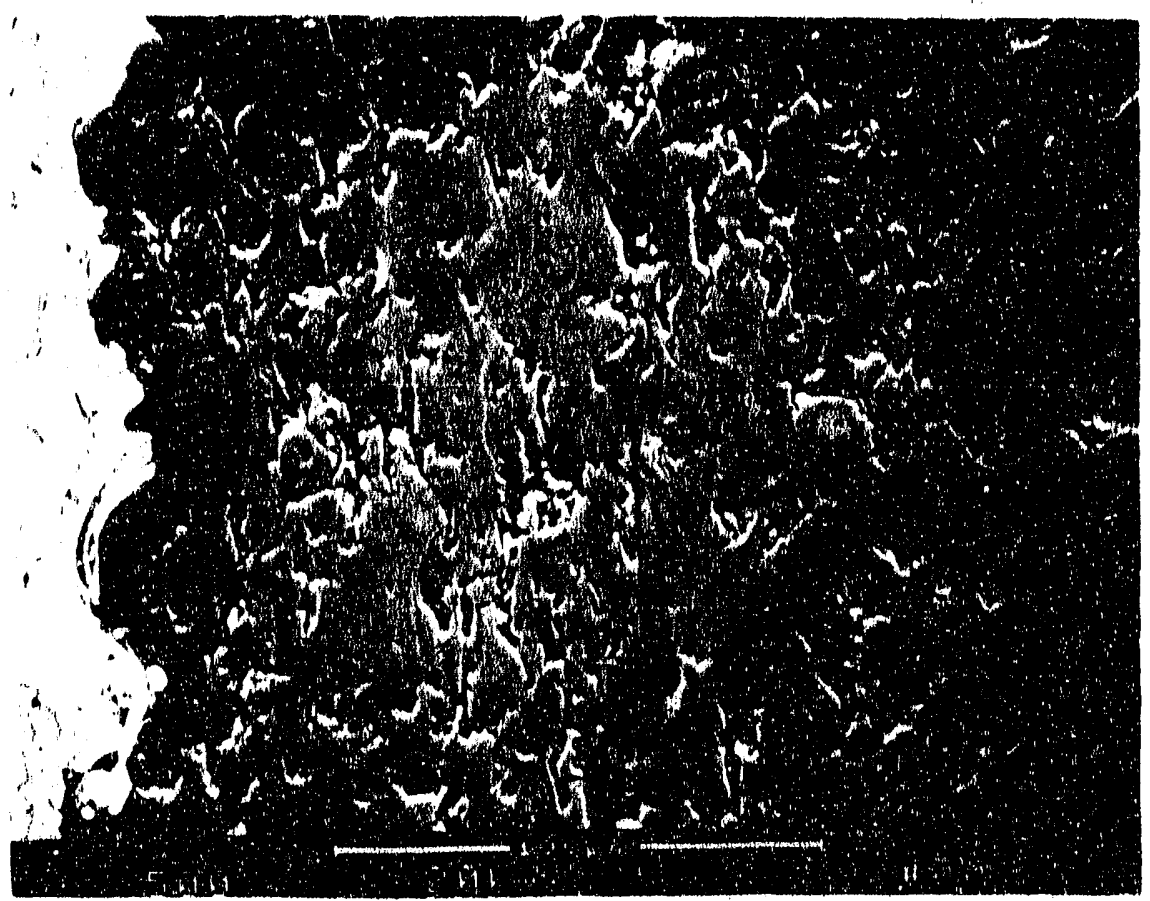

Figure 35. Microstructure of BIRL APS $\mathrm{Cr}_{2} \mathrm{O}_{3}-50 \% \mathrm{Al}_{2} \mathrm{O}_{3}$ coating (SEM, backscattered electron). High levels of porosity and inter-splat de-bond are visible. 


\subsubsection{Alumina-Zirconia Coatings}

Two alumina - zirconia compositions were evaluated: $\mathrm{Al}_{2} \mathrm{O}_{3}-25.7 \% \mathrm{ZrO}_{2}$ and $\mathrm{Al}_{2} \mathrm{O}_{3}-41.4 \% \mathrm{ZrO}_{2}$ (approximately the eutectic composhion). The $\mathrm{N}_{2} \mathrm{O}_{3}-\mathrm{ZnO}_{2}$ system exhibits a diep eutec ic, the eutectic temperature being approximately $1710^{\circ} \mathrm{C}$ compared to mefting points of 2040 and $2700^{\circ} \mathrm{C}$, respectlvely, for $\mathrm{Al}_{2} \mathrm{O}_{3}$ and $\mathrm{ZrO}_{2}$ [13]. The two compositions selected should be whin the two phase region of the phase diagram ( $\mathrm{Al}_{2} \mathrm{O}_{3}$ and $\mathrm{ZrO}_{2}$ solid solutions). The solubility of $\mathrm{ZrO}_{2}$ in $\mathrm{Al}_{2} \mathrm{O}_{3}$ is reported to be less than $1 \%$ and up to $7 \% \mathrm{~N}_{2} \mathrm{O}_{3}$ is soluble in $\mathrm{ZrO}_{2}[13]$.

Powders were obtained from Japan Abrasives, and were designated PC.AZ $\left(\mathrm{Al}_{2} \mathrm{O}_{3}-25.7 \% \mathrm{ZrO}_{2}\right)$ and PC-AZE $\left(\mathrm{A}_{2} \mathrm{O}_{3}-41.4 \% \mathrm{ZrO}_{2}\right)$. A SEM image of the $\mathrm{Al}_{2} \mathrm{O}_{3}-25.7 \% \mathrm{ZrO}_{2}$ potuder is shown in Figure 36 . Some of the particles appear to show a $\mathrm{ZrO}_{2}$-rich shell surrounding a core of $\mathrm{Al}_{2} \mathrm{O}_{3}$-rich material. By comparison, the $\mathrm{Al}_{2} \mathrm{O}_{3}-41.4 \% \mathrm{ZnO}_{2}$ powder was much more uniform (Figure $3 \%$ ), most particles showing a fine eutectic microstructure. Both powders contained small amounts of $\mathrm{fi}$, as revealed by EDS.

Both powders were plasma sprayed using the parameters listed in Table 18. Coatings were of exceptionally high quality in terms of low poroshy, inter-splat adhesion and bonding to the substrate. Both coatings were optically transiucent.

The $\mathrm{A}_{2} \mathrm{O}_{3}-25.7 \% \mathrm{ZrO}_{2}$ coating, shown in Figure 38, showed compositional variations consistent with those observed in the starting powder. In the backscattered electron image, $\mathrm{ZrO}_{2}$-rich material images lighter than $\mathrm{Al}_{2} \mathrm{O}_{3}$-rich material. The $\mathrm{Al}_{2} \mathrm{O}_{3}-41.4 \% \mathrm{ZrO}_{2}$ coating (Figure 39) showed a fine-scale eutectic microstucture in many locations, with some more uniformly imaging regions which may be single phase or too finely dispersed to resolve. In addition to a few larger inter-splat pores, this coating contained small, spherical ("pin hole") porosity within splats and at splat boundaries.

$X$-ray diffraction of the $\mathrm{Al}_{2} \mathrm{O}_{3}-\mathrm{ZrO}_{2}$ coatings revealed some interesting information. The powders both showed mixtures of $\alpha-\mathrm{Al}_{2} \mathrm{O}_{3}$ with tetragonal and monoclinic $\mathrm{ZrO}_{2}$. The as-sprayed $\mathrm{Al}_{2} \mathrm{O}_{3}-25.7 \%$ $\mathrm{ZrO}_{2}$ coating showed weak $\mathrm{y}-\mathrm{Al}_{2} \mathrm{O}_{3}$ peaks, but appeared largely arnorphous (Figulle 40), showing no $\mathrm{ZrO}_{2}$ peaks. The $\mathrm{Al}_{2} \mathrm{O}_{3}-41.4 \% \mathrm{ZrO}_{2}$ coating, on the other hand, revealed a mixture of $\mathrm{ol}-\mathrm{Al}_{2} \mathrm{O}_{3}$ and cubic and/or tetragonal zirconia (Figure 41). Heat treating the $\mathrm{Al}_{2} \mathrm{O}_{3}-25.7 \% \mathrm{ZrO}_{2}$ coating at $400^{\circ} \mathrm{C}$ for one hour resulted in larger $\mathrm{Y}-\mathrm{Al}_{2} \mathrm{O}_{3}$ peaks and the appearance of some weak cublc/tetragonal $\mathrm{ZrO}_{2}$ (Figure 42). Heat treating the $\mathrm{Al}_{2} \mathrm{O}_{3}-41.4 \% \mathrm{ZrO}_{2}$ coating under the same condhions resultecl in essentially no change in the XRD pattern (Figure 43). Comparing the $\mathrm{Al}_{2} \mathrm{O}_{3}-25.7 \% \mathrm{ZrO}_{2}$ and $\mathrm{Al}_{2} \mathrm{O}_{3}-411.4 \% \mathrm{ZrO}$ coatings, it is evident that the dominant alumina plase is gamma for the former and alpha for the latter (Figure 44). A further series of heat treatments at 600 and $800^{\circ} \mathrm{C}$ (for one hour) gave the same results as for the $400^{\circ} \mathrm{C}$ treatment. After heat treating at $1000{ }^{\circ} \mathrm{C}$, however, both coatings showed large tetragonal/cubic zirconia peaks, of much greater intensity than the alumina poaks (Figures 45 and 46). Agein, the dominant alumina phases were gamma for the $\mathrm{Al}_{2} \mathrm{O}_{3}-25.7 \% \mathrm{ZrO}_{2}$ coating and alpha for the $\mathrm{Al}_{2} \mathrm{O}_{3}-41.4 \% \mathrm{ZrO}_{2}$ material.

Thus, it would appear that the $\mathrm{Al}_{2} \mathrm{O}_{3}-25.7 \% \mathrm{ZrO}_{2}$ coating was largely almorphous as-sprayed. Gamma alumina crystallized fairly readily in this coating at or below $400^{\circ} \mathrm{C}$, but the zirconia phase remained largely amorphous unt $800-1000^{\circ} \mathrm{C}$. The $\mathrm{A}_{2} \mathrm{O}_{3}-41.4 \% \mathrm{ZrO}_{2}$ coating contained more crystalline material as-sprayed: some crystalline zirconia was present, and the dominant alumina phase was alpha. Again, crystallization of the remaining amorphous zirconia phase did not occur until 800 $1000^{\circ} \mathrm{C}$. The microhardness values of the two as-sprayed coatings were $1050 \mathrm{kgfmm}^{-2}$ for the $\mathrm{Al}_{2} \mathrm{O}_{3}$ $25.7 \% \mathrm{ZrO}_{2}$ coating and $840 \mathrm{kgimm}^{-2}$ for the $\mathrm{Al}_{2} \mathrm{O}_{3}-41.4 \% \mathrm{ZrO}_{2}$.

It would have been interesting to conduct wear tests with the $1000^{\circ} \mathrm{C}$ healt treated samples in order to investigate the effects of crystallinity on wear. Unfortunately, the coatings delsonded from the substrates during the heat trealment and could not be tested.

Table 18. Optimized spray parameters for $\mathrm{APS} \mathrm{Al}_{2} \mathrm{O}_{3}-2 \mathrm{rO}_{2}$ coatings. Miller Thermal SG 100 plasma gun

\begin{tabular}{|c|c|c|c|c|c|}
\hline Arc Current & Arc Voltage & Plasma Gas & RPM & $\begin{array}{c}\text { Prissure } \\
\text { (psi) }\end{array}$ & $\begin{array}{c}\text { Hopper } \\
\text { Distance } \\
\text { (in.) }\end{array}$ \\
\hline 6000 & 36 & Ait/Hs & 1.5 & 30 & 3.5 \\
\hline
\end{tabular}




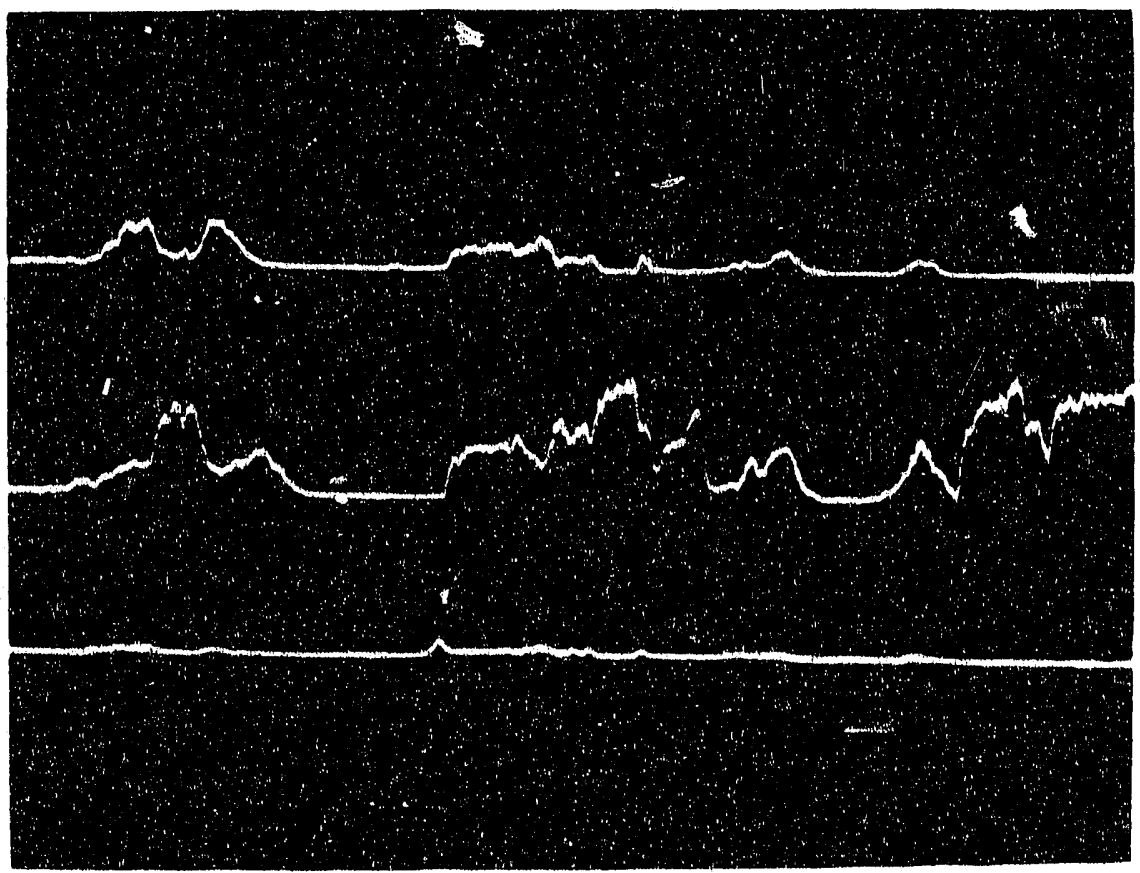

Figure 36. SEM micrograph of PC-AZ $\mathrm{A}_{2} \mathrm{O}_{3}-25.7 \% \mathrm{ZrO}_{2}$ pourder, with line scans for $\mathrm{Zr}$ (top), $\mathrm{Al}$ (middle) and fi (bottom). Some particles appear "cored", with a $\mathrm{ZrO}_{2}$-rich shell.

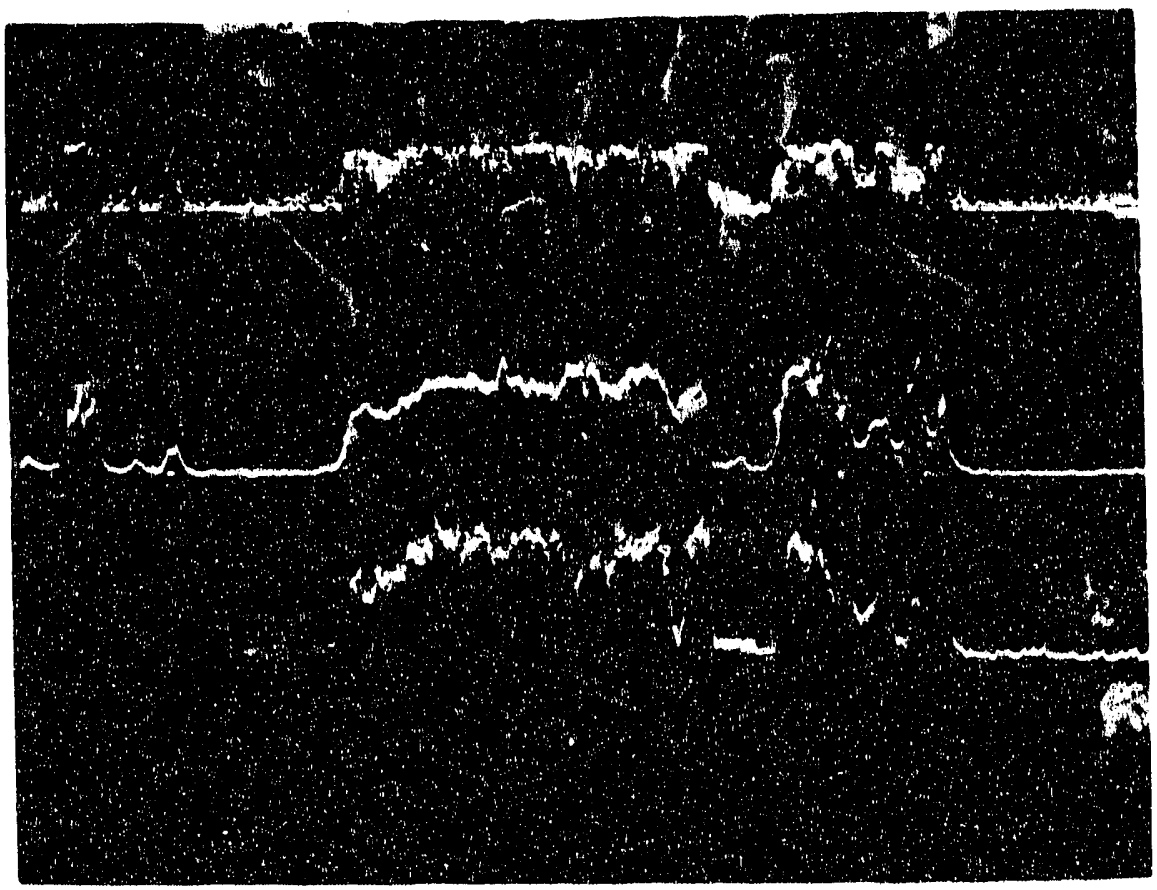

Figure 37. SEM micrograph of PC-AZE $\mathrm{A}_{2} \mathrm{O}_{3}-41.4 \% \mathrm{ZrO}_{2}$ powder with line scans for $\mathrm{TI}$ (top), Al (middle) and Zr (bottom). Many particles show a fine eutectic microstructure. 


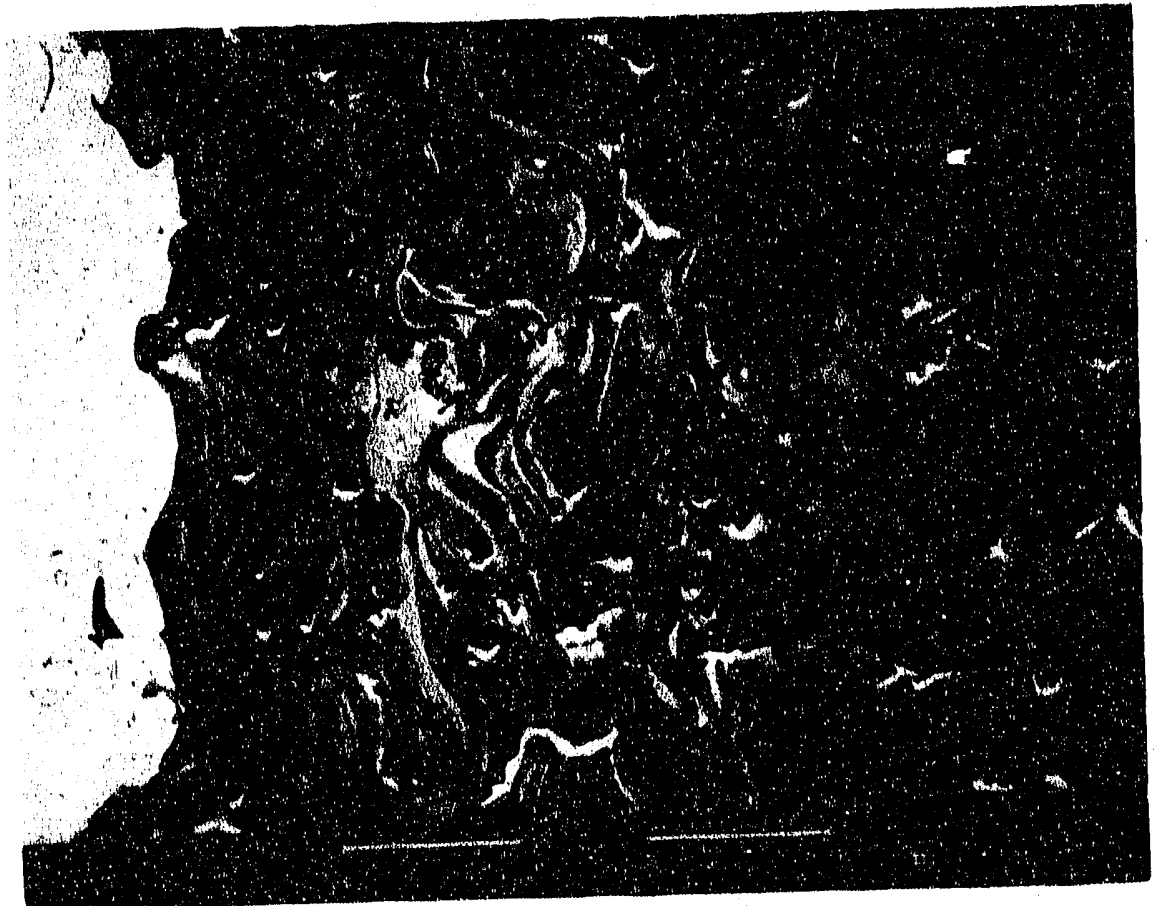

Figure 38. Microstructure of BIRL APS $\mathrm{Al}_{2} \mathrm{O}_{3}-25.7 \% \mathrm{ZrO}_{2}$ coating (SEM, backscattered electron). Good inter-splat bonding. Segregation as for powder (lighter phase $\mathrm{ZrO}_{2}$-rich).

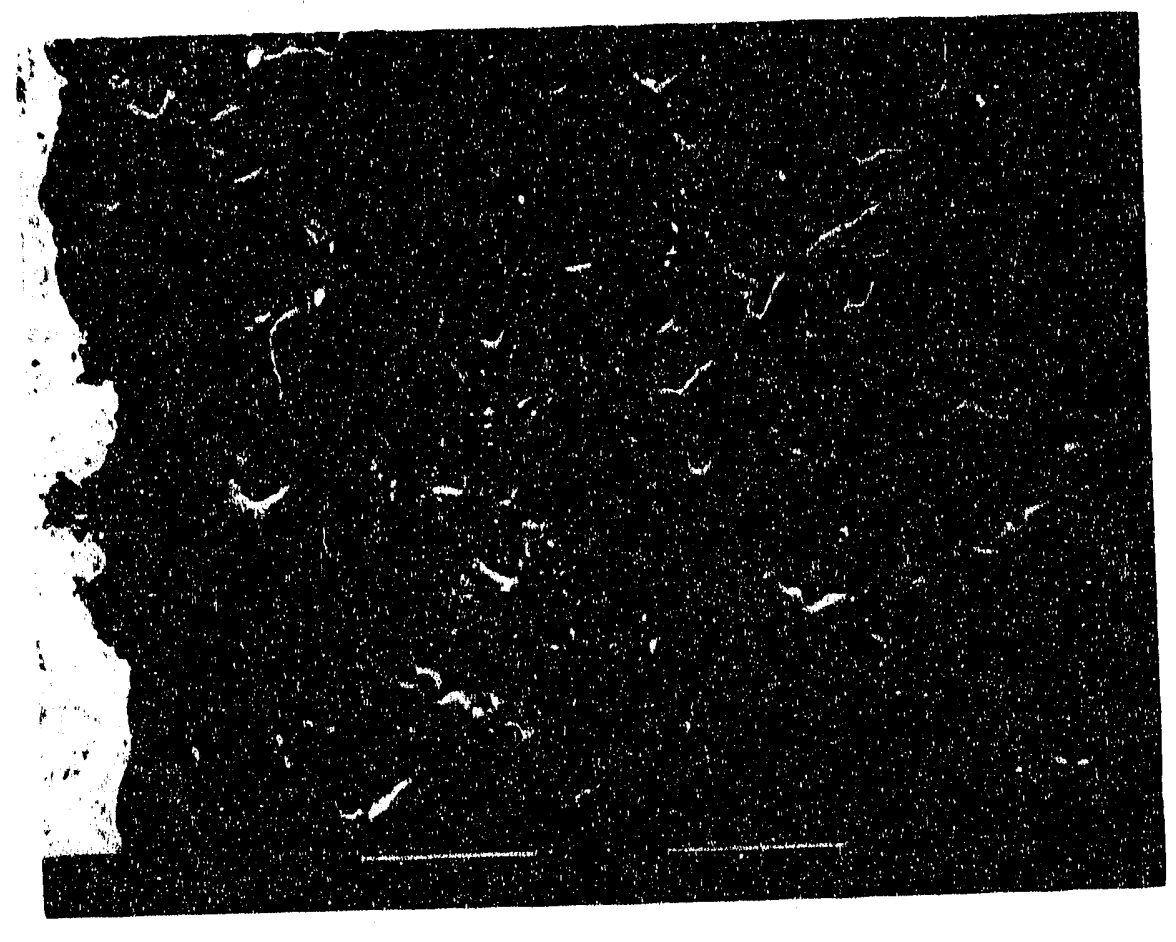

Figure 39. Microstructure of BIRL APS $\mathrm{Al}_{2} \mathrm{O}_{3}-41.4 \% \mathrm{ZrO}_{2}$ coating (SEM, backscattered electron). Good inter-splat bonding. Fine-scale eutectic microstructure visible in many locations. 


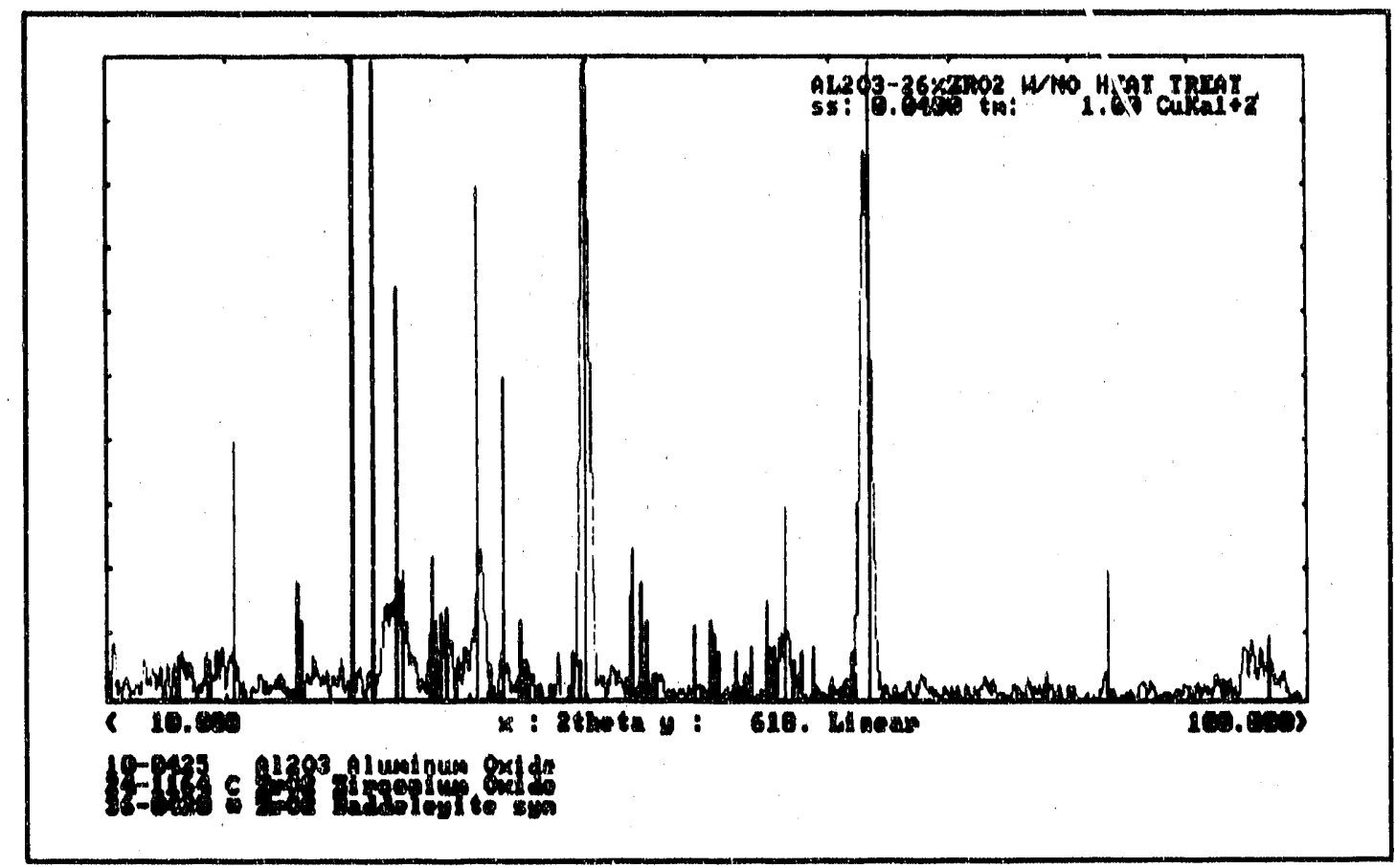

Figure 40. X-ray diffraction pattern of APS $\mathrm{A}_{2} \mathrm{O}_{3}-25.7 \% \mathrm{ZrO}_{2}$ coating, as-sprayed. Pattern shows weak $\mathrm{V}-\mathrm{Al}_{2} \mathrm{O}_{3}$ peaks, but no crystalline $\mathrm{ZnO}_{2}$ phases.

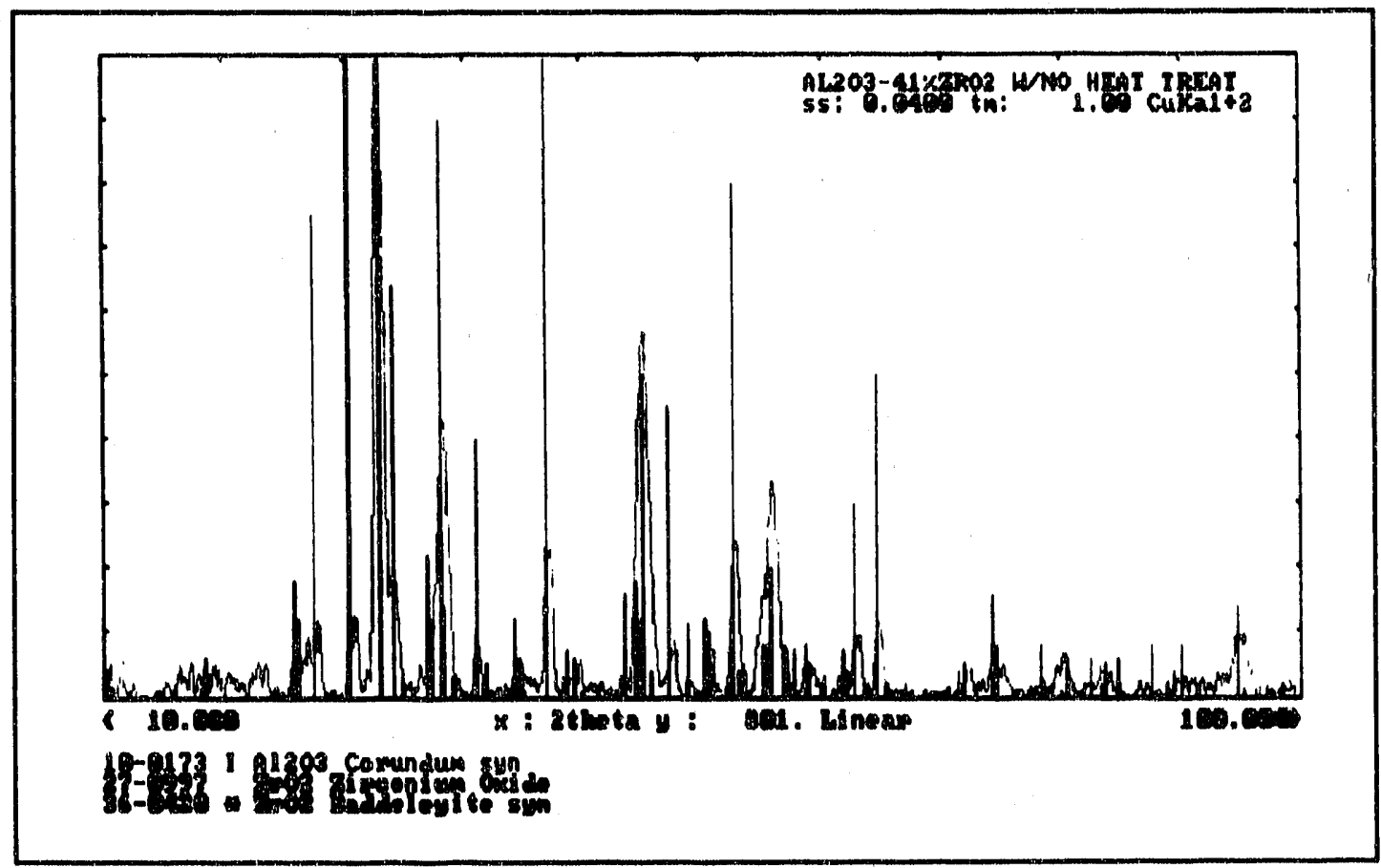

Figure 41. X-ray diffraction pattern of APS $\mathrm{Al}_{2} \mathrm{O}_{3}-41.4 \% \mathrm{ZnO}_{2}$ coating, as-sprayed.

Pattern shows $\alpha-\mathrm{Al}_{2} \mathrm{O}_{3}$ peaks with cubic/tetragonal $\mathrm{ZrO}_{2}$. 


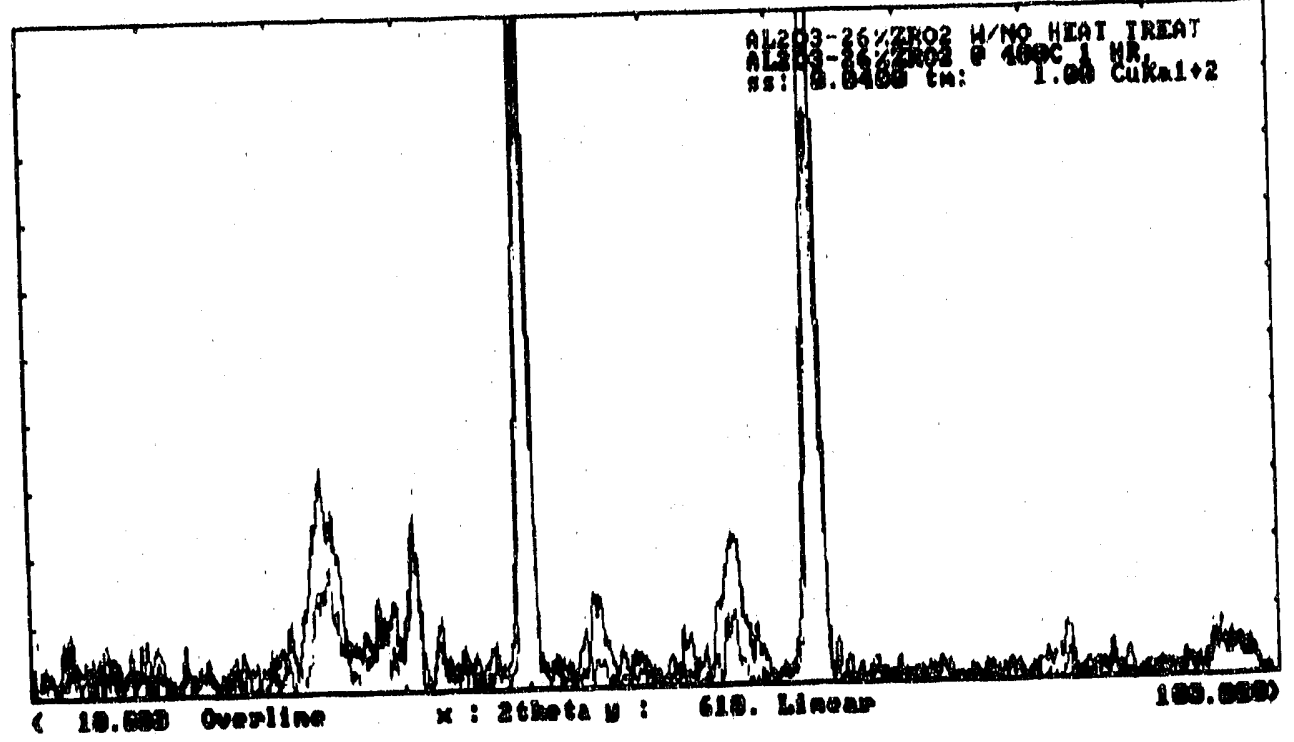

Figure 42. X-ray diffraction patterns for APS $\mathrm{Al}_{2} \mathrm{O}_{3}-25.7 \% \mathrm{ZnO}_{2}$ coating. as-sprayed (b/ue) and after 1 hour at $400{ }^{\circ} \mathrm{C}$ (orange). The heat treatment resulted in larger $\mathrm{Y}-\mathrm{A}_{2} \mathrm{O}_{3}$ peaks, and the formation of some weak cubic/tetragonal $\mathrm{ZnO}_{2}$ peaks.

Table 19. JCPDS files used for the analysis of APS $\mathrm{Al}_{2} \mathrm{O}_{3}-\mathrm{ZrO}_{2}$ coatings.

\begin{tabular}{|cc|cc|}
\hline \multicolumn{2}{|c|}{$\mathrm{Al}_{2} \mathrm{O}_{3}$} & \multicolumn{2}{|c|}{$\mathrm{ZrO}_{2}$} \\
\hline $10-173$ & $\alpha-\mathrm{Al}_{2} \mathrm{O}_{3}$ & $27-997$ & $\mathrm{~F}-\mathrm{ZrO}_{2}$ \\
\hline $10-425$ & $\gamma-\mathrm{Al}_{2} \mathrm{O}_{3}$ & $24-1164$ & $\mathrm{~T}-\mathrm{ZrO}_{2}$ \\
\hline & & $36-420$ & $\mathrm{M}-\mathrm{ZrO}_{2}$ \\
\hline
\end{tabular}




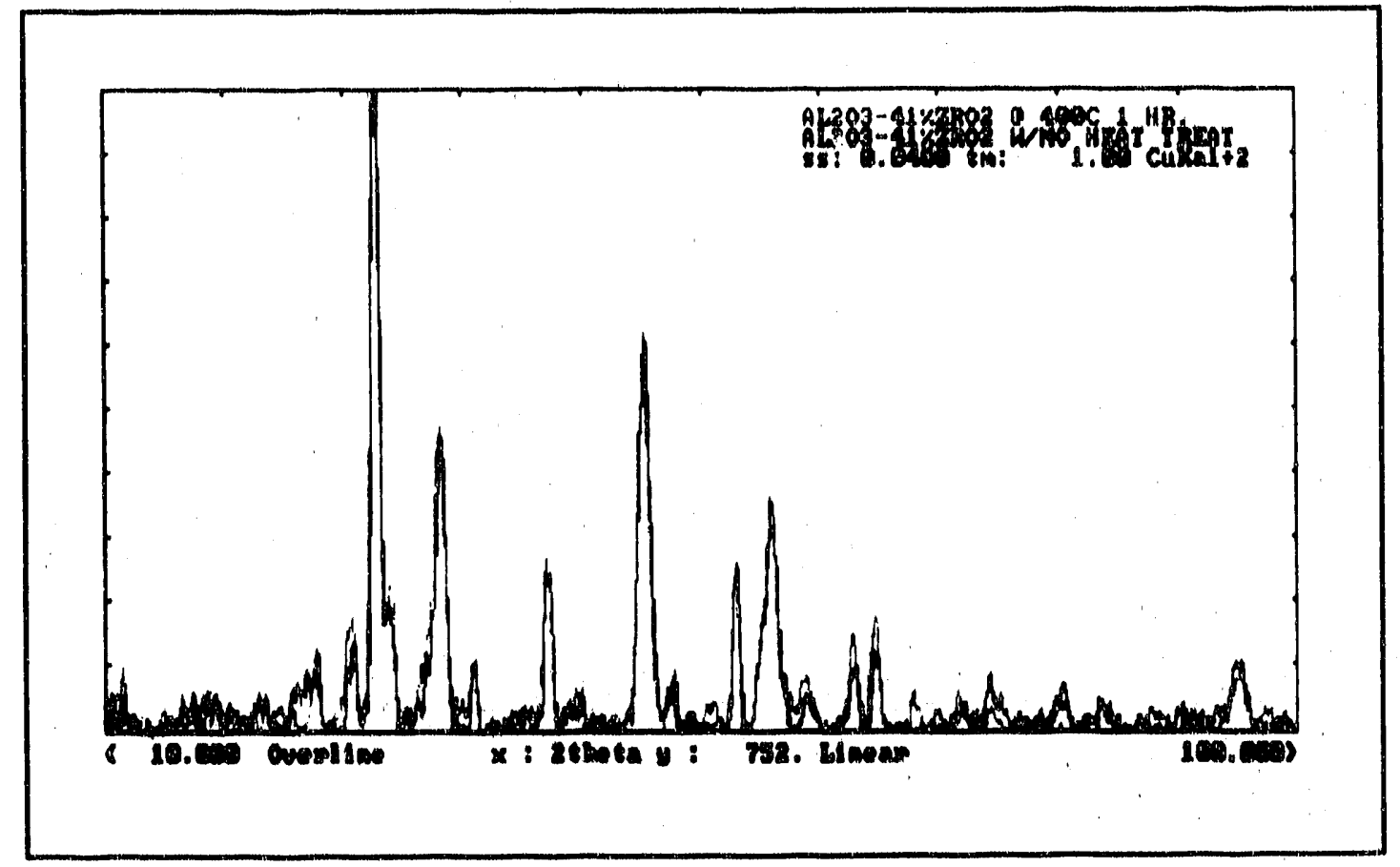

Figure 43. X-ray diffraction patterns for APS $\mathrm{Al}_{2} \mathrm{O}_{3}-41.4 \% \mathrm{ZnO}_{2}$ coating, as-sprayed (orange) and after 1 hour at $400^{\circ} \mathrm{C}$ (blue). The heat treatment caused no phase changes.

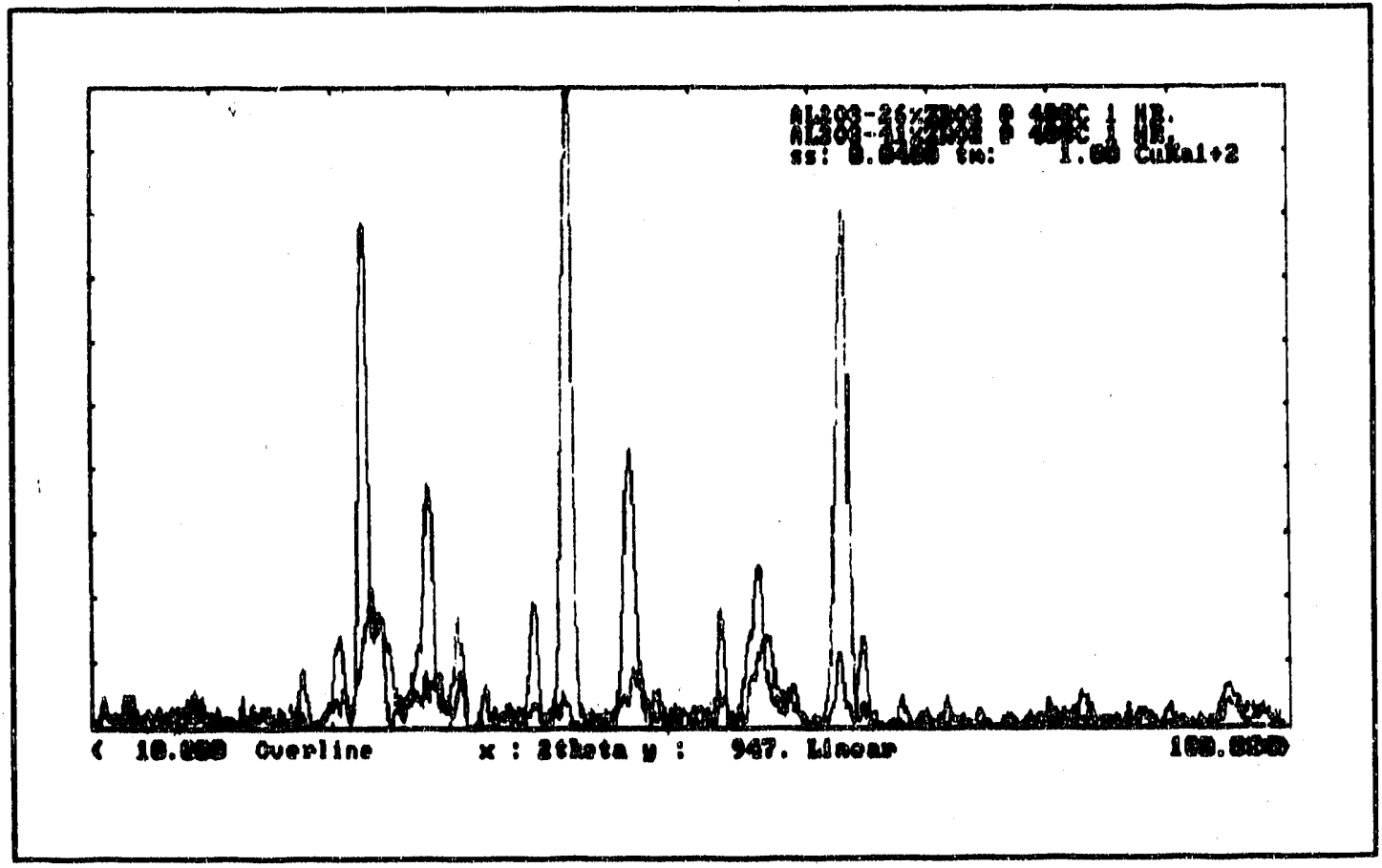

Figure 44. X-ray diffraction patterns for $\mathrm{Al}_{2} \mathrm{O}_{3}-25.7 \% \mathrm{ZrO}_{2}$ (blue) and $\mathrm{Al}_{2} \mathrm{O}_{3}-41.4 \% \mathrm{ZrO}_{2}$ (orange) coatings, after 1 hour at $4000 \mathrm{C}$. The dominarit $\mathrm{A}_{2} \mathrm{O}_{3}$ phases are $y$ and $\alpha$, respectively. 


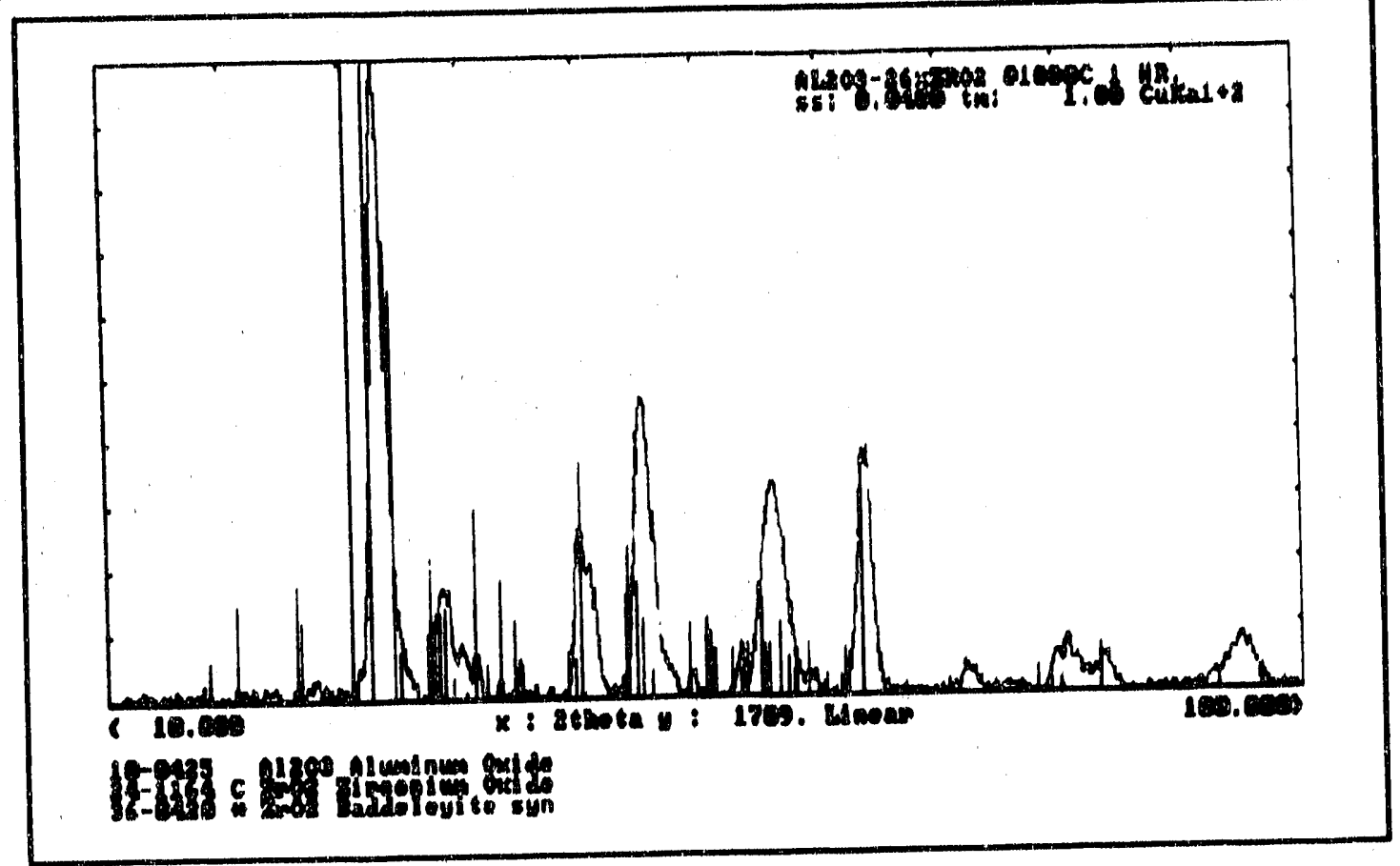

Figure 45. X-ray diffraction patterns for APS $\mathrm{A}_{2} \mathrm{O}_{3}-25.7 \% \quad 2 \mathrm{O}_{2}$ coating after 1 hour at $1000^{\circ} \mathrm{C}$. The heat treatment resulted in the formation of large cublc/tetragonal $\mathrm{ZrO}_{2}$ peaks.

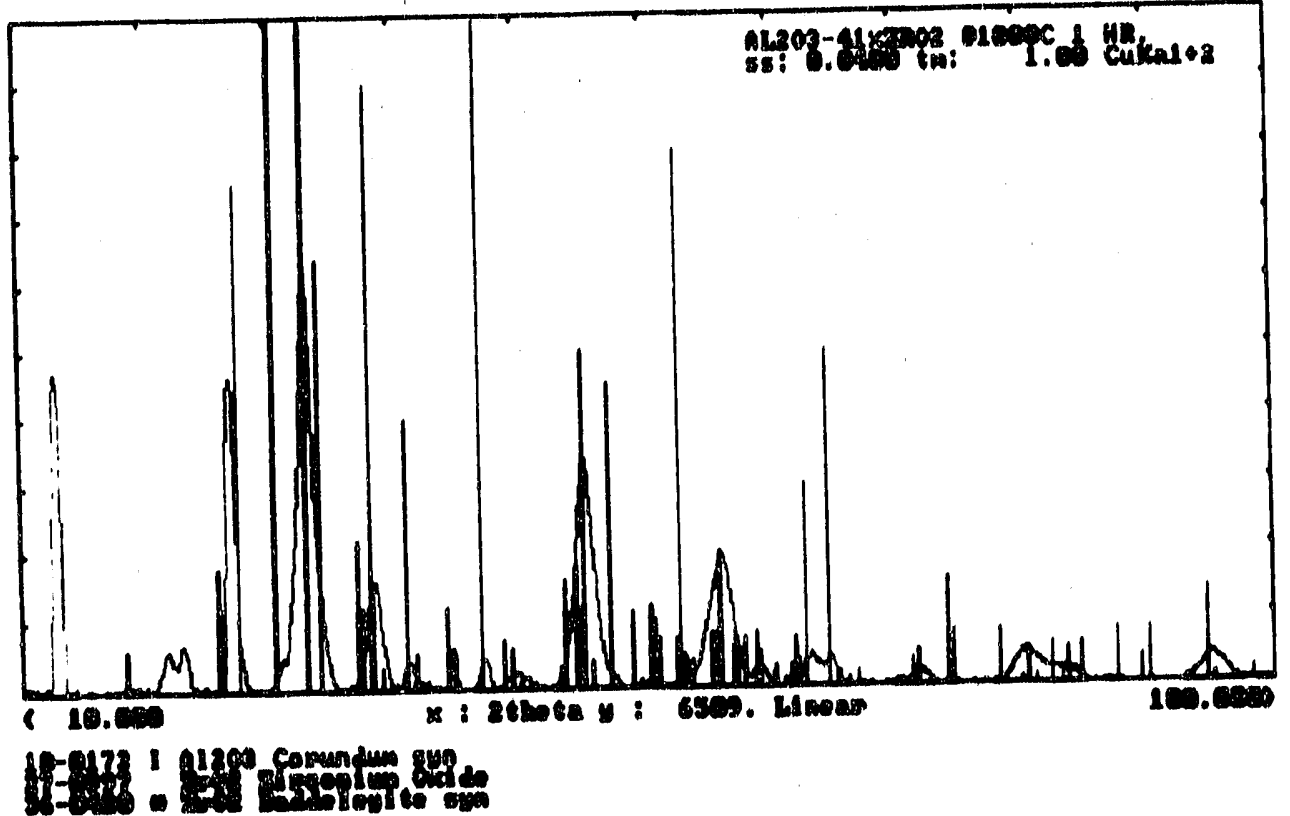

Figure 46. X-ray diffraction patterns for APS $\mathrm{Al}_{2} \mathrm{O}_{3}-41.4 \% \quad 2 \mathrm{O}_{2}$ coating after 1 hour at $10000 \mathrm{C}$. The heat treatment resulted in the formation of large cubic/totragonal $\mathrm{ZrO}_{2}$ peaks. 


\subsubsection{Laser Processed Alumina-Zirconia Coatings}

Lasers or electron beams appear to be sultable tools for densifying the surface of coatings without affecting the substrate. Their extremely high energy densittes can be used to melt a very thin surface layer and, under certain conditions, cause rapid re-solidification.

Features of laser treatment processes include:

1. High energy densities are applled to the surface over very short contact times.

2. For materlals with a deep eutectic the quench rate is sufficlent for the llquid to superoool to the glass transition temperature and form an amorphous microstructure upon solidification.

3. Where crystallization does occur, an extremely fine-grained microstructure can be produced, with improved wear and corrosion properties in some cases.

4. Supersaturated solid solutions can be formed.

5. For ceramic coatings, laser glazing provides the opportunity to produce smoother, denser, more homogeneous surface layers with compressive surface stresses.

6. For metallic and cermet systems, laser processing is a method of increasing hardness or causing non-equilibrium reactions to occur which may create novel microstructures.

The alumina-zirconia system was selected as a good candidate for laser glazing, since the system has a deep eutectic, and possibilities exist for producing novel phase distributions. Since the as-sprayed coatings were found to contain amorphous phases, there was interest in whether these phases could be crystallized using laser treatment processes and, if so, what phases would be formed.

All samples were glazed using an Electrox $1200 \mathrm{~W}$ laser operating with hellum shielding gas at $10^{10} \mathrm{~W} \mathrm{~cm}^{-2}$ power density and $2 \times 10^{-10} \mathrm{~s}$ contact time.

$X$-ray diffraction patterns for the laser processed $\mathrm{Al}_{2} \mathrm{O}_{3}-25.7 \% \mathrm{ZrO}_{2}$ and $\mathrm{Al}_{2} \mathrm{O}_{3}-41.4 \% \mathrm{ZrO}_{2}$ coatings are shown in Figures 47 and 48 . The laser treatment crystallized the surface layers of both coatings to produce mixtures of mostly tetragonal $\mathrm{ZrO}_{2}$ and $\alpha-\mathrm{Al}_{2} \mathrm{O}_{3}$. It is interesting that the laser treatment produced a different alumina phase than conventional heat treating for the $\mathrm{Al}_{2} \mathrm{O}_{3}-25.7 \% \mathrm{ZrO}_{2}$ coating.

SEM images of the laser processed coating surfaces and cross sections through the coatings are shown in Figures $49-52$. There was itttle evidence of surface melting, except perhaps for localized regions on the $\mathrm{Al}_{2} \mathrm{O}_{3}-41.4 \% \mathrm{ZrO}_{2}$ coating (Figure 52). For both coatings, networks of $50-100 \mu \mathrm{m}$ deep radial cracks were formed at the surface due to the thermal shock assoclated with the laser treatment. The effect of these crack networks was to roughen the surface considerably, rather than produce a "glaze". In fact, the surface roughness was too high for meaningful wear tests to be conducted with these samples.

Unfortunately, the surfaces could not be lapped without removing the laser-affected regions. 


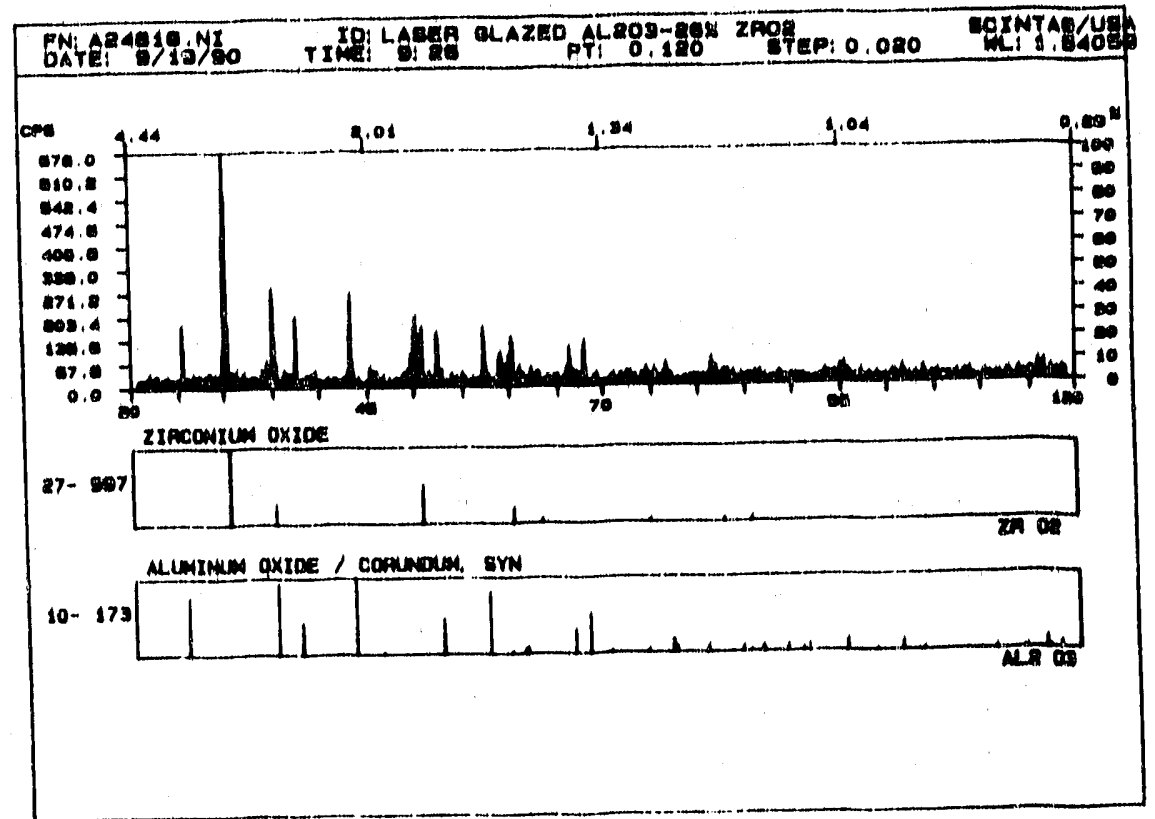

Flgure 47. X-ray diffraction pattern of laser-processed APS $\mathrm{A}_{2} \mathrm{O}_{3}-25.7 \% \mathrm{ZrO}_{2}$ coating. The pattern shows a mixture of mostly totragonal $\mathrm{ZnO}_{2}$ and $\alpha-\mathrm{A}_{2} \mathrm{O}_{3}$.

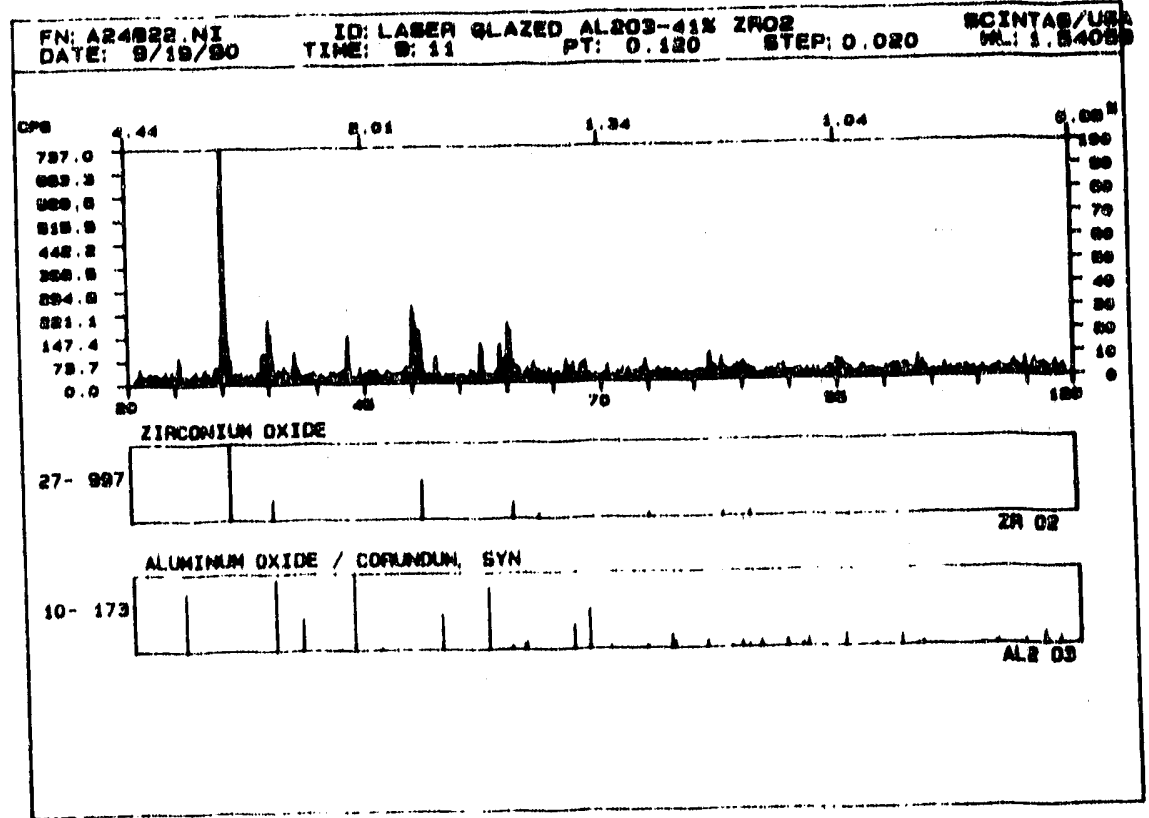

Figure 48. X-ray diffraction pattern of laser-processed APS $\mathrm{Al}_{2} \mathrm{O}_{3}-41.4 \% \mathrm{ZrO}_{2}$ coating. The pattern shows a mixture of mostly tetragonal $\mathrm{ZrO}_{2}$ and $\alpha-\mathrm{Al}_{2} \mathrm{O}_{3}$ 


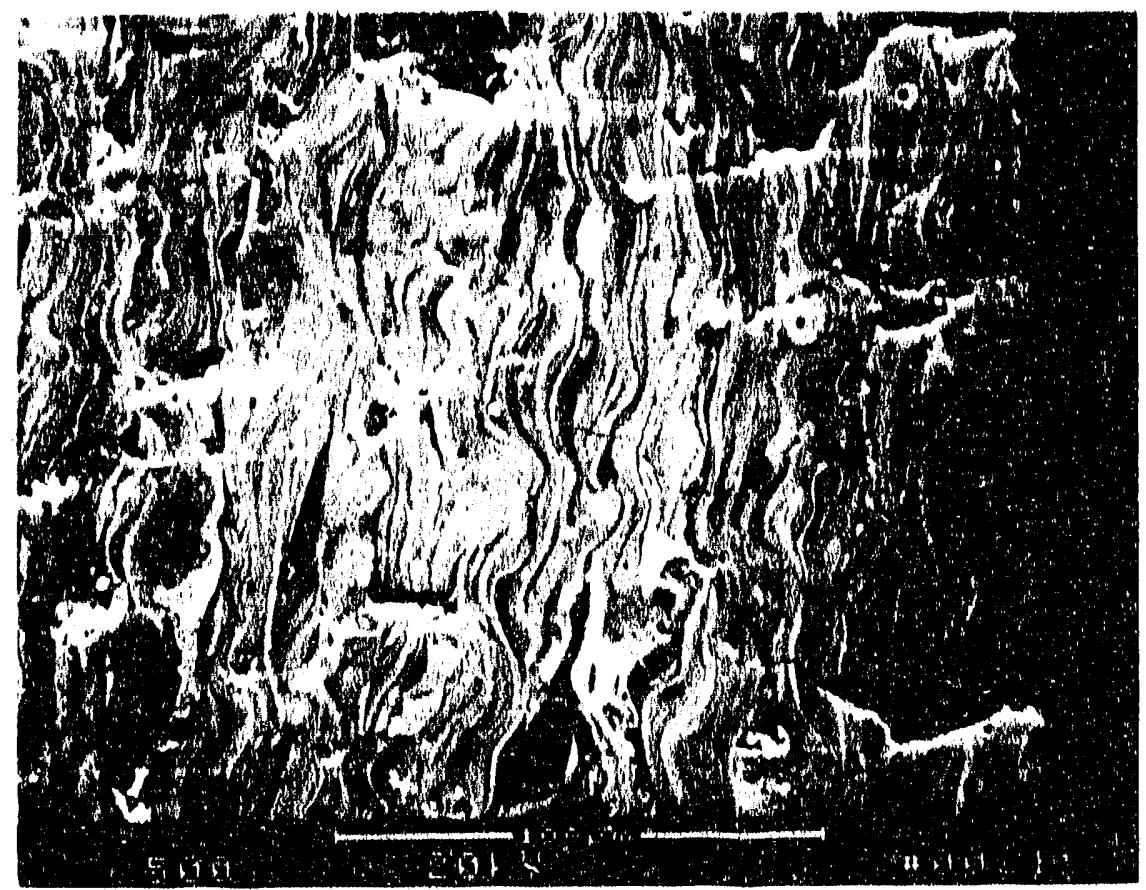

Figure 49. Section through BIRL laser processed APS $\mathrm{A}_{2} \mathrm{O}_{3}-25.7 \% \mathrm{ZrO}_{2}$ coating (SEM, backscattered electron image), showing thermal shock cracks.

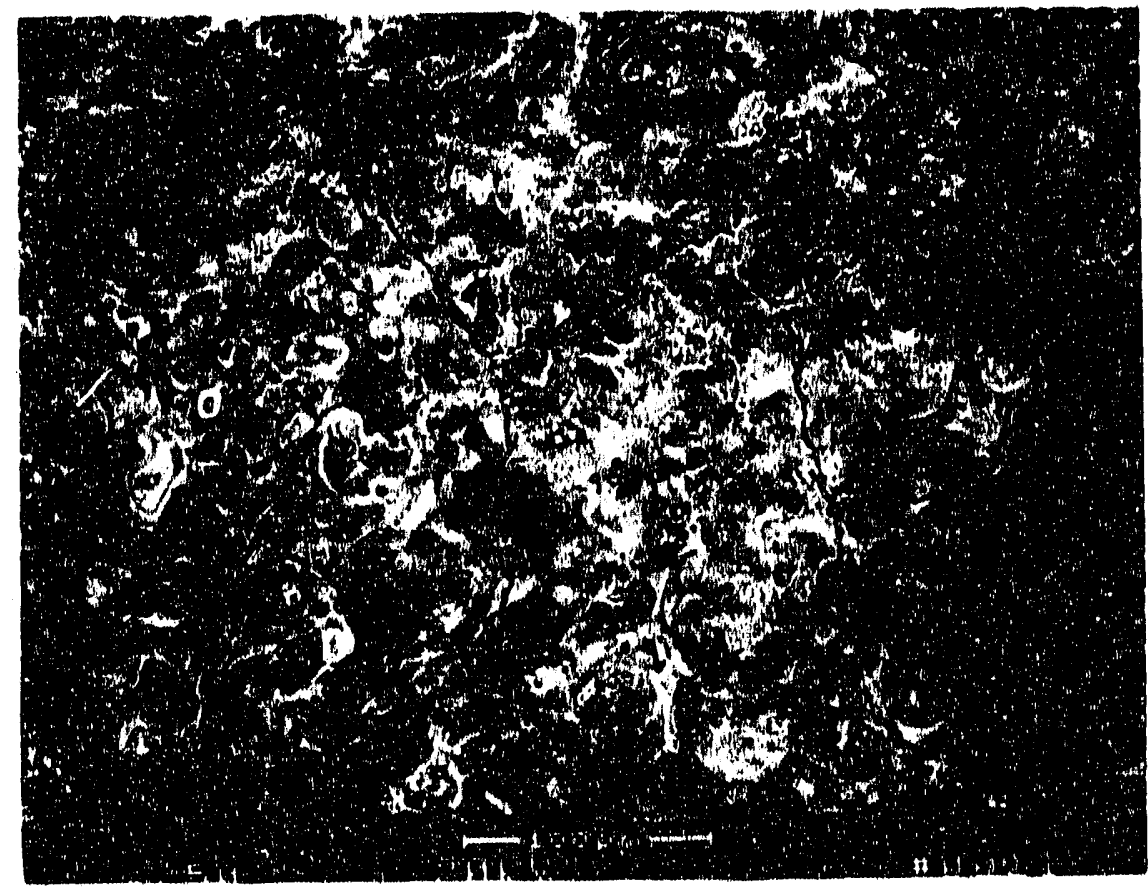

Figure 50. Surface of BIRL laser processed APS $\mathrm{Al}_{2} \mathrm{O}_{3}-25.7 \% \mathrm{ZrO}_{2}$ coating (SEM, backscattered electron image), showing thermal shock oracks. 


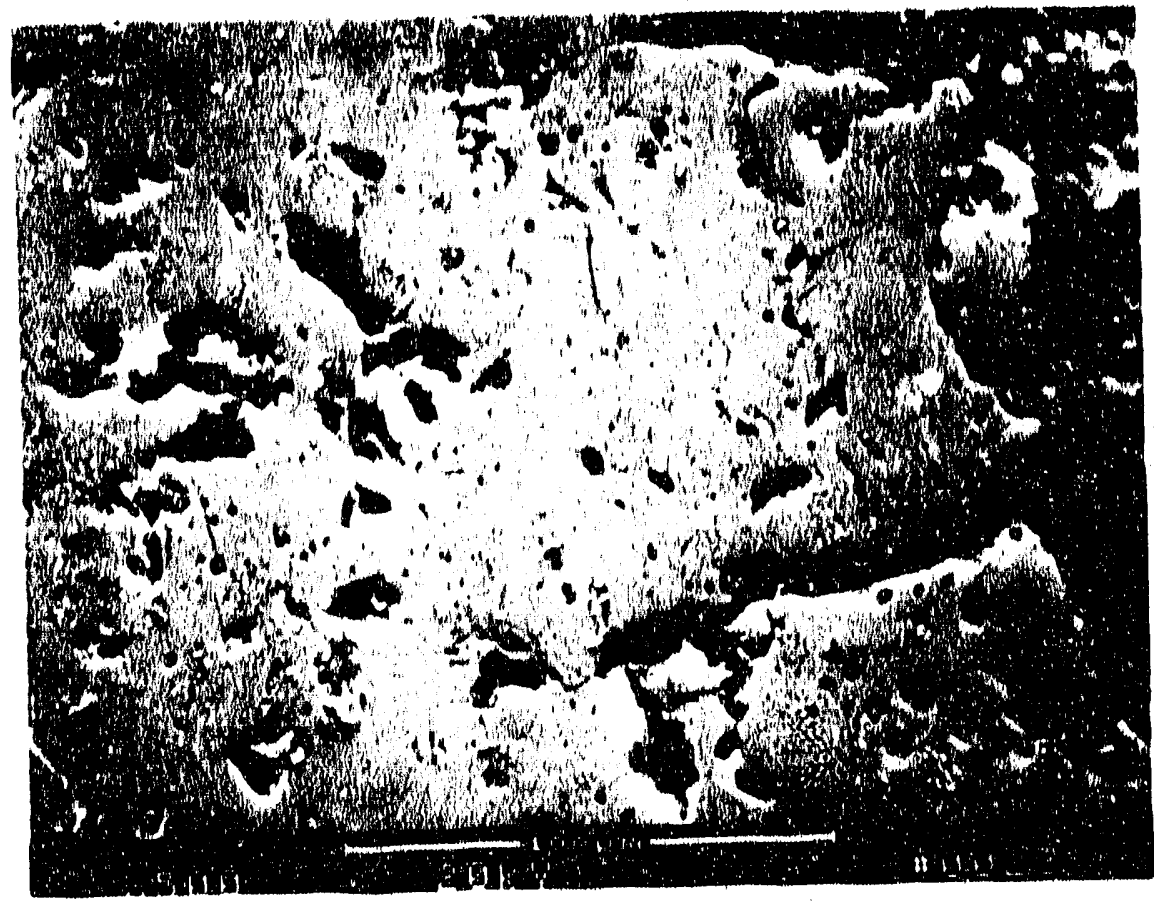

Figure 51. Sectlon through BIRL laser processed APS $\mathrm{Al}_{2} \mathrm{O}_{3}-41.4 \% \mathrm{ZrO}_{2}$ coating
(SEM, backscattered electron image), showing thermal shook cracks.

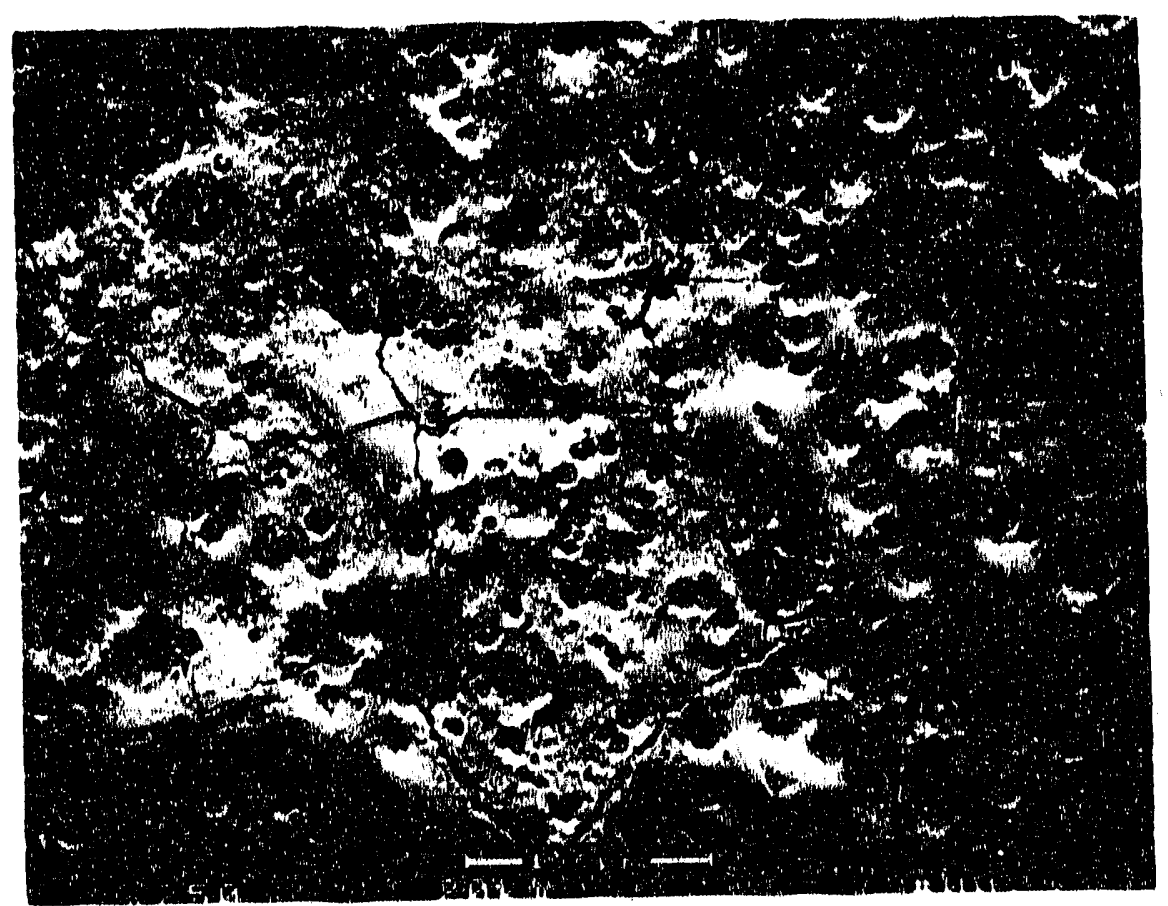

Figure 52. Surface of BIRL laser processed APS $\mathrm{A}_{2} \mathrm{O}_{3}-41.4 \% \mathrm{ZrO}_{2}$ cuating (SEM, backscattered electron image), showing thermal shock cracks. 
2.3 COATING DEVELOPMENT AT BOYD MACHINE AND REPAIR COMPANY, INC.

\subsection{Chromlum Oxide Coating}

The microstruoture of the Boyd chromium oxide coating contained a substantlal amount of unmelted particles, as evidenced by equiaxed regions containing porosity and a very fine-scale microstructure (Flgure 53). Inter-splat microoracking was average for plasma sprayed chromlum oxides, but the coating contained a relatively high concentration of largo pores.

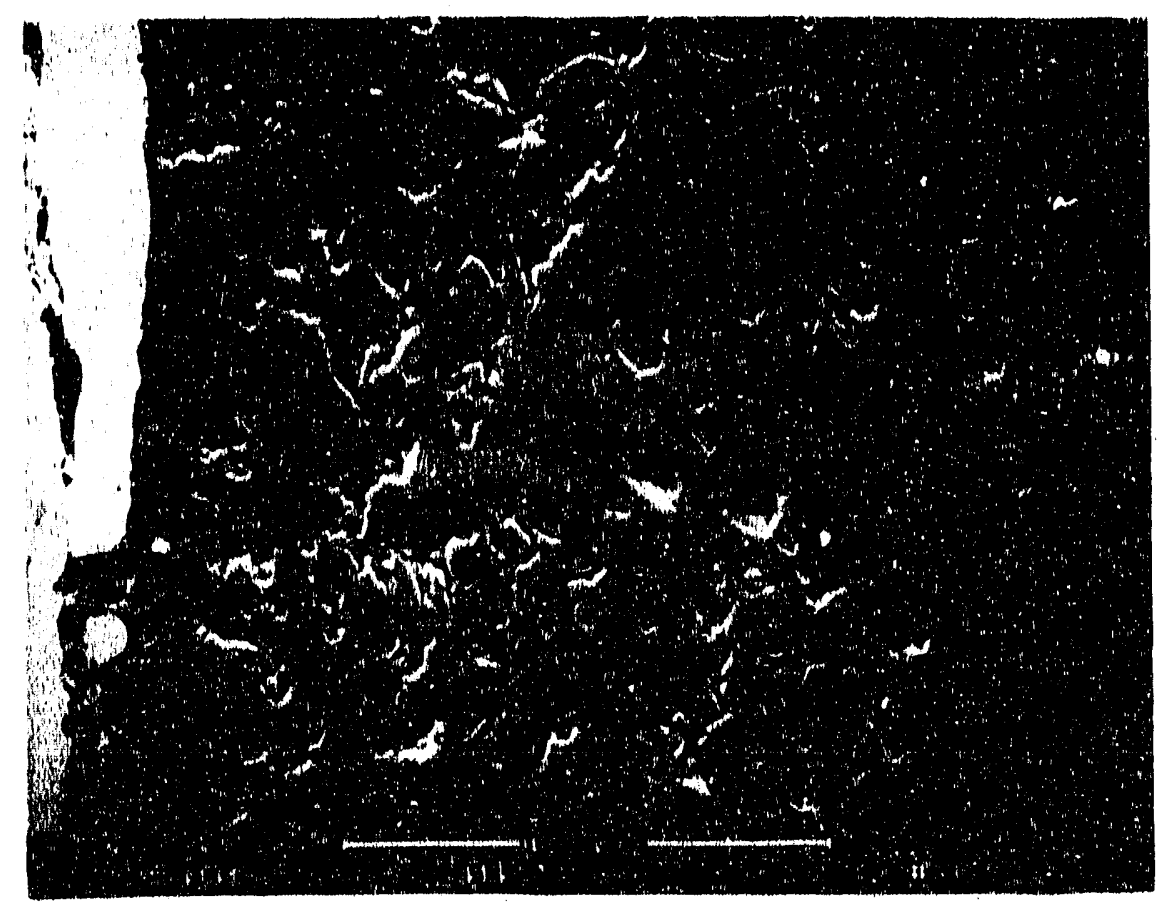

Figure 53. Microstructure of Boyd plasma sprayed chromium oxide coating (SEM, backscatiered electron Image), showing a high proportion of unmelted particles (fine, equiaxed microstructure) and high porosity. 


\subsubsection{Tuagaten Carbide - Cobalt Coating}

A WO - 12\% Co coating was sprayed using a Jetkote II HVOF system. The resulting microstruoture is shown in Figure 54. The coating showed almost continuous cracking at the substrate interface,

indicating poor adherence (Figure 54). At $250 \mu \mathrm{m}$ thickness, thls coating was thicker than other WC . Co coatings evaluated, and it is speculated that the poor adherence was due to high residual stresses. The coating microstructure was comprised of $5 \mu \mathrm{m}$ carbide particies in a $C_{0}$ and W-Co-C matrix with low levels of porosity (< 10\%). SEM images (Flgure 54) were simllar to those for the APS Materials APS arid LPPS WC - Co coatings described in section 3.1.2. X-ray diffraction revealed $W C$ and $\alpha-W_{2} C$ phases (evidence of decarburization), with relatively little solutionizing of the carbldes (Table 7, section 2.1.2). The hardness of the Boyd coating was $1120 \mathrm{~kg}^{\prime m m} \mathrm{~mm}^{-2}\left(\mathrm{HK}_{100}\right)$, which was comparable to many of the other WC - Co materials evaluated in this program.

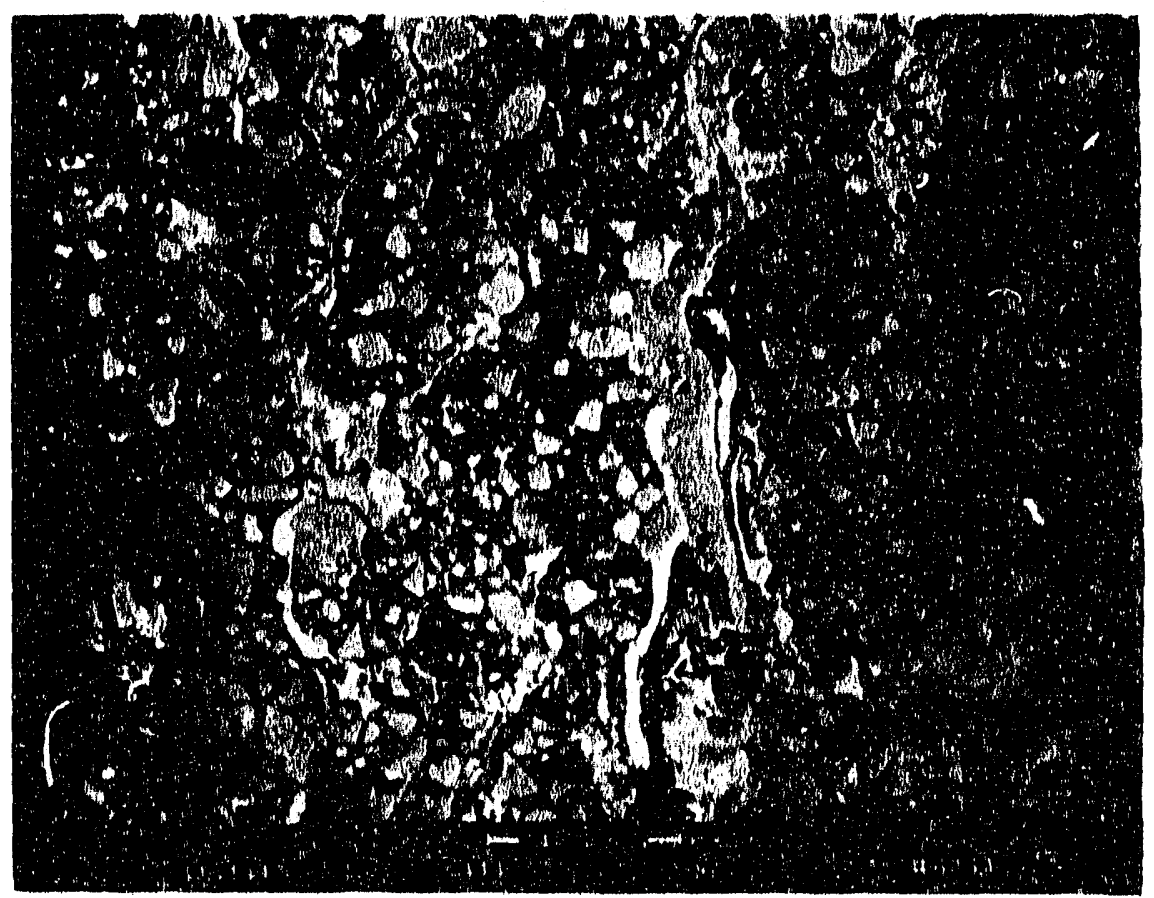

Figure 54. Microstructure of Boyd HVOF WC - Co coating (SEM, backscattered electron image). This coating shows a similar microstructure to the APS Materials APS and LPPS materials (figures 10 and 11), with blocky carbides and evidence of several phases formed by solutionizing, re-precipitation and decarburization. The "matrix" phase is actually a W-CO-C phase in most regions. Craoking at the coating - substrate interface is evidence of poor adherence. 


\subsection{COATING DEVELOPMENT AT CUMMINS ENGINE COMPANY, INC.}

Coating acthitties at Cummins fooussed on the Kaman process silloa chromla-alumina coating. The coating was developed primarily for oylirider liner appllcations, since it was felt that the maximum thiokness (approximately $20 \mu \mathrm{m}$ ) and the coating adherence would be insufficient for a piston ring coating.

The microstruoture of a slurry-sprayed sillica-chromia-alumina (SCA) coating prepared at Cummins is shown in Figure 55. The cjating was produced by 12. densification cycles (impregnatlon with ohromlc acld followed by heating) with no surface finishing operations. The coating comprised a mixture of $\mathrm{SiO}_{2}$ and $\mathrm{Al}_{2} \mathrm{O}_{3}$ particles from the original sprayed slurry with $\mathrm{Cr}_{2} \mathrm{O}_{3}$ formed in the dersiffication cycles. Porosity levels were low. The grain size was approximately $5 \mu \mathrm{m}$, much less than the coating thlokness $(20 \mu \mathrm{m})$. A thin layer of pure $\mathrm{Cr}_{2} \mathrm{O}_{3}$ was formed on the surface, and in places extended Into the bulk of the coating to fill oracks in the original slurry coatling. The composition of the coating was determineu by EDS analysis to be $55 \% \mathrm{Cr}_{2} \mathrm{O}_{3}-41 \% \mathrm{SiO}_{2}-4 \% \mathrm{Al}_{2} \mathrm{O}_{3}$ by weight.

$X$-ray diffraction was performed to compare the phase content of the present coating with a sample obtained from Kaman Sclences Inc. (Boulder, Colorado) (1986 vintage). The Cummins matorial was found to contain more $\mathrm{Cr}_{2} \mathrm{O}_{3}$ and less $\mathrm{Al}_{2} \mathrm{O}_{3}$ than the Kaman coating (Figure 56).

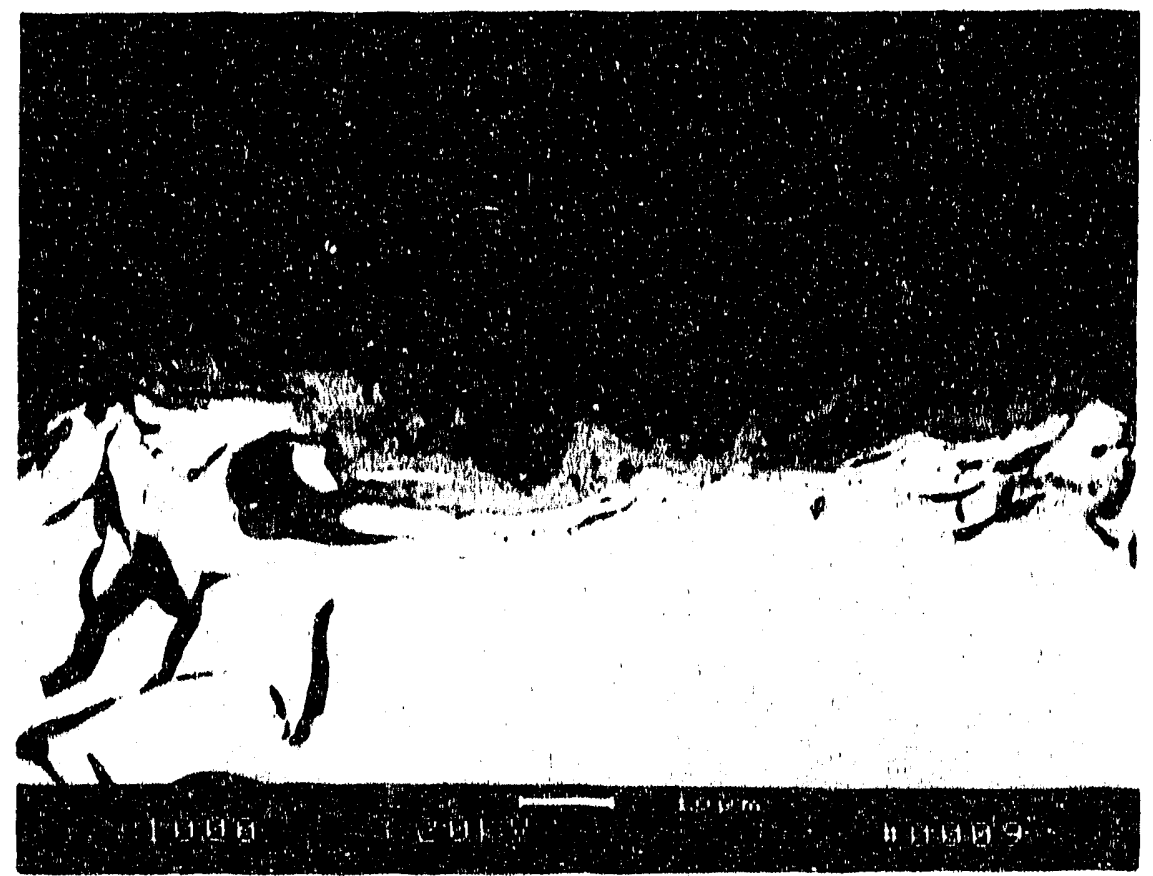

Figure 55. Miorostructure of Cummins slurry-sprayed sillca-chromia-alumina coating after 12 densification cycles (SEM, backscattered electron image). The coating comprises $5 \mu \mathrm{m}$ grains of $\mathrm{SiO}_{2}$ and $\mathrm{Al}_{2} \mathrm{O}_{3}$ from the original slurry, with a reaction-formed $\mathrm{Cr}_{2} \mathrm{O}_{3}$ matrix. A thin layer of pure $\mathrm{Cr}_{2} \mathrm{O}_{3}$ has formed on the surface. 


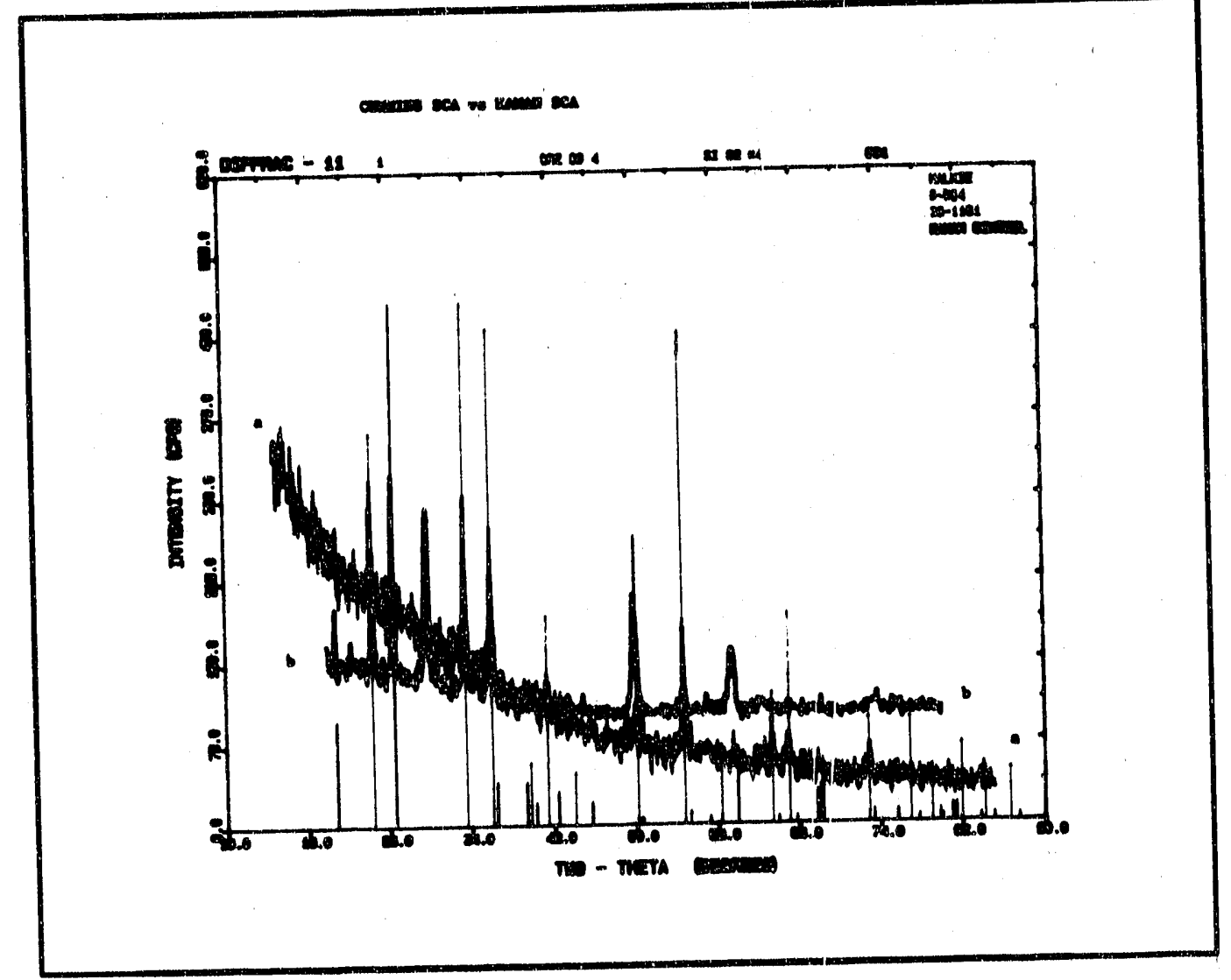

Figure 56. X-ray difiraction pattems from Cummins (red - a) and Keman Sctence (black - b)
SCA coatings. The Cummins matertal was found to (contain stightly moro $\mathrm{Cr}_{2} \mathrm{O}_{3}$ and loss $\mathrm{N}_{2} \mathrm{O}_{3}$ than the Kaman coating. 


\subsection{COATING DEVELOPMENT AT IMPLANT SCIENCFS CORPORATION}

Diamond-like coatings were prepared using a proprietary lon-assisted CVD process. Substrate materials were $\mathrm{H}_{13}$ tool steel (cylindrical "ring" and flat "iner" samples) and pearlitic grey cast iron (fiat "liner" samples only). Substrate materials were lapped prior to coating, since the surface finish of a thin coating of this type is often controlled by the finish of the substrate. SEM micrographs of the coating are shown in Figures 57 - 59. The coating was approximately $1 \mu \mathrm{m}$ thick and highly uniform. In some locations, large areas of the coating had spalled from the substrate (Figure 58), indicating high residual stress and/or low coating adhesion. High residual stress would be expected because of the extremely high elastic modulus of diamond compared to other materials. At high magnification, the surface texture of the coating was characteristic of a sputtered surface, with shallow craters and ridges. This coating contained a low concentration of sub-micron crystallites, which are presumed to be dlamond crystals. Information from the supplier suggested that this coating probably contained a substantial amount of amorphous carbon. The film was too thin for microhardness measurements.

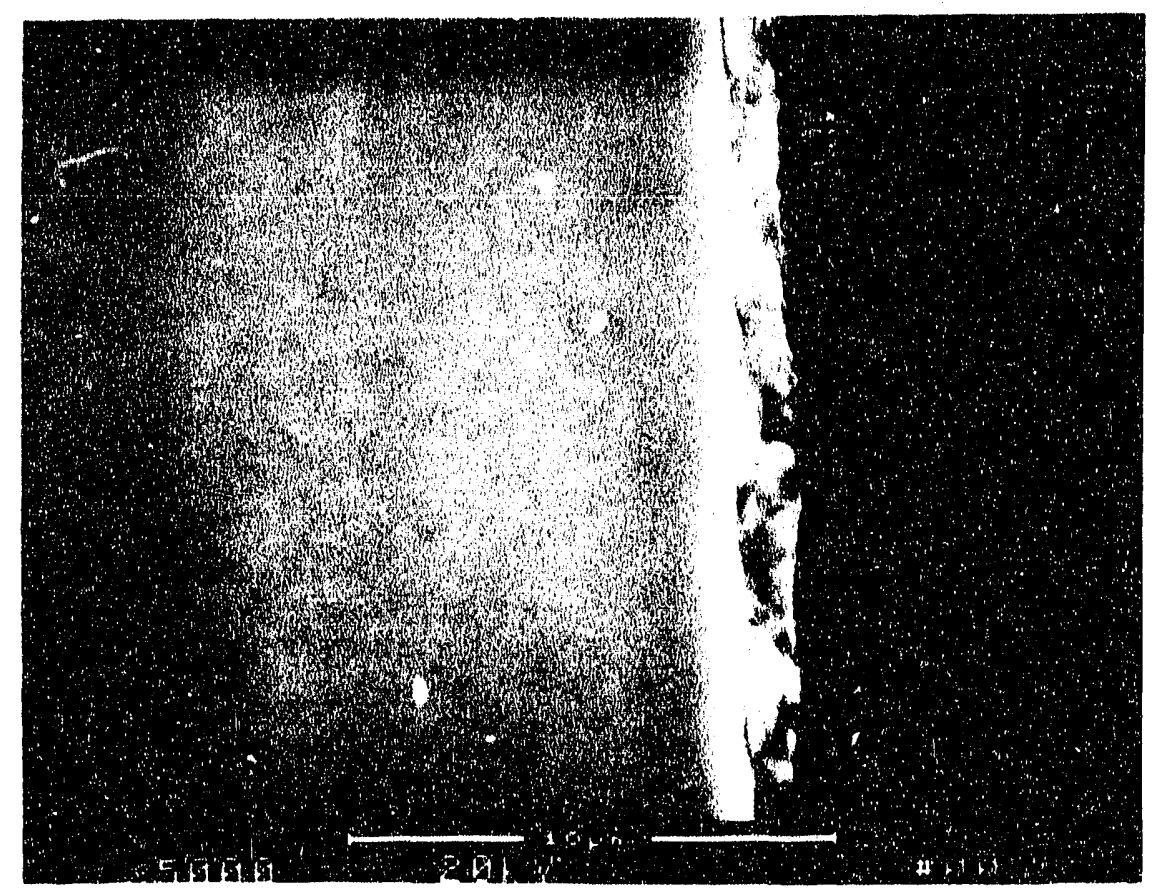

Figure 57. Microstructure of Implant Sciences diamond-like coating (SEM, backscattered electron image). The coating thickness is approximately $1 \mu \mathrm{m}$. 


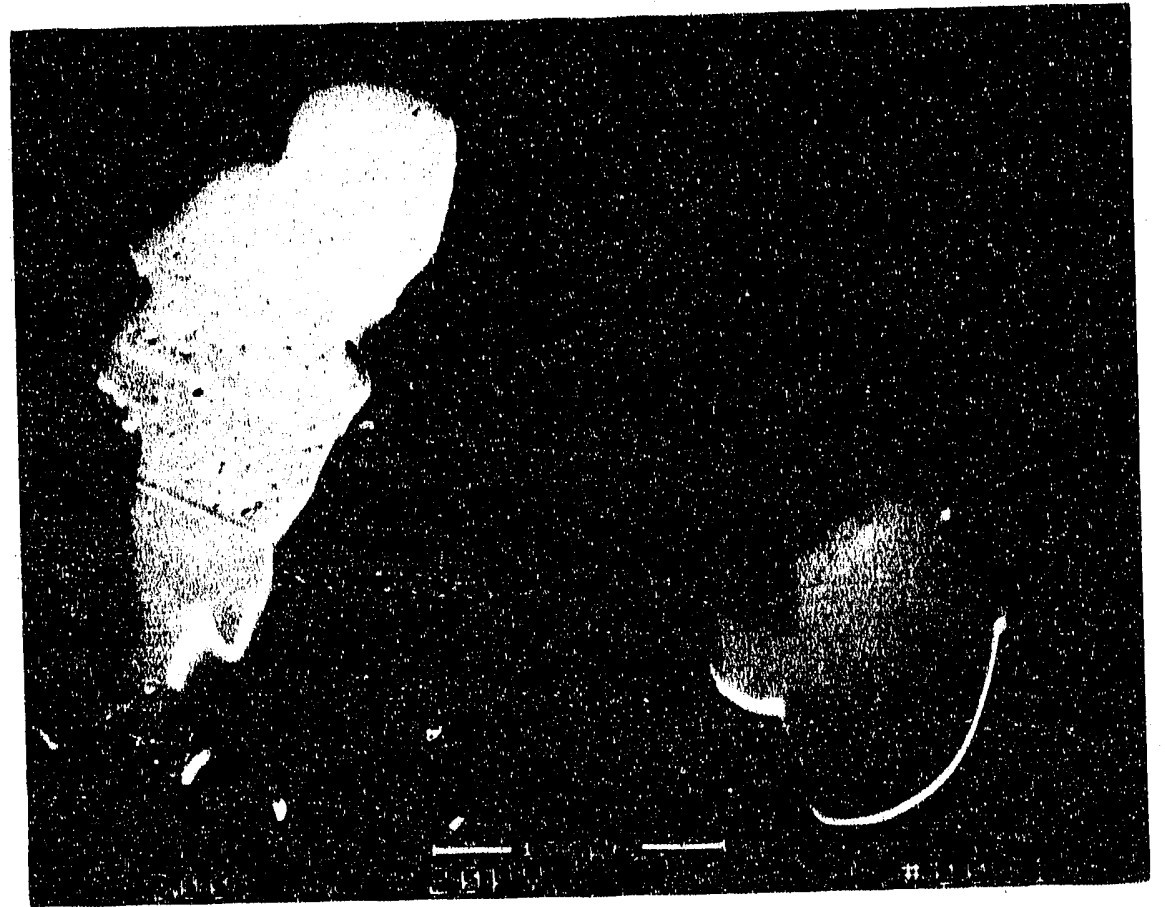

Figure 58. As-caated surface of Implant Sciences diamond-like coating, showing spallation of the coating (SEM, backscattered electron image).

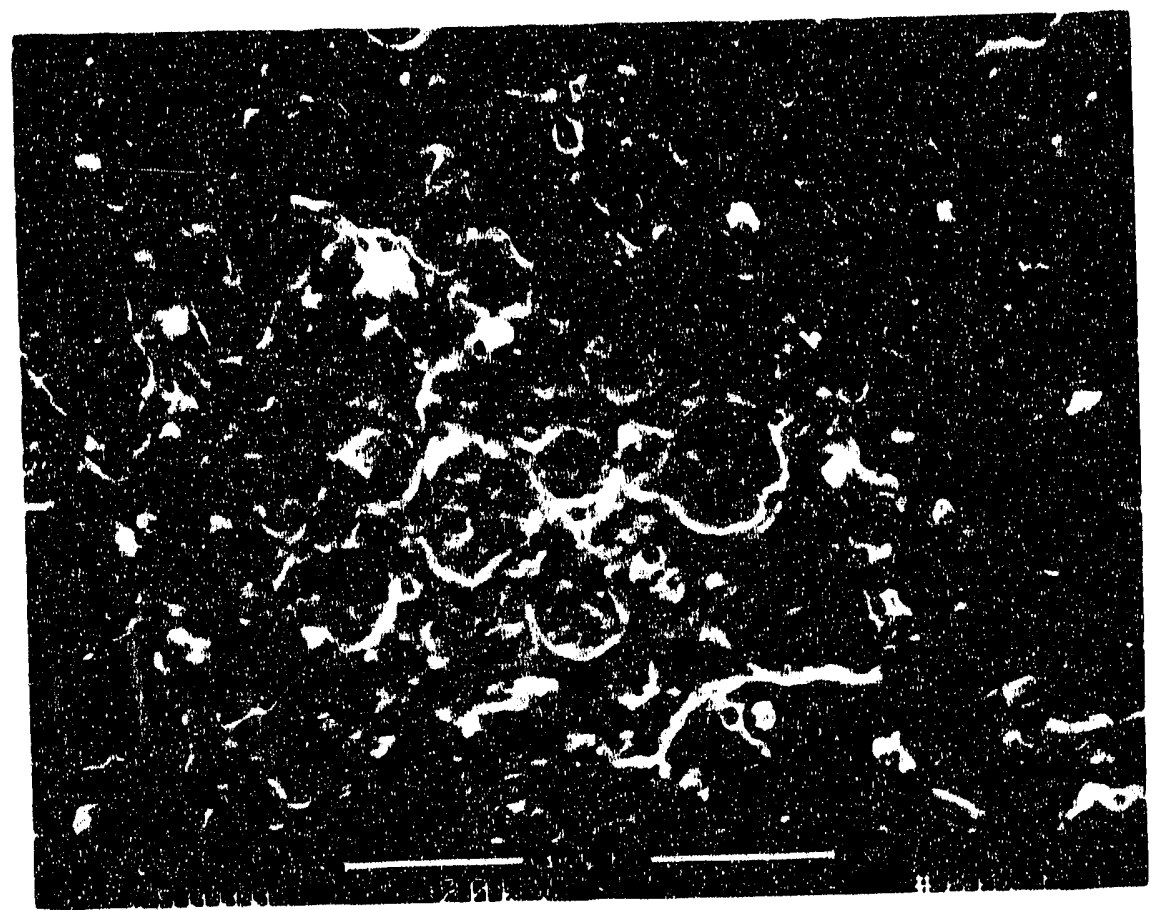

Figure 59. As-coated surface of Implant Sciences diamond-like coating (SEM, backscattered electron). Occasional sub-micron crystallites (oresumably diamond) are evident. 


\subsection{COATING DEVELOPMENT AT TURBINE METAL TECHNOLOGY INCORPORATED}

\subsubsection{Chromlum Carbide - Nichrome Coating}

A $\mathrm{Cr}_{3} \mathrm{C}_{2}-20 \%$ NiCr powder was sprayed by a proprletary HVOF process at Turbine Metal Technology (fMT). The powder was a mlxed $\mathrm{Cr}_{3} \mathrm{C}_{2}+(\mathrm{Ni}-20 \% \mathrm{Cr}$ ) materlal, as shown in Figure 60 . The HVOF coating (Figure 61), although failly dense, was very inhomogeneous, showing large unmixed regions of $\mathrm{Cr}_{3} \mathrm{C}_{2}$ and $\mathrm{Nl}$-Cr reflecting the mixture present in the original powder blend. A better dispersion of the carbide in the matrix phase would have been obtained with a clad powder, where each carbide particle would be pre-coated with the metallic binder phase. Grey-imaging phases elongated parallel to the splats may be evidence of oxidation of the matrlx phase or of carbide melting or solutionizing (Figure 61). The microhardness of the coating was $500 \mathrm{kgfmm}-2$ (HK ${ }_{100}$. which was low compared to the UTRC $\mathrm{Cr}_{3} \mathrm{C}_{2}$ $20 \% \mathrm{NiCr}$ coating sprayed from a clad powder, and probably reflects the compositional inhomogenelty of the coating.

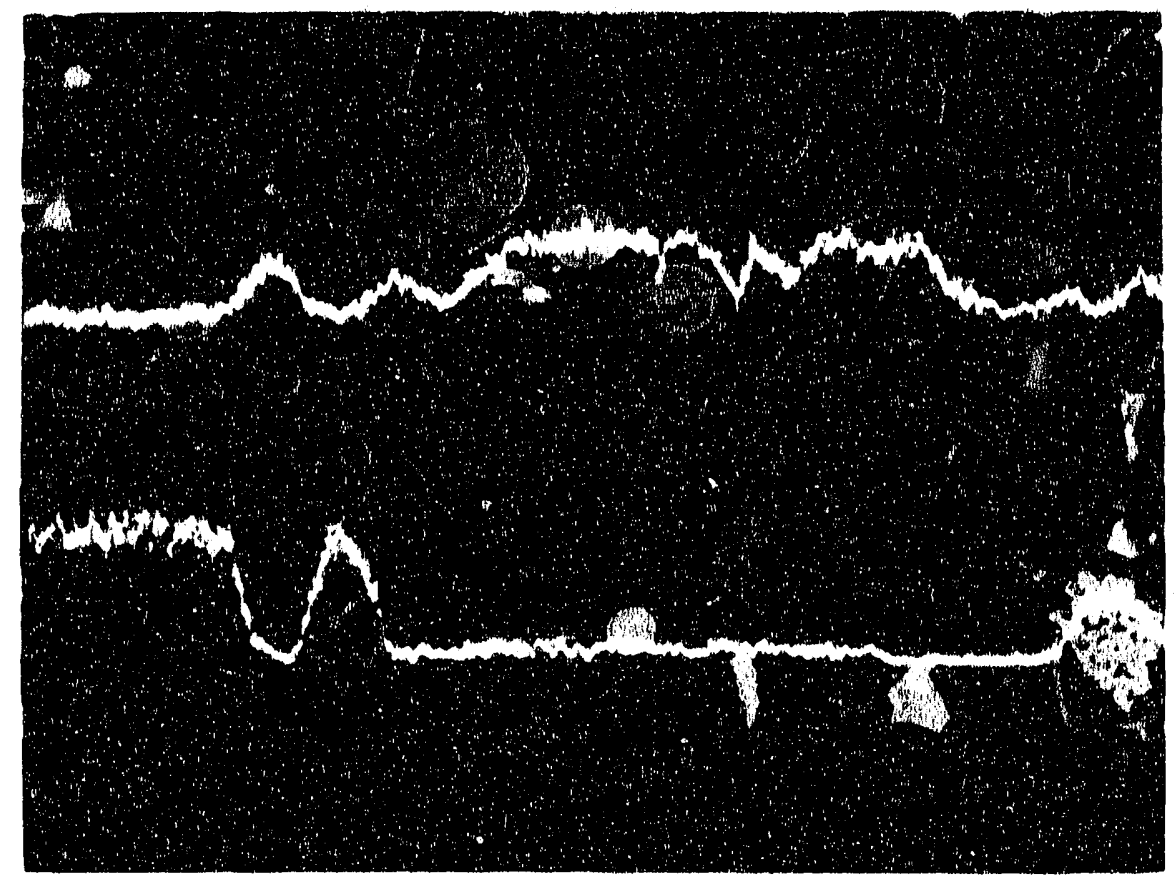

Figure 60. SEM micrograph of Turbine Metal Technology HVOF $\mathrm{Cr}_{3} \mathrm{C}_{2}-20 \%$ NiCr powder, showing $X$-ray line scans for $\mathrm{Cr}$ (top) and Ni (bottom). The powder was a mixed $\mathrm{Cr}_{3} \mathrm{C}_{2}$ $+20 \%(\mathrm{Ni}-20 \% \mathrm{Cr})$ material. 


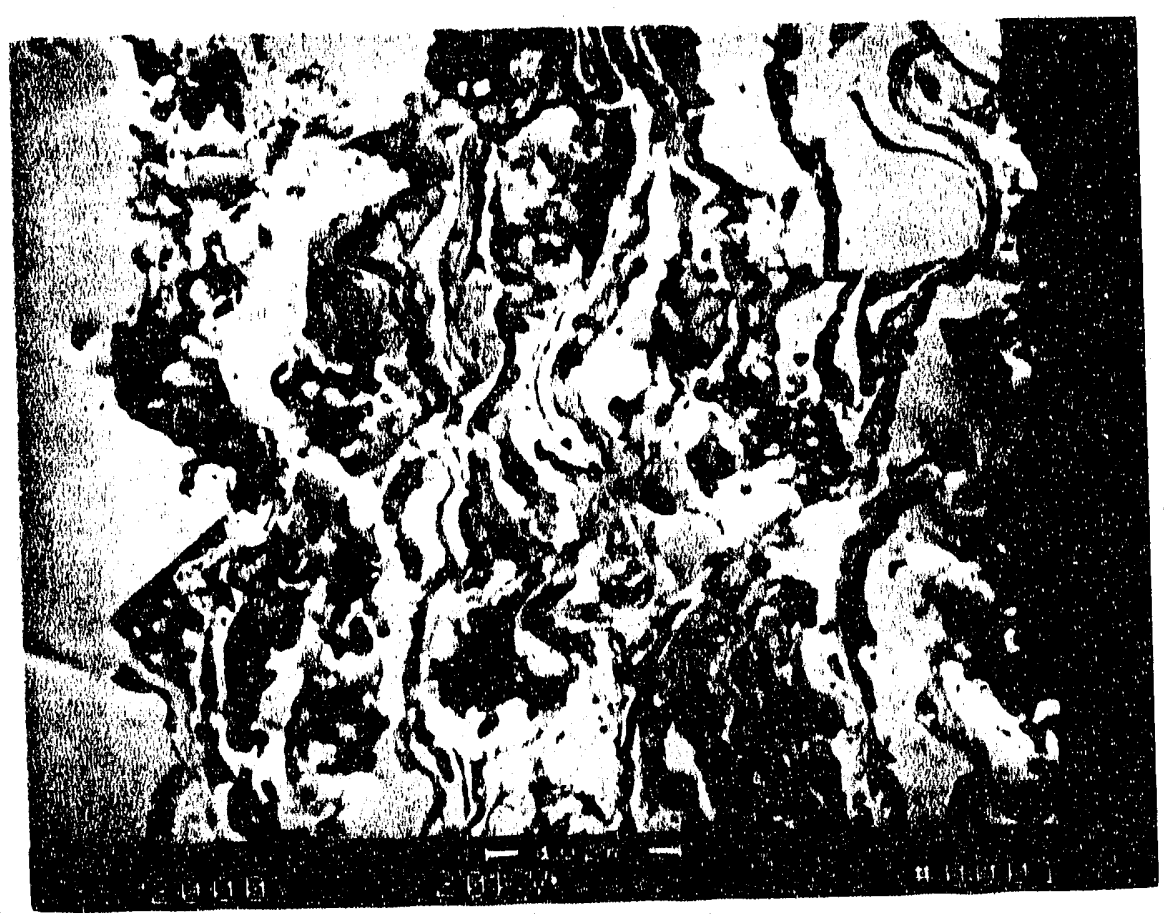

Figure 61. Microstructure of Turbine Motal Technology HVOF $\mathrm{Cr}_{3} \mathrm{C}_{2}-20 \% \mathrm{NICr}$ coating (SEM, backscattered eloctron image). The coating shows substantial inhomogeneity. Grey-imaging phases elongated parallel to the splats may be evidence of oxidation of the matrix phase or of carbide melting or solutionizing.

\subsubsection{Iungsten Carhide - Cobalt Coating}

A WC - $12 \%$ Co powder was sprayed by a proprietary HVOF process at Turbine Metal Technology. The powder appears to be a very uniform, fine grained sintered and crushed material (Flgure 62). The fine grain size of the HVOF coating (Figure 63) reflects that within the powder. Porosity levels were extremely low and adherence to the substrate was good. X-ray diffraction revealed $W C, W C_{1-x}$ and $\mathrm{CO}_{6} W_{6} C$ phases, with comparathely little oxidation and/or solutionizing (Table 7, section 2.1.2). The microhardness of the TMT coating was $960 \mathrm{kgfmm}^{-2}\left(\mathrm{HK}_{100}\right)$, which was simllar to many of the other WC - Co materials evaluated in this program. 


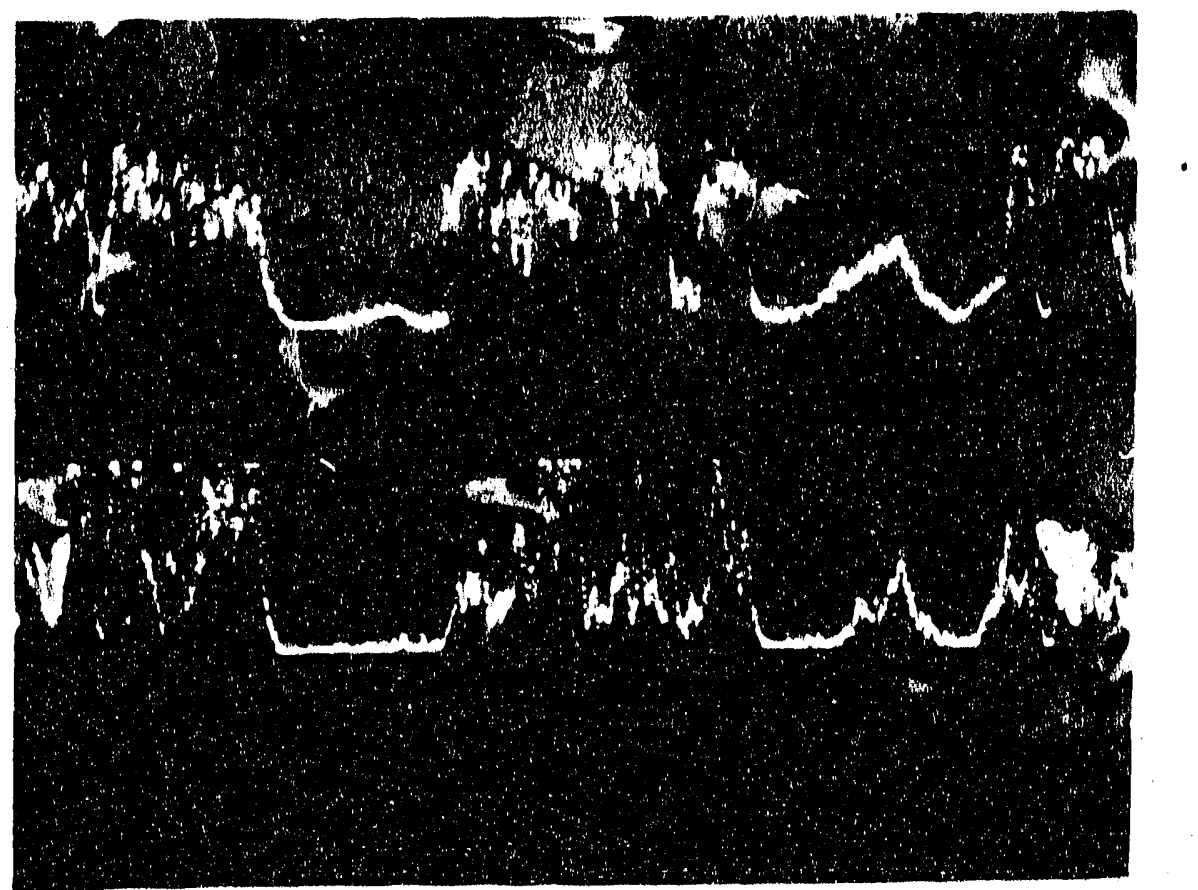

Figure 62. SEM micrograph of TMT WC - 12\% Co powder. The powder appears to be a very uniform, fine grained sintered and crushed material.

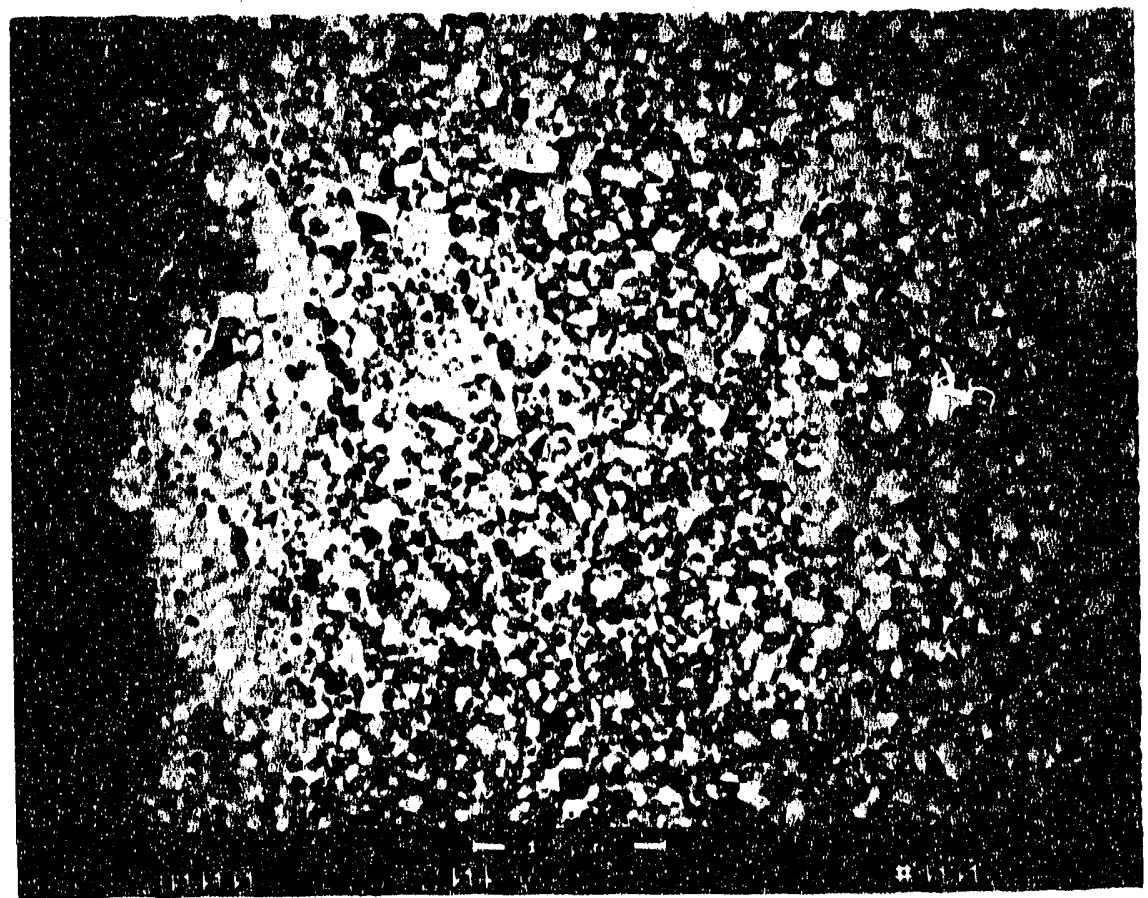

Figure 63. Microstructure of Turbine Metal Technology HVOF WC - 12\% Co (SEM, backscattered electron), showing fine grain size, low porosity and good adherence to the substrate. 


\subsubsection{Boride Diffusion Coating}

Attempts were made to borlde diffusion alloy the HVOF WC - Co coating described above. The process resulted in an interesting microstructure (Figure 64), with a $10 \mu \mathrm{m}$ thick darker imaging surface layer, and a $20 \mu \mathrm{m}$ thick lighter-imaging second layer. The inter-phase reglons were highly porous. WDS analysis of the coating showed no evidence of the original WC - Co coating, since no Co was present, and only W levels consistent with the 422 stainless steol substrate $(0.23 \% \mathrm{C}, 12 \% \mathrm{Cr}, 1 \% \mathrm{Mo}, 1 \% \mathrm{~W}, 0.8 \% \mathrm{NI}$, $0.25 \% \mathrm{~V}$, bal. Fe). It is speculated that the WC - Co coating may have de-bonded from the substrate during the diffusion treatment. The surface layers of the borlde coating were found to contain iron, chromium and carbon (from the 422 stainless steel substrate) and boron. WDS line scans for these elements are shown in Figures 65 - 68. The darker-Imaging top layer contalned a higher concentration of boron than the lighter-Imaging second layer and a slightly lower Iron content. Chromlum appeared to be randomly distributed through the surface layers. Carbon appeared to be concentrated at the interface between the two layers. The hardness of the coating, measured with $25 \mathrm{~g}$ Knoop indentatlons in the lighter-imaging second layer, was approximately $1490 \mathrm{~kg}^{\mathrm{mm}} \mathrm{mm}^{-2}$.

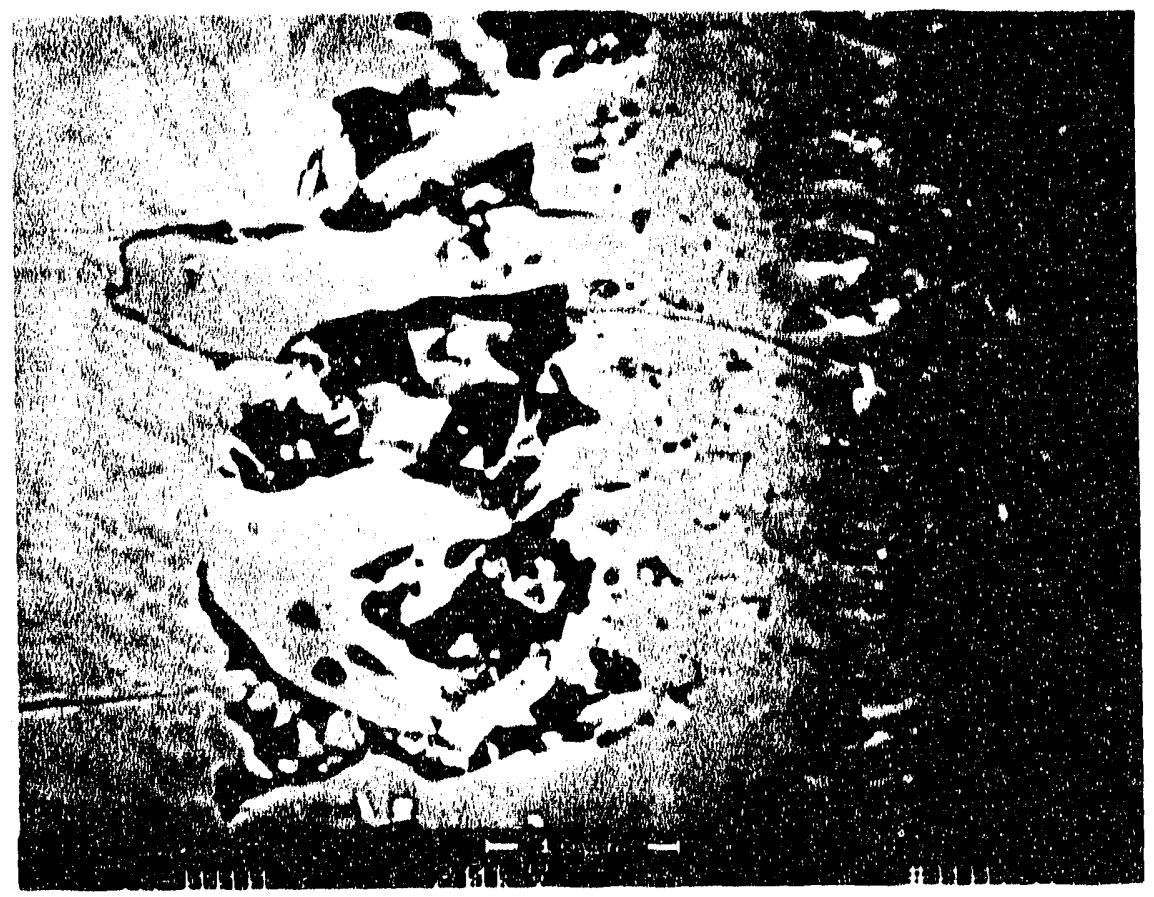

Figure 64. Microstructure of Turbine Metal Technology boride diffusion coating (SEM, backscattered electron image), showing various surface layers of different compositions. 


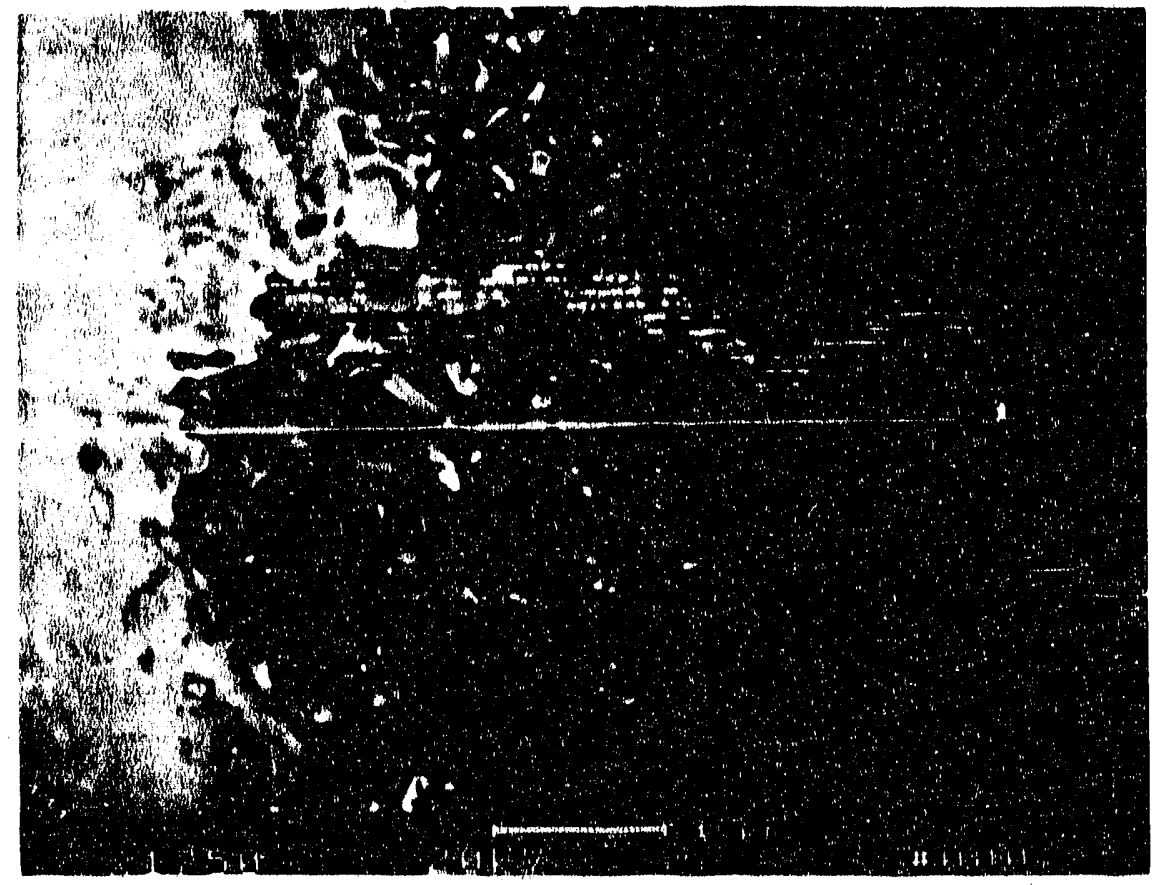

Figure 65. Tubine Metal Tecinnology boride diffusion coating: backscattered electron image with WDS line scan for $F \theta K \alpha$.

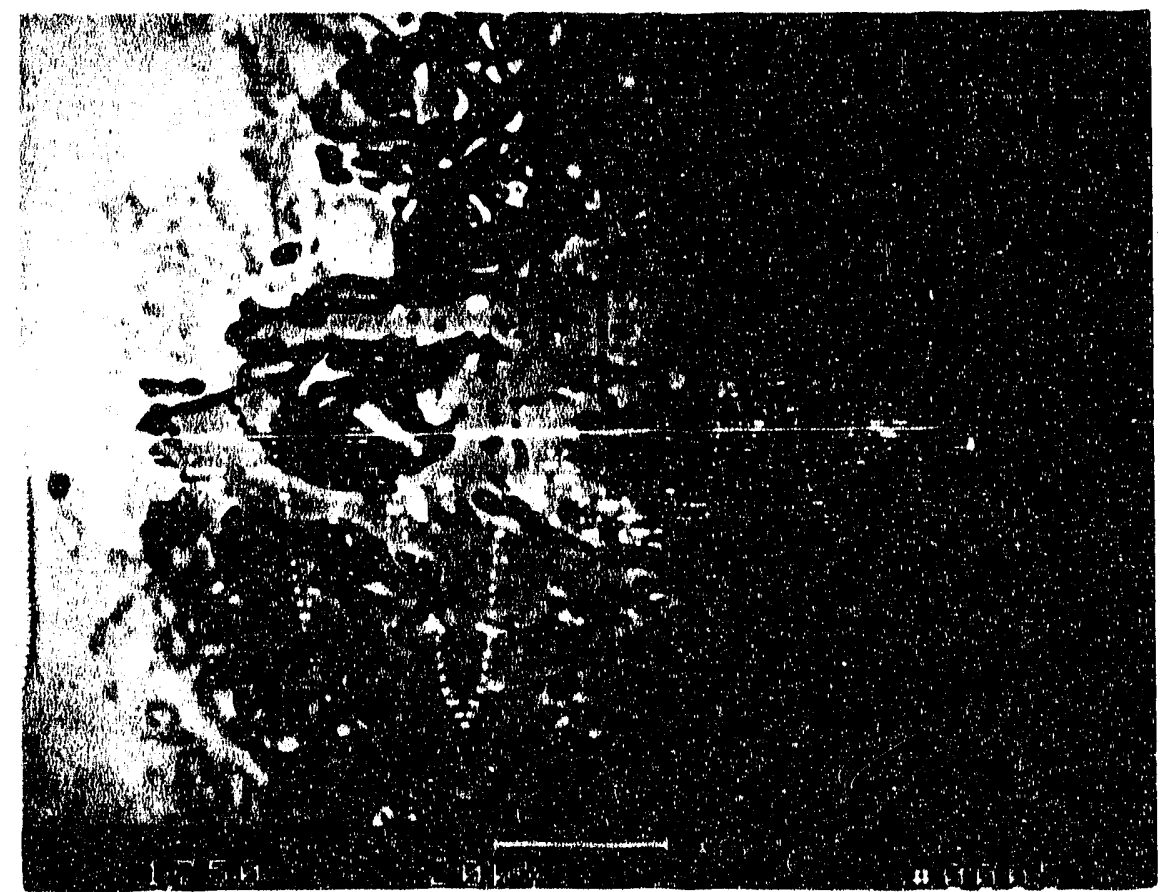

Figure 66. Tubine Metal Technology boride diffusion coating: backscattered electron image with WDS line scan for $\mathrm{Cr} K \alpha$. 


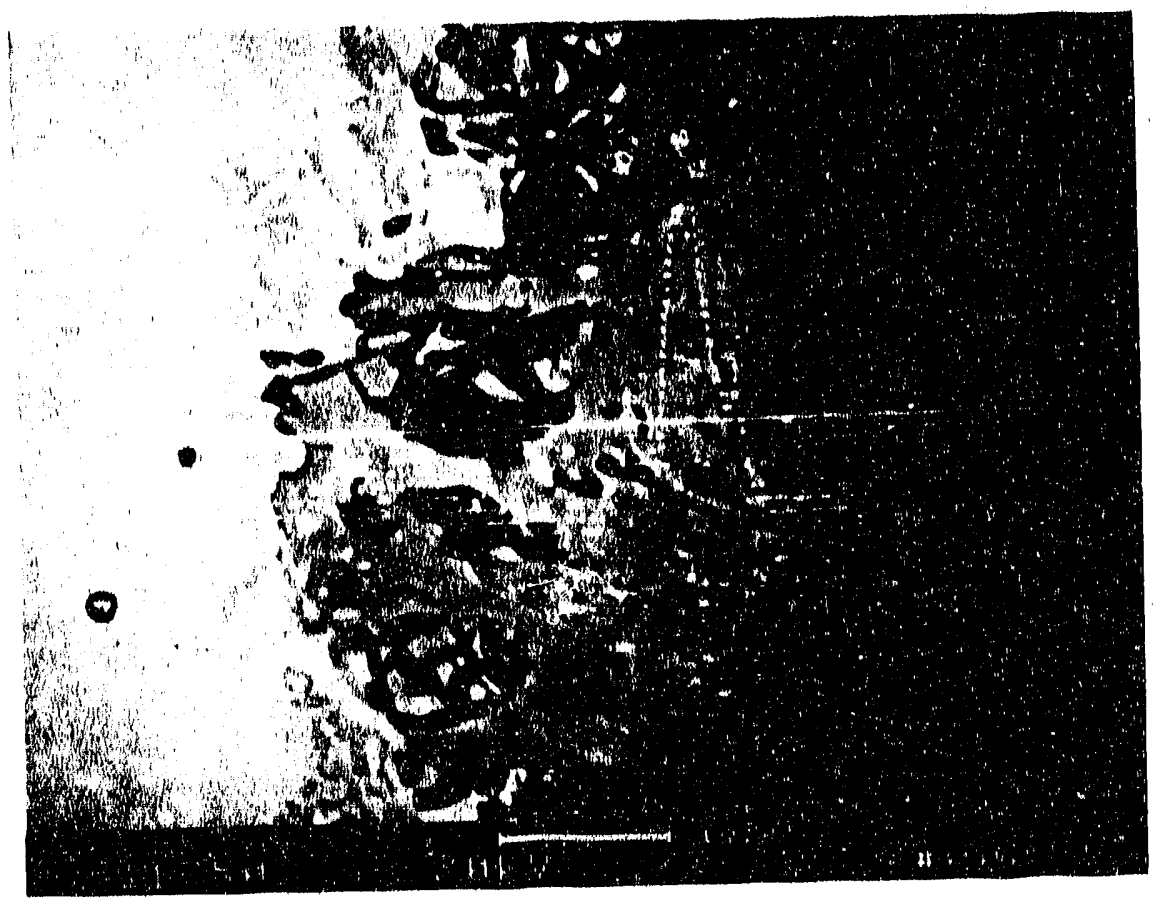

Figure 67. Tubine Metal Technology boride diffusion coating: backscattered electron image with WDS line scan for $C K \alpha$.

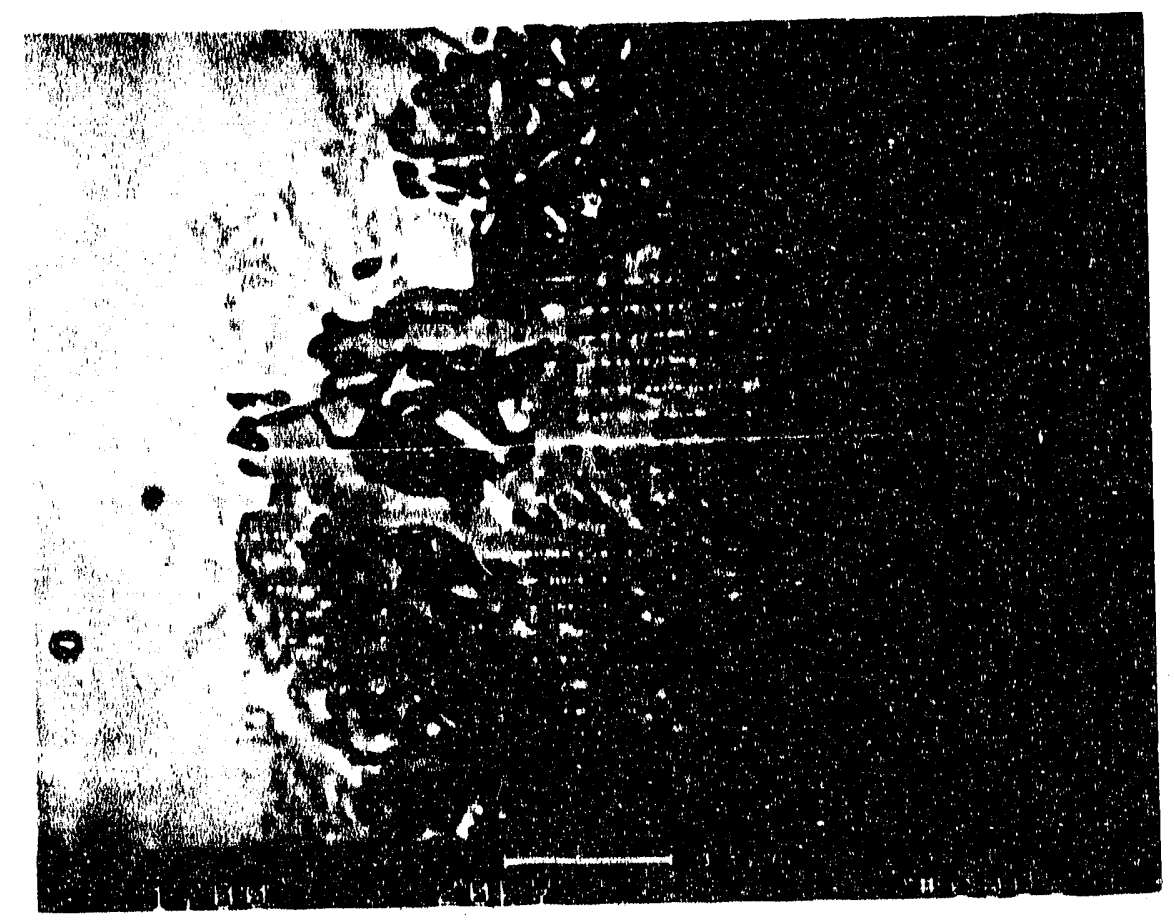

Figure 68. Tubine Metal Technology boride diffusion coaing: backscattered electron Image with WDS line scan for $B K \alpha$. 


\subsection{COATING DEVELOPMENT AT UNITED TECHNOLOGIES RESEARCH CENTER (UTRC)}

\subsubsection{Chromium Carbide -Nlahrome Coating}

A Metco Diamalloy $3007 \mathrm{Cr}_{3} \mathrm{C}_{2} \cdot 20 \%$ NICr powder, in which each $\mathrm{Cr}_{3} \mathrm{C}_{2}$ particle was first olad with $\mathrm{NI}$ and then with $\mathrm{Cr}$ metal, was sprayed with a Metco "Dlamond Jet" HVOF system. The coating was found to comprise an even distrlbution of fine (approximately $8 \mu \mathrm{m}$ dlameter) chromlum carbide particles in a NiCr matrix, with little carbide solutionizing and very low (approximately 1\%) porosity levels (Figure 69). The microhardness of the costing was $990 \mathrm{kgfmm}^{-2}$, comparable to the hardness of the WC. $12 \%$ Co coatings, and higher than for the TMT HVOF $\mathrm{Cr}_{3} \mathrm{C}_{2}-20 \%$ NiCr sprayed from a mixed powder.

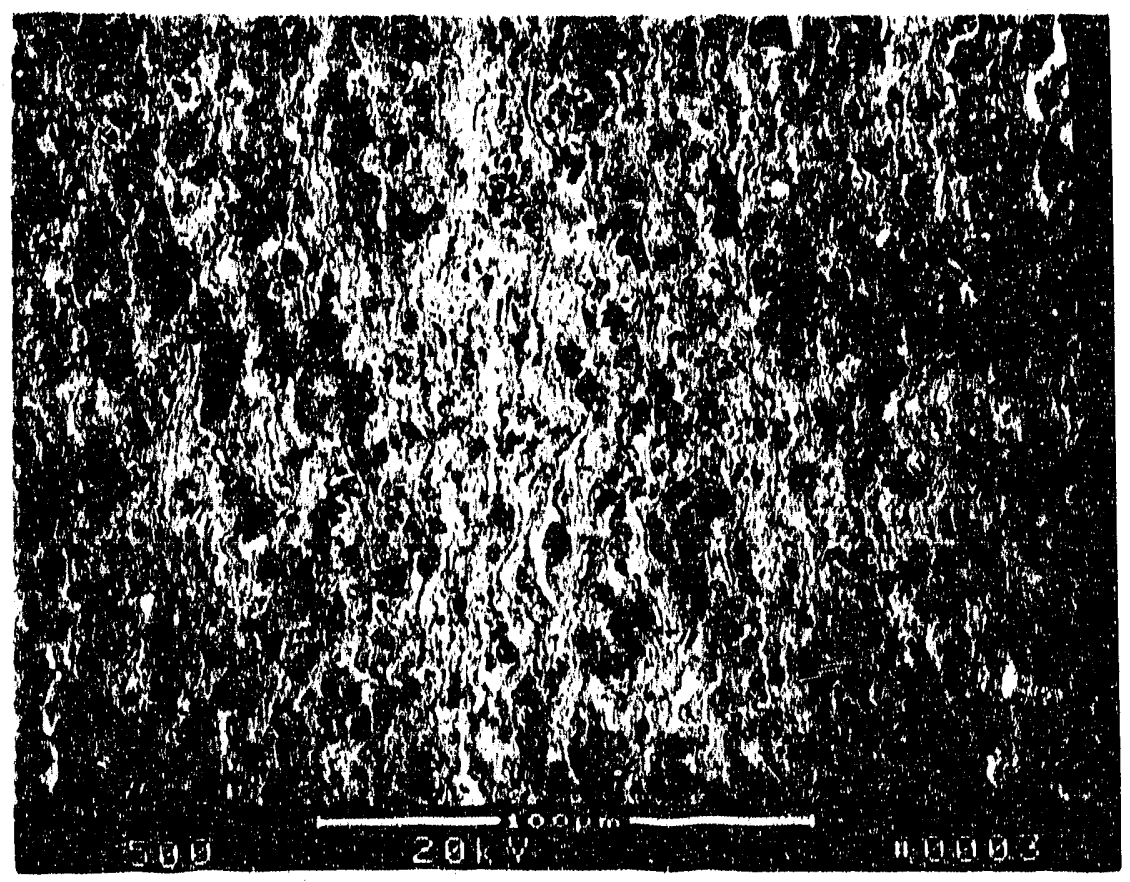

Figure 69. Microstructure of UTRC HVOF $\mathrm{Cr}_{3} \mathrm{C}_{2}-20 \%$ NICr coating (SEM, backscattered electron image). The coating was homogeneous, with little carbide solutionizing and very low porosity levels 


\subsubsection{Zirconla-Iltanla-Yttria Coating}

A Metco $143 \mathrm{ZrO}_{2}$ - 18\% $\mathrm{TIO}_{2}$ - $10 \% \mathrm{Y}_{2} \mathrm{O}_{3}$ (ZTY) powder was plasma sprayed. The coating was less porous than many of the chromlum oxide coatings evaluated, but showed very poor inter-splat bonding as evidenced by a "brick wall" type of inter-splat mlorocrack distribution (Flgure 70). A small amount of unmelted powder was present in the coating, assoclated with large pores. The backscattered electron signal from this material showed substantlal varlations in atomio number contrast within the costing (Flgure 70), suggesting Inhomogeneity of the stanting powder. Also, a serles of $10 \mathrm{gf}$ Knoop microhardness indentations showed extreme variatlons in microhardness (from 390 to $1180 \mathrm{kgfmm}^{-2}$ ) across the mlerostructure (Figure 71). This variation is not thought to have been caused solely by interactions with oracks/pores, but may reflect a high degree of composittonal inhomogenelty and/or the presence of amorphous materlal within the coatling. X-ray diffraotion showed the presence of a cublo $\mathrm{ZrO}_{2}$-based solld solution, but it is possible that amorphous phases may also have been present, as for the $\mathrm{Al}_{2} \mathrm{O}_{3}-\mathrm{ZrO}_{2}$ coatings. The mean hardness of the coating ( $\left.450 \mathrm{kgfmm}^{-2}\right)$ was surprisingly low compared to other ceramlo coatings evaluated.

Approximately $10 \%$ of the ZTY test samples were found to have cracked or chipped to some degree during grinding of the coating, ranging from complete de-bond to small corner chips. Bonding of the ceramic materlals to the substrate (422 stainless steel) was generally poor, as revealed by light microscopy of the interface, but may be improved by the use of a bond coat (none was used for these samples).

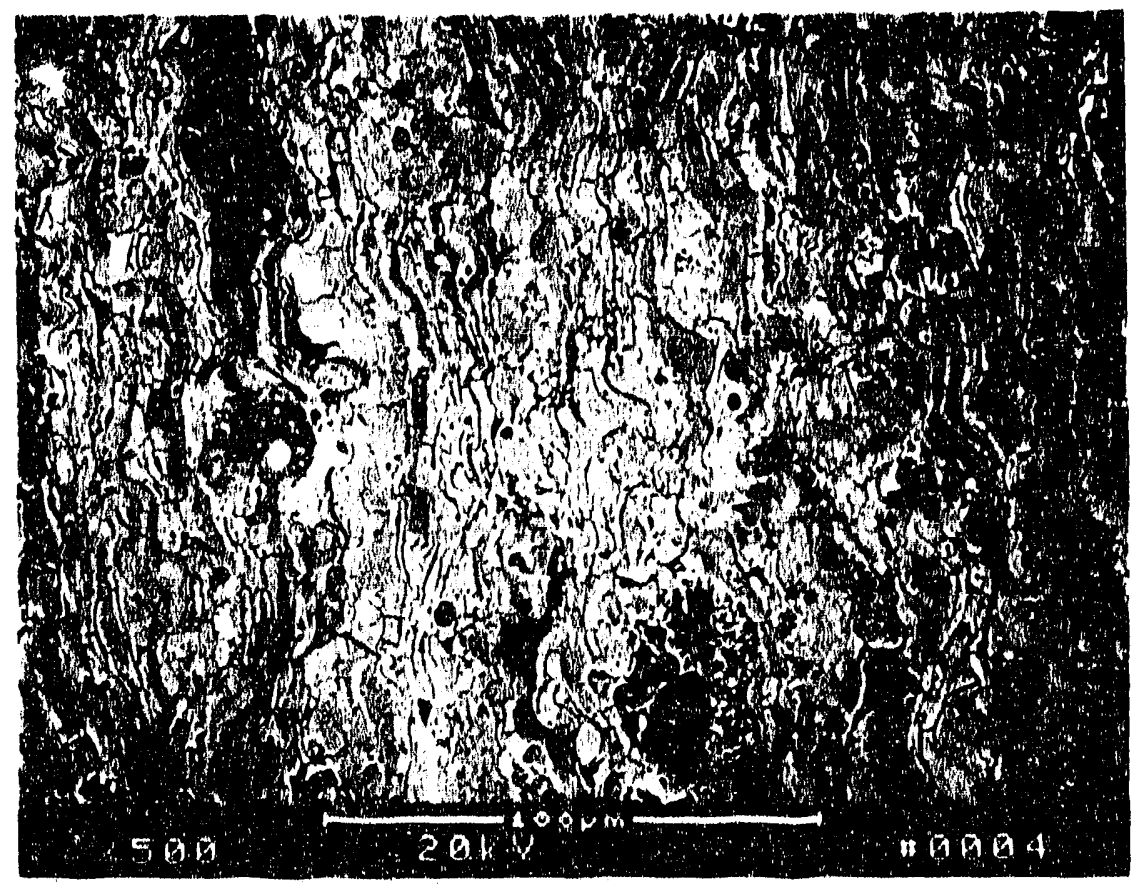

Flgure 70. Microstructure of UTRC plasma sprayed $\mathrm{ZrO}_{2}-18 \% \mathrm{TIO}_{2}-10 \% \mathrm{Y}_{2} \mathrm{O}_{3}$ coating (SEM, backscattered electron image). The coating showed very poor inter-splat bonding with substantial inter-splat microcracking. A small amount of unmelted powder was present, associated with large pores. Compositional inhomogeneity was revealed by the atomic number contrast between different grains. 


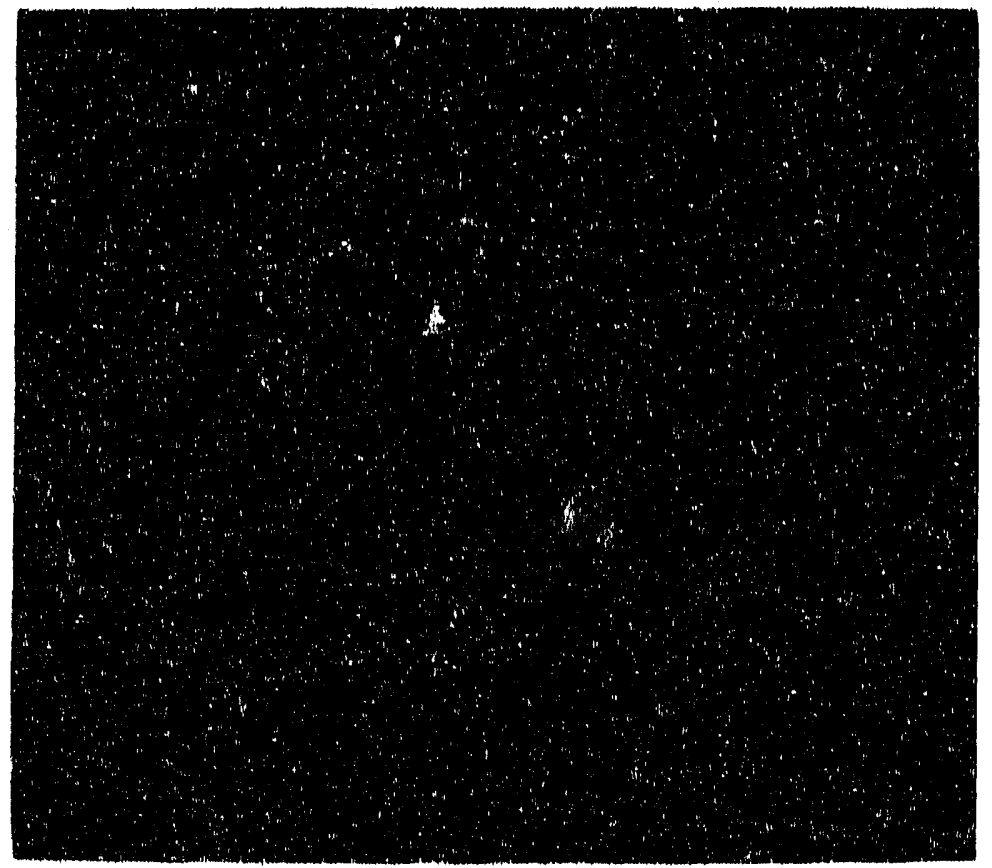

Figure 71. $\quad$ logf Knoop indentations in UTRC plasma sprayed $\mathrm{ZrO}_{2}-18 \% \mathrm{TIO}_{2}-10 \% \mathrm{Y}_{2} \mathrm{O}_{3}$ coating (llght miorograph - Nomarski d.l.c.), showing substantial variations in microhardness (from 390 to $1180 \mathrm{kgfmm}^{-2}$ ) across the microstructure. 


\subsubsection{Chromium Oxide Coating}

A coating was plasma sprayed from a Metco $106 \mathrm{FP} \mathrm{Cr}_{2} \mathrm{O}_{3}$ powder containing $2 \% \mathrm{SlO}_{2}$ and $2 \%$ other oxides. The coating showed high porosity levels (approximately 20\%) with extensive networks of Inter-splat oracks ana volds, with apparently loose materlal trapped in the microstruoture (Figure 72). Adherence to the substrate was poor, primarlly because no bond coat was used for this costing. The miorohardness of this coating was low (850 kgfmm.2 $\mathrm{HK}_{100}$ ) compared to other chromlum oxides evaluated, probably due to the high porosity rather than intrinsio softness of the material.

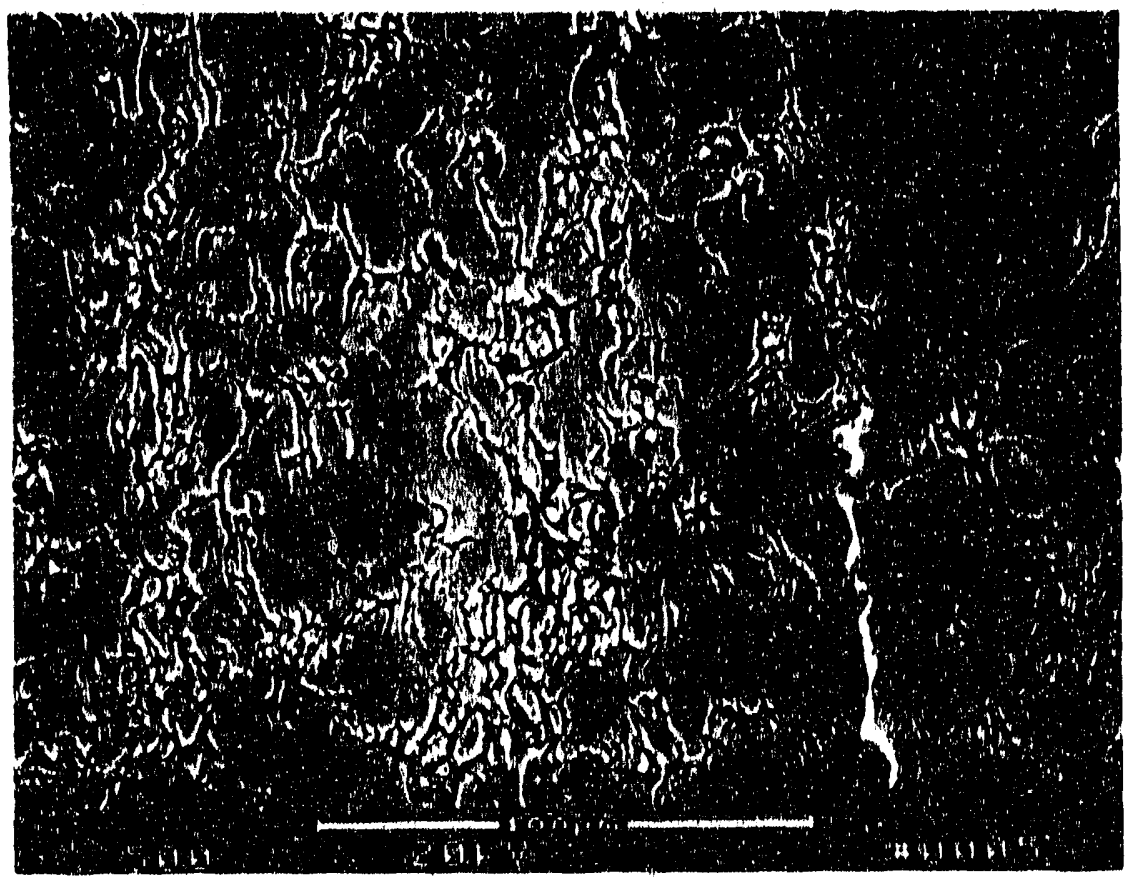

Flgure 72. Mlorostructure of UTRC plasma sprayed $\mathrm{Cr}_{2} \mathrm{O}_{3}$ coating (SEM, backscattered electron image). Thie coating showed high porosity levels with extensive networks of inter-splat cracks and volds, with apparenth, loose material trapped in the microstructure. 


\subsection{4_Nlokel-Chromium-Boron-Sillicon Costing}

A Dlamalloy 2001 NICrBSI powder was sprayed using a Meico "Dlamond Jet" HVOF system. The coating showed some coarse porosity, primarlly assoclated with a high volume fraction of unmelted powder particles (Figure 73). Porosity/pullout occurred within the unmelted particles and at the intertace between unmelted and melted materlal. The miorostruoture showed an extremely fine dispersion of sub-micron sized low atomio number particles (presumably carbldes or borldes) In a metallic matrlx (Flgure 73). The coating rniorohardness was relatively high: $900 \mathrm{~kg}^{\prime m m} \cdot 2 \mathrm{HK}_{100}$.

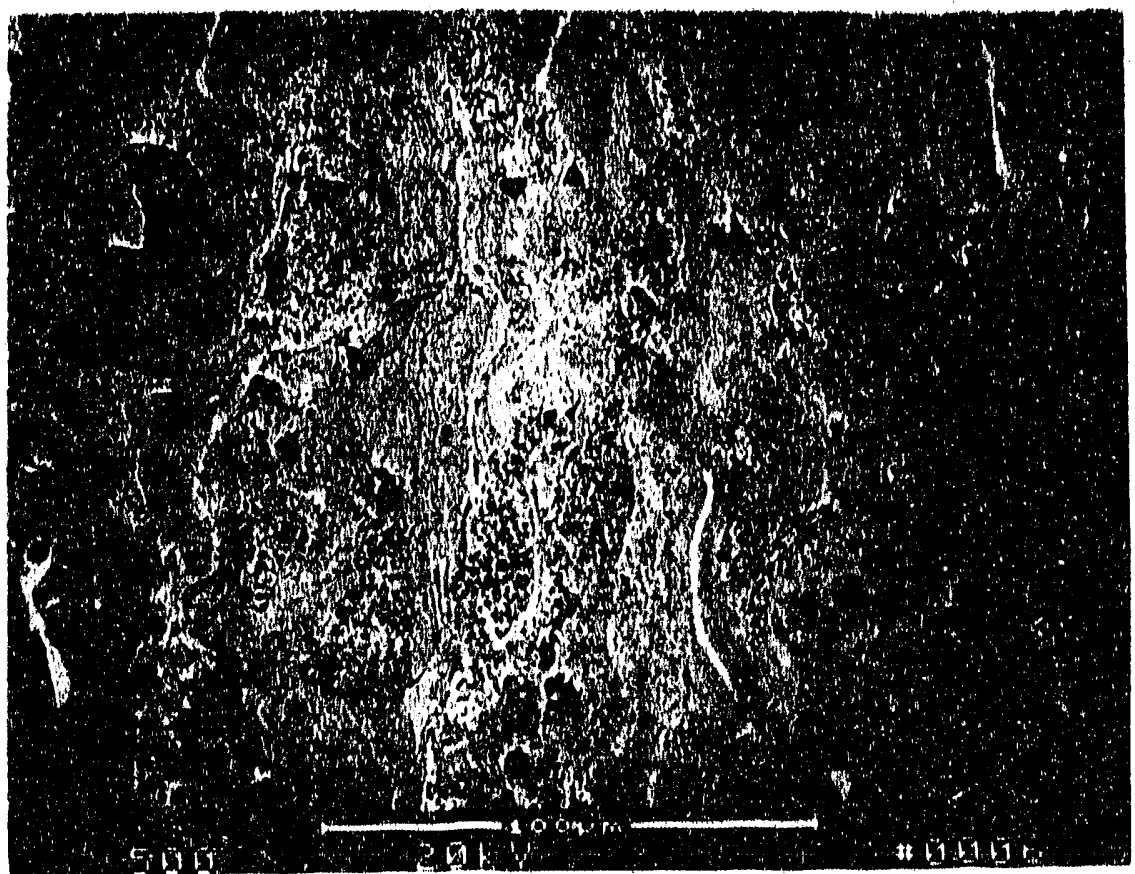

Figure 73. Microstructure of UTRC HVOF NICrBS/ coating (SEM, backscattered electron image), showing coarse porosity associated with a high volume fraction of unmelted powder perticles. Porosity/pullout occurred within the unmelted particles and at the interface between unmelted and melted material. The microstructure showed an extremely fine dispersion of sub-micron sized low atomic number particles (presumably carbides or borides). 


\section{7 .5 Propenty Measurements}

In any coatings development effort, it is important to have rellable materials property data to facilitate thermal and stress modelling. UTRC have used this "engineered coatings" approach successfully in many applications, including abradable seal coatings for gas turbine engines and thermal barrier coatings for diesel engines. Thermul and mechanical property measurements were made for $\mathrm{HVOF} \mathrm{Cr}_{3} \mathrm{C}_{2}-\mathrm{NiCr}$ and NiCrBSi coatings and plasma sprayed zirconia-titania-yttria (ZTY) coatings. Properties were measured on free-standing coating materials sprayed to $2.5 \mathrm{~mm}$ thicknesis and removed from the substrate. Attempts were also made to produce thick chromium oxide coatings for evaluation, with no success. The properties measured were: four point bend strength (Figure 74), four point strain to fallure (Figure 75), four point bend modulus (Figure 76), thermal expansion coefficient (Figure 77), thermal conductivity (Figure 78) and specific heat capachy (Figure 79). Mechanical properties inere determined at room temperature and $316^{\circ} \mathrm{C}$, while thermal properties were determined from room temperature to $538^{\circ} \mathrm{C}$.

The tensile stress-strain response during four-point bending was linear regardless of test temperature for the three coatings. The average four-point tensile bend strength for both NICrBSI and ZTY remained relatively constant with temperature up to $316^{\circ} \mathrm{C}$, at approximately 620 and $70 \mathrm{MPa}$, respectively (Figure 74). Not surprisingly, the cerainic ZTY coating had a significantly lower tensile loading capability than the metallic NiCrBSi coating. The mean tensile bend strength of $\mathrm{Cr}_{3} \mathrm{C}_{2}-\mathrm{NiCr}$ at $316^{\circ} \mathrm{C}$ was slightly reduced relative to the room temperature value (534 vs $618 \mathrm{MPa}$ ) but was still comparable with the NiCrBSi material.

The mean strain-to-failure of the NiCrBSi system was approximately $50 \%$ higher than that of ZTY and more than $80 \%$ higher than for $\mathrm{Cr}_{3} \mathrm{C}_{2}-\mathrm{NiCr}$ (Figure 75). The higher strain capacity of NiCrBSi may make the coating morc accomodating to tensile loads. In absolutis terms, the mean strain-to-failure values for ZTY and $\mathrm{Cr}_{3} \mathrm{C}_{2}-\mathrm{NiCr}$ were comparable, but since the elastic modulus of $\mathrm{Cr}_{3} \mathrm{C}_{2}-\mathrm{NiCr}$ was approximately five times higfier than for $Z T Y$, the $\mathrm{Cr}_{3} \mathrm{C}_{2}-\mathrm{NiCr}$ tensile strength was significantly higher.

The mean elastic modulus of both the $\mathrm{Cr}_{3} \mathrm{C}_{2}-\mathrm{NiCl}$ and $\mathrm{ZTY}$ coatings remained relatively constant up to $316^{\circ} \mathrm{C}$ (Figure 76 ), at approximately 162 and $33 \mathrm{GPa}$, respectively. The mean elastic modulus for NiCrBSi decreased slightly from $141 \mathrm{GPa}$ at room tempierature to $126 \mathrm{GPa}$ at $316^{\circ} \mathrm{C}$. The ceramic $2 T Y$ elastic modulus was substantially less than for the NiCri3Si and $\mathrm{Cr}_{3} \mathrm{C}_{2}-\mathrm{NiCr}$ coatings, probably due to the porosity and microcracking described above.

For all three coating systems, the coefficient of thermal expansion (CTE) was relatively constant from room temperature to $538^{\circ} \mathrm{C}$ (Figure 77). The mean CTE was greatest for NiCrBSi at 13.1. $14.0 \times 10^{-6} \mathrm{~K}^{-1}$, with $\mathrm{Cr}_{3} \mathrm{C}_{2}-\mathrm{NiCr}$ next at $10.8-11.7 \times 10^{-6} \mathrm{~K}^{-1}$ and $\mathrm{ZTY}$ the lowest at $9.4-9.9 \times 10^{-6} \mathrm{~K}^{-1}$. These values are consisient based on general metallic and ceramic properties with the metallic NiCrBSi coating having a larger CTE than the cerarnic ZTY.

As expected, the metallic and cermet coating materials had a significanily greater thermal conductivity than the ceramic ZTY material (Figure 78). The thermal conductivity of both NICrBSI and $\mathrm{Cr}_{3} \mathrm{C}_{2}$-NiCr increased substantially (by more than two times) from room temperature to $538^{\circ} \mathrm{C}$. However. the thermal conductivity of $Z T Y$ remained essentially constant at $1 \mathrm{Wm}^{-1} \mathrm{~K}^{-1}$ over the evaluated temperature range.

Specific heat capacity increased with temperatlure for all three coating systems (Figure 79). $\mathrm{Cr}_{3} \mathrm{C}_{2}$-NiCr had the g! satest specific heat, iollowed by ' $2 T Y$ and $\mathrm{NiCrBSi}$. The specific heat for $\mathrm{Cr}_{3} \mathrm{C}_{2}-\mathrm{NiCr}$ was higher than expected, but the results were repeatable. In general, the specific heat capacity of a cermet material should lie between that for the ceramic and metallic phases. Possibly, the low porosity of this coating was a factor. Hoviever, this discrepancy did not affect the relative ranking of the thermal conducthity values which are calculated from a material's density, speciffs heat capacity and thermal diffusivity. 


\section{FOUR POINT BEND STRENGTH \\ UTFC Wear Coating Materiale}

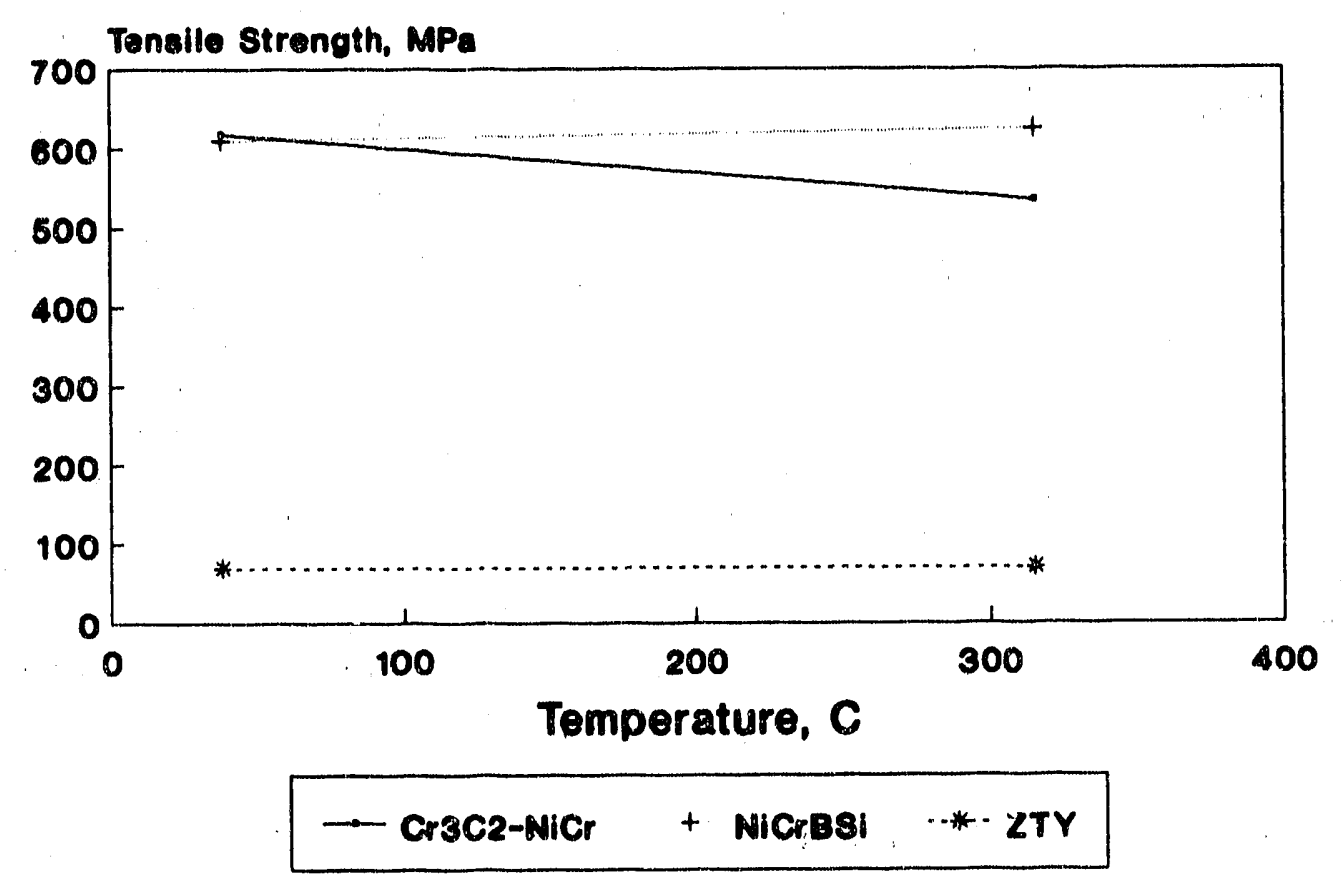

Figure 74. Variation of four point bend strength with temperature for UTRC coatings. 


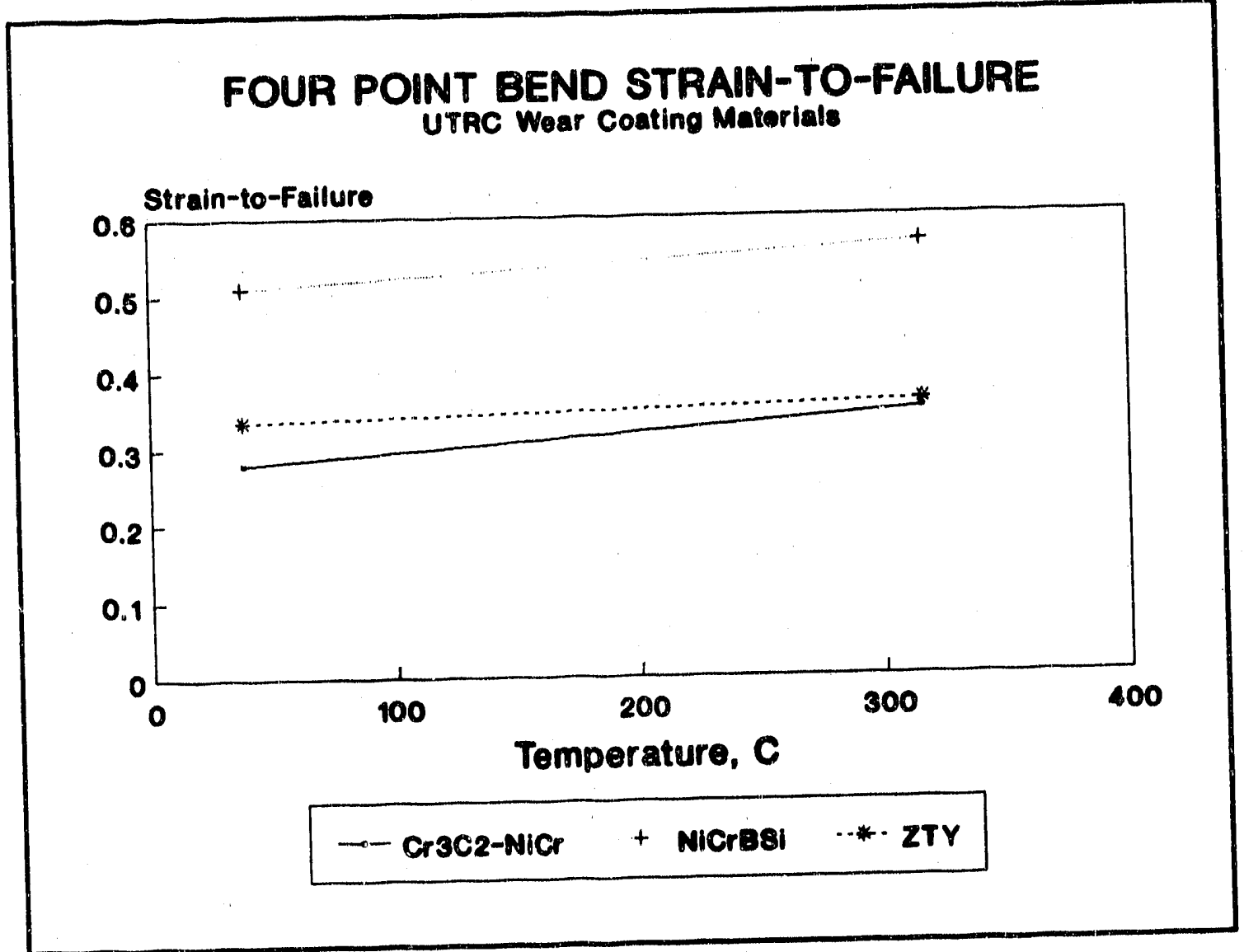

Figure 75. Variation of strain-to-failure with temperatum for UTRC coatings. 
FOUR POINT BEND MODULUS

UTRC Wear Coating Materiale

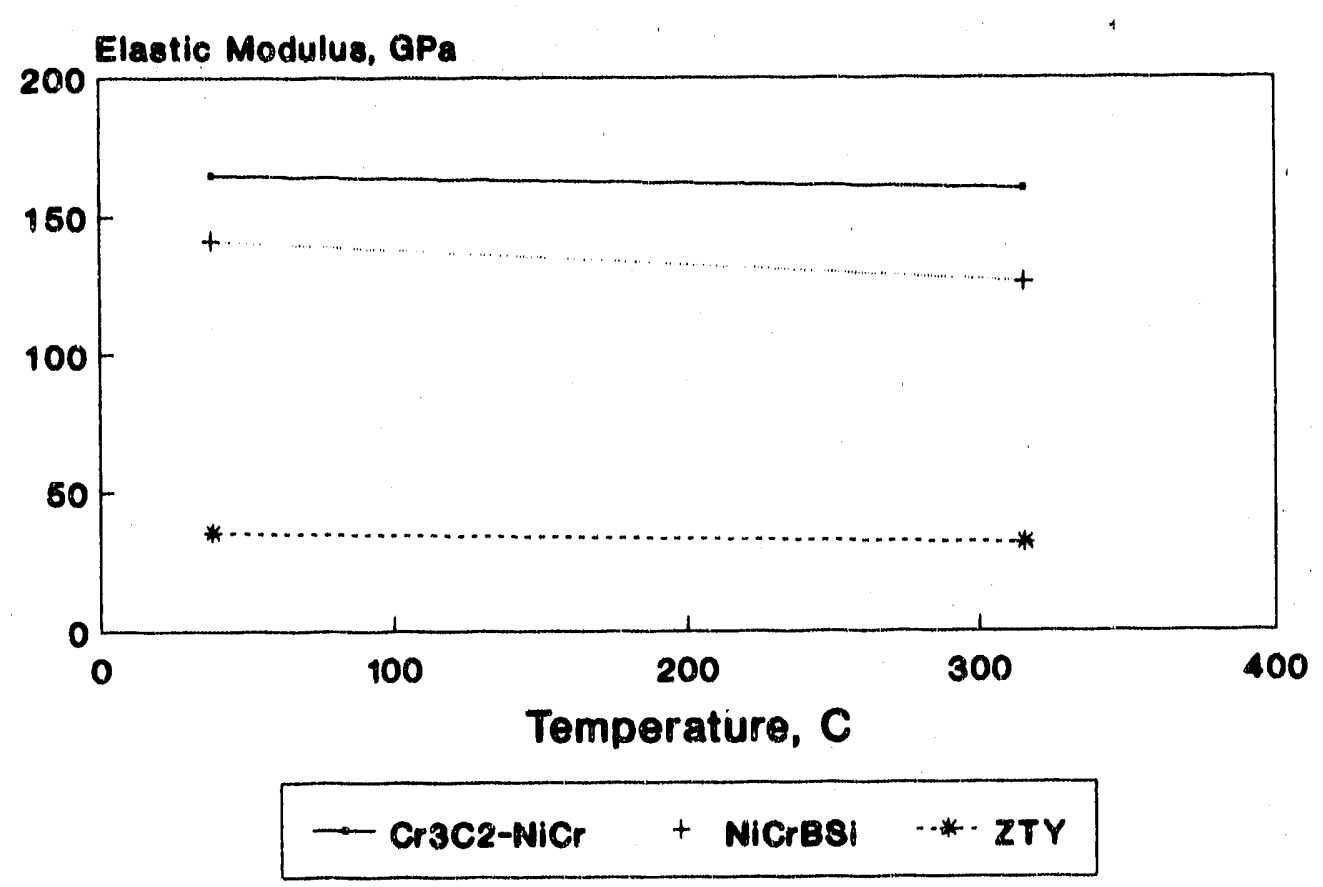

Figure 76. Variation of four point bend modulus with temperature for UTRC coatings. 


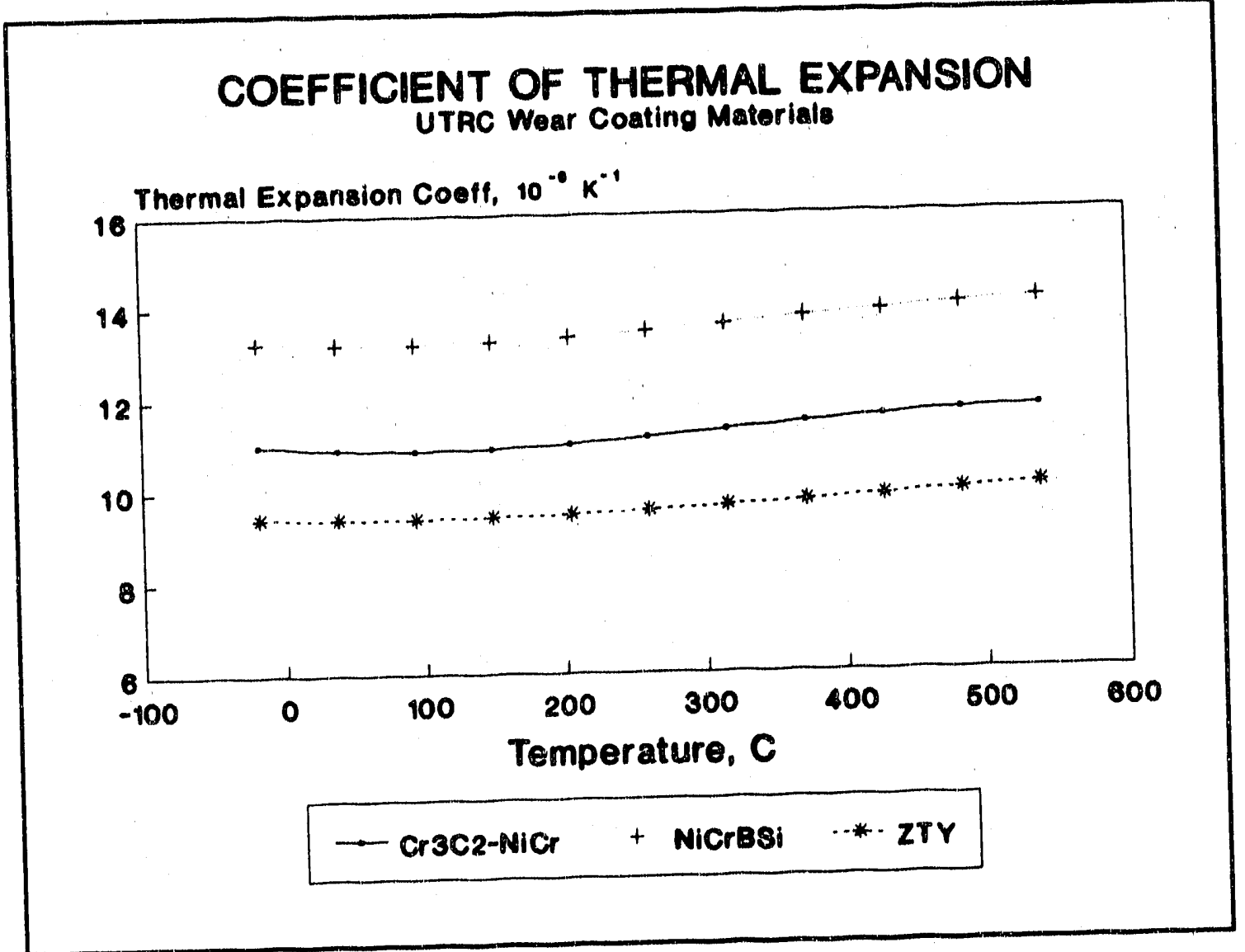

Figure 77. Variation of thermal expansion with temperature for UTAC coatings. 


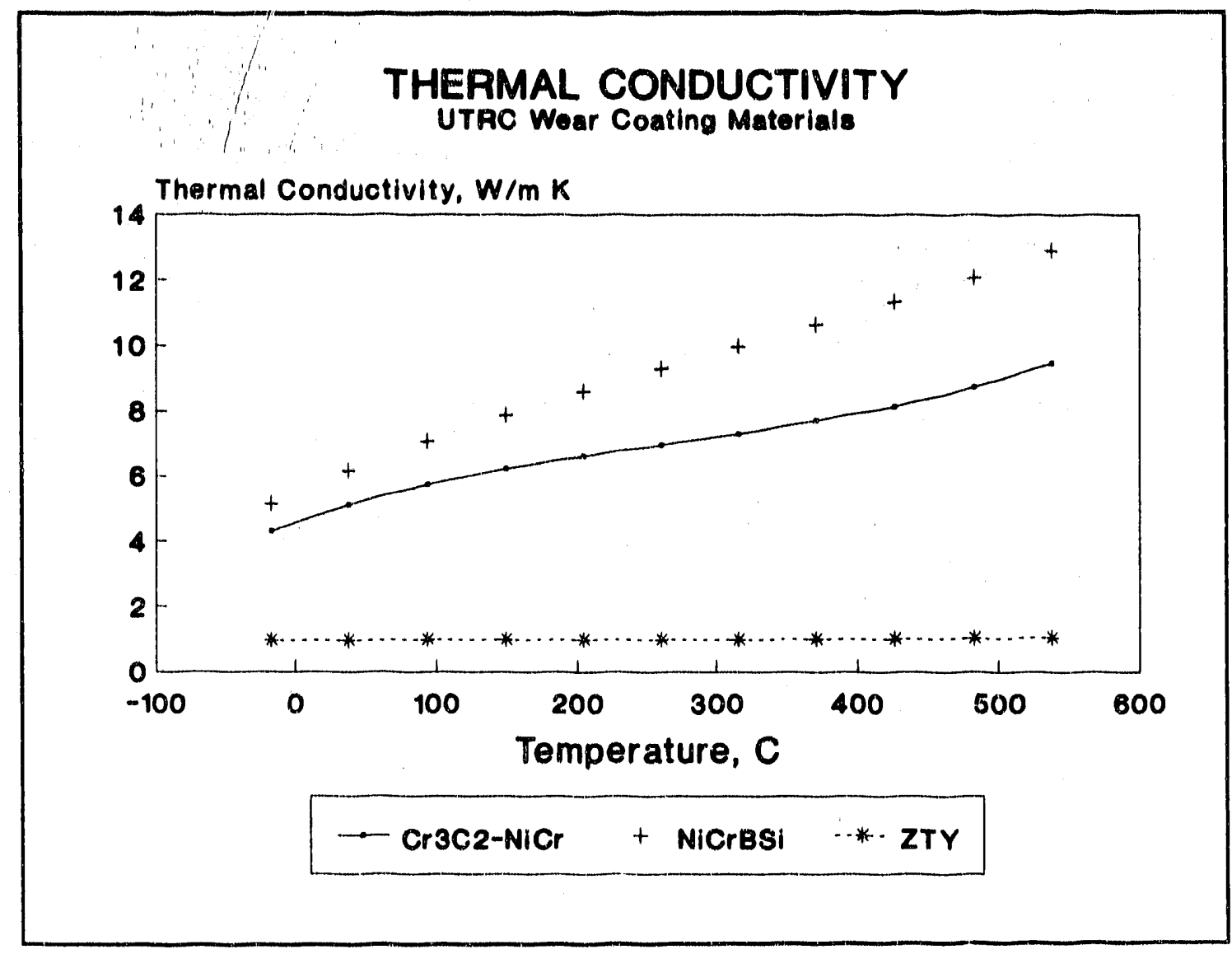

Figure 78. Variation of thermal conductivity with temperature for UTRC coatings. 


\section{SPECIFIC HEAT CAPACITY UTRC Wear Coating Materials}

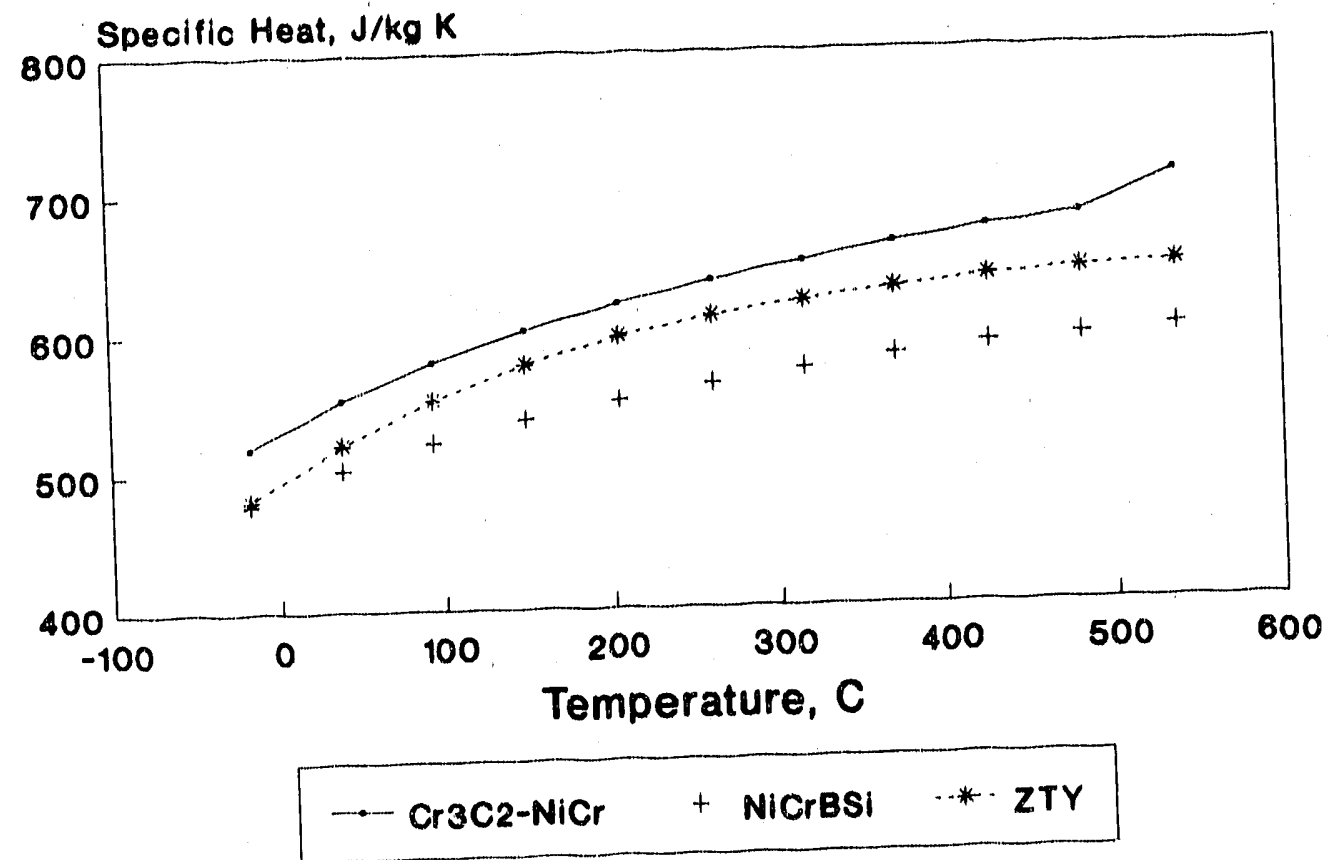

Figure 79. Variation of specific heat capacity with temperature for UTRC coatings. 


\subsection{COATING DEVELOPMENT AT VAPOR TECHNOLOGIES INCORPORATED}

Vapor Technologies deposited two ceramic coatings for evaluation using a proprietary cathodic arc physical vapor deposition process, which is designated "Low Temperature Arc Vapor Deposition" (LTAVD).

\subsubsection{Chromium Nitride Coating}

A LTAVD CrN coating was depostted to a thickness of approximately $4 \mu \mathrm{m}$ (Figure 80) onto lapped H13 tool steel substrates. The substrate temperature used for processing these samples was approximately $350^{\circ} \mathrm{C}$. A substantlal amount of spallation of the coating was observed near the edges of some of the samples, indicating high residual stress or low adhesion (Figure 81). High magnification SEM images of the coating surface showed a typical "sputtered" surface, with shallow craters and ridges (Figure 82). In addition, several $5 \mu \mathrm{m}$ sized Cr-rich macroparticles are observable on the coating surface (Figure 82). These macroparticies are a common feature for PVD coatings, and are caused by the formation of molten microdroplets in the vaporization of the metal from the target. Knoop microhardness values for a 10 gf load were approximately $1520 \mathrm{kgimm}^{-2}$ for the CrN coating, although it was questionable whether the coating was sufficiently thick for the measurements to be accurate.

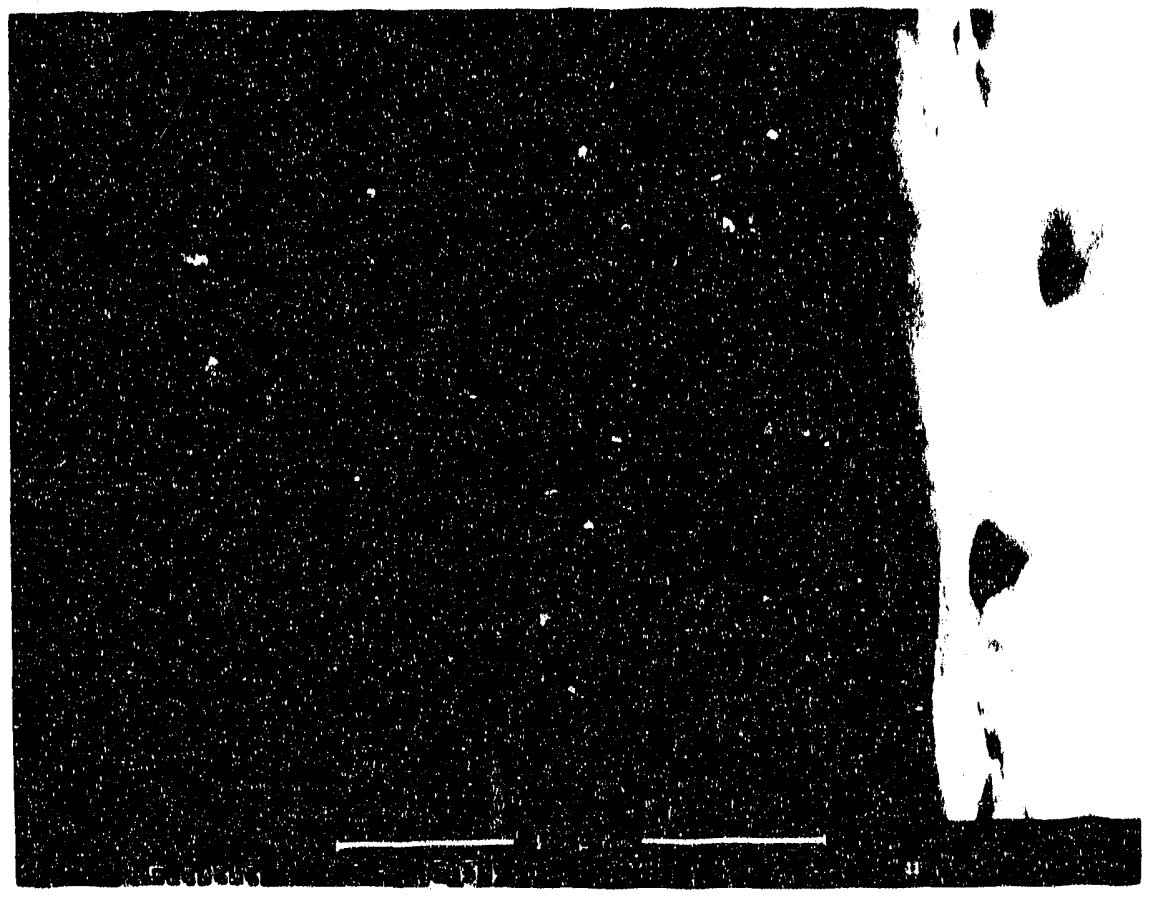

Figure 80. Microstructure of Vapor Technologies LTAVD CrN coating (SEM, backscattered electron image). Coating thickness was approximately $4 \mathrm{\mu m}$. 


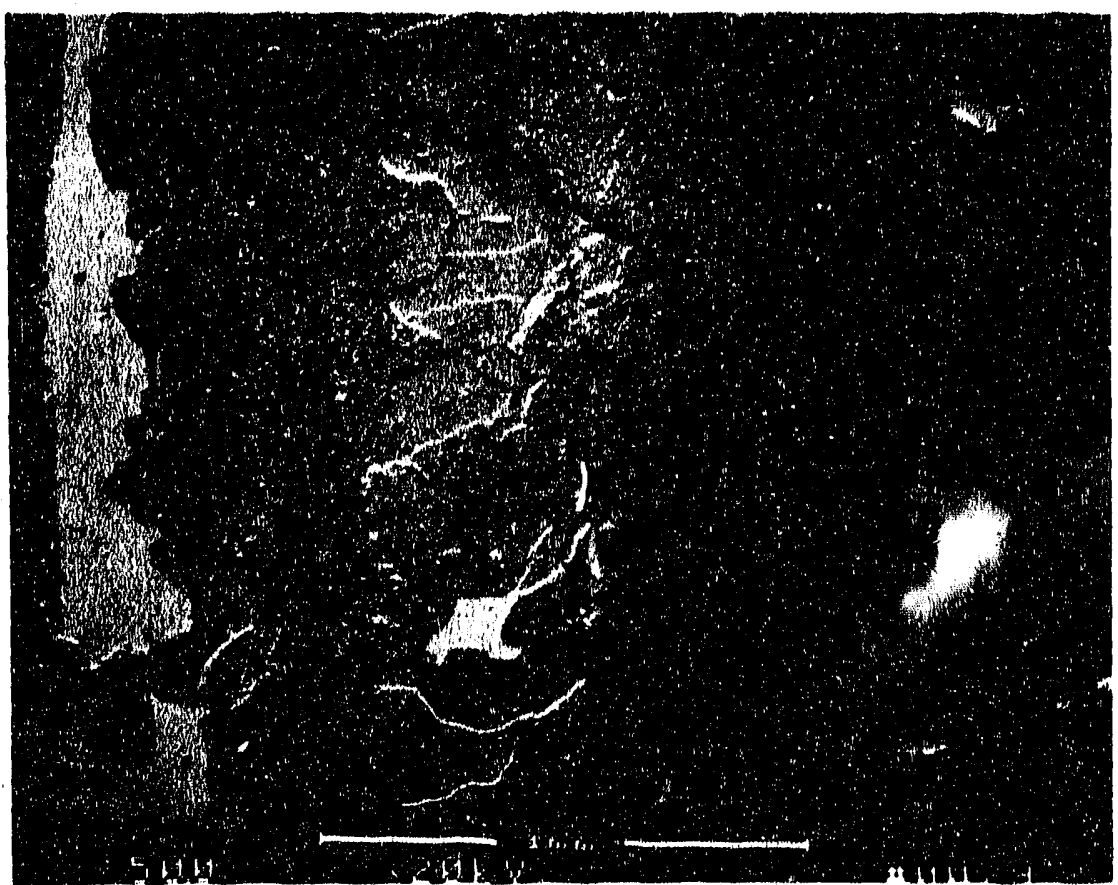

Figure 81. Low magnification image of as-coated surface of LTAVD CrN (SEM, backscattered). Some samples showed spallation, indicating high residual stress or low adhesion.

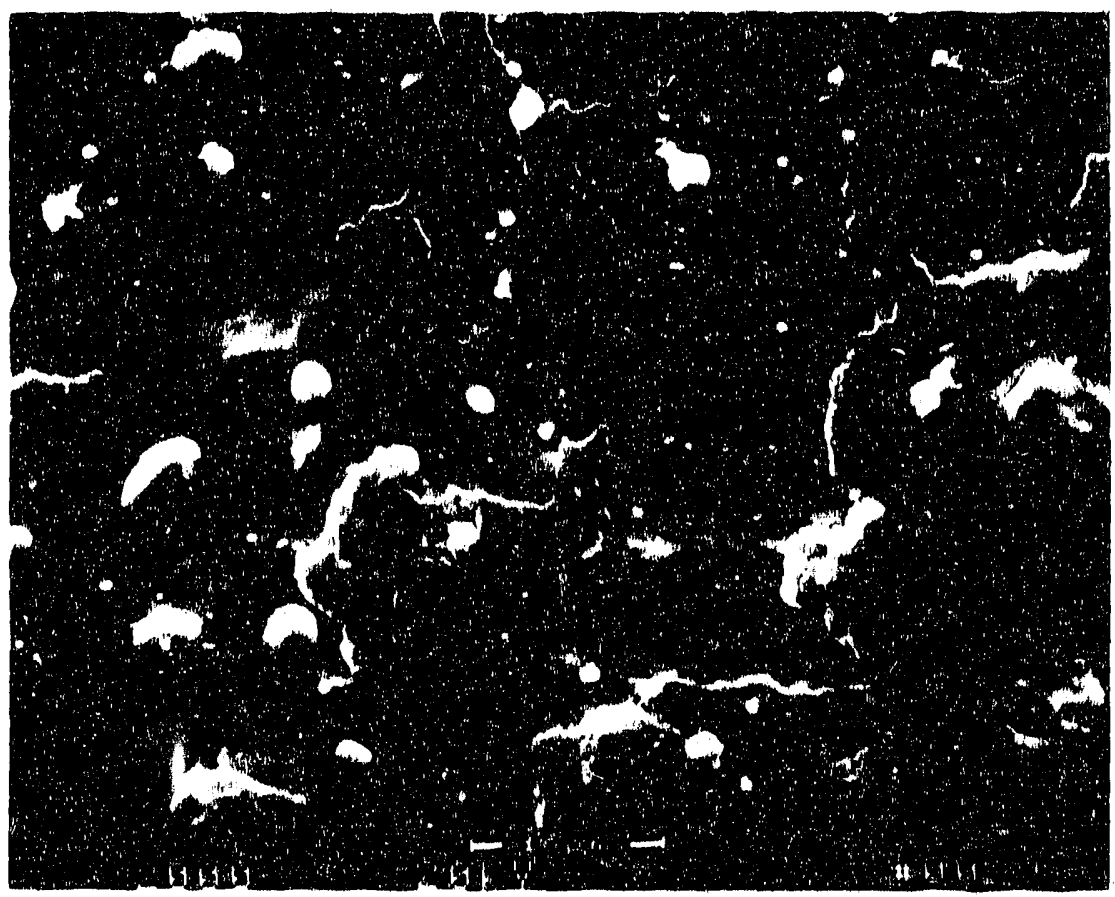

Figure 82. As-coated surface of Vapor Technologies LTAVD CrN (SEM, backscattered electron image), showing Cr macroparticles and "cratered" surtace. 


\subsubsection{Tantalum Nittride Coating}

A LTAVD tantalum nitride coating was deposited to a thlokness of approximately $3.2 \mu \mathrm{m}$ (Flgure 83) onto lapped $\mathrm{H} 13$ tool steel substrates. SEM images of the coating surface showed a high concentration of 5. $15 \mu \mathrm{m}$ sized Ta-rich macroparticles (Figure 84). Macroparticles were embedded in the coating more deeply than for the $\mathrm{CrN}$ coating. The tantalum nitride coating was too thin for microhardness measurements. The phase composition of the coating was investlgated by $X$-ray diffraction (Figure 85). The closest match to the observed peaks was found to be hexagonal $T a_{2} N$, with some metallic $T a$ also present, presumably due to the macroparticles. Some of the predicted fa $\mathrm{N}$ peaks were absent, perhaps due to a preferred texture of the coating. Neither of the two TaN phases referenced in the JCPDS file (9-257 and 32-1283) gave good matches with the observed pattern.

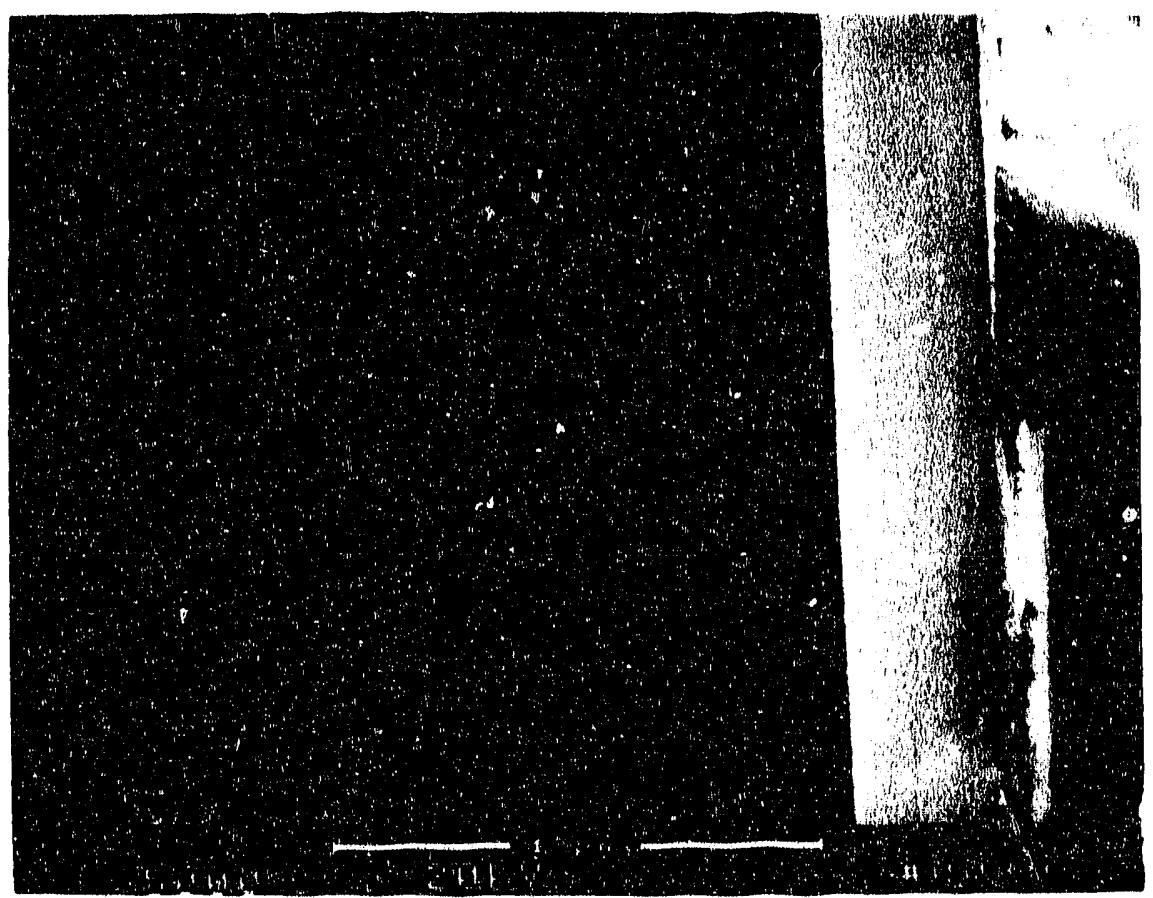

Figure 83. Microstructure of Vapor Technologies LTAVD Ta $T_{2} N$ coating (SEM, backscattered electron image). Coating thickness was approximately 3 um. 


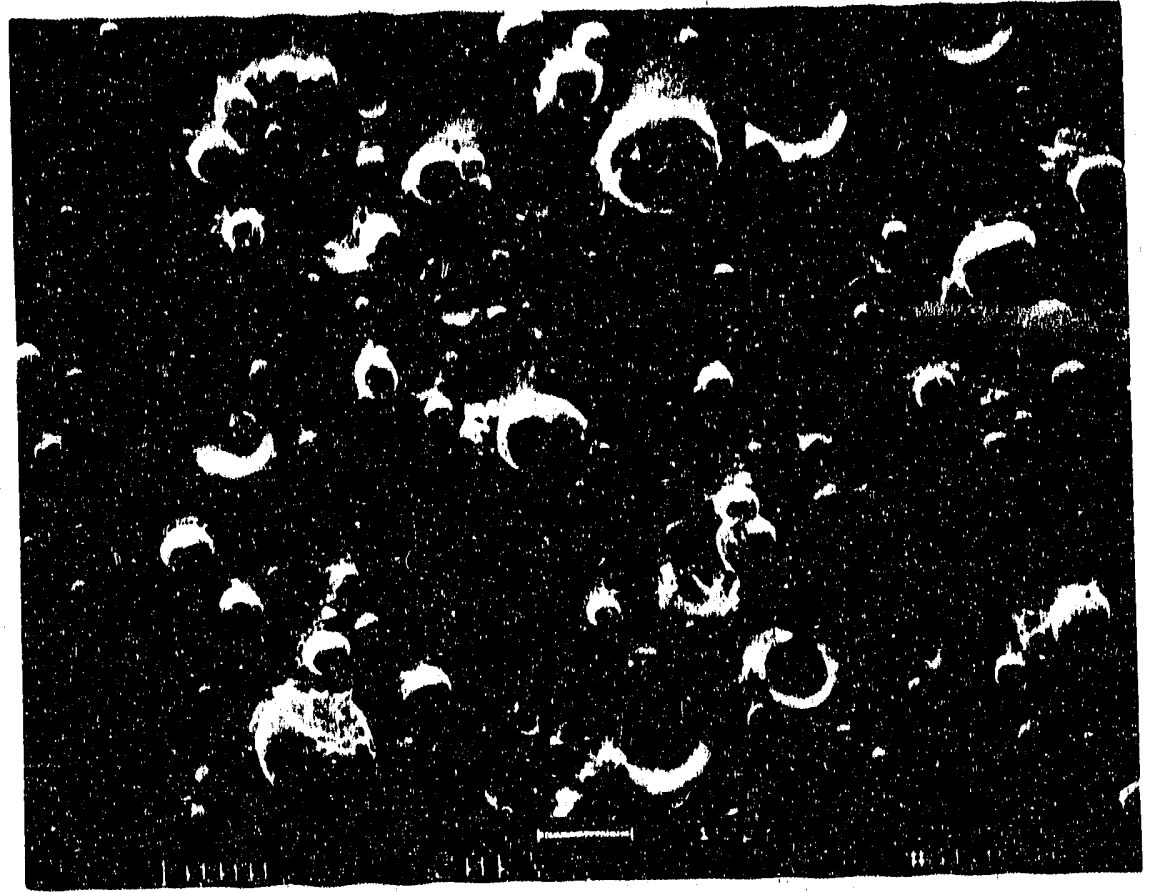

Figure 84. As-coated surtace of Vapor Technologles LTAVD Ta 2 N coating (SEM, backscattered electron image), showing large Ta macroparticles and "cratered" surface.

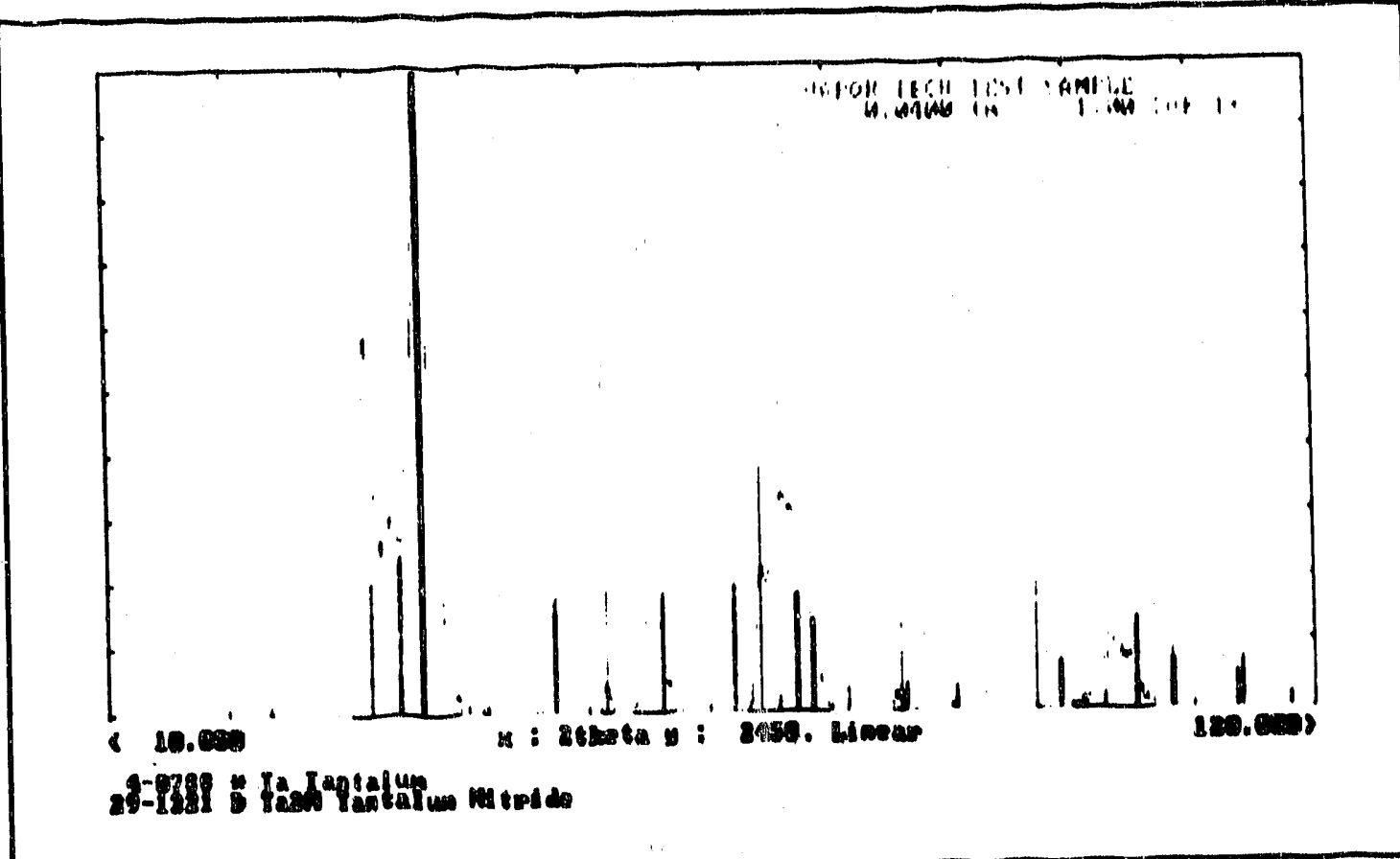

Figure 85. X-ray diffraction pattern for Vapor Technologies LTAVD Tag N coating, showing poaks for hexagonal $\mathrm{Ta}_{2} \mathrm{~N}$, with some motallic $\mathrm{Ta}$. 


\section{EXPERIMENTAL PROCEDURES FOR WEAR EVALUATION}

\subsection{TRIBOLOGICAL TEST CONFIGURATION}

Wear tests were performed using test conditions chosen to represent the ring-liner engine environment close to the top ring reversal position, and are detailed in Table 20. Tests were performed using a Cameron Plint TE77 reciprocating wear tester, shown schematically in Figure 86. The test geometry was a line contact cylinder against flat configuration, where the "piston ring" samples had a $50 \mathrm{~mm}$ oylindrical radius on the (coated) test face (Flgure 87) and the "oylinder liner" samples Were flat plates (Flgure 88). Thls sample geometry was chosen for three reasons: (a) to simulate a barrel faoed piston ring geometry, (b) for ease of sample fabrication and (o) to facilitate measurements on the "ring" samples alter wear tests.

The test load of $225 \mathrm{~N}\left(30 \mathrm{Nmm}^{-1}\right)$ was determined by estimating the maximum loading which would be experienced by the top compression ring at top dead center in a heavy duty diesel engine, making allowances for friction between the ring and piston groove. This level of loading is fairly high compared to that used by many laboratories for materials evaluation. In particular, the load used was approximately an order of magnitude higher than the "mild wear" to "severe wear" transition load found for unlubricated tests with many ceramio materials. For example, alumina is reported to show a transition to "ultra severe Wear" (seizure) in the load range $10-100 \mathrm{~N}$ in dry air at a sliding speed of $0.3 \mathrm{~ms}^{-1}[14]$.

Table 20. Wuar test conditions.

Test Schedule for Each Coating:

Fresh CE/SF $15 W 40$ mineral oll lubricant, $200^{\circ} \mathrm{C}$

Fresh CE/SF $15 W 40$ mineral oll lubricant, $350 \circ \mathrm{C}$

$3.3 \%$ Soot Engine-tested CE/SF $15 \mathrm{~W} 40$ oll, $200^{\circ} \mathrm{C}$ Unlubricated, $200^{\circ} \mathrm{C}$

Test Conditions:

$225 \mathrm{~N}$ on a $7.5 \mathrm{~mm}$ wide sample $\left(30 \mathrm{Nmm}^{-1}\right)$

"Ring" samples crowned (50 $\mathrm{mm}$ radius of curvature)

"Liner" samples flat

$5 \mathrm{~mm}$ stroke $(2.5 \mathrm{~mm}$ amplitude)

$20 \mathrm{~Hz}$ frequency

Speed at mid-stroke: $0.314 \mathrm{~ms}^{-1}$

Lubricated tests: 6 hrs, 1 drop of oll every 10 seconds

Unlubricated tests: 5 minutes 


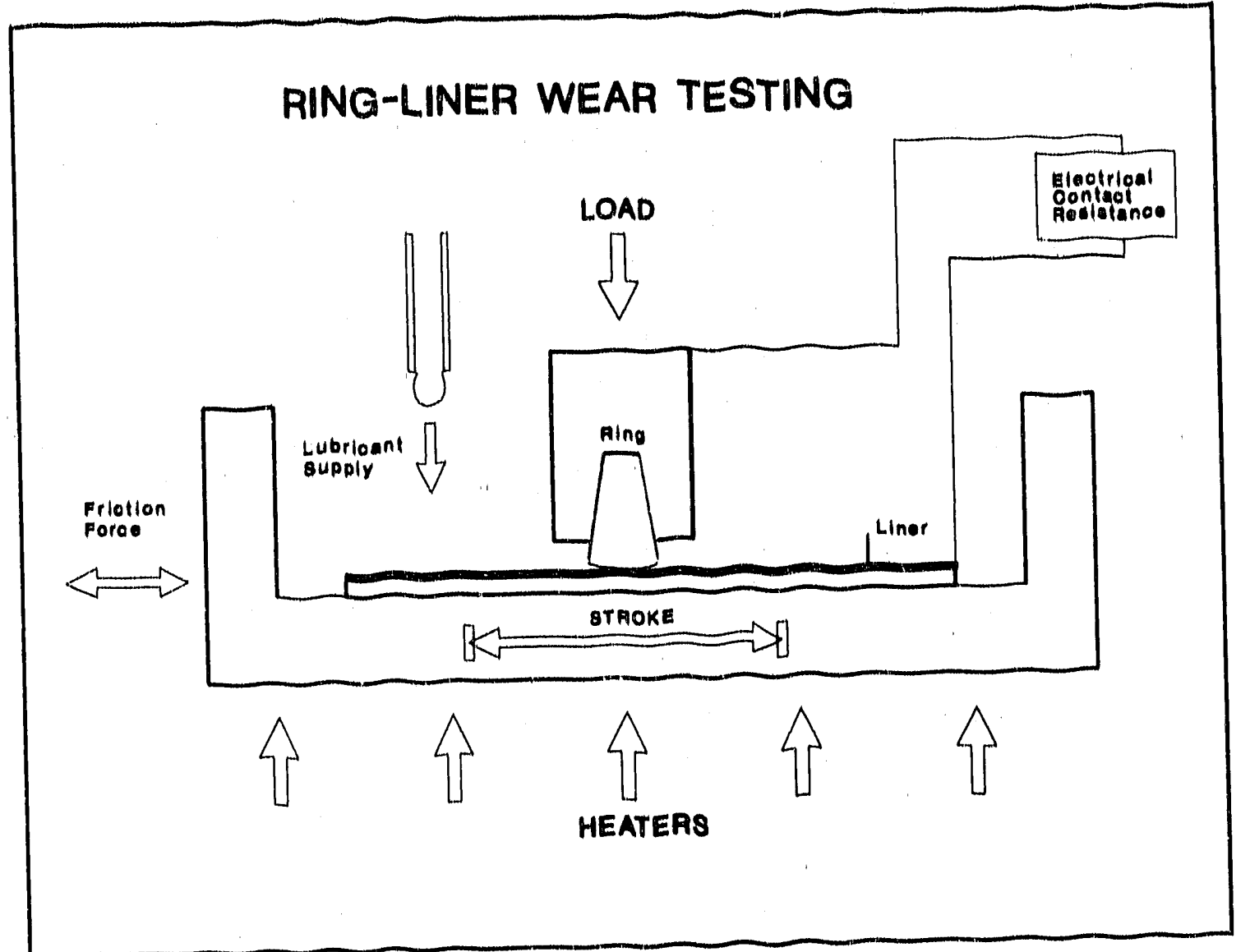

Figure 86. Schematic of the reciprocating wear tests (Cameron Plint TE77 tester). 


\section{CAMERON PLINT PISTON RING SAMPLE}

Samples cul from cyllnder with $101.6 \mathrm{~mm} \cdot 0 . \mathrm{d}$ $83.3 \mathrm{~mm} \mathrm{l.c}$ 9.15 min wall Crown drop on wear surlaco $=$ $0.135-0.142 \mathrm{~mm}$

Radius of curvature of wear surface must be measured and recorded

Dimensions: millimeters

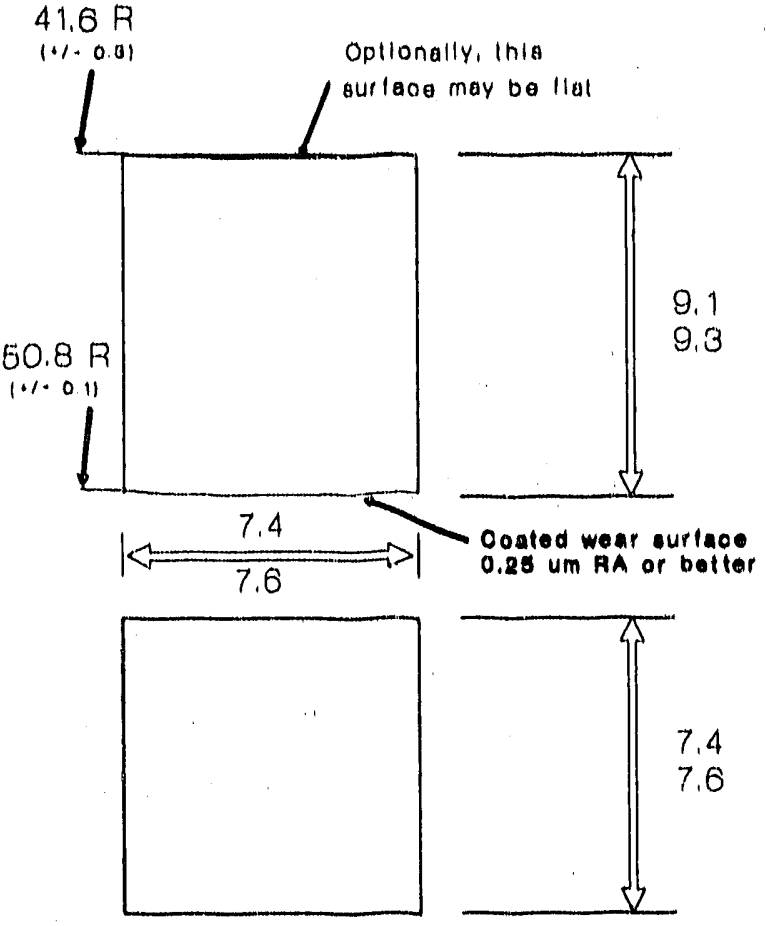

Figure 87. Simulated plston ring sample geometry. 


\section{CAMERON PLINT LINER SAMPLE}

0.25 um RA or better

Dimensions: millimeters

on wear surlaces
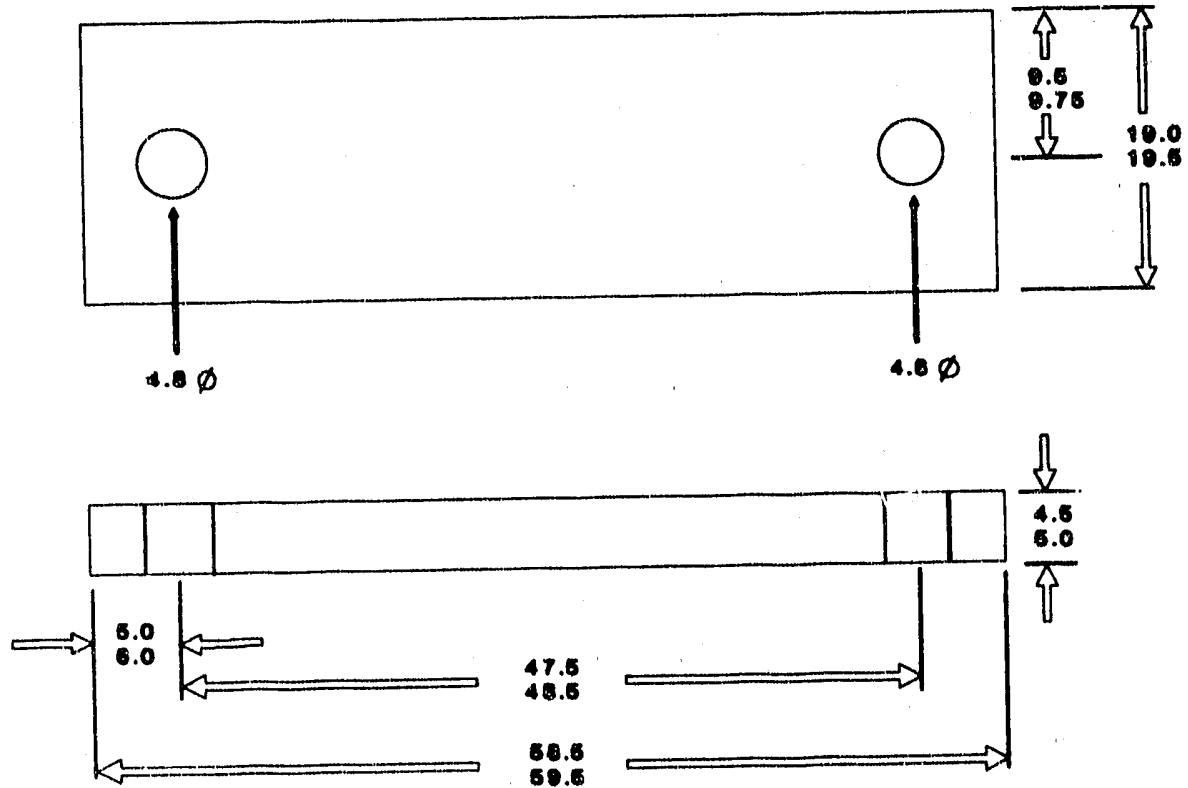

Figure 88. Simulated cylinder liner sample geometry. 


\subsection{TRIBOLOGICAL TEST VARIABLES}

After reviewing the literature on commercial plston ring caatings [0.g. 4], it became apparent that materials could score highly in some wear categorles, but perform poorly in others. For example, a coating might be very "scuff resistant" but have only average wear resistance under well-lubricated conditions. Accordingly, it was decided to rank tribological propertles under a multiplicity of test conditions, rather than comparing materials properties under one fixed test condition.

During the tribological testing program, emphasis was placed on the variables of greatest interest for diesel engine plston ing coatings: (1) lubricated wear rates as a function of temperature, (2) the effects of lubricant contamination and degradation on wear and (3) scuff reslatance. For each coating, tests were conducted at 200 and $350^{\circ} \mathrm{C}$ with a fresh CE/SF $15 \mathrm{~W} 40^{\circ}$ lubricant, at $200^{\circ} \mathrm{C}$ whth a high-s0ot, engine-tested oil and at $200^{\circ} \mathrm{C}$ with no lubrication. The $200^{\circ} \mathrm{C}$ test temperafure was selected to represent the top ring reversal temperature for a typical current commercial heavy duty diesel engine. The $350^{\circ} \mathrm{C}$ target temperature was selected to represent an advanced design low heat rejection engine with conventional liquid lubrication. $350^{\circ} \mathrm{C}$ was considered to be the highest temperature attainable with current lubricant technology. A liquid lubricated system is considered to be necessary for a high-durabillty (e.g. 1 million miles to first major overhaul) commercial engine. In addition to these tests, some of the most promising coatings were tested at $450^{\circ} \mathrm{C}$ with a syntheilc (poly-alpha-clefin) lubricant, in order to demonstrate what might be possible with more advanced lubricant systems.

Lubricated tests were run with: (a) a fresh commercial CE/SF quality $15 \mathrm{~W} 40$ mineral oil based lubricant and (b) a lubricant obtained from an experimental engine test, in order to assess the effects of oil contamination and degradation from a realistic dlesel engine environment on wear of ring and liner materials. The starting lubricant used for this engine test was a CE/SF 15 W40 mineral ofl based lubricant with identical wear properties to fresh oil (a), but with a slightiy different formulation. Characterization of the fresh and engine-tested olls is summarlzed in Table 21. The engine-tested oll was highly soot-loaded, with moderate levels of oxidation and little additive package depletion. Soot levels were higher than would normally be produced in a commercial engine.

In addition to the lubricated tests, materials were evaluated with no lubrication (at $200^{\circ} \mathrm{C}$ ), in order to rank the silding wear properties of different materlals under "scuffing" conditions. A matertal with good scuff resistance is desirable in case of temporary loss of olf fllm in the engine (on start-up or under short duration conditions of extreme hot running, for example). Due to the high loads experienced at top ring reversal, it is generally accepted that dry wear coefficients are too high to permit extended engine operation without lubrication [15].

Athough not treated explicitly as a test variable, a factor which is llkely to have influenced wear rates of the coatings and especially of the comparathely soft liner material is the coating surface finish. This was found to be a function of the inish machining operations and also of the coating microstructure, porosity and microcrack content being critical. Initially, coatings were tested in the as-ground condition, with $\mathrm{R}_{\mathrm{a}}$ values in the range $0.2-0.7 \mu \mathrm{m}$. As the program progressed, techniques for diamond lapping surfaces to better finishes (down to $0.02 \mu \mathrm{m}$ in some cases) were developed. $R_{\mathrm{a}}$ values for each coating, measured parallel to and at $90^{\circ}$ to the sfiding direction, are listed in Tables 22 - 24. For as-ground surfaces, the sliding direction was always parallet to the grinding direction (the direction of minimum $\mathrm{A}_{\mathrm{a}}$ ). 
Table 21. Properties of fresh and engine-tested lubricants used for woar tests.

\begin{tabular}{|l|c|c|}
\hline \multicolumn{1}{|c|}{ Property } & Fresh & Engine Tested \\
\hline Viscosity, 40C (cSt) & 95.2 & 161.0 \\
\hline Viscosity, 100\% (cSt) & 14.1 & 18.6 \\
\hline Viscosity Index & 152 & 130 \\
\hline TBN (mg KOH/g) & 6.8 & 4.2 \\
\hline TAN (mg KOH/g) & 2.9 & 8.3 \\
\hline Zinc Content (ppm) & 1800 & 1750 \\
\hline Phosphorus Content (ppm) & 1460 & 1380 \\
\hline Calclum Content (ppm) & 1500 & 860 \\
\hline Magneslum Content (ppm) & 0 & 1280 \\
\hline Fe Wear Motal (ppm) & 0 & 285 \\
\hline Cr Wear Metal (ppm) & 0 & 10 \\
\hline TGA Soot (\%) & 0.5 & 3.3 \\
\hline
\end{tabular}

Table 22. Sufface roughness $\left(\boldsymbol{R}_{\mathbf{Q}}\right)$ of mevtallic ring conting materials evaluated

\begin{tabular}{|c|c|c|c|c|}
\hline Coating & Suppller & Finleh & $\begin{array}{l}R_{a} \text { parallel to } \\
\text { ollaing } \\
\text { divertion }(\mu \mathrm{m})\end{array}$ & $\begin{array}{c}R_{\mathrm{a}} 90^{\circ} \text { to } \\
\text { salding } \\
\text { direction }(\mu \mathrm{m}) \\
\end{array}$ \\
\hline Electroplated Chromium & Cummins & Ground & $0.27-0.63$ & \\
\hline APS Chromlum & APS Materials & Lapped & 0.694 & 1.047 \\
\hline HVOF NiCrBSI & UTRC & Ground & 0.215 & 0.385 \\
\hline APS MO-Ni & BIRL & Lapped & 0.018 & 0.023 \\
\hline HVOF Mo-Ni & BIRL & Lapped & 0.055 & 0.088 \\
\hline APS $\mathrm{MO}-\mathrm{MOO}_{2}$ & BIRL. & Lapped & 0.194 & 0.232 \\
\hline APS Tribolte & APS Materials & Lapped & 0.079 & 0.043 \\
\hline APS Armacor M & APS Materials & Ground & 0.660 & \\
\hline APS Armacor T & APS Materials & Ground & 0.881 & \\
\hline
\end{tabular}


Table 23. Surface roughness $\left(R_{a}\right)$ of ceramic ring coating materials evaluated

\begin{tabular}{|c|c|c|c|c|}
\hline Coating & Suppiler & Finish & $\begin{array}{c}R_{\mathrm{a}} \text { parallel to } \\
\text { silding } \\
\text { direction }(\mu \mathrm{m})\end{array}$ & $\begin{array}{c}\mathbf{R}_{\mathbf{a}} \mathbf{9 0} 0^{\circ} \text { to } \\
\text { sliding } \\
\text { direction }(\mu \mathrm{m})\end{array}$ \\
\hline APS $\mathrm{Cr}_{2} \mathrm{O}_{3}$ & APS Materials & $\begin{array}{l}\text { Ground } \\
\text { Lapped }\end{array}$ & $\begin{array}{l}0.523 \\
0.656\end{array}$ & 0.653 \\
\hline APS $\mathrm{Cr}_{2} \mathrm{O}_{3}$ & BIRL & Lapped & 0.022 & 0.019 \\
\hline HVOF $\mathrm{Cr}_{2} \mathrm{O}_{3}$ & BIRL & Lapped & 0.045 & 0.065 \\
\hline APS Metco $136 \mathrm{Cr}_{2} \mathrm{O}_{3}-\mathrm{SiO}_{2}-\mathrm{TIO}_{2}$ & APS Materials & $\begin{array}{l}\text { Grnund } \\
\text { Lapped }\end{array}$ & $\begin{array}{l}0.448 \\
0.344 \\
\end{array}$ & 0.350 \\
\hline APS Metco $136+3 \% \mathrm{SiO}_{2}(\mathrm{~m} \mid \mathrm{x})$ & APS Materials & Lapped & 0.574 & 0.554 \\
\hline APS Metco $136+15 \% \mathrm{Al}_{2} \mathrm{O}_{3}(\mathrm{mix})$ & APS Materials & $\begin{array}{l}\text { Ground } \\
\text { Lapped }\end{array}$ & $\begin{array}{l}0.578 \\
0.570 \\
\end{array}$ & 0.564 \\
\hline APS $\mathrm{Cr}_{2} \mathrm{O}_{3}-50 \% \mathrm{Al}_{2} \mathrm{O}_{3}$ & BIRL & Lapped & 0.201 & 0.195 \\
\hline APS $\mathrm{Cr}_{2} \mathrm{O}_{3}-2 \% \mathrm{SiO}_{2}-2 \%$ other ox. & UTRC & Ground & 0.526 & 0.451 \\
\hline APS Boron Carbide & APS Materials & Lapped & 0.894 & 0.986 \\
\hline APS $\mathrm{ZrO}_{2}-18 \% \mathrm{TIO}_{2}-10 \% \mathrm{Y}_{2} \mathrm{O}_{3}$ & UTRC & Ground & 0.495 & 0.561 \\
\hline APS $\mathrm{Al}_{2} \mathrm{O}_{3}-26 \% \mathrm{ZrO}_{2}$ & BIRL & Lappod & 0.119 & 0.124 \\
\hline APS $\mathrm{Al}_{2} \mathrm{O}_{3}-26 \% \mathrm{ZrO}_{2}$ & BIRL & Laser Treated & 0.368 & 0.333 \\
\hline APS $\mathrm{Al}_{2} \mathrm{O}_{3}-41 \% \mathrm{ZrO}_{2}$ & BIRL & Lapped & 0.087 & 0.094 \\
\hline APS $\mathrm{Al}_{2} \mathrm{O}_{3}-41 \% \mathrm{ZrO}_{2}$ & BIRL & Laser Treated & 2.194 & 1.892 \\
\hline Boride diffusion coating & BIRL - TMT & Lapped & 0.664 & 0.563 \\
\hline LTAVD CrN & Vapor Tech & As coated & 0.173 & 0.205 \\
\hline LTAVD $\mathrm{Ta}_{2} \mathrm{~N}$ & Vapor Tech & As coated & 1.059 & 1.102 \\
\hline Diamond-like & Implant Sci & As coated & 0.096 & 0.084 \\
\hline
\end{tabular}


Table 24. Surface roughness ( $\left.\boldsymbol{R}_{2}\right)$ of cermet ring coating materials evaluated

\begin{tabular}{|c|c|c|c|c|}
\hline Coating & Supplier & Finish & $\begin{array}{c}R_{a} \text { parallel to } \\
\text { sliding } \\
\text { direction }(\mu \mathrm{m})\end{array}$ & $\begin{array}{c}\mathrm{R}_{\mathrm{a}} 90^{\circ} \text { to } \\
\text { siliding } \\
\text { direction }(\mu \mathrm{m})\end{array}$ \\
\hline APS WC - $12 \%$ Co & APS Materials & Ground & 0.315 & 0.710 \\
\hline LPPS WC - $12 \%$ Co & APS Materials & Ground & 0.177 & 0.626 \\
\hline HVOF WC - $12 \%$ Co & APS Materials & Lapped & 0.246 & 0.173 \\
\hline HVOF WC - $12 \%$ Co & Boyd Machine & Lapped & 0.042 & \\
\hline HVOF WC - $12 \%$ Co & BIRL - TMT & Lapped & 0.112 & 0.236 \\
\hline HVOF $\mathrm{Cr}_{3} \mathrm{C}_{2}-20 \% \mathrm{NiCr}$ & BIRL - TMT & Lapped & 0.051 & 0.076 \\
\hline HVOF $\mathrm{Cr}_{3} \mathrm{C}_{2}-20 \% \mathrm{NiCr}$ & UTRC & Ground & 0.182 & 0.416 \\
\hline LPPS Ferrotic CM TiC + Tool Steel & APS Niaterials & Lapped & 0.159 & 0.146 \\
\hline LPPS Ferrotic CS40 TIC + MSS & APS Materials & Lapped & 0.126 & 0.105 \\
\hline LPPS Ferrotic HTGA TIC + NI Alloy & APS Materlals & Lapped & 0.130 & 0.092 \\
\hline APS Metco $136+33 \%$ Stellite $6 \mathrm{mix}$ & APS Materials & Lapped & 0.435 & 0.465 \\
\hline
\end{tabular}

\subsection{SELECTION OF THE COUNTERFACE MATERIAL FOR COATING WEAR TESTS}

An important factor to be considered in evaluating the tribological properties of a piston ring coating material is the amount of wear it: produces on the cyllinder liner counterface. For optimum engine durability, low wear rates are rizquired of both ings and liners, therefore a systems approach is necessany in materials selection, rather than simply minimizing the wear on one surface. Published engine test data for commercial piston ring ccatings has shown that there is generally a trade-off between the wear rates of the ring coating and the cylinder liner material, the more wear resistant ring coatings generally giving higher liner wear [4].

Due to the large number of coatings evaluated and the multiplicity of test conditions, screening of ring coating materials was performed using one liner material as the counterface. The decision to test coated rings rather than coated liners was made primarily because current high speod diesel engines normally use a hard ring facing (typically electroplated hard chromium) sliding against a softer cylinder liner, although in some automotive, motorcycle and medium/low spoed diesel engines, the reverse combination (coated liners and uncoated grey iron rings) is used. In order to maintain low oil consumption of the engine over a long service life (commonly greater than 500,000 miles to first major overhaul), it is essential to maintain certain critical dimensions of the ring profile. Liner wear depths are typically low enough with current materials that geometry and surface finishes (at least in the mid-stroke region) are not changed to the point of affecting oil consumption. For these reasons, the approach taken was to develop.a highly wear resistant ring facing which would not cause increased liner wear compared to iraditional materials. A conventional liner material (pearlitic grey cast iron) was selected as the sliding counterface for this program because it is likely that any new ring coating would have to be compatible with existing cylinder liner materials. Alternative liner materials and coatings were also evaluated for one ring coating: a HVOF $\mathrm{Cr}_{3} \mathrm{C}_{2}-20 \%$ NiCr identified as providing the best combination of low ring and liner wear in the first round of testing with conventional liners. 
The pearlitic grey cast iron material selected as the counterface for coating wear tests was chosen to be representative of materials used for heavy duty dlesel engine cylinder liners. The chemical composition of the material is given in Table 25. The microstructure of this material consisted of predominantly type $A$ graphite flakes in a matrix of fine pearlite with less than $5 \%$ ferrite. Carbides and steadite phases were less than 5\% each. The hardness of this material was in the range $70-90 \mathrm{HRG}$. All grey cast iron test samples for this program were machined from cylinder liners in order to provide a realistic counterface for the wear tests. However, a common practice in diesel and automotlve industries is to apply a thin manganese phosphate ("Lubrite") coating to the cylinder liners, to faciltate "break-in" of the engine. Except where otherwise stated, the wear tests performed during this program used uncoated (non-Lubrited) grey cast iron cylinder liners.

In addition to the coating evaluation tests, which all used the conventional cylinder liner material, a second series of tests was performed with various alternative cylinder liner counterface materials in order to optimize the system for lowest total wear (ring plus liner). "ests were conducted with only one ring coating, the UTRC HVOF $\mathrm{Cr}_{3} \mathrm{C}_{2}-20 \%$ NiCr, which was selected because it gave one of the best combinations of low coating and liner wear in the initial screening tests. The coating was used in the as-ground condition, with a surface finish of $0.18 \mu \mathrm{m}$ measured parallel to the sliding direction (the grinding direction) and $0.42 \mu \mathrm{m}$ RA measured perpendicular to the sliding direction. The following liner materials were evaluated (see Table 25 for compositions):

1. pearlitic grey iron ( $70-90 \mathrm{HRG})$

2. hardened grey cast iron (42 HRC)

3. high-phosphorus grey cast iron (79-83 HRG)

4. bainitic grey cast iron ( $88-90 \mathrm{HRG)}$

5. centrifugally cast $\mathrm{H} 13$ tool steel hardened to $50 \mathrm{HRC}$

6. a slurry-sprayed silica-chromia-alumina (SCA) coating ( $\left.960 \mathrm{kgfmm}^{-2}, \mathrm{HK}_{100}\right)$

7. an ion-assisted CVD "diamond-like" coating supplied by Implant Sciences, Inc. The coating substrate was $\mathrm{H} 13$ tool steel.

Table 25. Chemical composition of cylinder liner materials evaluated.

\begin{tabular}{|c|c|c|c|c|c|c|c|c|c|}
\hline Liner Material & C & Si & $M n$ & $P$ & s & Mo & $\mathrm{Ni}$ & $\mathrm{Cr}$ & $\bar{V}$ \\
\hline $\begin{array}{l}\text { Pearlitic, } \\
\text { Hardened Grey } \\
\text { Irons }\end{array}$ & $\begin{array}{l}3.2- \\
3.5\end{array}$ & $\begin{array}{l}1.8 \\
2.6\end{array}$ & $\begin{array}{l}0.5 \\
0.8\end{array}$ & $\begin{array}{l}0.15 \\
\max \end{array}$ & $\begin{array}{l}0.1 \\
\max \end{array}$ & $\begin{array}{l}0- \\
0.5\end{array}$ & $\begin{array}{l}0- \\
0.5\end{array}$ & $\begin{array}{l}0.2- \\
0.8\end{array}$ & \\
\hline $\begin{array}{l}\text { High Phosphorus } \\
\text { Grey Iron }\end{array}$ & $\begin{array}{l}3.2- \\
3.5\end{array}$ & $\begin{array}{l}1.8- \\
2.3\end{array}$ & $\begin{array}{l}0.5 \\
0.8\end{array}$ & $\begin{array}{l}0.6 \\
0.9\end{array}$ & $\begin{array}{l}0.1 \\
\max \end{array}$ & & & $\begin{array}{l}0.15 \\
0.4\end{array}$ & \\
\hline Bainitic Iron & $\begin{array}{l}2.6- \\
2.8\end{array}$ & $\begin{array}{l}1.1- \\
1.6\end{array}$ & $\begin{array}{l}0.8 \\
\max \end{array}$ & $\begin{array}{l}0.08 \\
\max \end{array}$ & $\begin{array}{l}0.08 \\
\max \end{array}$ & $\begin{array}{l}1.0- \\
1.5\end{array}$ & $\begin{array}{l}1.0- \\
1.5\end{array}$ & & \\
\hline Hi3 Tool Steel & 0.35 & 1.0 & 0.35 & & & 1.5 & & 5.0 & 1.0 \\
\hline
\end{tabular}




\subsection{WEAR MEASUREMENT ERRORS AND TEST REPEATABILITY}

For each test, wear volumes were determined from binocular microscope measurements of wear scar widths for the rings and by stylus profilometry (longitudinal and transverse directions) for the liners. Wear results were then expressed as wear coefficients, calculated by dividing the total volume of wear $\left(\mathrm{mm}^{3}\right)$ by the product of silding distance $(\mathrm{mm})$ and applled normal load $(\mathrm{N})$.

Since wear coefficients were normally much lower for the ring coatings than for the pearlitic grey cast iron liners, measurement errors were greater for the coatings, particularly for the most wear resistant materials after the least severe tests $\left(20^{\circ} \mathrm{C}\right.$ with fresh off). The equation relating wear volume to scar width for the crowned ring coating samples is:

$$
V=l\left[R^{2} \sin ^{-1}\left(\frac{\omega}{2 R}\right)-\frac{\omega}{2}\left(R^{2}-\frac{\omega^{2}}{4}\right)^{1 / 2}\right]
$$

where: $\quad V=$ wear volume $\left(\mathrm{mm}^{3}\right)$

$$
\begin{aligned}
& l=\text { breadth of sample (approximately } 7.5 \mathrm{~mm} \text { ) } \\
& R=\text { crown radius (approximately } 50 \mathrm{~mm} \text { ) } \\
& W=\text { scar width (mm). }
\end{aligned}
$$

Observing that this is a very non-linear function, estimates were made of the effect of scar width measurement error on volumetric wear (hence wear coefficient). For the lowest wear conditions, end-of-test scar widths weie of the order of $0.5 \mathrm{~mm}$ with a measurement error of approximately $+0.1 \mathrm{~mm}$ (representing the uncertainty in defining the edge of the wear scar, rather than the accuracy of reading the graticule in the microscope). This results in a potentlal measurement error of $+60 \%$ in the wear volume. For high wear conditions, scar widths of the order of $4 \mathrm{~mm}$ with the same measurement error would givo a volumetric error of only $+7.5 \%$. Note that the maximum depth of wear would be only $0.16 \mu \mathrm{m}$ for a $0.5 \mathrm{~mm}$ wide scar (less than many of the Initial $\mathrm{A}_{\mathrm{a}}$ values) and $10 \mu \mathrm{m}$ for a $4 \mathrm{~mm}$ wide scar. One advantage of the sample geometry used, apart from simulating a barrel-faced piston ring, was that very small wear volumes could be measured relatively easily.

In addition to measurement errors, errors would also arise due to non-repeatability of tests (statistical scatter in the actual wear rates). This factor was not investigated at length, due to the already large test matrix, but an idea of the potentlal scatter (measurement error plus non-repeatability) is given by Table 26, which shows data for four repeat tests for electroplated chromium sliding against pearlitic grey cast iron with fresh oil at $350^{\circ} \mathrm{C}$. The standard deviation for the wear coefficients was approximately $50 \%$ of the mean, irdicating a high degree of scatter. In order to differentlate one material from another, a difference in wear coefficient of at least a factor of two would be required. Since the results often showed orders of magnitude differences between materials and test conditions, this does not invalidate the study, although subtle microstructurat effects would probably not have been detected. Normally, only one test was completed for each coating and for each of the test conditions described above, although repeat tests were performed to establish consistency in many cases.

Table 26. Friction and wear coefficients for four repeat tests with electroplated chromium ring coatings sliding against pearlitic grey cast iron liners at $350^{\circ} \mathrm{C}$ with fresh oil.

\begin{tabular}{|c|c|c|c|}
\cline { 2 - 4 } & $\begin{array}{c}\text { Ring Wear } \\
\left(\mathrm{mm}^{3} / \mathrm{mm} / \mathrm{N}\right)\end{array}$ & $\begin{array}{c}\text { Liner Wear } \\
\left(\mathrm{mm}^{3} / \mathrm{mm} / \mathrm{N}\right)\end{array}$ & Friction Coefficient \\
\hline & $3.44 \times 10^{-11}$ & $7.09 \times 10^{-9}$ & 0.128 \\
\hline & $9.96 \times 10^{-11}$ & $1.42 \times 10^{-8}$ & 0.148 \\
\cline { 2 - 4 } & $1.67 \times 10^{-10}$ & $7.73 \times 10^{-9}$ & 0.101 \\
\hline Mean: & $1.47 \times 10^{-10}$ & $4.52 \times 10^{-9}$ & 0.103 \\
\hline St. Deviation: & $1.12 \times 10^{-10}$ & $8.39 \times 10^{-9}$ & 0.120 \\
\hline Standard Error: & $0.59 \times 10^{-10}$ & $4.12 \times 10^{-9}$ & 0.022 \\
\hline
\end{tabular}




\section{WEAR TEST RESULTS}

In this section, tribological data for the coatings evaluated are presented and discussed. Detailed discussion of wear mechanisms and microstructural effects is deferred to the Appendices, in which SEM micrographs of wear surfaces are presented.

\subsection{RESULTS USING FRESH LUBRICANT}

\subsubsection{Piston Ring Coating Wear}

A summary of wear results for all the coatings evaluated is shown in Figures $89\left(200^{\circ} \mathrm{C}\right.$ tests) and 90 $\left(350^{\circ} \mathrm{C}\right.$ tests). Ring and liner wear coefficients are shown for each material couple on a logarithmic scale. Under the test conditions imposed, all materials systems operated in the boundary lubrication regime at both test temperatures, with friction coefficients in the range 0.1 to 0.3 . For the lubricant and oil supply rate used in these tests, the "scuffing" temperature (the temperature above which an oll film could not be maintained and friction coefficients in excess of 0.5 were measured) was approximately $360^{\circ} \mathrm{C}$ ' Thus, the $350^{\circ} \mathrm{C}$ tests are very close to the scuffing limit of the mineral oil based lubricant.

Wear coefficients for the coatings investigated ranged over approximately three orders of magnitude (Figures 89 and 90). Broadly, the ranking of coatings was simllar at both 200 and $350^{\circ} \mathrm{C}$. In general, the lowest wear rates were obtained with ceramic and cermet materials and the highest wear rates with metallic thermal spray coatings, even though some of the metallic coatings showed comparatively high hardness levels (Table 1). There was virtually no correlation between microhardness and wear for these tests (Figure 3). Although many ceramic coatings performed well (e.g. CrN, $\mathrm{Cr}_{2} \mathrm{O}_{3}$ ), others were found to give much higher wear rates (e.g. zirconia - titanla - yttria, boron carbide). No data are shown for the diamond-like material because the coating was removed from the substrate in all tests, presumably due to low bond strength.

The baseline for comparison of coating wear rates was electroplated hard chromium (EP Cr). Wear coefficients for EP Cr shown in Figures 89 and 90 were measured for sections machined from production piston rings sliding against pieces machined from grey cast iron cylinder liners, rather than the test geometry described in section 4.1. At $200^{\circ} \mathrm{C}$, EP Cr was one of the more wear resistant materials compared to other coatings (Figure 89), but at $350^{\circ} \mathrm{C}$ many other materials gave better wear performance (Figure 90). The wear tests clearly showed that coating materlals are available which would provide substantial improvements in wear resistance compared to the conventional materials, particularly at high temperatures. The LTAVD CrN, HVOF $\mathrm{Cr}_{3} \mathrm{C}_{2}-20 \% \mathrm{NiCr}$ and $\mathrm{WC}-12 \% \mathrm{Co}$ and $\mathrm{APS} \mathrm{Cr}_{2} \mathrm{O}_{3}$ coatings all showed outstanding wear properties at both test temperatures. 


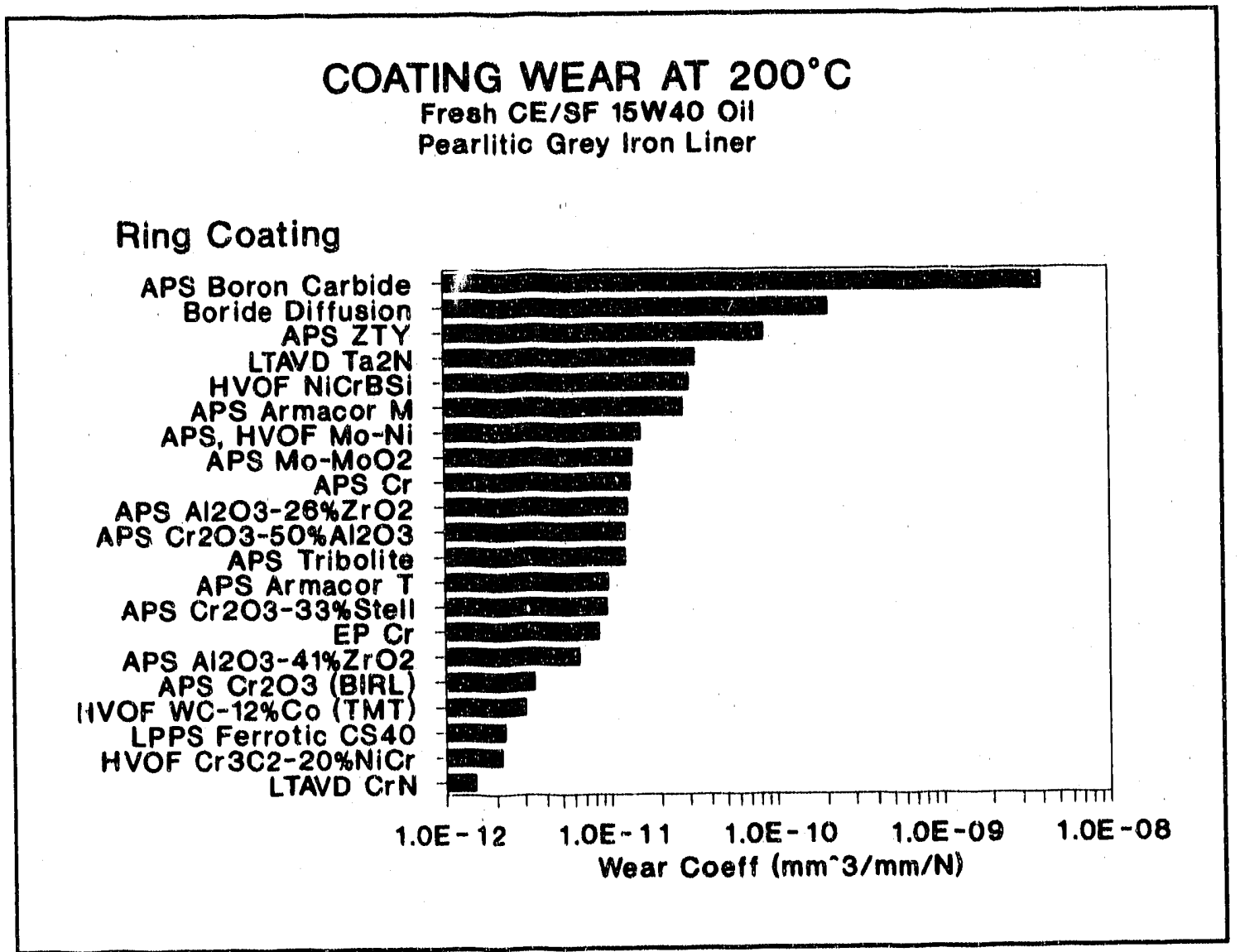

Figure 89. Wear coefficients for various coatings sliding against pearlitic grey Iron liners at $200^{\circ} \mathrm{C}$. Tests were run with fresh CE/SF $15 \mathrm{~W} 40$ mineral oil based lubricant. 


\section{COATING WEAR AT $353^{\circ} \mathrm{C}$ \\ Fresh CE/SF 15 W 40 Oil \\ Pearlitio Grey Iron Liner}

\section{Ring Coating}

APS Boron Carbide APS ZTY

Boride Diffusion LTAVD Ta2N

APS A1203-26\%ZrO2 APS Tribolite HVOF NiCrBSi APS $\mathrm{Cr}$

APS Cr203-33\%Stell APS $\mathrm{MO}-\mathrm{MOO} 2$ APS Armacor $M$

LPPS Ferrotic CS40

APS A1203-41\% ZrO2 APS Armacor T

APS Cr203-50\%Al2O3

APS Cr203 (BIRL)

HVOF Cr3C2-20\% NiCr

HVOF WC-12\%Co (TMT)

LTAVD CrN

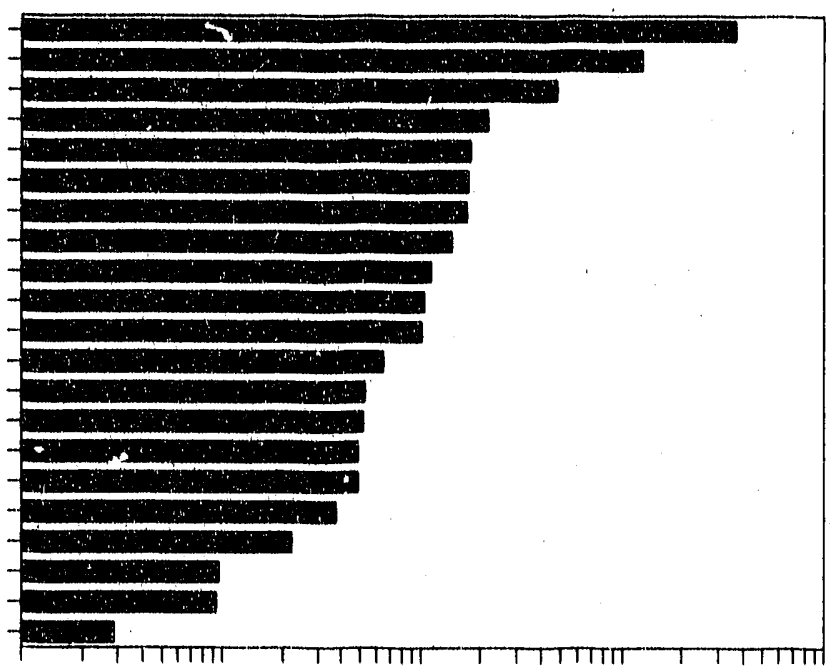

$\begin{array}{lllll}1.0 E-12 & 1.0 E-11 & 1.0 E-10 & 1.0 E-09 & 1.0 E-08\end{array}$

Wear Coeff $\left(\mathrm{mm}^{\wedge} 3 / \mathrm{mm} / \mathrm{N}\right)$

Figure 90. Wear coefficients for varlous coatings sliding against pearlitic grey iron liners at $350^{\circ} \mathrm{C}$. Tests were run with fresh CE/SF 15 W40 mineral oll based lubricant. 


\subsubsection{Motallic Coatings}

At $200^{\circ} \mathrm{C}$, none of the thermally sprayed metallic coatings showed lower wear than electroplated hard chromlum (Figure 89), although many showed only slightly higher wear. At $350^{\circ} \mathrm{C}$, both Armacor coatings and the $\mathrm{MO}-\mathrm{MOO}_{2}$ materlal showed superior wear properties to EP Cr (Figure 90). Note that the electroplated and plasma sprayed chromium showed virtually identical wear properties at thie higher test temperature, desplte the blg difference in microhardness measured at room 'omperature $\left(880 \mathrm{~kg}^{-2} \mathrm{~mm}^{-2}\right.$ for EP Cr versus $250 \mathrm{kgfmm}^{-2}$ for APS Ci). The plasma sprayed materlal was observed to contain substantial amounts of chromium oxide in a soft chromium matrix, which may have offset the difference in bulk hardness. Triboltte and Mo - Nl coatings showed comparattvely high wear at $350^{\circ} \mathrm{C}$, and would not be candidates for high temperature applications.

A surprising result was that woar coefficients for the HVOF NICrBSI material were found to be high at both test temperatures, despite a i elatwely high Knoop microhardness of approximately $900 \mathrm{kgfmm}^{-2}$. The general lack of correlation between microhardness and wear suggests that some mechanism other than abrasion may be important for these test conditions. It is speculated that the wear mechanism may involve chemical interactions between the lubricant and the metal, for example. However, it would be instructive to repeat the correlation using high temperature hardness data.

\subsubsection{Ceramic Coatings}

Of the ceramic coatings studied, the LTAVD CrN gave the lowest wear coefilicients at both test temperatures. Wear rates were approximately six times lower than for EP $\mathrm{Cr}$ at $200^{\circ} \mathrm{C}$ and forty times lower at $350^{\circ} \mathrm{C}$. However, even these low wear rates would probably not compensate for the low thickness $(4 \mu \mathrm{m})$ of this coating compared to typical thickness values of $150 \mu \mathrm{m}$ for EP Cr.

Surprisingly, the LTAVD Ta $\mathrm{Ta}_{2} \mathrm{~N}$ coating gave relatively high wear rates. In fact, for this coating, test durations had to be reduced to $30^{2}$ minites for $200^{\circ} \mathrm{C}$ fresh oil tests and 5 minutes for $350^{\circ} \mathrm{C}$ fresh oil and $200^{\circ} \mathrm{C}$ high-soot tests in order not to wear through the coating.

Chromium oxide coatings showed lower wear coefficients than for the baseline electroplated hard chromium material. Figures 89 and 90 show values for one of the best $\mathrm{Cr}_{2} \mathrm{O}_{3}$ materials, the BIRL air plasma sprayed coating. Microstructural effects on wear of chromilum oxfdes are discussed in section 4.5.1. In addition to the $\mathrm{Cr}_{2} \mathrm{O}_{3}$-rich materials, a $\mathrm{Cr}_{2} \mathrm{O}_{3}-50 \% \mathrm{Al}_{2} \mathrm{O}_{3}$ coating, sprayed from pre-alloyed powder, was tested and found to give comparatively high wear coefficients, which is thought to be due to the hirgh levels of porosity and microcracking in this coating.

Of the two $\mathrm{Al}_{2} \mathrm{O}_{3}-\mathrm{ZrO}_{2}$ coatings studied, the more crystalline eutectic composition $\left(\mathrm{Al}_{2} \mathrm{O}_{3}-41.4 \%\right.$ $\mathrm{ZrO}_{2}$ ) gave wear coefficients two to three times lower than the largely amorphous $\mathrm{Al}_{2} \mathrm{O}_{3}-26 \% \mathrm{ZrO}_{2}$ material, despite lower microhardness. The $\mathrm{Al}_{2} \mathrm{O}_{3}-4.1 .4 \% \mathrm{ZrO}_{2}$ coating gave lower wear rates than EP $\mathrm{Cr}$ at both test temperatures.

The zirconia - titania - yttria material gave consistently disappointing wear results, possibly due to the high degree of inter-splat cracking/voiding present in the coating (Figure 70, section 2.7.2), or to low hardness or chemical incompatiblity with the lubricant. Wear surfaces showed an "etched" morphology. with evidence of fine-scale spallation and fracture, and no large contiguous load-bearing areas (see Appendix A3.4).

The boron carbide coating was found to be highly porous, giving extremely high wear coefficients due to the poor bonding of the powder particles. In many cases, the coating was completely removed by the end of the test. The wear properties of this caating were probably controlled by the microstructure, rather than intrinsic to boron carbide materials.

The boride diffusion coating was found to show very high wear in these teste, perhaps due to fracture of the highly porous surface layers. 


\subsubsection{Cermet Coatings}

Several WC - 12\% Co materials were evaluated, generally giving very low wear coefficients. Figures 89 and 90 shovi data for one of the best WC - Co coatings, the Turbine Metal Technology HVOF WC - $12 \%$ Co material. Microstructural effects are discussed in section 4.5.2.

The HVOF $\mathrm{Cr}_{3} \mathrm{C}_{2}-20 \% \mathrm{NICr}$ coatings gave similar wear coefficients to the WC - $12 \%$ Co materials. Data for the UTRC material sprayed from clad powder is shown in Figures 89 and 90 . Microstructural effects are discussed in section 4.5.3. Both WC- $12 \%$ Co and $\mathrm{Cr}_{3} \mathrm{C}_{2}-20 \% \mathrm{NiCr}$ coatings can he thermally sprayed to the same thickness as EP Cr, making these two coatings the top contenders for "s $p$ compression ring facings.

LPPS Ferro-Tic materials showed excellent wear properties at $200^{\circ} \mathrm{C}$, but comparatively high wear at $350^{\circ} \mathrm{C}$ (although still better than EP Cr). The CS40 grade (martensitic stainless steel matrix phase) gave the besi wear characteristics of the Ferro-Tic materials investigated, and data for this material are shown in Figures 89 and 90 . Microstructural effects are discussed in section 4.5.4.

\subsection{Cylinder Liner Wear}

An important factor to be considered in evaluating the tribological properties of a piston ring coating material is the amount of wear occurring on the cylinder liner counterface. For optimum engine durability, low wear rates are required of both rings and liners, therefore a systems approach is necessary in materials selection. Wear coefficients for pearlitic grey cast iron counterface materials are shown in Figures 91 $\left(200^{\circ} \mathrm{C}\right)$ and $92\left(350^{\circ} \mathrm{C}\right)$. Liner wear coefficients varied by two to three orders of magnitude for the range of ring coatings investigated, with less sensitivity to ring material at $350^{\circ} \mathrm{C}$ than at $200^{\circ} \mathrm{C}$. Generally, there was a reasonable correlation between liner wear rankings at the two test temperatures, with some exceptions such as the relatively good performance of the ZTY coating at $350^{\circ} \mathrm{C}$ compared to $200^{\circ} \mathrm{C}$.

For a hard vs soft wear couple, the wear of the softer material will generally be influenced by the surface finish of the harder. In this study, as-ground chromium oxide coatings were found to produce much higher liner wear than lapped coatings, especially at the lower test temperature. At $200^{\circ} \mathrm{C}$, a lapped $\mathrm{Cr}_{2} \mathrm{O}_{3}\left(0.02 \mu \mathrm{m} \mathrm{R} \mathrm{a}_{\mathrm{a}}\right)$ gave approximately twenty times less liner wear than the same coating abraded with 320 \# SiC paper to an $R_{2}$ of $0.4 \mu \mathrm{m}$ (Table 27). However, at $350^{\circ} \mathrm{C}$, the difference was only a factor of 2.5. The temperature sensithity may arise because the higher coating wear rate at $350^{\circ} \mathrm{C}$ would cause the original surface finish to be removed in a shorter time than at $200^{\circ} \mathrm{C}$. Thus, the original coating surface finish should be less important at the higher test temperature. This factor may explain the reduced liner wear sensitivity to ring material at the higher iest temperature.

Although the lapped coatings generally produced the lowest liner wear, an irteresting finding was that the as-ground $\left(0.4 \mu \mathrm{m} \mathrm{R}_{\mathrm{a}}\right.$ ) HVOF $\mathrm{Cr}_{3} \mathrm{C}_{2}-\mathrm{NiCr}$ coating (one of the best for ring wear) gave consistently low values for liner wear at both tesi temperatures. In fact, this as-ground coating gave lower liner wear than lapped WC - Co coatings. Thus, the microstructure of the coating ma'; also play an important role in influencing liner wear, although the controlling factors are difficult to resolve. For example, the softer ring coatings (e.g. APS chromium, Mo-Ni) did not necessarlly produce the lowest liner wear in these tests, so again hardness may not be an impcrtant factor. The Tribolite coating gave the lowest liner wear at both test temperatures. Many of the plasma sprayed ceramic coatings (especially $\mathrm{Cr}_{2} \mathrm{O}_{3}$ and $\mathrm{Al}_{2} \mathrm{O}_{3}-\mathrm{ZrO}_{2}$ ) also gave very low liner wear, especially at the higher test temperature. 


\section{CYLINDER LINER WEAR AT $200^{\circ} \mathrm{C}$ \\ Frosh CE/SF 15 W40 OII \\ Pearlitic Grey Iron Liner}

\section{Ring Coating}

APS Boron Carbide

LTAVD Ta2N

APS ZTY

Boride Diffusion LTAND CrN APS Cr203-33\%Stell

HVOF WC-12\%CO (TMT)

APS Cr203-50\%A12O3

APS $\mathrm{Cr}$

HVOF NiCrBSi

APS, HVOF MO-NI

ÁPS Mo-MoO2

APS A1203-26\% ZrO2

APS Cr203 (BIRL)

HVOF Cr3C2-20\%NiC

APS Armacor T

APS Al2O3-41\%ZrO2
LPPS Ferrotic CS40

APS Tribolite

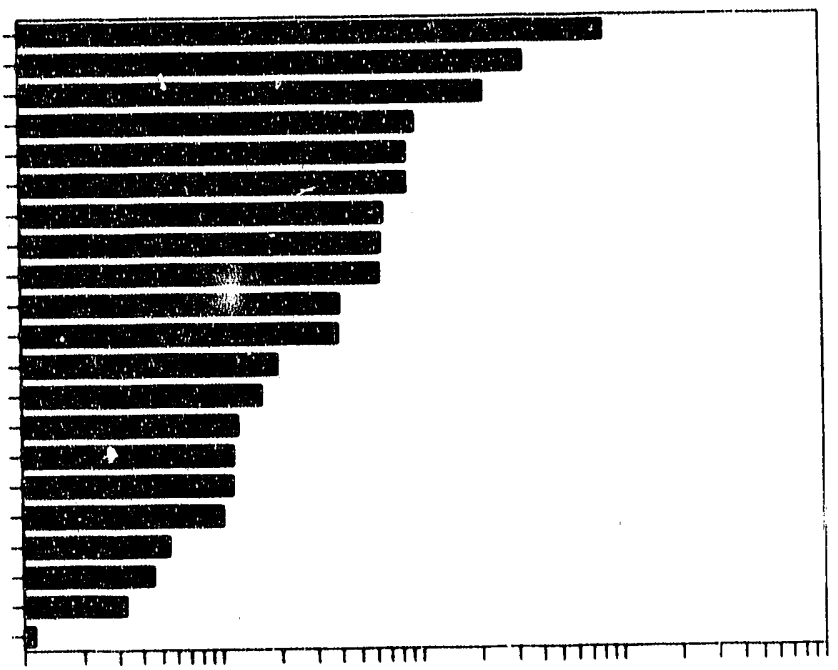

$$
\begin{array}{cccc}
1.0 E-11 & \begin{array}{c}
1.0 E-10 \\
\text { Wear Coeff }(\mathrm{mm} / 3 / \mathrm{mm} / \mathrm{N})
\end{array} & \text { 1.0E-0 }-07
\end{array}
$$

Figure 91. Wear coefficients for poarlitic grey cast iron cylinder liners at 2000 C. Tests were run with fresh CE/SF $15 W 40$ mineral oil based lubricant.

Table 27. Wear coefficients of a pearlitic grey cast iron cytinder liner material as a function of the pre-test surface finish of the ring counterface for an APS chromium oxiole ring coating, at 200 and $350^{\circ} \mathrm{C}$.

\begin{tabular}{|c|c|c|c|}
\hline $\begin{array}{c}R_{a} \text { Parallel to Sliding } \\
\text { Direction } \\
(\mu \mathrm{m})\end{array}$ & $\begin{array}{c}\mathbf{R}_{\mathrm{a}} 90^{\circ} \text { to Sliding } \\
\text { Direction } \\
(\mu \mathrm{m})\end{array}$ & $\begin{array}{c}\text { Cylinder Liner Wear Coeff. at } \\
200^{\circ} \mathrm{C} \\
\left(\mathrm{mm}^{3} / \mathrm{mm} / \mathrm{N}\right)\end{array}$ & $\begin{array}{c}\text { Cylinder Lingr Wear Coeff. at } \\
350^{\circ} \mathrm{C} \\
\left(\mathrm{mm}^{3} / \mathrm{mm} / \mathrm{N}\right)\end{array}$ \\
\hline 0.242 & 0.398 & $2.11 \times 10^{-9}$ & $3.20 \times 10^{-8}$ \\
\hline 0.022 & 0.019 & $1.14 \times 10^{-10}$ & $1.34 \times 10^{-9}$ \\
\hline
\end{tabular}




\section{CYLINDER LINER WEAR AT $350^{\circ} \mathrm{C}$ Fresh CE/SF $15 W 40$ Oil \\ Pearlitic Grey Iron Liner}

\section{Ring Coating}

APS Mo-Ni

APS Boron Carbide

APS Armacor $M$

LTAVD Ta2N

Boride Diffusion

EPC

HVOF WC-12\%Co (TMT)

APS Mo-MoO2 APS $\mathrm{Cr}$

APS Cr203-33\%stel

HVOF NiCrES

LTAVD CrN

APS Armacor T

APS Al2O3-41\%ZrOZ

LPPS Ferrotic CS40

APS ZTY

HVOF Cr3C2-20\%NiC

APS $\mathrm{Cr} 203$ (BIRL)

APS Al203-26\%2rO2

APS Cr2O3-50\% A12O3

APS Tribolite

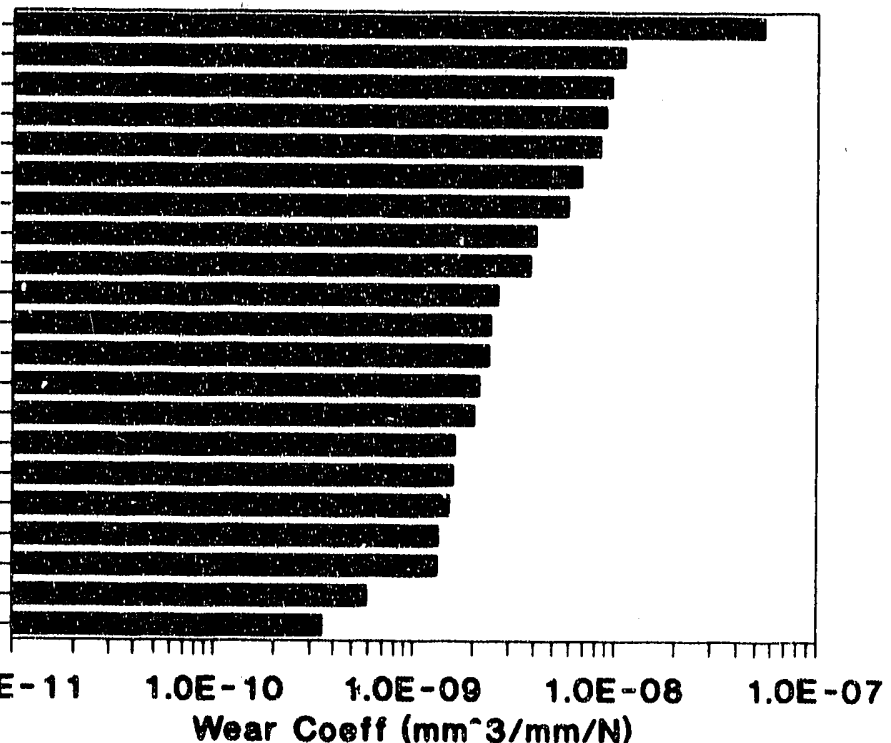

Wear Coeff (mm-3/mm/N)

Figure 92. Wear coefficients for pearlitic grey cast iron cylinder liners at $350^{\circ} \mathrm{C}$. Tests were run with fresh CE/SF 15 WAO mineral oil based lubricant. 


\section{1 .3 Friction Cosefficients}

Friction coefficients for the fresh oll tests are shown in Figures $93\left(200^{\circ} \mathrm{C}\right)$ and $94\left(350^{\circ} \mathrm{C}\right)$. At $200^{\circ} \mathrm{C}$, friction coefficients were relatively insensitive to the sliding materlals, with the exceptlon of the highly porous boron carbide coating, which showed comparatively hizh friction. For most coatings, the friction coefficient was in the range $0.10-0.13$. At $350^{\circ} \mathrm{C}$, friction cuefficients were more dependant on materials, ranging from approximately 0.08 to 0.18 . For some materlais, friction decreased compared to the $200^{\circ} \mathrm{C}$ values; for others it increased. The magnitude of the friction coefficients indicates that all tests ran under boundary lubricated conditions.

A surprising feature of the friction data was the lack of any clear correlations with other measured data, such as wear rates or microhardness values. Also, there was no correlation between the initial surface finish ( $R_{\mathrm{a}}$ values) of the coatings and friction coefficient. In the boundary lubricated regime, friction is thought to occur primarlly due to energy dissipation in lubricant films adsorbed onto the sliding surfaces, and may thus depend primarily on the chemistry and tiriskness of the adsorbed films. This, in turn may depend on the chemistry of the sliding surfaces rather than on mechanical properties such as hardness. Clearly, there is a need for funther characterization of surface films in order to explain the friction data obtained. From a practical standpoint, it is unfortunate that the best wear materlals do not necessarily give the lowest friction coefficients.

\section{FRICTION COEFFICIENTS AT $200^{\circ} \mathrm{C}$ Fresh CE/SF 15 W 40 OII Pearlitic 3rey Iron Liner}

\section{Ring Coating}

APS Boron Carbide HVOF Cr3C2-20\%NiCr

APS ZTY APS Armacor APS Cr203-33\% Stell APS Cr2O3-50\%A1203 APS MO-MOO2

LTAVD CrN

APS A1203-41\% Z $\mathrm{rO2}$

LPPS Ferrotic CS40

APS $\mathrm{Cr} 2 \mathrm{O} 3$ (BIRL)

APS A1203-26\%ZrO2

ITAVD Ta2N

HVOF NICrBSi

APS Cr

HVOF WC-12\%Co (TMT)

APS MO-Ni

APS Tribolite

Boride Diffusion EP Cr

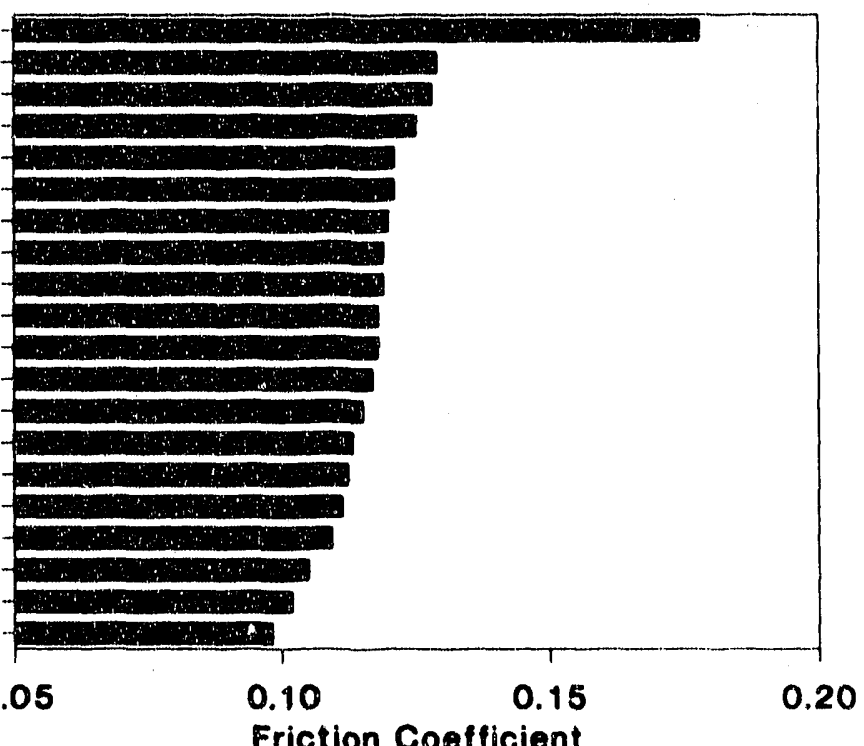

Friction Coefficient

Figure 93. Friction coefficients for $200^{\circ} \mathrm{C}$ fresh oll tests. 


\section{FRICTION COEFFICIENTS AT $350^{\circ} \mathrm{C}$ \\ Frosh CE/SF $15 W 40$ Oil \\ Pearlitic Grey Iron Liner}

\section{Ring Coating}

HVOF WC-12\% Co (TMT) APS Boron Carbide APS Cr203-50\%A1203

APS Cr203-33\% stell APS MO-Ni Boride Diffusion APS MO-MOO2 HVOF $\mathrm{Cr} 3 \mathrm{C2}-20 \% \mathrm{EP} \mathrm{Cr}_{\mathrm{Cr}}$ APS ZTY APS Armacor T APS Al2O3-41\%Zro?

LTAVD Ta2N HVOF NiCrBSi

LPPS Ferrotic CS40 APS $\mathrm{Cr}$

APS Cr203 (BIRL) APS Tribolite

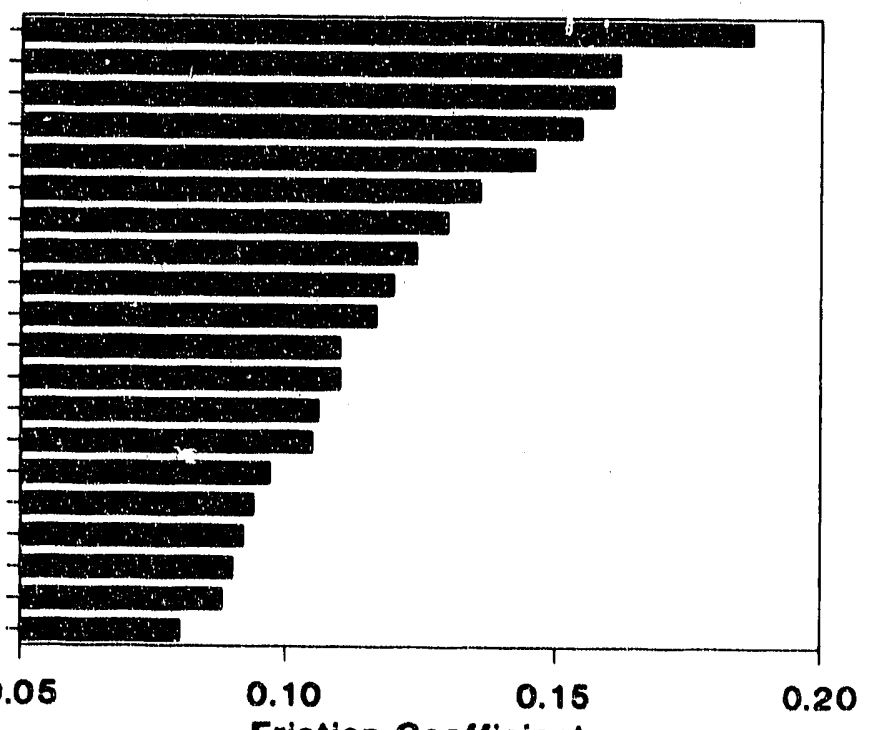

Friction Coofficient

Figure 94. Friction coefficients for $350^{\circ} \mathrm{C}$ fresh oil tests. 


\subsubsection{Hiah Temperatur L Wear Tests Whith A Synthatic Lubrican}

Tests were perfoimed with various coatings sliding against hardened $\mathrm{H} 13$ tool steel at $450^{\circ} \mathrm{C}$ with a poly-alpha-olefin (PAO) base stock as the lubricant, in order to demonstrate the potential for extremely high temperature tribological systems using a synthetic lubricant. The viscosity of the PAO was relatively high: $39 \mathrm{cSt}$ at $100^{\circ} \mathrm{C}$, compared to $14 \mathrm{CSt}$ at $100^{\circ} \mathrm{C}$ for the $15 \mathrm{~W} 40$ lubricant used for other tests. The benefits of higher viscosity are greater oll film thickness and, usually, greater oxidation resistance and lower volatility. For engine use, the major disadvantages would be poor filidity at low temperatures and excessive deposits at high temperatures.

Three coatings were tested at $450^{\circ} \mathrm{C}$ : HVOF $\mathrm{Cr}_{3} \mathrm{C}_{2}-\mathrm{NiCr}, \mathrm{APS} \mathrm{Cr}_{2} \mathrm{O}_{3}$ and APS $\mathrm{Al}_{2} \mathrm{O}_{3}-41 \% 2 \mathrm{ZrO}$. During several of these tests, the oll film periodically underwent spontaneous combustion due to the high test temperature. Despite this, low friction coeficients were maintained throughout the tests (Table 28). Wear coefficients were much higher than for 200 and $350^{\circ} \mathrm{C}$ tests, but low compared to umlubricated values. The ceramic coatings were slightly more wear resistent than the cermet material at this temperature, the $\mathrm{Cr}_{2} \mathrm{O}_{3}$ material showing the lowest wear cotficient (Figure 95). At lower temperatures, with a fully formulated mineral oll lubricant, the HVOF $\mathrm{Cr}_{3} \mathrm{C}_{2}-\mathrm{l}$-fiCr coating showed greater wear resistance than either Ceramic material (Figures 89 and 90).

Table 28. Friction coefficients for various piston ring coatings sliding against hardened H13 tool steel at $450^{\circ} \mathrm{C}$. Tests were run with unformulated poly-alpha-olefin lubricant.

\begin{tabular}{|l|l|c|}
\hline Ring Coating & Liner Material & $\begin{array}{c}\text { Friction } \\
\text { Coefficient }\end{array}$ \\
\hline HVOF $\mathrm{Cr}_{3} \mathrm{C}_{2}-20 \% \mathrm{NiCr}$ (UTRC) & H13 Tool Steel & 0.17 \\
\hline APS Al $\mathrm{O}_{3}-41 \% \mathrm{ZO}_{2}$ & H13 Tool Steel & 0.12 \\
\hline APS $\mathrm{Cr}_{2} \mathrm{O}_{3}$ (BIRL) & H13 Tool Steel & 0.10 \\
\hline
\end{tabular}




\section{WEAR COEFFICIENTS AT $450^{\circ} \mathrm{C}$ PAO BASESTOCK \\ H13 Tool Steel Liner}

\section{Ring Coating}

HVOF Cr3C2-20\% NiCr

APS A12O3-41\% ZrO2

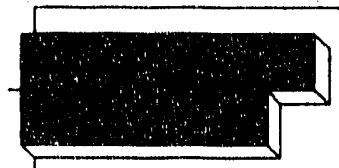

APS Cr203
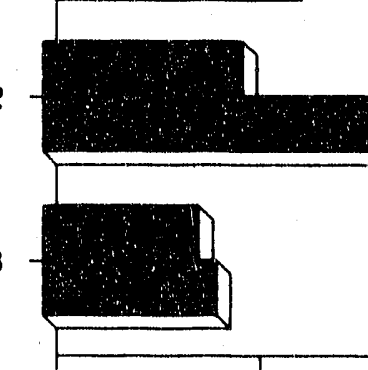

$0.0 E+00$

1.OE- 10

2.0E -10

3.OE-10

4.0E - 10

Wear Coeff $\left(\mathrm{mm}^{\wedge} 3 / \mathrm{mm} / \mathrm{N}\right)$

Ping Woar

Liner Wear

Figure 95. Wear coefficients for various coatings sliding against handened $\mathrm{H} 13$ tool stoel liners at $450^{\circ} \mathrm{C}$. Tests were run with unformulated poly-alpha-olefin lubricant. 
4.2 WEAR AS A FUNCTION OF TEMPERATURE (FRESH OIL)

\subsection{Piston Aing Coatina Wear}

Figure 96 shows the variation of wear coefficients whth temperature for electroplated hard chromium piston rings sliding against lubrited (manganese phosphate coated) pearlitic grey cast iron cylinder liners, lubricated with fresh CE/SF 15 W40 oll.

A reasonably grod fit to the observed variation of wear coefficient with temperature was obtained with an Arrhenius function of the form

$$
W=W_{0} \exp \left(-\frac{Q}{R T}\right) \text {. }
$$

where: $\quad W$ is the wear coefficient $\left(\mathrm{mm}^{3} / \mathrm{mm} / \mathrm{N}\right)$

$W_{0}$ is a constant whth the same dimensions as the wear coefficient $(\mathrm{mm} / \mathrm{mm} / \mathrm{N})$

$Q$ is an "activation energy" ( $\mathrm{J} \mathrm{\textrm {mol } ^ { - 1 } )}$

$A$ is the gas constant $\left(8.314 \mathrm{~J} \mathrm{~mol}^{-}(\mathrm{K}-1)\right.$

$T$ is the absolute teriperature (K).

"Actlvation energies" were determined to be $26.5 \mathrm{~kJ} \mathrm{~mol}^{-1}$ for the chromium plated rings and $15.6 \mathrm{~kJ} \mathrm{~mol}^{-1}$ for the lubrited pearlitic iron liners. The above analysis is empirical only, since wear coefficients are not true rate constants (dimensions $\mathbf{s}^{-1}$ ) and wear processes are probably stress-activated as well as thermally activated (perhaps more analogous to "power-law creep", If the rate of materlal loss is controlled by plastic deformation, for example). More detalled analysis would require a greater understanding of wear mechanisms for the tribological systems investigated, and is beyond the scope of this study. In particular, we would like to be able to separate the effects of thermally induced changes in lubricant properties (e.g. viscosity; chemical reactivity with the surfaces) from materials properties (e.g. hardness, oxidation rate).

Figures 89 and 90 clearly show that wear coefficients increased markedly with increasing temperature lor all of the coating materials tested with grey iron counterfaces. Typically, wear coefficients increased by almost an order of magnitude between 200 and $350^{\circ} \mathrm{C}$. For the purpose of comparing the temperature sensitivities of wear coefficients, Arrhenius equations were fitted to wear data obtained for several metallic, ceramic and cermet coatings (Figures 97 - 99). This is an extrapolation through only two temperature points, so the analysis should be viewed with caution.

For the metallic coatings shown in Figure 97 , the extrapolated fitting curves were relatively parallel, with "activation energles" falling in the range $25-45 \mathrm{~kJ} \mathrm{~mol}^{-1}$. Thus, ranking materials in order of decreasing wear coefficients produced broadly similar results at 200 and $350^{\circ} \mathrm{C}$ (Figures 89 and 90 ).

The ceramic coatings showed a much greater range of wear coefficlents (Figure 98), although the "activation energles" were mostly in the same range as for the metallic coatings. One exception was the boron carbide coating, which essentially showed no variation of wear coefficient with temperature. For this coating, it is speculated that the wear process was dominated by fracture of the highly porous material.

The cermet coatings showed two kinds of behavior (Figure 99). The HVOF WC - Co and $\mathrm{Cr}_{3} \mathrm{C}_{2}-\mathrm{NiCr}$ coatings showed relatively small changes in wear coefficient with temperature (activation energies 18.4 and $24.3 \mathrm{~kJ} \mathrm{~mol}^{-1}$, respectively). while the ferro-Tic coatings all showed a greater temperature dependency $\left(47.51 \mathrm{~kJ} \mathrm{~mol}^{-1}\right)$. It is speculated that wear of the Ferro-Tic materials was controlled by the wear of the ceramic pinase at low temperatures, but by the softening/wear of the metallic binder phases at high temperatures. The $\mathrm{Cr}_{2} \mathrm{O}_{3}$-Stellite curve was essentially parallel to the curve for $\mathrm{Cr}_{2} \mathrm{O}_{3}$ in Figure 98 .

Air interesting observation was that plasma sprayed $\mathrm{Cr}_{2} \mathrm{O}_{3}$ slid ag against slurry-sprayed silica chromia - alumina (iresh oil lubricated) showed no variation of wear coefficient with temperature for either material (Figure 100). This observation suggests that the form of the temperature dependence of wear for the ring coating is influenced by the liner material. For example, with pearlitic grey cast iron liner materials, wear of the ring coating may be controlled by the amount of corrosive wear debris (e.g. oxide) generated by the liner rather than (or, perhaps, in addition to) abrasion by the hard phases present in the cast iron (e.g. F $e_{3} \mathrm{C}$ or other alloy carbides). With a $\mathrm{Cr}_{2} \mathrm{O}_{3}$-based liner material, liner oxidation would obviously not be a factor. However, understanding of the materials interactions on the temperature sensitivity of wear must await more detailed understanding of wear mechanisms for these systems. 


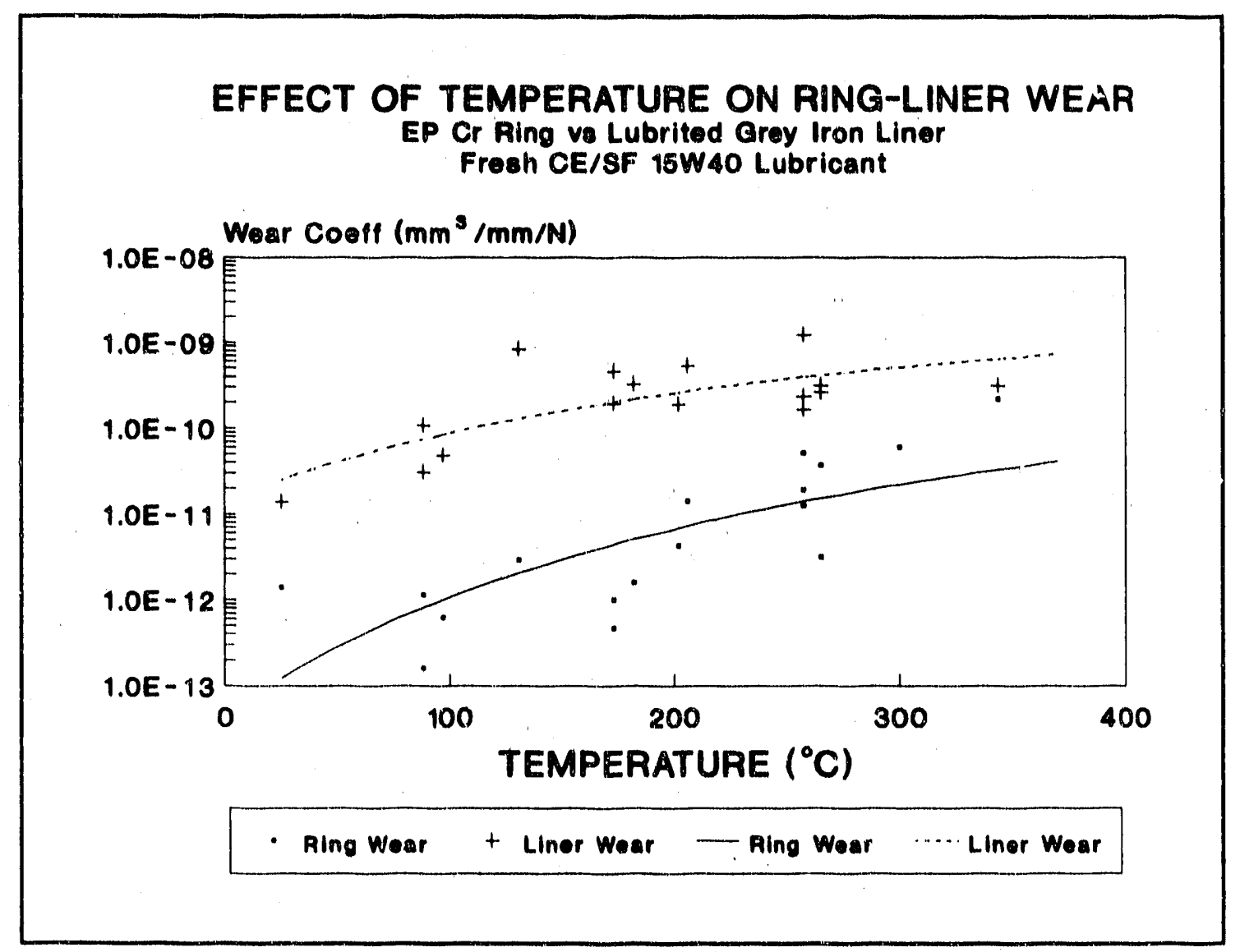

Figure 96. Variation of wear coefficients with temperature for the baseline system: electroplated hard chromium rings and lubrited (manganese phosphate coated) pearlitic grey cast iron liners. Tests were run with fresh oil. 


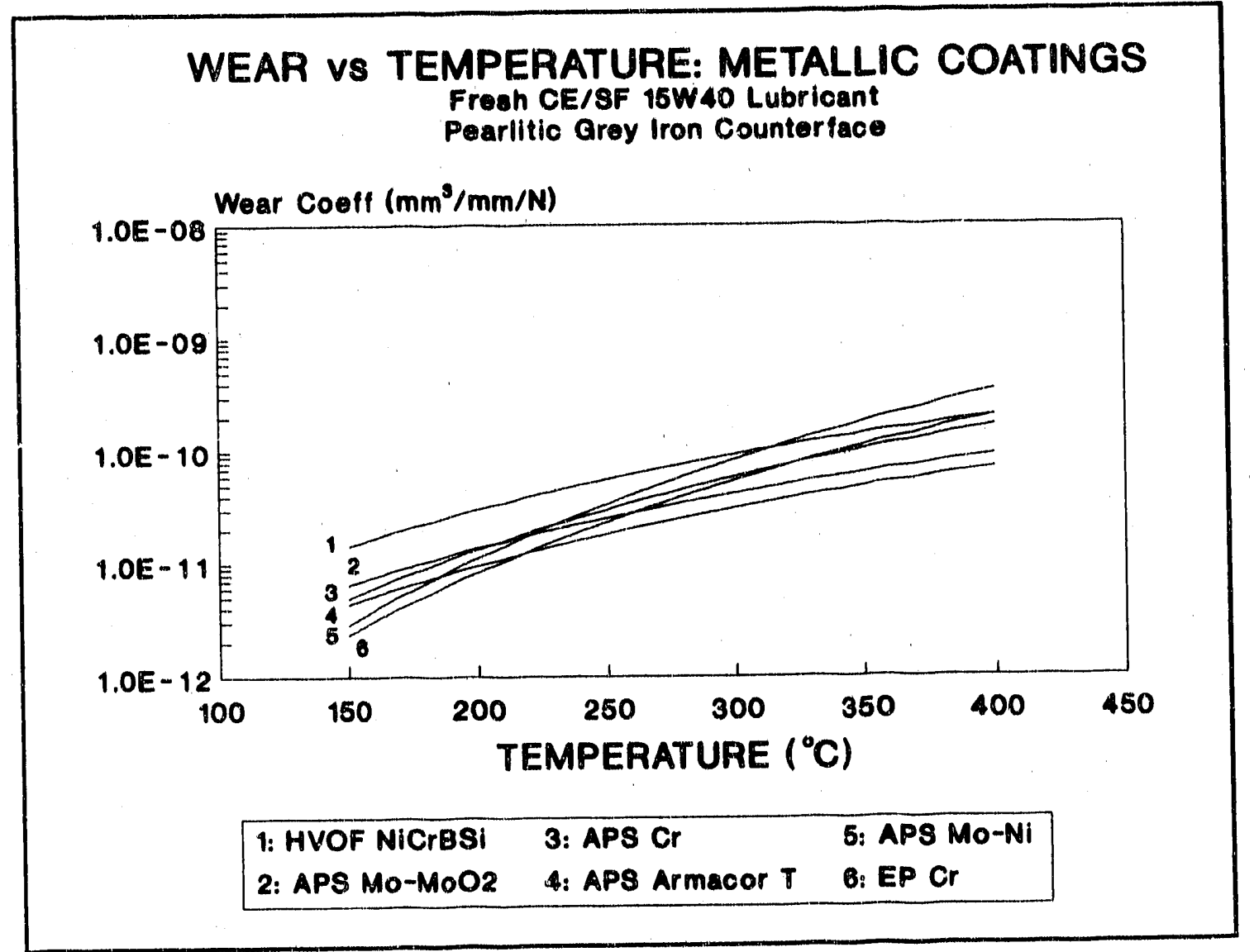

Figure 97. Extrapolated variation of wear coefficients with temperature for metallic coatings sliding against uncoated pearlitic grey cast iron liners. Tests were run with fresh oil. 


\section{WEAR vS TEMPERATURE: CERAMIC COATINGS Fresh CE/SF 15 W40 Lubricant Pearlitic Grey Iron Counterface}

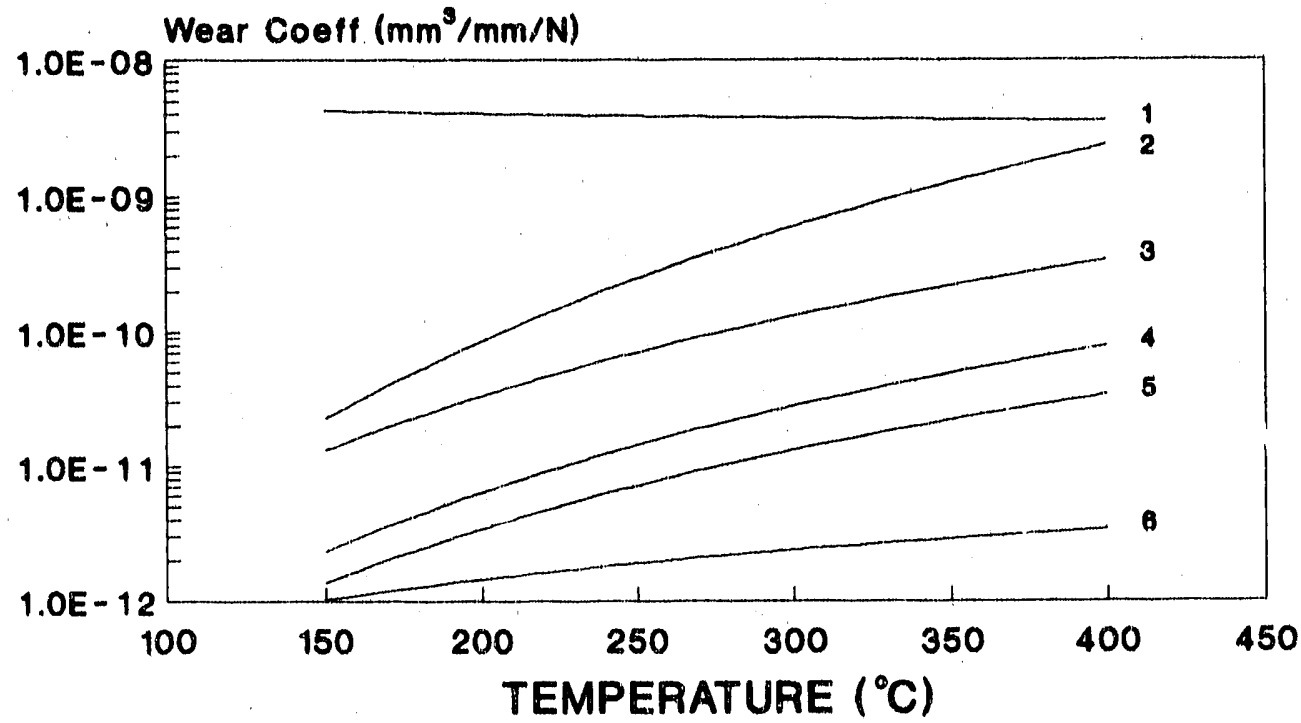

\begin{tabular}{|lll|}
\hline 1: APS B4C & 3: PVD Ta2N & 5: APS Cr2O3 \\
2: APS ZTY & 4: Al2O3-41\%ZrO2 & 6: PVD CrN \\
\hline
\end{tabular}

Figure 98. Extrapolated variation of wear coefficients with temperature for ceramic coatings sliding against uncoated pearlitic grey cast iron liners. Tests were run with fresh oll. 


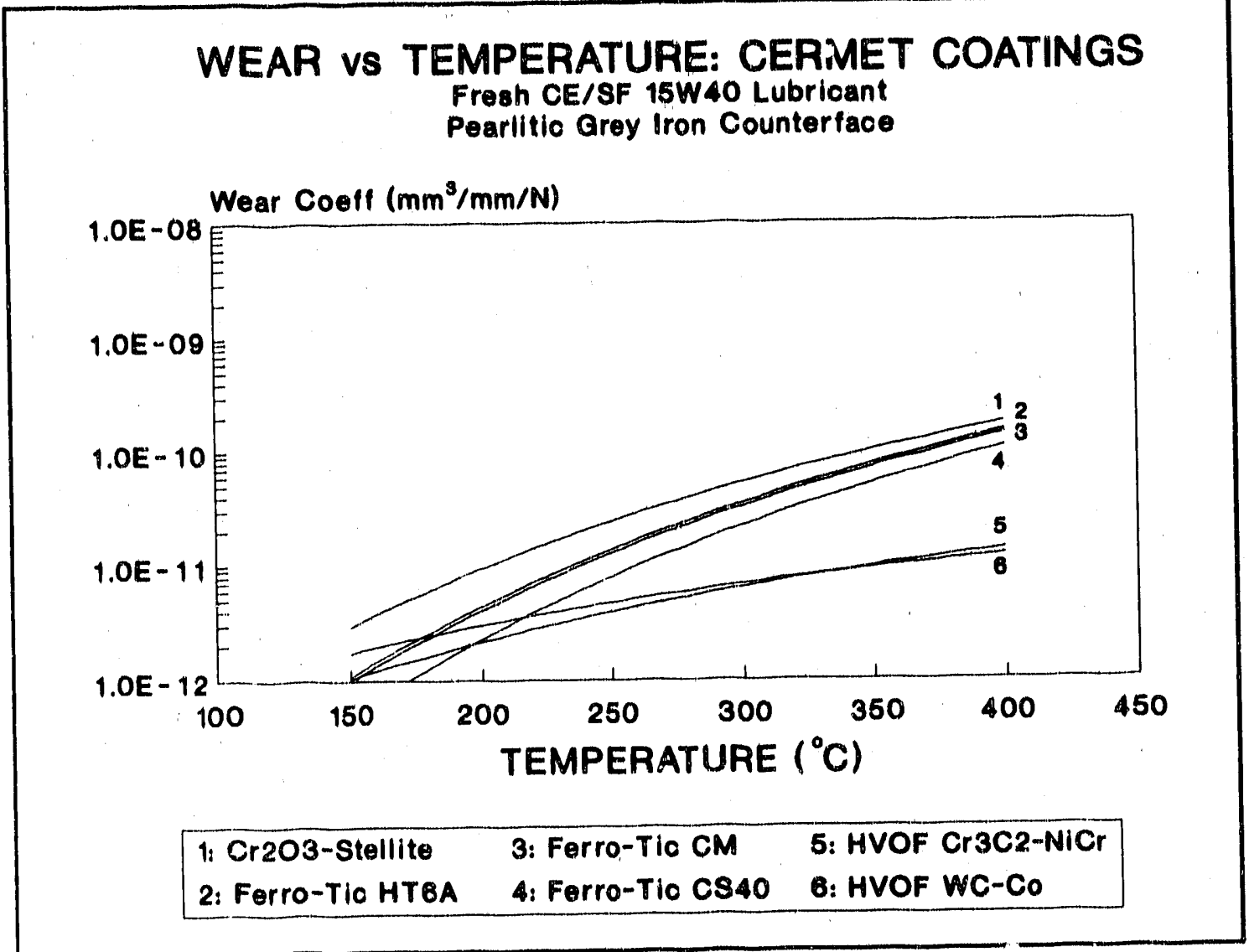

Figure 99. Extrapolated variation of wear coefficients with femperature for cermet coatings sliding against uncoated pearlitic grey cast iron liners. Tests were run with fresh oil. 


\section{WEAR OF APS $\mathrm{Cr}_{2} \mathrm{O}_{3}$ vs SCA} Fresh CE/8F 15W40 Minoral Oll

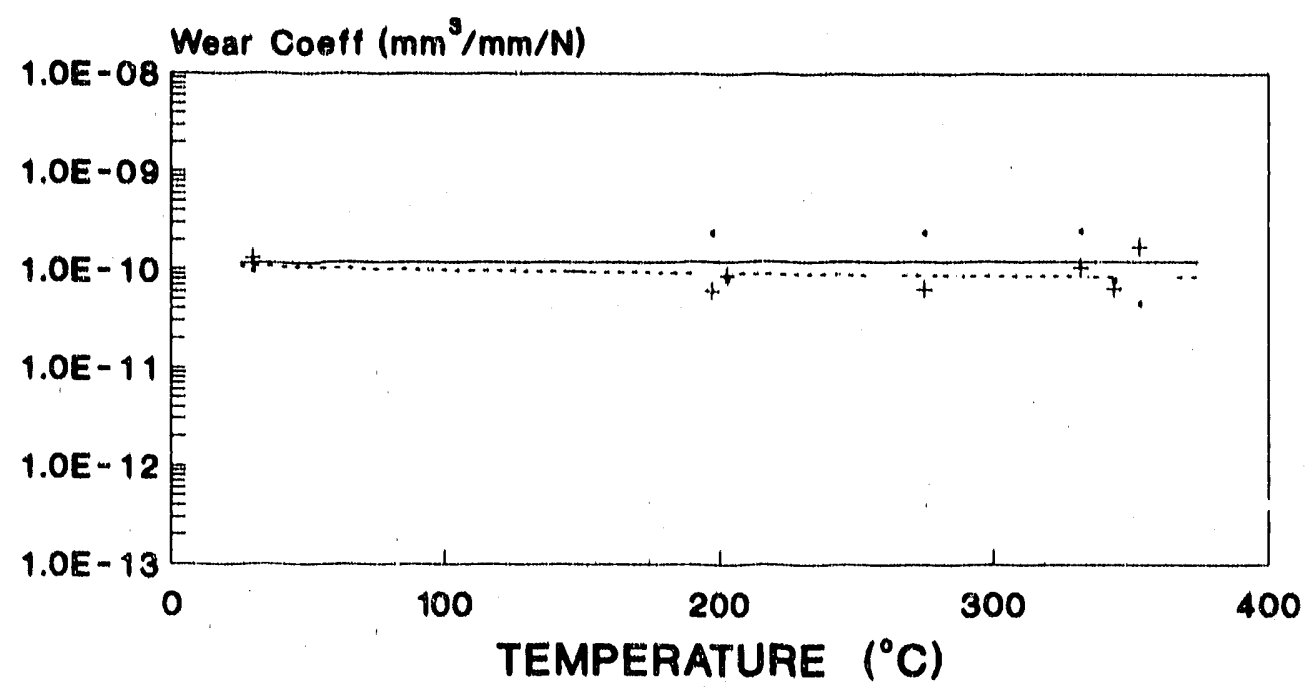

\begin{tabular}{|c|c|c|}
\hline- & APS Cr2O3 Ring & … SCA LIner \\
\hline • & APS Cr2OS Hing & + SCA Liner \\
\hline
\end{tabular}

Figure 100. Variation of wear coefficients with temperature for APS chromium oxide (APS Materials UCAR and Boyd materials) sliding against slurry-sprayed silica-chromia-alumina liner coatings. Tests were run with fresh oll. 


\section{2 .2 Cyllinder Liner Wear}

The temperature sensitivity of lubricated wear coefficients for non-lubrited pearlitic grey iron cylinder liners is shown in Figures 101 (metallic and cerrnet ring coatings) and 102. (ceramic coatings). For metallic and cermet coatings, the liner wear showed a similar form of temperature dependence to the coating wear. Activation energies were typlcally in the range $40-70 \mathrm{~kJ} \mathrm{~mol}^{-1}$, averaging approximately $55 \mathrm{kJmol}^{-1}$, slightly higher than for the coatings. The APS Mo-Ni coating produced an anomalously high temperature sensitivity of liner wear (Flgure 101).

The similarity of activation energles for both sllding surfaces indicates that the wear processes may be controlled by a common mechanism (e.g. both surfaces undergoing corrosive wear), or that the wear of one surface is controlled by thie rate of wear of the other (e.g. abrasive wear of the coating controlled by the rate of oxidative wear of the liner).

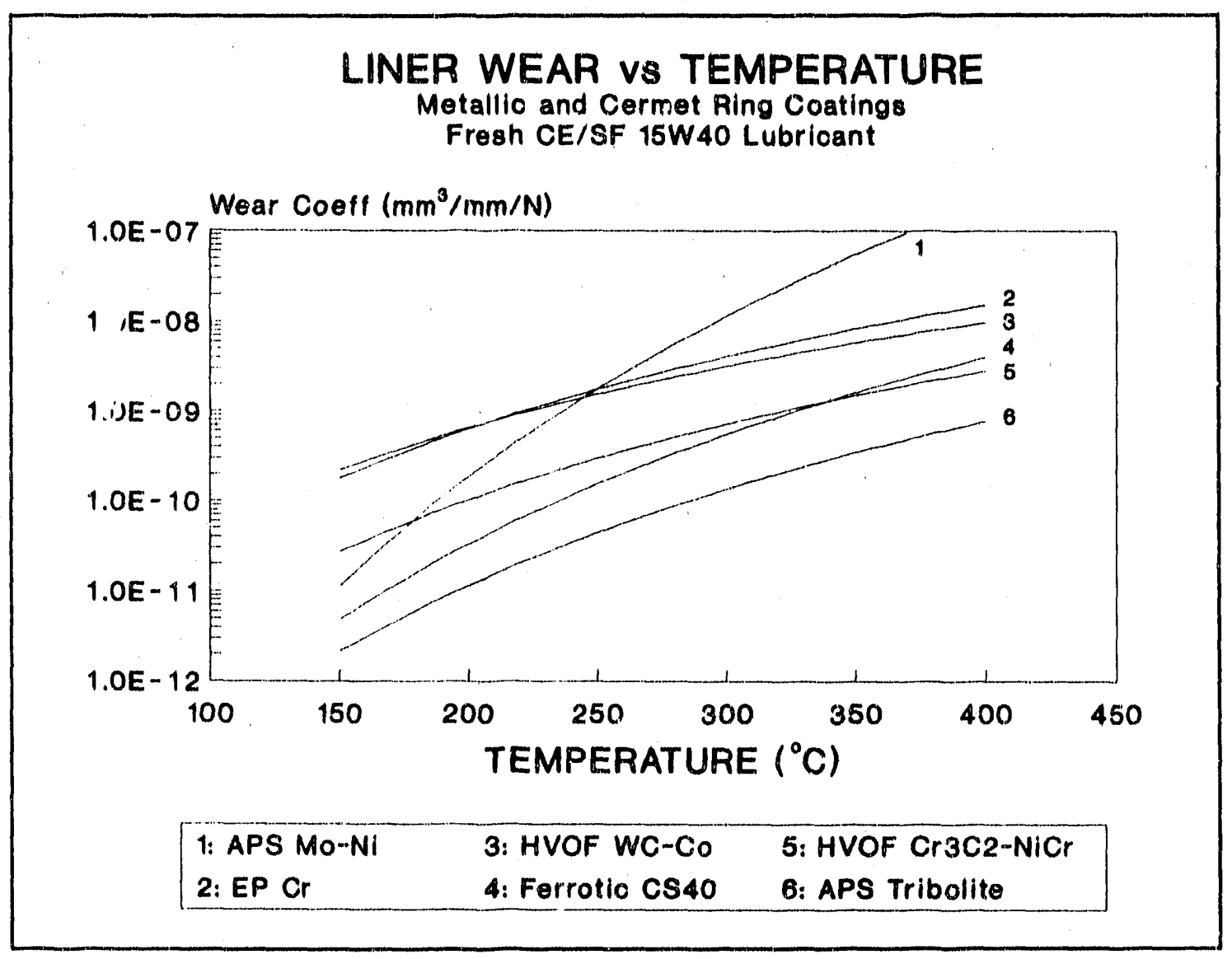

Figure 101. Variation of wear coefficients with temperature for pearlitic grey cast iron cylinder liner material tested against various metallic and cermet coatings with fresh oll. 


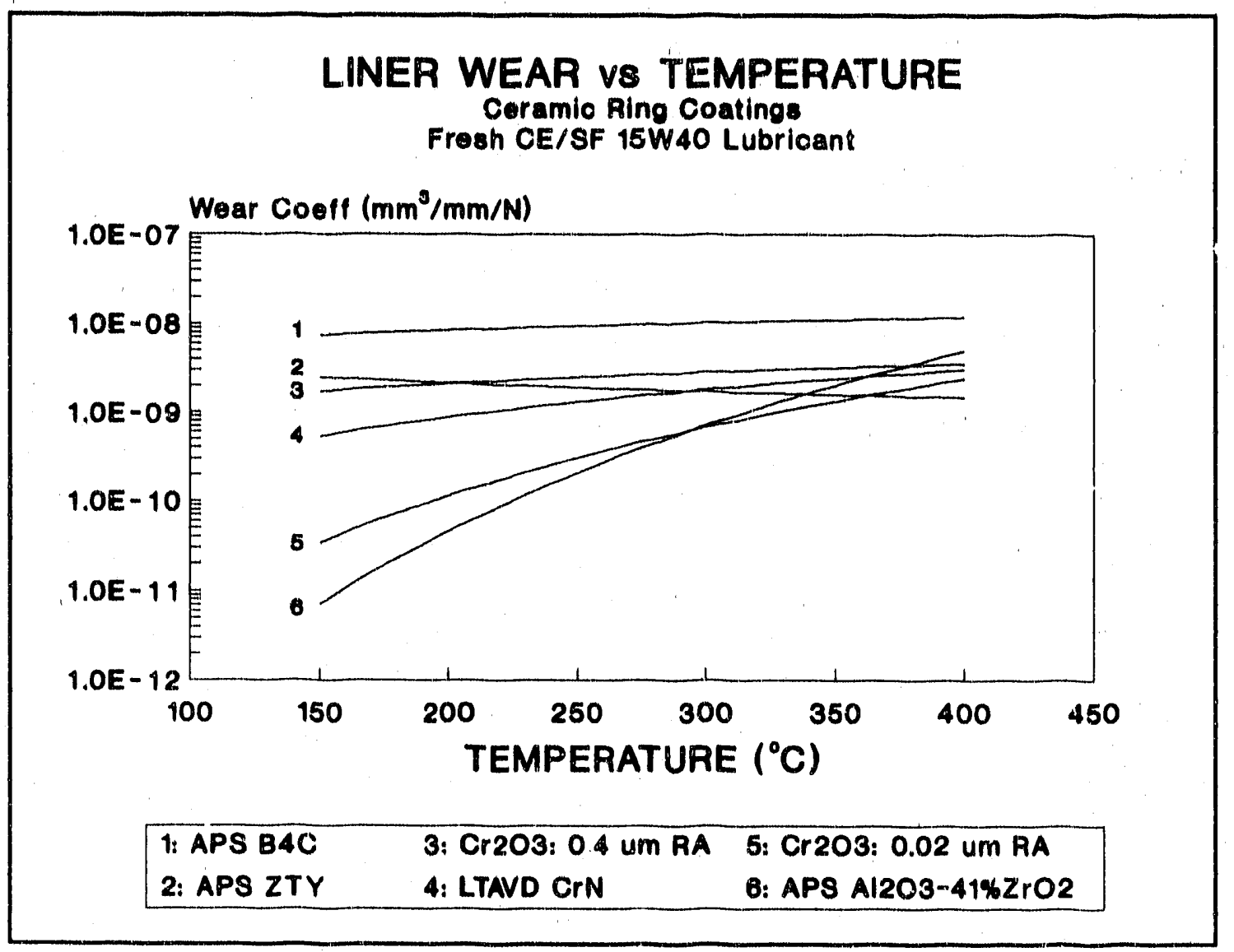

Figure 102. variation of wear coefficients with temperature for pearlitic grey cast iron cyllinder liner material tested against various ceramic coatings with fresh oil.

The ceramic coatings showed much greater diversity in the temperature sensitivity of liner wear (Figure 102), activation energies ranging from -5 to $62 \mathrm{kJmol}^{-1}$. Data is included for a lapped plasma sprayed chromlum oxide (activation energy for liner wear: $40.3 \mathrm{kJmol}^{-1}$ ) and the same coating abraded with 320 \# SIC paper to a coarser surface finish (activation energy for liner wear: $6.8 \mathrm{kJmol}^{-1}$ ). Increasing surface roughness thus appears to decrease the temperature sensitivity of liner wear, perhaps due to an increased contribution of mechanical abrasion processes. The ZTY and boron carbide coatings, which gave almost flat liner wear curves, tended to give fragmented wear surfaces which may have maintained a high degree of abrasive wear throughout the tests. The LTAVD coatings, which had somewhat high surface roughness due to the presence of macroparticles, both gave intermediate liner wear activation energies of $16.4 \mathrm{kJmol}^{-1}$. The lapped $\mathrm{Al}_{2} \mathrm{O}_{3}-\mathrm{ZrO}_{2}$ coatings gave values of 40 and $62 \mathrm{kJmol}^{-1}$. 


\subsection{RESULTS USING HIGH-SOOT, ENGINE-TESTED LUBRICANT}

Bench wear tests conducted with engine-tested lubricants have estabilshed that: wear rates may be significantly increased compared to tests with fresh oll. The reasons for this behaviour have not been fully determined, however an important factor for diesel engines is the accumulation of conbustion-derived soot (typically $50-500 \mathrm{~nm}$ sized particles of microcrystalline carbon) in the lubricating oll [16]. Many hypotheses have been proposed to explain the "pro-wear" characteristics of soot, including removal of lubricant anti-wear films, chemical attack by species adsorbed on the soot particles and mechanical abrasion [e.g. 16 - 20]. Evidence for all these mechanisms is claimed in the literature, but there is currently no consensus of opinion as to which mechanisms: Tost important.

It is emphasized that the increases in wear ratus observed with used diesel engine olls are not necessarily all attributable to soot. Other contributing factors might include, for examiple, build-up of corrosive species (e.g. sulphuric acid, organic acids) in the oll, increasing levels of abrasive contaminants not removed by the of fther and depletion of antl-wear additwes. The mechanisms by which wear rates are increased may perhaps also depend on the silding materials. However, Falex 1 block on ring wear experiments at Cummins have established that, for 52100 steel self-mated sliding wear couples at least, soot is the most likely cause of increased wear rates for used diesel oils [21]. This was determined by extracting the soof from a used oll by means of high-speed centrifugation for inany hours and verifying that wear rates of the centrifuged oll were the same as for the fresh oll. If was also verified that the centrifugation process removed soot without changing the additive metal content of the oil slignificantly. In view of the lengthy test matrix, and the difficulty of removing soot from large quantities of oil in a reasonable time, no attempts were made to repeat this experiment for coatings imvestigated in this program.

\subsubsection{Piston Ring Coatina Wear}

Wear coefficients measured for $200^{\circ} \mathrm{C}$ tests with the high-soot, engine-tested CE/SF isW40 lubricant described previously are shown in Figure 103. Comparing Figures 103 (3.3\% soot) and 89 (fresh oil), it is apparent that most of the coatings evaluated showed higher wear rales with high-soot, engine-tested oil than with fresh oll, with increases of more than a factor of ten in some cases. Wide variations in the sensitivity to degraded, soot-loaded oll were observed, and sio it is important to take these effects into account when evaluating materials for diesel engine applications.

Metallic coatings were generally found to show dramatically accelerated wear in high-scot oil, whereas ceramic and cermet coatings showed only modest increases. For example, woar rates for electroplated chromium were approximately sixteen times higher with used oll than with fresh, whereas chromium oxide coatings were subject to only a twofold increase on average. For used oll, the only coatings with wear coefficients less than $2 \times 10^{-11} \mathrm{~mm}^{3} / \mathrm{mm} / \mathrm{N}$ were ceramic and cermet materials (Figure 103). Thus, decreased "scot sensitivity" is a significant driving force for utilizing ceramil: and cermet coatings in diesel engine wear ervironments.

The best coatings for resistance to soot/oll degradation were plasma sprayed chromium oxide and LTAVD CrN, both ceramic coatings. Cermet coatings such as the $\mathrm{Cr}_{3} \mathrm{C}_{2}-20 \% \mathrm{NiCr}$, WC $-12 \%$ Co and Ferro-Tic materials also performed extremely well in these tests. 


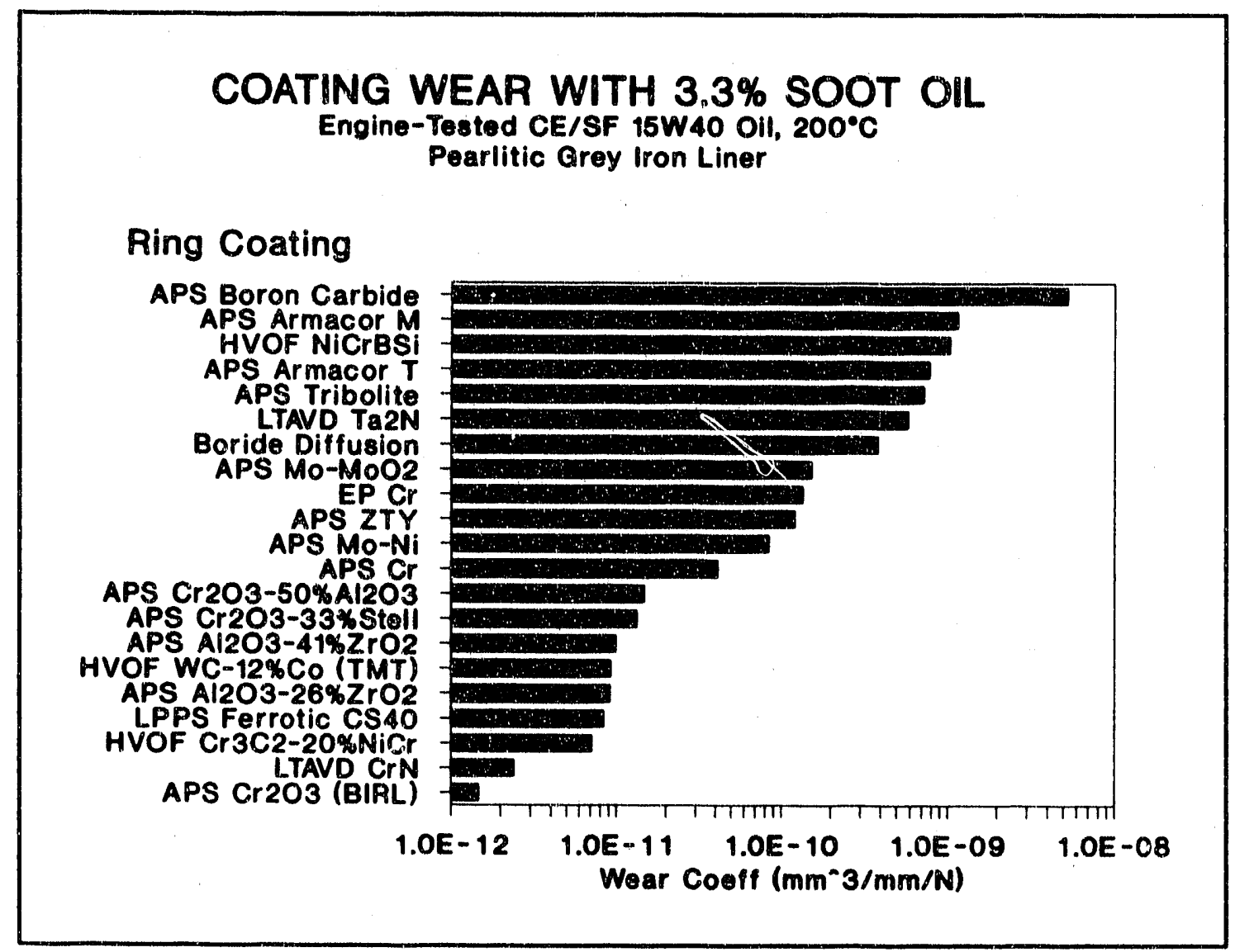

Figure 103. Wear coefficients for various coatings sliding against pearlitic groy iron liners. Tests were run with $3.3 \%$ soot, engine-tested oll at $200{ }^{\circ} \mathrm{C}$. 


\subsubsection{Cylinder Liner Wear}

Wear coefficients for pearlitic grey casi iron cyllinder liners tested against various coatings with high-soot, engine-tested ol are shown in Figure 104. Comparing Figure 104 with Figure 91 (fresh oll, $200^{\circ} \mathrm{C}$ ), it is apparent that liner woar rates generally increased with high-soot, degraded oll, as for the coatings. However, for some coatings, such as the WC - 12\% Co materlals, liner wear increased very little compared to fresh oll values; for other materials, such as the UTRC HVOF $\mathrm{Cr}_{3} \mathrm{C}_{2}-\mathrm{NiCr}$, wear rates increased substantially (by up to an order of magnitude). The BIRL plasma sprayed chromlum oxide gave the lowest liner wear in these tests, but it should be pointed out that other chromium oxides, which were not lapped to the same excellent surface finish, tended to give much higher liner wear (section 5.5.1). In general, there was little correlation between liner wear with fresh and used olls.

\section{CYLINDER LINER WEAR WITH 3.3\% SOOT OIL Engine-Tested CE/SF $15 W 40$ Oil, $200^{\circ} \mathrm{C}$ Pearlitic Grey Iron Liner}

\section{Ring Coating}

LTAVD Ta2N

APS Boron Carbide

APS Cr203-33\% Stell

LTAVD CrN

APS Armacor 7

HVOF $\mathrm{Cr} 3 \mathrm{C2}-20 \% \mathrm{NiCr}$

APS Armacor $M$

APS $\mathrm{Cr}$

Boride Diffusion EP Cr

LPPS Ferrotic CS40

APS A1203-41\%2rO2

APS MO-NI

APS Mo-MoO?

APS A1203-26\%ZrO2

APS ZTY

APS Tribolite

HVOF WC-12\%Co (TMT)

APS Cr203-50\%Al203

HVOF NiCrBS

APS Cr2O3 (BIRL)

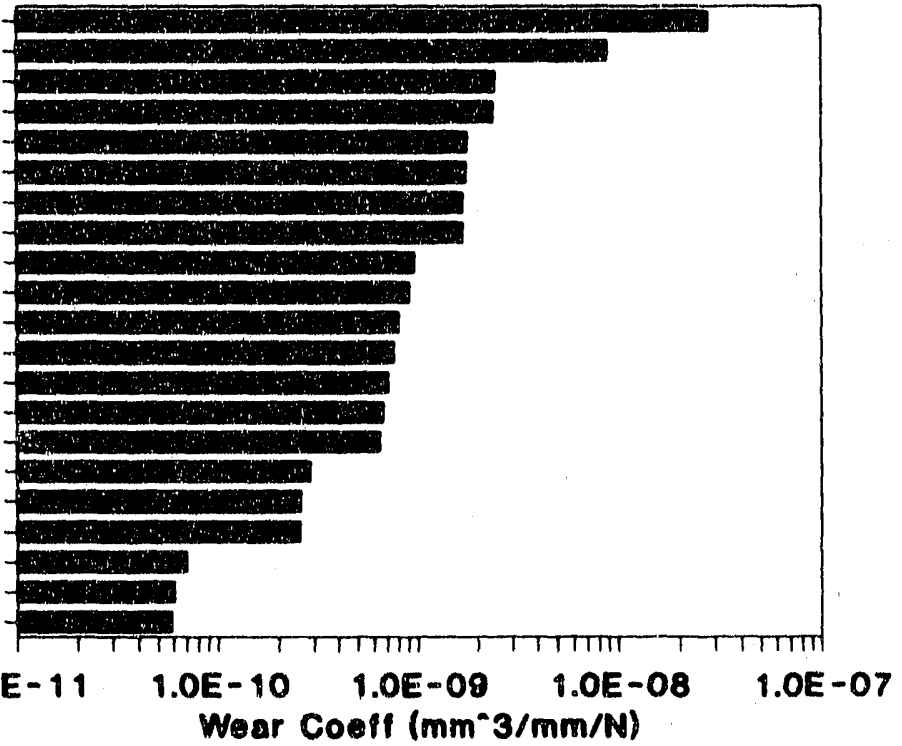

Figure 104. Wear coefficients for pearlitic groy iron liners tested against various ring coatings. Tests were run with $3.3 \%$ soot, engine-iested oll at $200 \mathrm{C}$. 


\subsubsection{Friction Coefficients}

Friction coefficients for the high-soot oll tests are shown in Figure 105. Compared with fresh oll data for the same test temparature (Figure 93), the high-soot oll friction values showed slightly more dependence on materials, friction coefficients ranging from approximately 0.08 to 0.15 . Some materials showed lower friction with high-soot oll; others showed higher friction. Ranking the materials in order of decreasing friction produced a different order for the high-soot tests than for fresh oll tests (at elther temperature). A general result for both fresh and high-soot oll tests was that no correlation between friction and wear could be found. Again, explanation of these results must await further clarification of the mechanisms of friction and wear for these systems. For these tests, it is interesting that the three lowest friction materials $\left(\mathrm{Cr}_{2} \mathrm{O}_{3}\right.$, WC $-12 \%$ Co and $\left.\mathrm{A}_{2} \mathrm{O}_{3}-26 \% \mathrm{ZrO}_{2}\right)$ also gave low wear.

\section{FRICTION COEFFICIENTS WITH 3.3\% SOOT OIL Engine-Tested CE/SF $15 \mathrm{~W} 40$ Oil, $200^{\circ} \mathrm{C}$ Pearlitic Grey Iron Liner}

\section{Ring Coating}

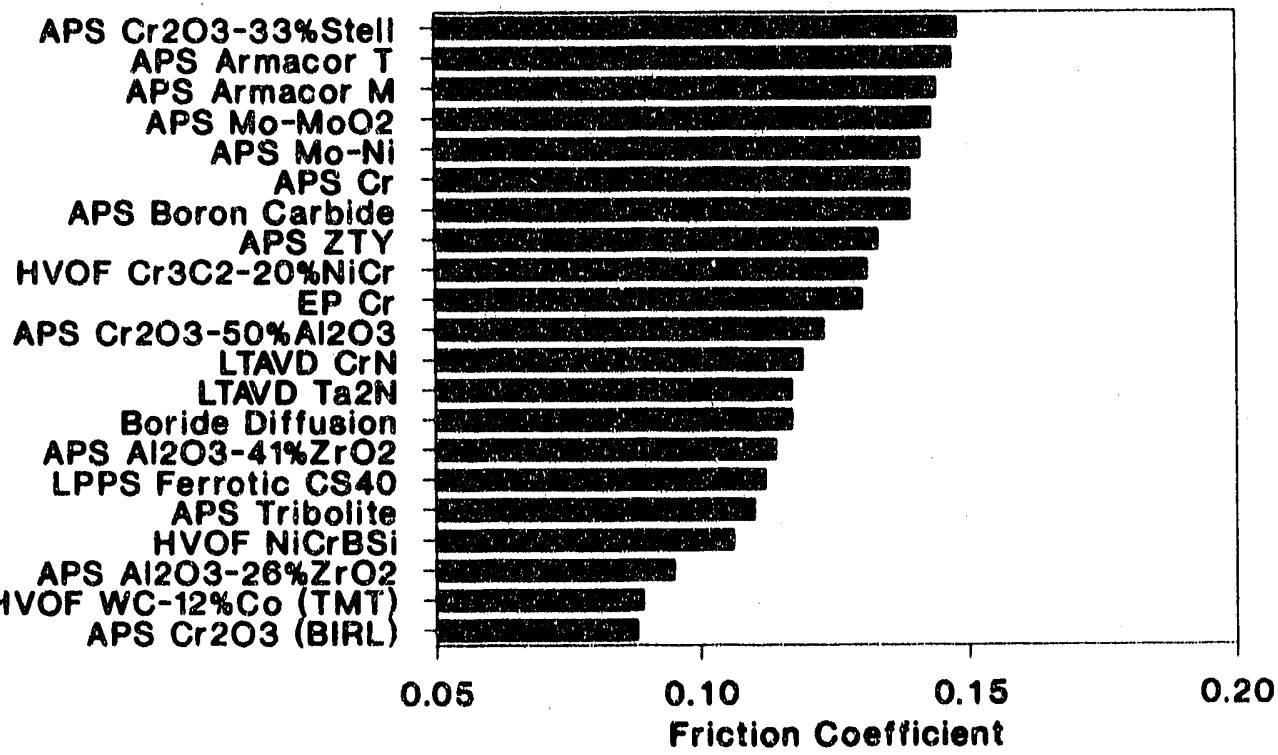

Figure 105. Friction coefficients for $2000^{\circ} \mathrm{C}$ high-soot oll tests. 


\subsection{UNLUBRICATED WEAR TEST RESULTS}

\subsubsection{Piston Bino Coating Wear}

Wear data for unlubricated tests at $200^{\circ} \mathrm{C}$ are shown In Figure 106. All tests were conducted with a pearlitic grey iron "liner" counterface and were of five minute duration. Unlubricated wear coefficlents were typically two to four orders of magnitude higher than for lubricated tests. None of the coatings evaluated would provide sufficiently low wear coefficlents to provide acceptable engine durability without lubrication. Generally, there was little correlation between lubricated and unlubricated wear values.

These tests operated in a "severe wear" regime, with the cast Iron liner material producing large amounts of oxide debris which transferred to the coating surface and would presumably have created three-body abrasive wear conditions for both ring and liner surfaces. Many of the ceramic coatings showed evidence of local fracture and spallation in these tests: evidence of high asperity contact stresses.

One of the objectives of the uniubricated tests was to evaluate "scuff resistance", which is here taken to mean the tendency of a material to show severe adhestve wear (material transfer) under conditions of temporary loss of oll film. Litterature on commercial piston ring coatings suggests that scuff resistance is not necessarily related to wear resistance under well-lubricated conditions [4]. For example, engine test experience suggests that Mo-based ring coatings are more scuff resistant than electroplated chromium (EP Cr) under severe operating conditions, but EP $\mathrm{Cr}$ shows slightly better wear resistance under well lubricated conditions. The data obtained in this program (Figure 106) showed the uniubricated wear resistance of EP $\mathrm{Cr}$ to be intermediate between that of $\mathrm{Mo}-\mathrm{NI}$ and Mo - MoO 2 coatings. For fresh oll lubricated tests at $200^{\circ} \mathrm{C}$, EP Cr showed lower wear than elther of the Mo-based coatings. Thus, there is at least a partial correlation between the unlubricated test data and engine experience.

Figure 106 shows that the best materials for scuff resistance were ceramic coatings: chromium oxide and the two alumina - zirconia materials. However, not all the ceramic coatings showed low wear in these tests, since the ZTY and $\mathrm{Cr}_{2} \mathrm{O}_{3}-50 \% \mathrm{Al}_{2} \mathrm{O}_{3}$ coatings gave the highest wear. Wear surfaces of these latter two coatings showed evidence of spallation and fracture, which may have been caused by the high degree of inter-splat microcracking observed in both materials. The BIRL chromium oxide and alumina zirconia coatings contained much less microcracking, and exhibited less fracture on the unlubricrated wear surfaces (Appendix AB).

The performance of the BIRL chromium oxide in these tests was spectacular, since the wear rate was approximately an order of magnitude lower than for the next best material. Abrading the surface of this coating with 320 \# SiC paper prior to the test was found to cause a significantly higher wear coefficient of $1.32 \times 10^{-9} \mathrm{~mm} / \mathrm{mm} / \mathrm{N}$ (six times higher than for the lapped coating). This may indicate that a flaw-free surface provides the best wear resistance under fracture-controlled sliding conditions. However, even the abraded surface gave outstanding wear performance compared to other coatings.

The HVOF WC - Co and $\mathrm{Cr}_{3} \mathrm{C}_{2}$ - NiCr cermet materials showed low wear in these tests, but the Ferro-Tic coatings showed much higher wear rates, more typical of the metallic coatings. Thus, it appears that under severe test conditions $\left(350^{\circ} \mathrm{C}\right.$ lubricated and $\left.200^{\circ} \mathrm{C} \mathrm{dry}\right)$, scuffing and wear of the Ferro-fic materials is dominated by the properties of the metallic binder phase. Only in the $200^{\circ} \mathrm{C}$ lubricated tests were low wear coefficlents obtained with these materials.

The metallic coatings showed comparatively sinall differences in wear rates, the best coatings being the Mo $-\mathrm{MOO}_{2}$, Armacor, EP Cr and Mo - Ni materlals. 


\section{COATING WEAR WITHOUT LUBAICATION $200^{\circ} \mathrm{C}$ \\ Pearlitic Grey Iron Liner}

\section{Ring Coating}

APS ZTY

APS Cr203-50\%A1203

Boride Diffusion HVOF NICrBSi

LTAVD Ta2N

APS Cr

APS Tribolite

APS MO-Ni

LPPS Ferrotic CS40

EP Cr

APS Armacor M

APS Armacor T

APS Cr203-33\%stell

APS MO-MOO2

LTAVD CrN

HVOF Cr3C2-20\%NICr

HVOF WC-12\% Co (TMT)

APS Al203-41\% ZrO2

APS AI2O3-26\%ZrO2

APS Cr2O3 (BIRL)

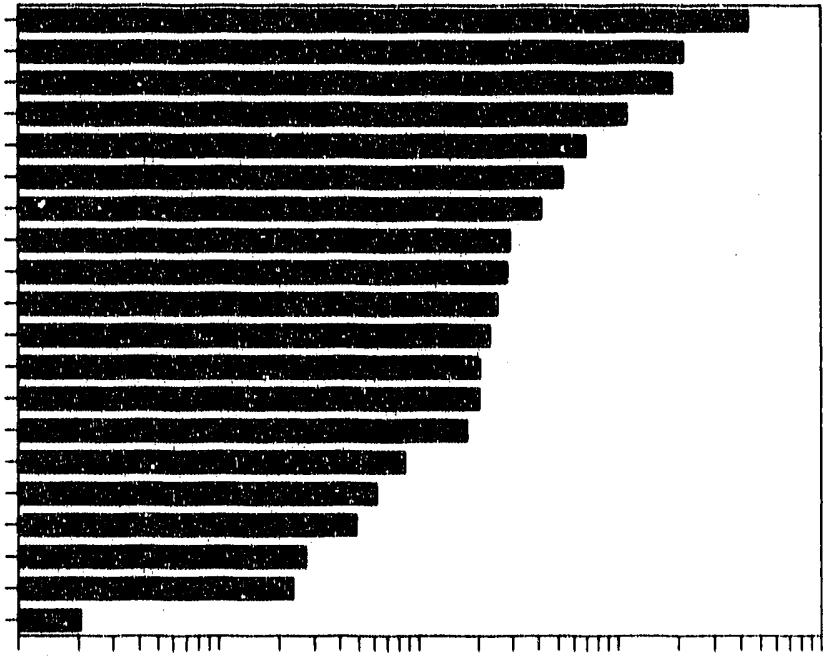

1.0E- $10 \quad \begin{gathered}1.0 E-09 \quad 1.0 E-08 \quad 1.0 E-07 \\ \text { Wear Cooff }\left(\mathrm{mm}^{\wedge} 3 / \mathrm{mm} / \mathrm{N}\right)\end{gathered}$

Figure 106. Wear coefficients for various coatings sliding against pearlitic grey iron liners. Tests run with no lubrication at $2000^{\circ} \mathrm{C}$. 


\subsubsection{Cylinder Liner Wear}

Unlubricated wear coefficients for the pearlitic grey cast iron liner counterfaces showed comparatively little sensitivity to the coating materlal in these tests (Figure 107), the wear coefficlents varying by approximately one order of magnitude from best to worst case. For fresh oll lubricated tests at $200^{\circ} \mathrm{C}$, the variation was approximately three orders of magnitude (Figure 91). The lowest liner wear rates were obtained for the four most wear resistant ceramic coatings: $A P S \mathrm{Cr}_{2} \mathrm{O}_{3}, \mathrm{Al}_{2} \mathrm{O}_{3}-26 \% \mathrm{ZrO}_{2}$, LTAVD $\mathrm{CrN}$ and $\mathrm{Al}_{2} \mathrm{O}_{3}-41 \% \mathrm{ZrO}_{2}$. Thus, for unlubricated conditions, a variety of coatings are avallable which provide comparatively low ring and liner wear.

\section{CYLINDER LINER WEAR WITHOUT LUBRICATION $200^{\circ} \mathrm{C}$ \\ Pearlitio Grey Iron Liner}

\section{Ring Coating}

Boride Diffusion APS MO-Ni LTAVD Ta2N HVOF NICrBS APS ZTY

APS MO-MOO2 APS Tribolite APS Armacor T

HVOF WC-12\% CO (TMT) APS Cr203-50\%Al203 APS Armacor $M$ HVOF Cr $3 \mathrm{C}_{2}-20 \% \mathrm{NICr}$ APS Cr2O3-33\% Stell

EP $\mathrm{Cr}$ APS $\mathrm{Cr}$

LPPS Ferrotic CS40 APS Al203-41\% Z LTAVD CrN APS Al203-26\% Z $\mathrm{rO}_{2}$ APS Cr2O3 (BIRL)

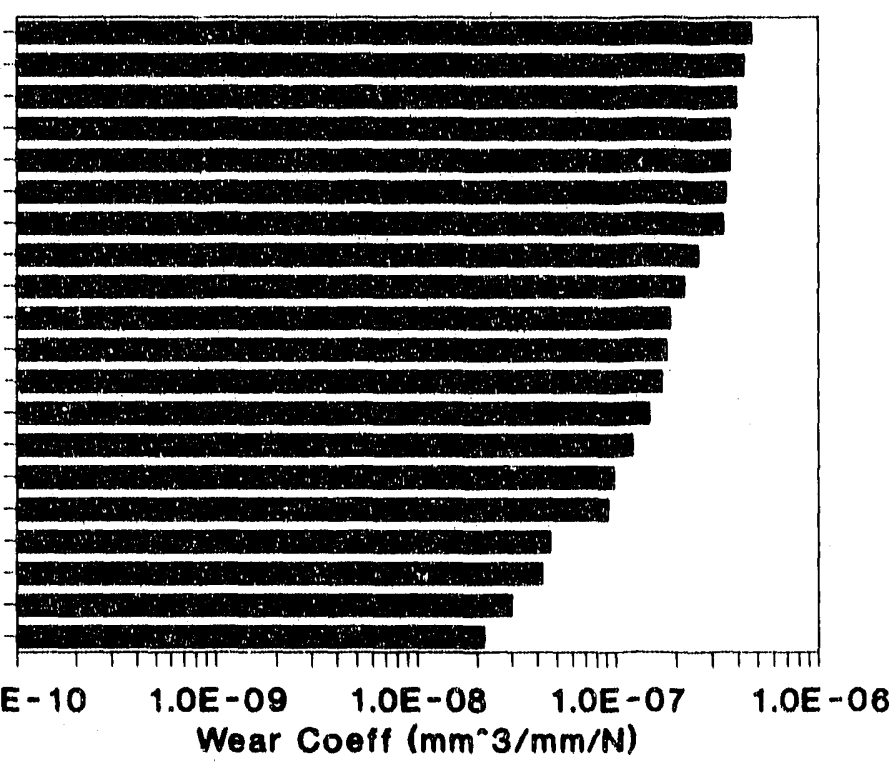

Figure 107. Wear coefficients for pearlitic grey iron liners tested against various ring coatings. Tests run with no lubrication at $200^{\circ} \mathrm{C}$. 


\subsubsection{Friotion Coefficients}

Friction coefficients for the unlubricated tests varied from approximately 0.4 to 0.7 for the range of materials investigated (Figure 108). There was ittlle correlation between lubricated and unlubricated friction values, or between dry friction and dry wear coefficients. Under the test conditions used, and with cast iron cylinder liners, it is thought unllkely that the program goal of $0.2 \mathrm{dry}$ friction coefficient can be met, at least without the use of a solld lubricant. The test conditions used for this program were designed to simulate the top ring reversal environment in a heavy duty diesel engine, and the load selected (225 N) was sufficiently high to create "severe" wear conditions (transfer of material, severe oxidation of the liner, fracture of some coatings) in unlubricated tests. Possibly, "mild" wear conditions with lower friction coefficients may have prevalled at lower test loads, but this would be of no practical value for a diesel engine ring facing material.

\section{UNLUBRICATED FRICTION COEFFICIENTS $200^{\circ} \mathrm{C}$ \\ Pearlitic Grey Iron Liner}

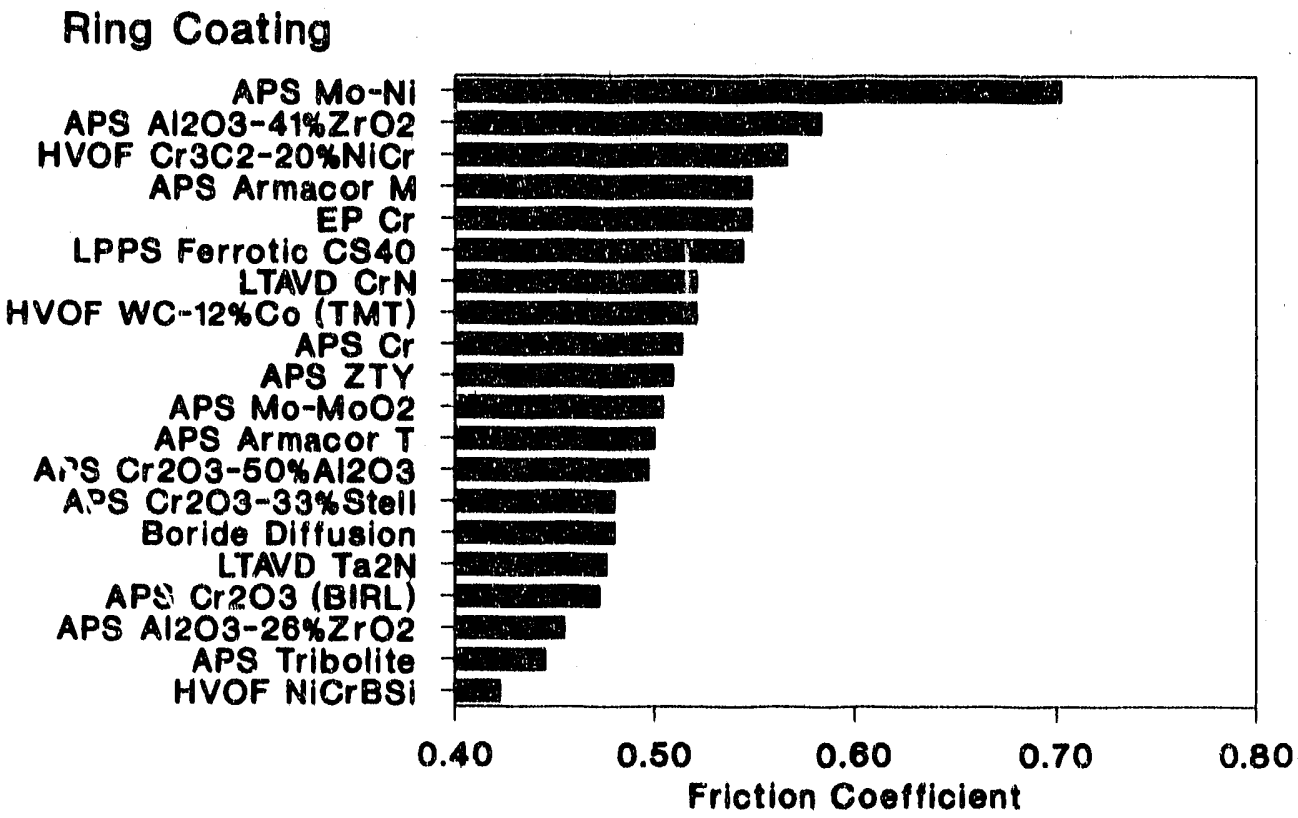

Figure 108. Friction coefficients for $200^{\circ} \mathrm{C}$ unlubricated tests. 


\subsection{MICROSTRUCTURAL EFFECTS ON FRICTION AND WEAR}

In this section, correlations between coating microstructures and measured friction and wear properties are examined for four types of coating: plasma sprayed chromlum oxides, tungsten carblde cobalt (varlous coating methods), HVOF chromium carbide - nlchrome and LPPS Ferro-tlo materlals. For more detailed analysis of the effects of miorostructure on wear mechanisms, see the Appendices.

\subsubsection{Chromium Oxide Coatings}

A breakdown of the wear coefficients for various chromium oxide materials is shown in Figure 109. With fresh oll, differences in wear rates were relatively small, the variation from best to worst material being a factor of approximately 4. With high-soot oil, the dffferences were somewhat greater (14x variation), and the unlubricated tests showed a factor of 1000 difference between best and worst materlals. The ranking of materials was not consistent from one test condition to another, in part because the differences between materials for fresh oil tests were mostly within experimental error. However, the BIRL $\mathrm{Cr}_{2} \mathrm{O}_{3}-50 \% \mathrm{Al}_{2} \mathrm{O}_{3}$ (material 7 in Figures $109-11$ ) and UTRC APS Metco 106FP (material 8) coatings were generally found to have the highest wear, especially in unlubricated tests. The best wear coatings were the BIRL APS $\mathrm{Cr}_{2} \mathrm{O}_{3}$ (material 2) and APS Materials Metco 136 (material 4).

An important microstructural feature of thermally sprayed chromium oxide materials is the degree of inter-splat microcracking and porosity. For the eight 14 materials shown in Figure 109, the ranking from lowest microcrack levels to highest was:

$$
\begin{aligned}
& \text { BIRL APS } \mathrm{Cr}_{2} \mathrm{O}_{3} \\
& \text { BIRL HVOF } \mathrm{Cr}_{2} \mathrm{O}_{3} \\
& \text { APS Materials Metco } 136+15 \% \mathrm{Al}_{2} \mathrm{O}_{3} \\
& \text { APS Materials Metco } 136 \\
& \text { APS Materials Metco } 136+3 \% \mathrm{SiO}_{2} \\
& \text { APS Materials UCAR } \mathrm{Cr}_{2} \mathrm{O}_{3} \\
& \text { BIRL } \mathrm{Cr}_{2} \mathrm{O}_{3}-50 \% \mathrm{Al}_{2} \mathrm{O}_{3} \\
& \text { UTRC APS Metco } 106 \mathrm{FP}
\end{aligned}
$$

(material 2 in Figures $109-111$ )
(material 3 in Figures $109-111$ )
(material 6 in Figures $109-111$ )
(material 4 in Figures $109-111$ )
(material 5 in Figures $109-111$ )
(material 1 in Figures $109-111$ )
(material 7 in Figures $109-111$ )
(material 8 in Figures $109-111$ )

The first four coatings on this list all showed generally excellent microstructures.

Thus, it appears that the wear data show an approximate correlation with the level of microcracking and porosity within the coating, especially for the most severe test conditions (which were most likely to cause fracture of the coating).

Attempts to determine the effect of $\mathrm{Al}_{2} \mathrm{O}_{3}$ additions on the tribological propertles of chromium oxide were compromised by the poor microstructure of the $\mathrm{Cr}_{2} \mathrm{O}_{3}-50 \% \mathrm{Al}_{2} \mathrm{O}_{3}$ coating. The Metco $136+15 \%$ $\mathrm{Al}_{2} \mathrm{O}_{3}$ coating (material 6) showed low wear coefficients with fresh oil ( 200 and $350^{\circ} \mathrm{C}$ ), but comparatively high wear with high-soot oil.

14 The Boyd material was not included in this series of tests due to insufficient test samples. This material was tested against the SCA liner coating (data included in Figure 100). 


\section{WEAR OF CHROMIUM OXIDES \\ Pearlitio Grey Iron Cylindor Linor}

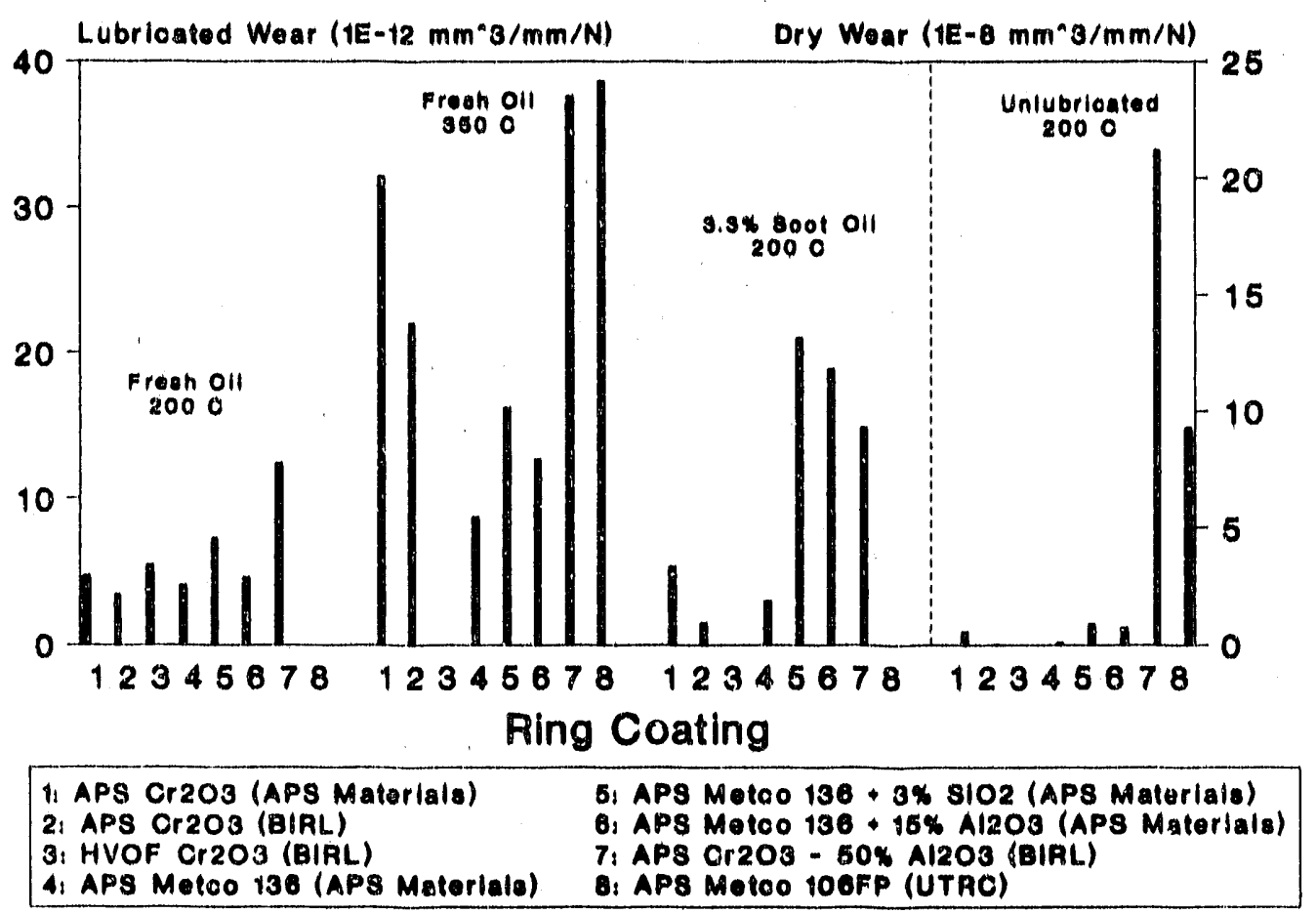

Figure 109. Wear coefficients for various chromium oxide based coatings sliding against pearlitio grey cast iron liners. 


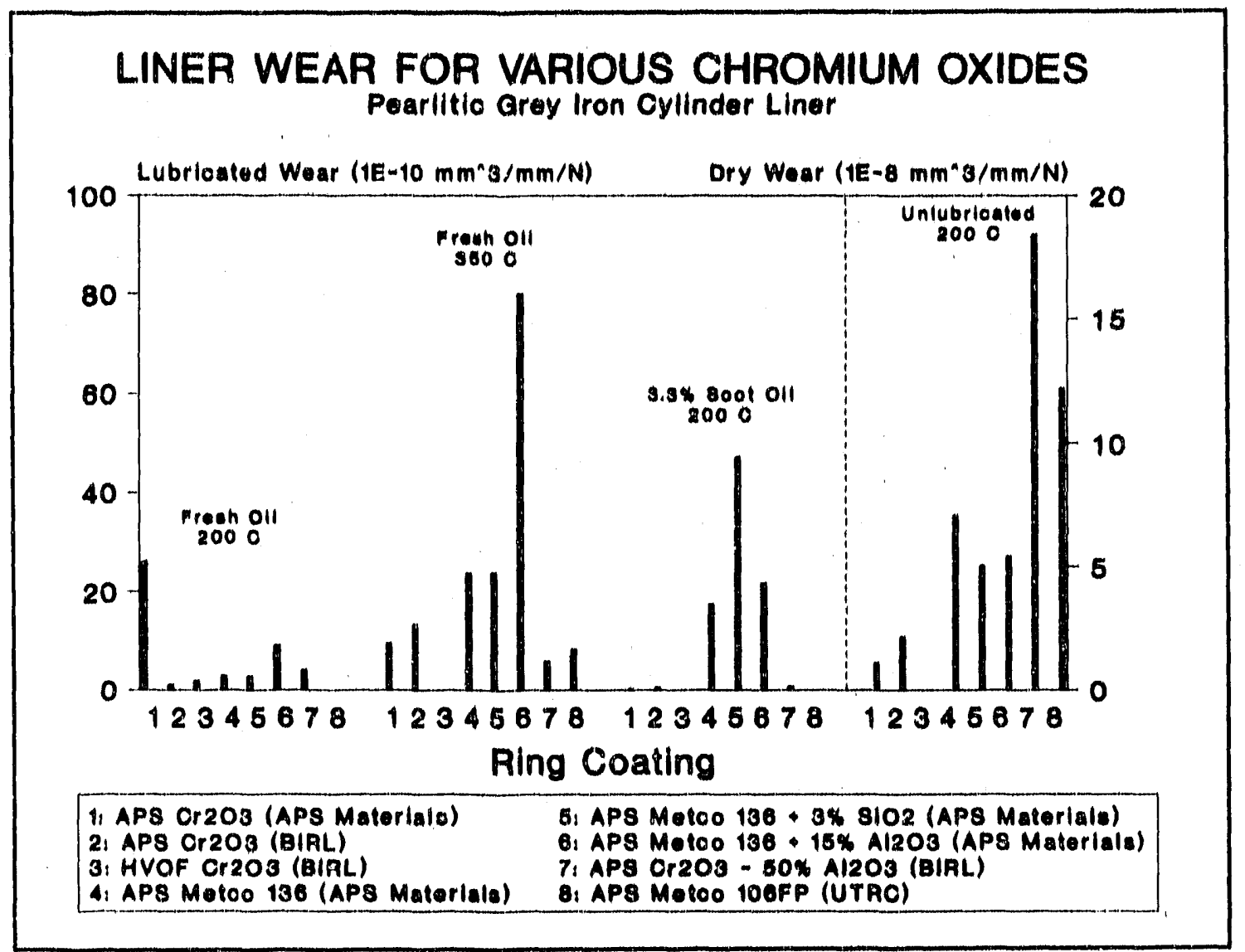

Figure 110. Liner wear coefficlents for various chromium oxide based coatings silding against pearlitic grey cast iron liners.

Liner wear coefficients are shown in Figure 110. Generally, th is difficult to resdve consistent trends from these data, suggesting that the wear values were mostly similar, within experimental error. However, the highly lapped BlRL $\mathrm{Cr}_{2} \mathrm{O}_{3}$ coating (materlal 2) gave the most consistently low liner wear values for the four test conditions. Materials 4, 5 and 6 (powders based on Metco 136) tended to show the highest liner wear in lubricated tests. Interestingly, the $\mathrm{Cr}_{2} \mathrm{O}_{3}-50 \% \mathrm{~A}_{2} \mathrm{O}_{3}$ (material 7) showed very low liner wear in lubricated tests, despite the high porosity and microcracking within this coating. However, the Metco 136 $+15 \% \mathrm{Al}_{2} \mathrm{O}_{3}$ coating (material 6 ) gave consistently high liner wear in lubricated tests. In unlubricated tests, materials 7 and 8 , the most porous, microcracked coatings, showed the highest liner wear. 


\section{CHROMIUM OXIDE FRICTION COEFFICIENTS}

Pearlitio Grey Iron Cylinder Liner

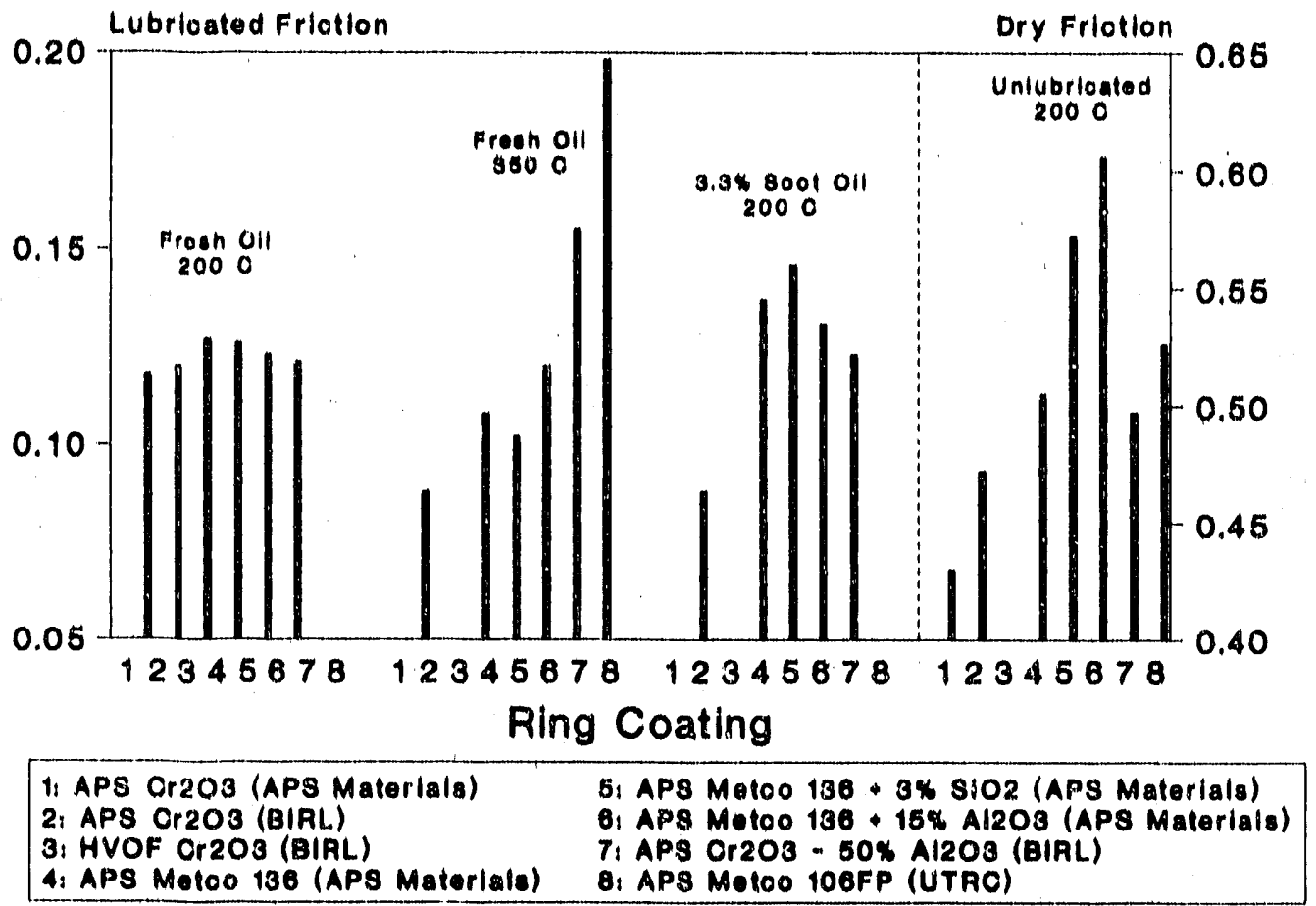

Figure 111. Friction coefficients for various chromium oxide based coatings sliding against pearlitic grey cast iron liners.

Friction coefficients were similar for all coatings at $200^{\circ} \mathrm{C}$ with fresh oll (Figure 111). For fresh oll, $350^{\circ} \mathrm{C}$ and high-soot oll, $200^{\circ} \mathrm{C}$ tests, the BIAL $\mathrm{Cr}_{2} \mathrm{O}_{3}$ material gave the lowest friction coefficients. This material was lapped and had the lowest $R_{8}$ value of all the coatings tested (Table 23). Otherwise, it is difficult to resolve consistent trends in friction. In unlubricated tests, the more pure $\mathrm{Cr}_{2} \mathrm{O}_{3}$ coatings (materials 1 and 2) showed lower friction than the Metco 136 based coatings (materials 4,5 and 6). 


\subsubsection{WC-Co Coatings}

Five WC - 12\% Co coatings were evaluated during the program, Including air plasma sprayed, low pressure plasma sprayed and HVOF materlals. The coatings are listed in Table 29, together with X-ray diffraction data showing the phase contents of each coating. It is difficult to draw firm conclusions from the analysis, but it appears that the Boyd and Turbine Metal Techriology HVOF coatings showed relatively low degrees of carbide solutionizing, and the APS Materlals HVOF coating showed a relatively high amount.

Wear data for the five coatings are shown in Figure 112. In order of increasing wear, the ranking of the coatings was: Boyd HVOF, APS Materlals APS, TMT HVOF, APS Materials LPPS and APS Materials HVOF. The ranking of the coatings was relatively consistent for all test conditions. Typically, wear coefficients varied from best to worst materlal by a factor of 9 with fresh oll, 20 with high-soot oil and 3 with no lubricant. Although the Boyd material generally showed the lowest wear, the coating was found to crack during several of the tests, particularly at high test temperatures. This coating was the thiokest of the WC - Co materials evaluated $(250 \mu \mathrm{m})$, and may have contained high levels of residual stress.

From the above ranking, it appears that there may be a correlation between the degree of carblde solutionizing and wear: the greater the amount of solutionizing, the higher the wear rate.

Wear data for cast iron cylinder liner counterfaces are shown in Figure 113. The as-ground coatings (APS Materials APS and LPPS coatings) showed higher liner wear than the lapped surfaces in lubricated tests. Figure 113 also shows that liner wear was a strong function of temperature, but was not affected appreciably by soot/oil degradation for WC - Co ring coatings.

Friction coefficients showed no consistent trends from one material to another (Figure 114).

Table 29. Phase analysis of WC - Co coatings used in this program. X-ray diffraction analysis and phase identification was performed at BIRL. Important: Percentage values in brackets [] represent the peak intensity of the strongest peak from the minor phase divided by the strongesi WC peak intensity. These numbers do not indicate that the minor phase exists in that abundance.

\begin{tabular}{|c|c|c|}
\hline Coating Process & Supplier & Analysis \\
\hline Air Plasma & APS Materials & $\begin{array}{l}\mathrm{WC}+\mathrm{Co}_{3} \mathrm{~W}_{9} \mathrm{C}_{4}[12 \%]+ \\
\mathrm{Co}_{3} \mathrm{~W}_{3} \mathrm{C}[10 \%]\end{array}$ \\
\hline Low Pressure Plasma & APS Materials & $\begin{array}{l}\mathrm{WC}+\mathrm{Co}_{2} \mathrm{~W}_{4} \mathrm{C}[16 \%]+ \\
\mathrm{Co}_{3} \mathrm{~W}_{9} \mathrm{C}_{4}[14 \%]\end{array}$ \\
\hline HVOF (Jetkote II) & APS Materials & $\begin{array}{l}\mathrm{WC}+\mathrm{Co}_{2} \mathrm{~W}_{4} \mathrm{C}[24 \%]+ \\
\mathrm{Co}_{3} \mathrm{~W}_{8} \mathrm{C}_{4}[10 \%]\end{array}$ \\
\hline HVOF (Jetkote II) & Boyd Machine \& Repair & $W C+\alpha-W_{2} C[13 \%]$ \\
\hline $\begin{array}{l}\text { HVOF (proprietary } \\
\text { gun) }\end{array}$ & Turbine Metal Technology & $\begin{array}{l}W C+W C_{1-x}[7 \%]+C_{6} W_{6} C \\
{[6 \%]}\end{array}$ \\
\hline
\end{tabular}




\section{WEAR OF WC - $12 \%$ CO COATINGS \\ Pearlitio Grey Iron Liner}

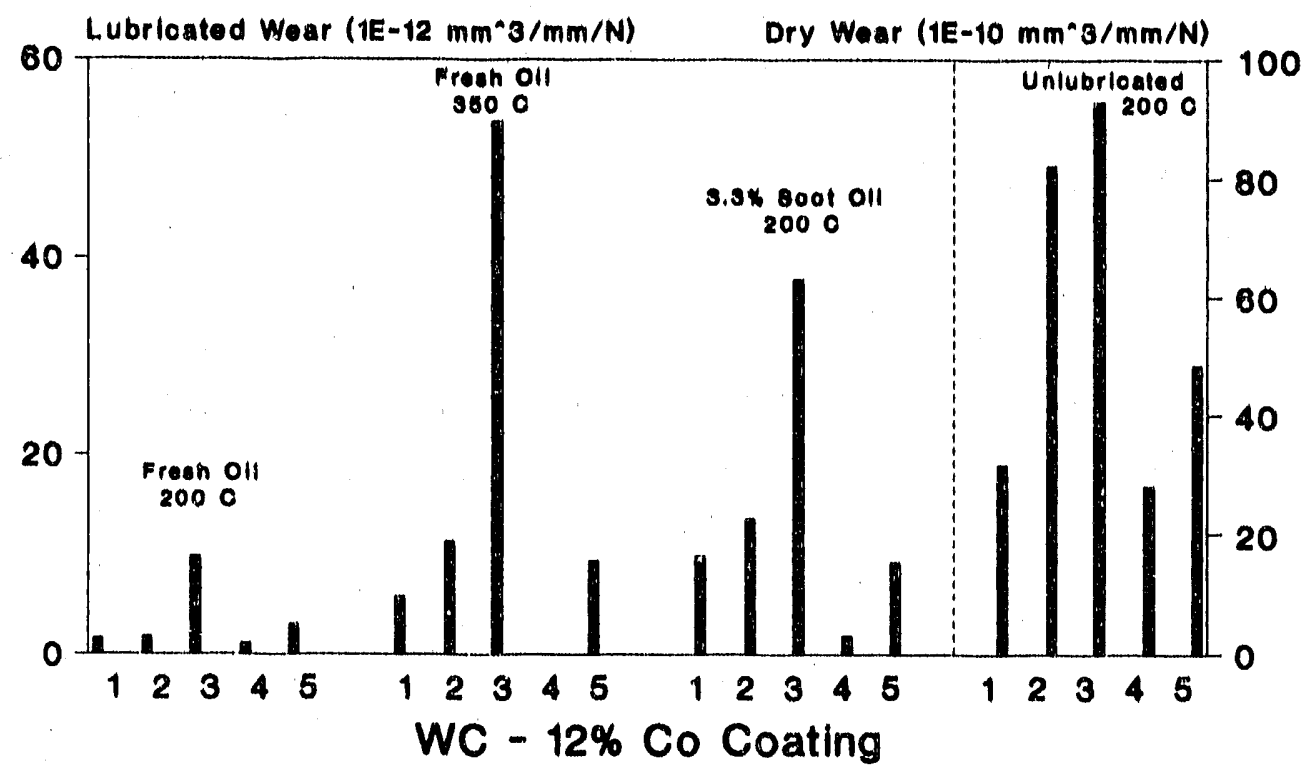

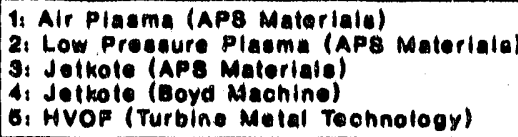

Figure 112. Wear coefficients for various tungsten carbide - cobalt coatings sliding against pearlitic grey cast iron liners. 


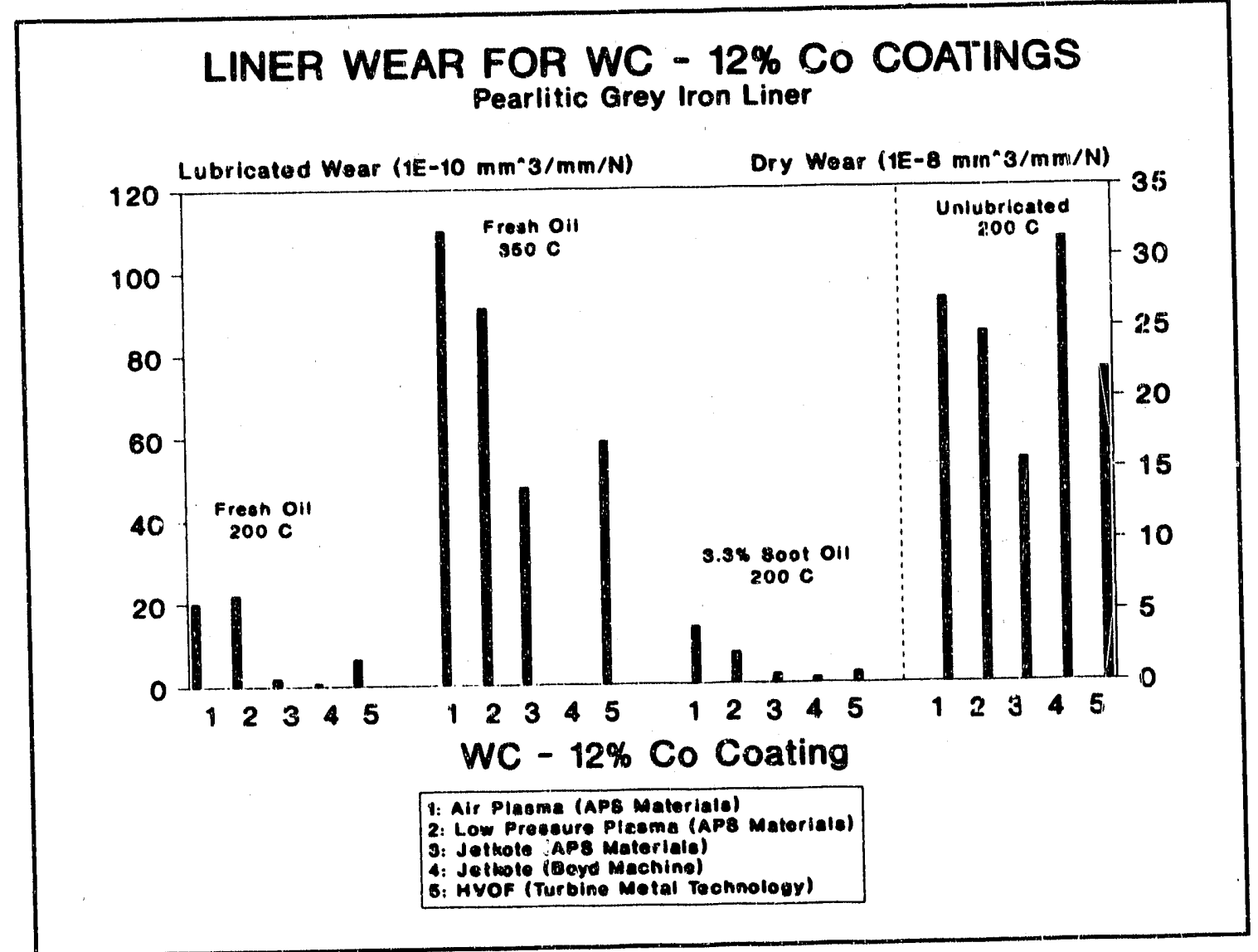

Figure 113. Liner woar coefficients for various tungsten carbide - cobalt coatings sliding against pearlitic grey cast iron liners. 


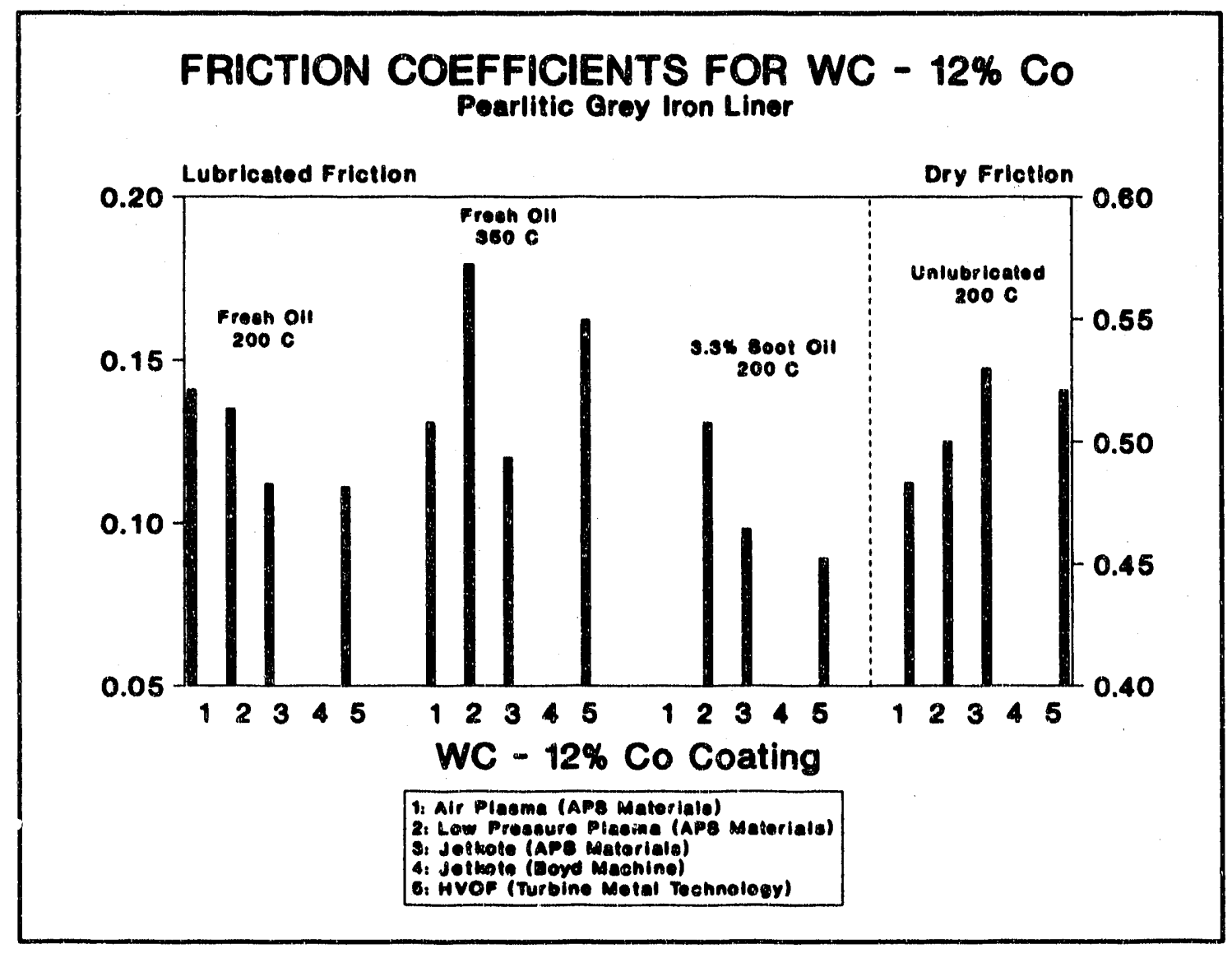

Figure 114. Friction coefficients for various tungsten carbide - cobath coatings sliding against pearlitic grey cast iron liners. 


\subsubsection{Chromium Carbide - Nichrome Coatings}

Two HVOF $\mathrm{Cr}_{3} \mathrm{C}_{2}-20 \%$ NICr materials were evaluated during this program: a clad powder sprayed by UTRC and a mixed powder sprayed by Turbine Metal Technology (see section 3 for microstructural characterization). Wear data for the two materlals are shown in Figures 115 (coating wear) and 116 (liner wear). The clad UTRC materlal was found to give lower woar under all test conditions, typically by a factor of two.

Liner wear was approximately the same for both materials, even though the surface finish of the lapped TMT material was much finer $(0.08 \mu \mathrm{m}$ RA) than for the ground UTRC materlal $(0.42 \mu \mathrm{m}$ RA). For both materials, liner wear was much higher with high-soot oll than with fresh oll. In this respect, the $\mathrm{Cr}_{3} \mathrm{C}_{2}$ $\mathrm{NiCr}$ coatings differed from WC - Co materials, for which liner wear was relatively insensitive to soot/oll degradation. For the UTRC $\mathrm{Cr}_{3} \mathrm{C}_{2}-20 \% \mathrm{NICr}$, wear was higher at $200^{\circ} \mathrm{C}$ with high-soot oll than at $350^{\circ} \mathrm{C}$ with fresh oll.

Friction coefficients for the two coatings were broadly similar, although the UTAC material gave a much higher friction coefficient than the TMT coating in the high-soot oll test (Figure 117).

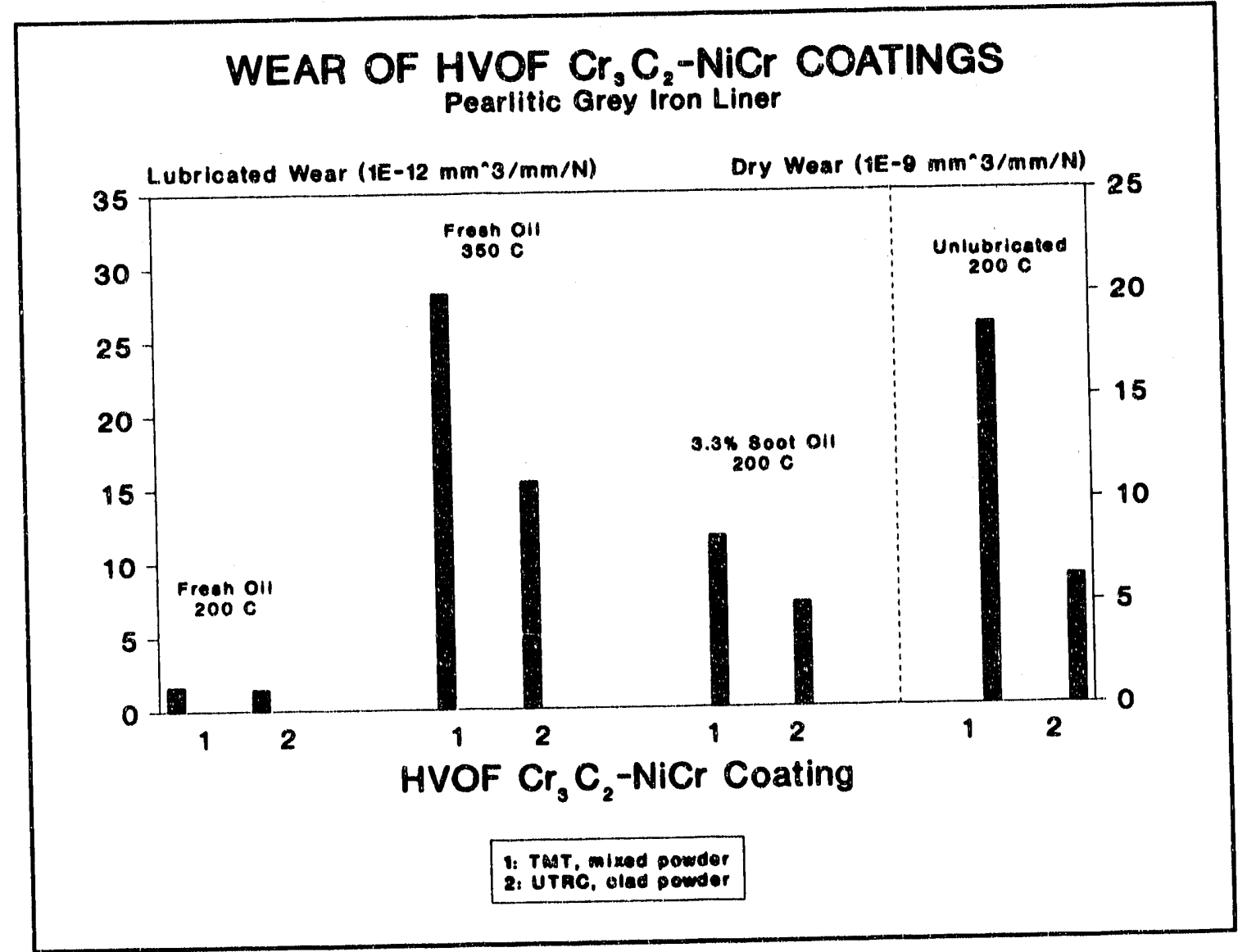

Figure 115. Wear coefficients for $\mathrm{Cr}_{3} \mathrm{C}_{2}$ - NiCr coatings sliding against pearlitic grey cast iron liners. 


\section{LINER WEAR vs HVOF $\mathrm{Cr}_{3} \mathrm{C}_{2}-\mathrm{NICr}$ COATINGS}

Pearlitic Groy Iron Liner

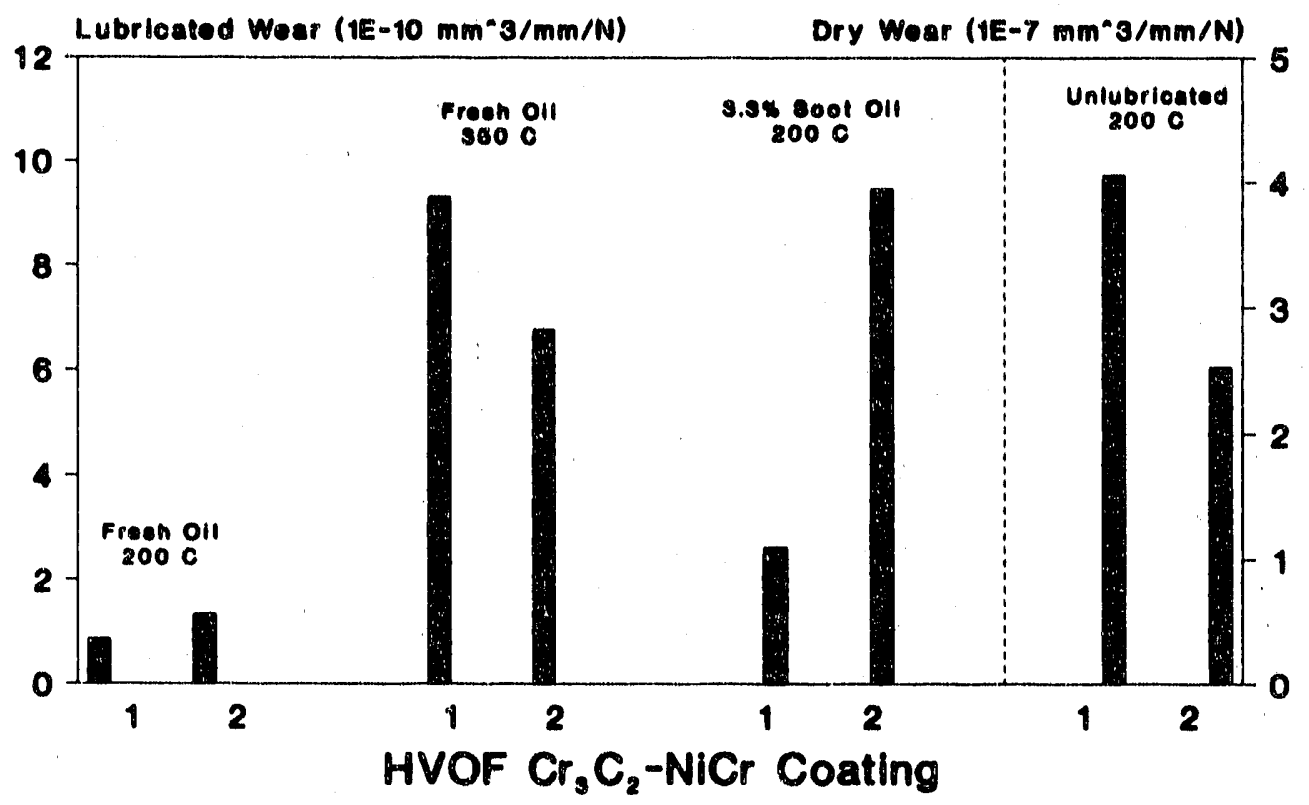

1: YMT, mined powder

2. UTHC. olen powder

Figure 116. Liner wear coefficients for $\mathrm{Cr}_{3} \mathrm{C}_{2}$ - NiCr coatings sllding against pearlitic grey cast iron finers. 


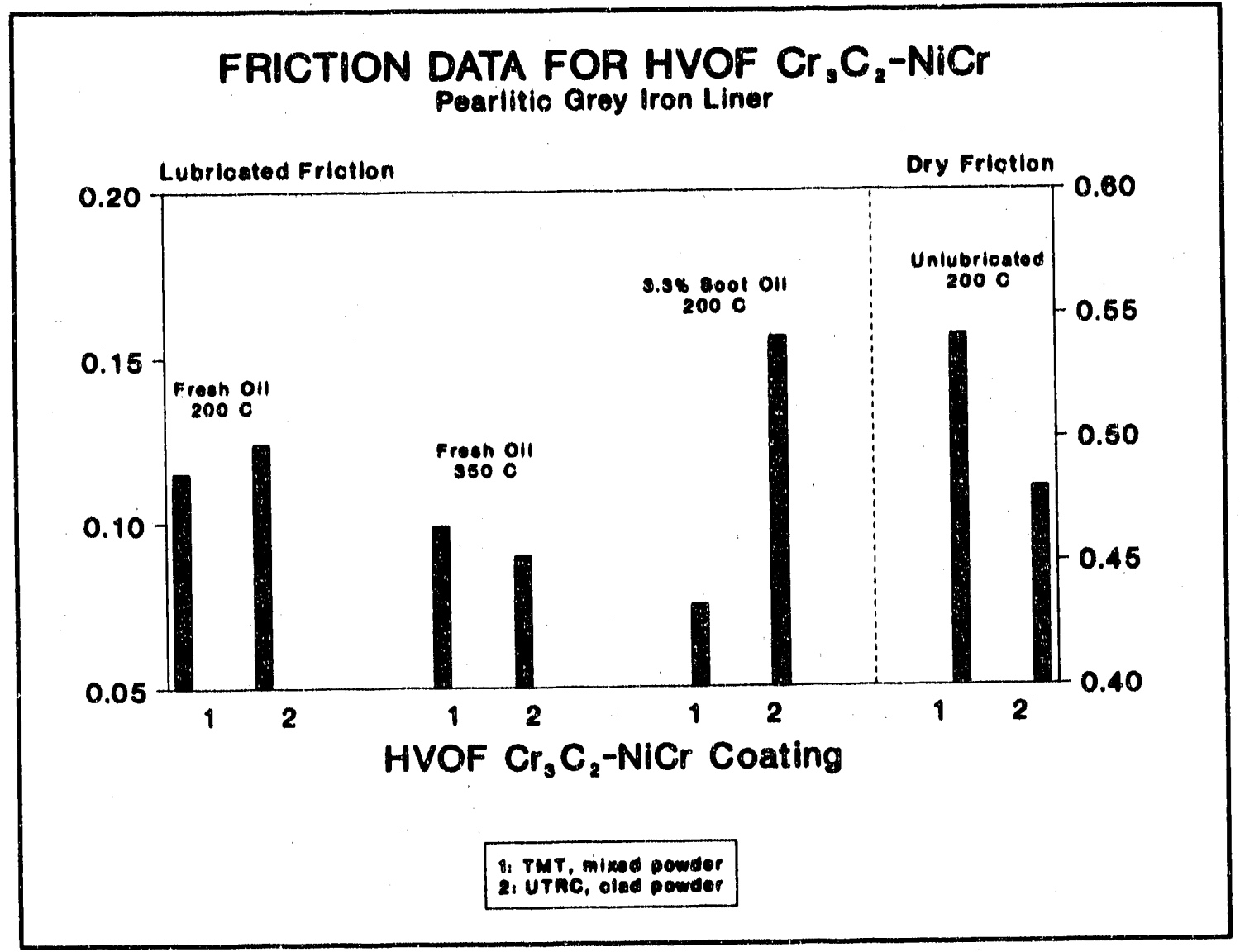

Figure 117. Friction coefficients for $\mathrm{Cr}_{3} \mathrm{C}_{2}-\mathrm{NiCr}$ coatings sliding against pearlitic grey cast iron liners. 


\subsubsection{Ferro-Tic Coatings}

Three Ferro-Tic materials were evaluated:

1. Ferro-TiC CM $\quad 45 \%$ TIC in a high chrome tool steel matrix

2. Ferro-TiC CS-40 45\% TIC in a martensitic stainless steel matrix

3. Ferro-Tic HT-6A 35\% TIC in an age hardenable nickel base matrix.

Microstructures for the throe materials are described in section 3.1.3.

In lubricated tests, the three materials gave similar wear performance (Figure 118), the CS-40 grade giving marginally lower wear. All three materlals showed a dramatic increase in wear rates with increasing temperature (for example, compare the WC - Co data in Figure 112 with Figure 118). In unlubricated tests, the HT-6A material, containing a lower percentage of TIC, showed substantially higher wear than the steel matrix grades.

Liner wear coefficients for the Ferro-Tic materials were generally a strong function of temperature and a weaker function of soot/oll degradation (Figure 119). In this respect, the Ferro-Tic materials behaved similarly to the WC - Co coatings. There were no consistent differences between the three Ferro-Tic materials as regards liner wear. It is perhaps surprising that the HT-6A grade, which contains a lower volume fraction of fiC, did not show lower liner wear than the other grades.

Friction coefficients were similar for all the Ferro-Tic coatings in lubricated tests (Figure 120). The HT-6A grade showed a relatively low friction coefficient in the unlubricated tests, despite a much higher wear coefficient. 


\section{WEAR OF FERRO-TIC COATINGS \\ Pearlitic Groy Iron Liner}

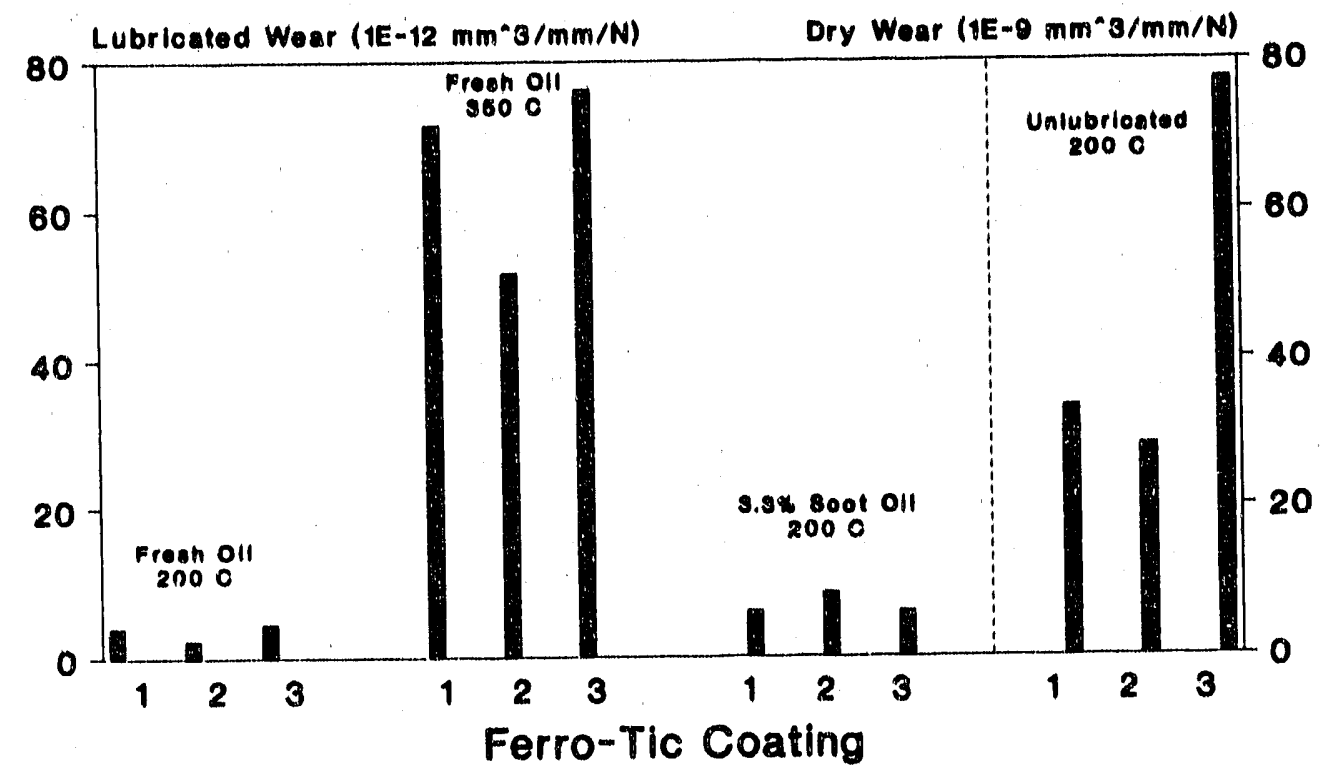

$$
\begin{aligned}
& \text { 1: CM } \\
& \text { 2. CB4O } \\
& \text { 3. HTSA }
\end{aligned}
$$

Figure 118. Wear coefficients for Ferro-Tic coatings sliding against pearlitic grey cast iron liners. 


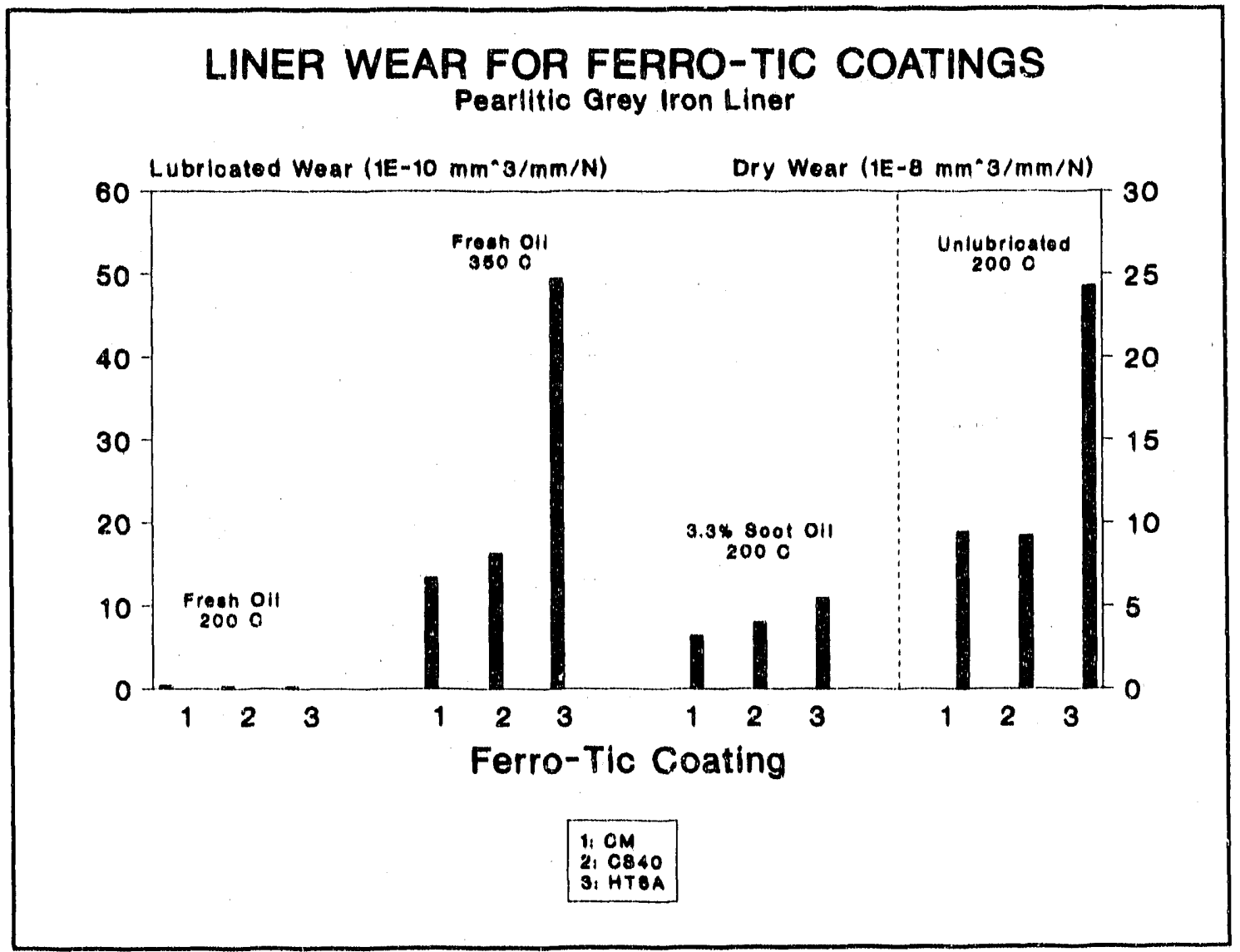

Figure 119. Liner wear coefilicients for Ferro-Tic coatings sliding against pearlitic grey cast iron liners. 


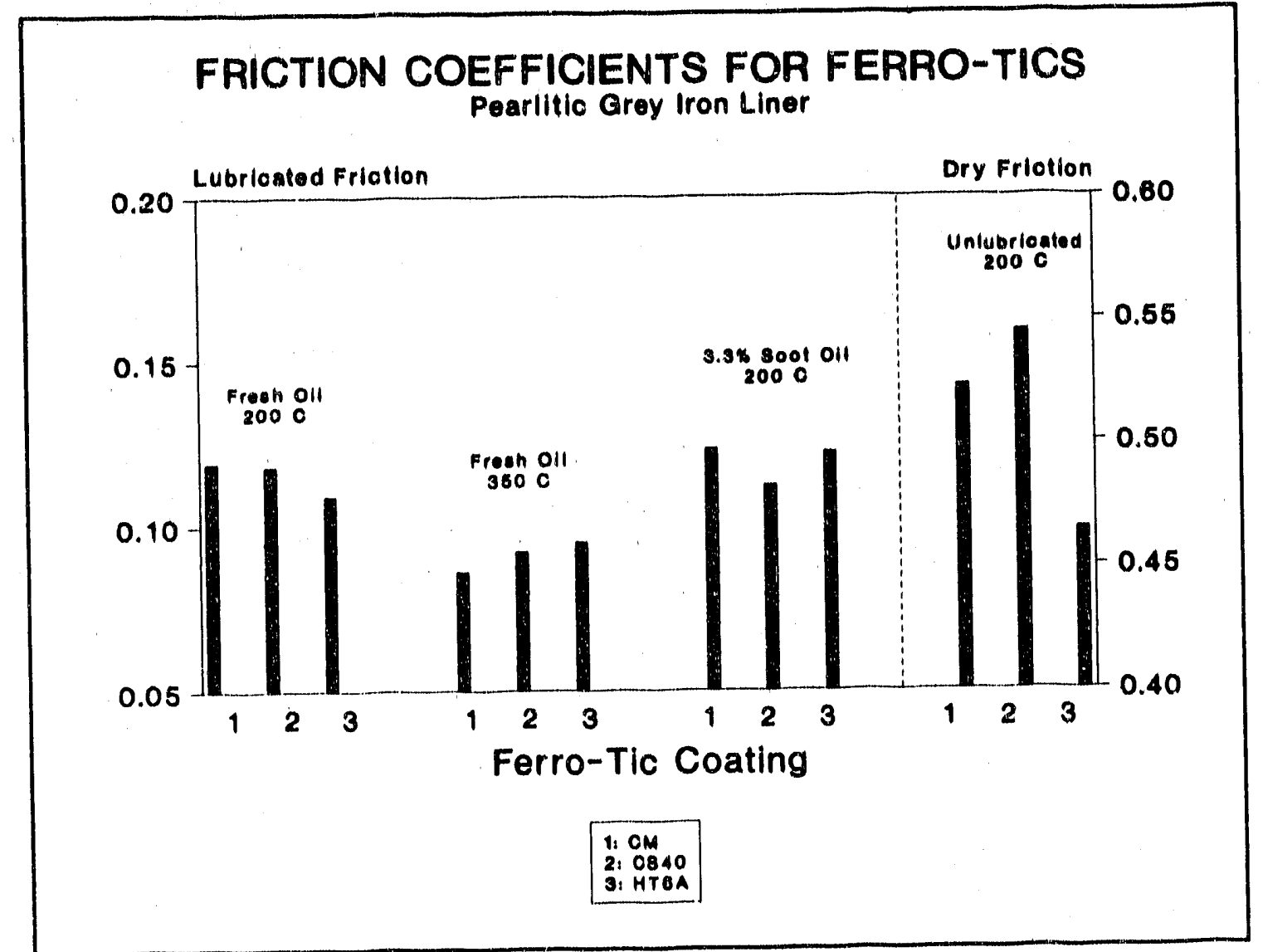

Figure 120. Friction coefficlents for Ferro-Tic coatings sliding against pearlitic grey cast iron liners. 


\subsection{CYLINDER LINEA OPTIMIZATION}

The results of the cylinder liner optimization tests, performed with the UTRC HVOF $\mathrm{Cr}_{3} \mathrm{C}_{2}-\mathrm{NICr}$ ring coating sliding against various alternative cylinder liner materials are described in this section. The oylinder liner materials evaluated were (see Table 25, section 3.3 for compositions):

1. pearltic grey iron $(70-90 \mathrm{HAG})$

2. hardened grey cast iron (42 HAC)

3. high-phosphorus grey rast iron (79 - 83 HAG)

4. bainitic grey cast iron ( 88 - 90 HRG)

5. centrifugally cast $\mathrm{H} 13$ tool stecl hardened to $50 \mathrm{HRC}$

6. a slurry-sprayed silica-chromla-alumina (SCA) coating ( $\left.960 \mathrm{kgfmm}^{-2}, \mathrm{HK}_{100}\right)$

7. an ion-assisted CVD "dlamond-like" coating supplled by Implant Sclences, Inc. The coating substrate was $\mathrm{H} 13$ tool steol.

Coating and liner wear rates for lubricated tests are shown in Figure 121. Of the cast iron liners, the pearlitic iron and high-phosphorus materlals gave approximately the same ring and liner wear coefficients, but the bainitic material showed significantly (up to ten times) lower liner wear rates In lubricated tests, with only slightly higher ring wear (Figure 121). The excellent wear properties of the bainitio Iron may have been partly due to the alloy content, which results in a fine dispersion of molybdenum carbides through the microstructure, in addition to the effect of the slightly higher matrix hardness. Hardening the pearlitic grey Iron material resulted in three times lower liner wear in the $200^{\circ} \mathrm{C}$ tests but very little effect at $350^{\circ} \mathrm{C}$, even though the tempering effect during the wear test was small at $350^{\circ} \mathrm{C}$ (38 HRC at end of test compared to an Initial value of $42 \mathrm{HAC}$ ). It is speculated that this result may be due to the increased importance of corrosive wear processes at the higher test temperature.

The dlamond-like coating was found to be too thin to survive the six hour tests, and liner wear rates for the fresh oil tests were often higher than for uncoated $\mathrm{H} 13$ tool steel. In addition, wear rates of the $\mathrm{Cr}_{3} \mathrm{C}_{2}-\mathrm{NiCr}$ ring coating were extremely high, suggesting that the diamond-like coating was very abrasive while still intact.

Of the cylinder liner materlals tested, the SCA coating showed the lowest liner wear rates, especlally with high-soot, engine-tested oil, but this was at the expense of significantly higher ring wear (Figure 121).

Overall, the best wear performance was obtained with the hardened $\mathrm{H} 13$ tool steel liner material, which gave consistently lower wear than all the cast Irons evaluated, and even produced lower wear of the ring coating. Thus, by optimizing piston ring and cylinder liner materials, very low wear coefficients may be achieved, corning very close to meeting the aggresstve wear goals described in the objectlves. It should be noted that tests were conducted with an as-ground surface finish of $0.42 \mu \mathrm{m}$ RA for the HVOF $\mathrm{Cr}_{3} \mathrm{C}_{2}$ - NiCr. Lapping the coating would result in a significantly better surface finish and potentially lower liner wear.

Unlubricated tests showed relatively little difierence between the cast iron materials (Figure 122). The best liner material for dry tests was the SCA coating. $\mathrm{H} 13$ tool steol also gave lower wear than cast irons in these tests. The diamond-like coating was completely removed during the unlubricated test, and the wear coefficient was the same as for the $\mathrm{H} 13$ tool steet substrate. 


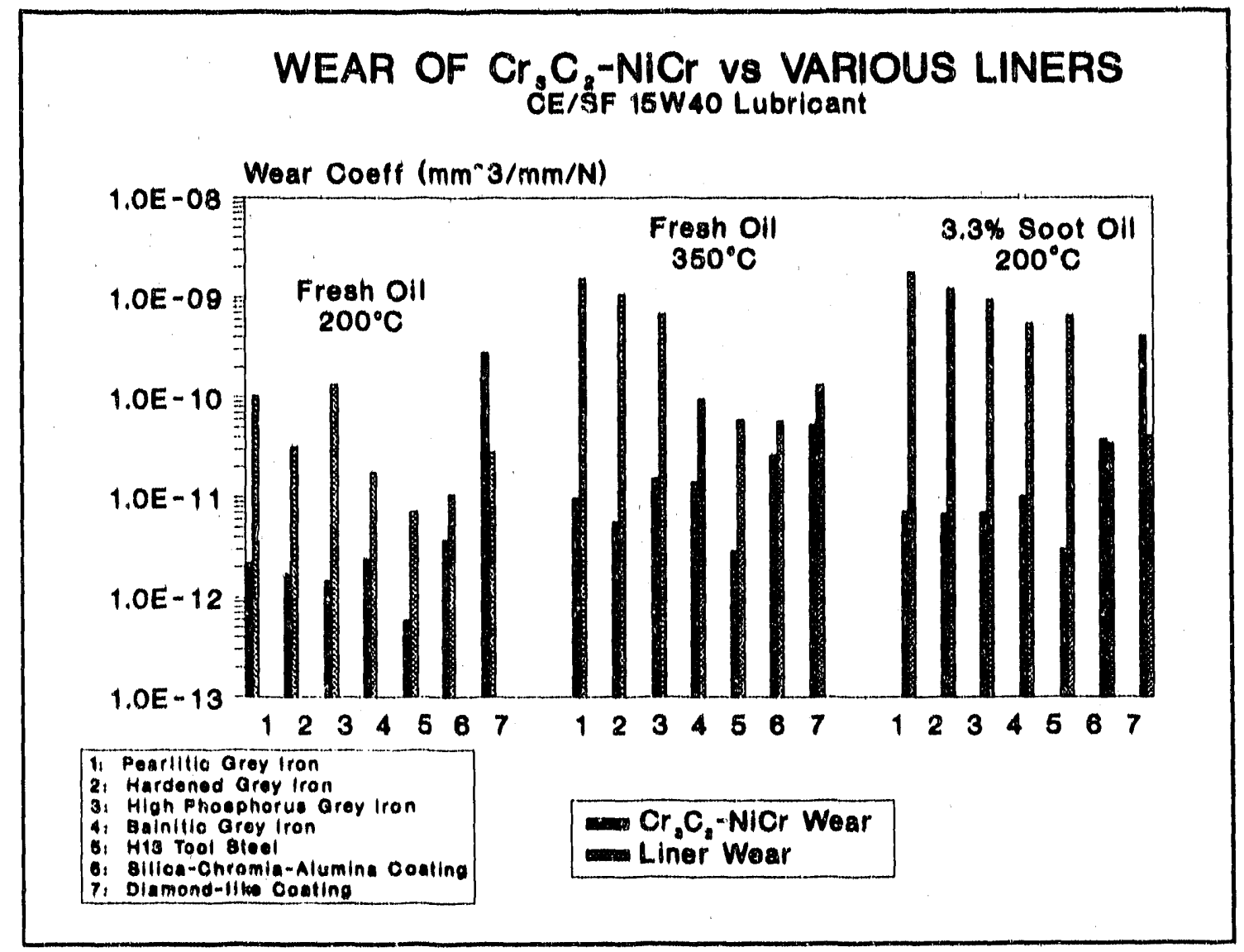

Figure 121. Wear coefficients for HVOF $\mathrm{Cr}_{3} \mathrm{C}_{2}-\mathrm{NICr}$ coating sliding against various cylinder liner materials (lubricated tests). 


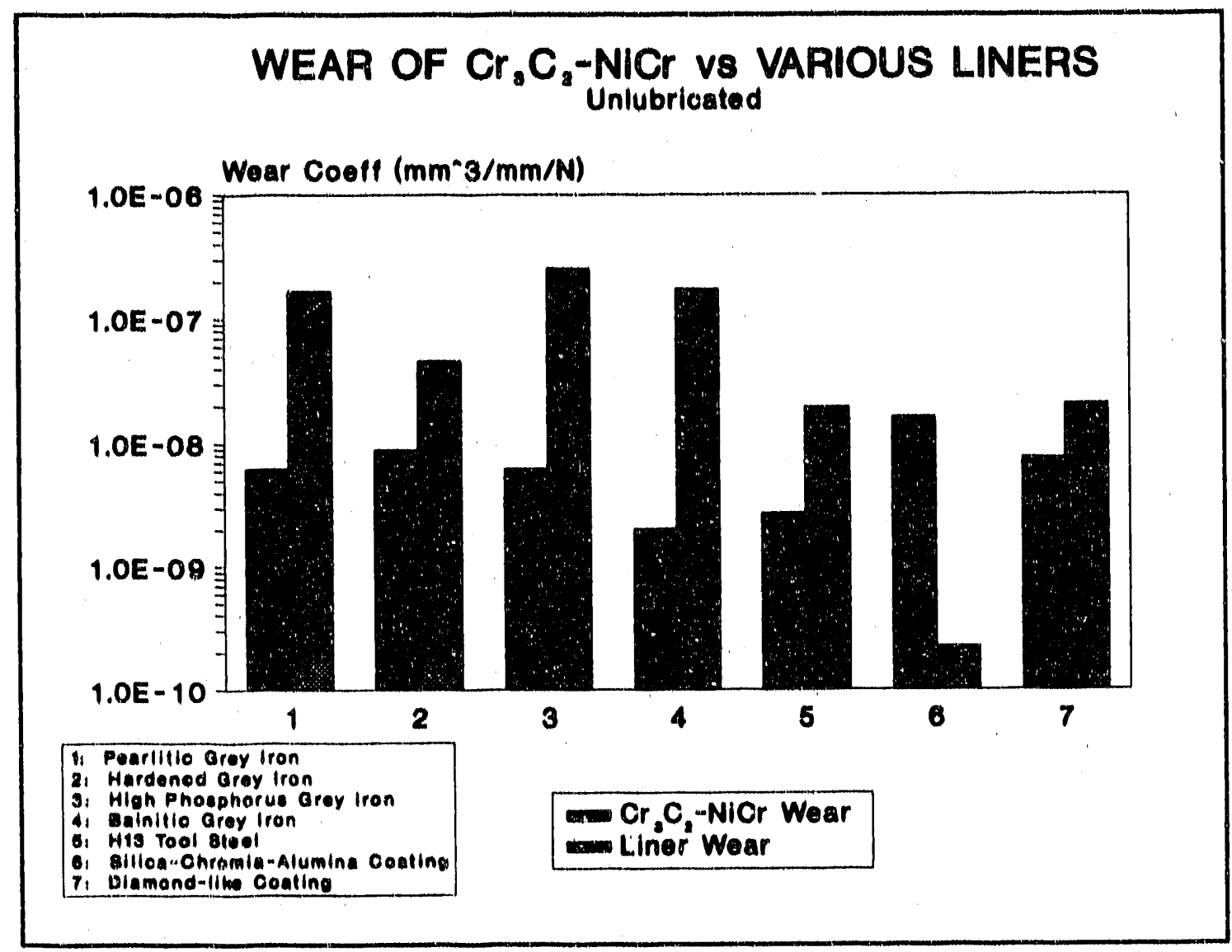

Figure 122. Wear coefficients for $\mathrm{HVOF} \mathrm{Cr}_{3} \mathrm{C}_{2}-\mathrm{NiCr}$ coating sliding against varlous cylinder liner materials (unlubricated tests). 


\subsection{CORRELATIONS BETWEEN WEAR DATA FOR DIFFERENT TEST CONDITIONS}

The testing phillosophy adopted in this program was to evaluate coatings under multiple test conditions (fresh oll: 200 and $3500^{\circ} \mathrm{C}$, high-800t oll: $200^{\circ} \mathrm{C}$, unlubricated: $200{ }^{\circ} \mathrm{C}$ ). Thls decislon was made after reviewing the literature on commerolal plston ring coatings $[\theta, g, 4,8]$, which showed that miaterlals could score highly in some wear categorles, but perform poorly in others. For example, a particular coating might be very scuff resistant but have only average wear resistance under well-lubricated conditions. The test conditions used were designed to provide the maximum information from the smallest number of tests. It is instructive to review the level of correlation between the four kinds of wear tests. Concelvably, if there were sufficient correlation, it would be unnecessary to perform each kind of test on every sample because it would be possible to extrapolate data from one type of test to predict the performance under every test condition. Conversely, if the correlation between tests were poor, our original test design would be justfiled. This is an extremely important point for future tribologlcal evaluations of materials for diesel engine applications.

Least squares regression analysis was performed to try to correlate wear coefficlents measured under one test condition with those measured under another. The correlation coefficlents are shown in Tables 30 (ring coatings) and 31 (cylinder liners). In no case was the correlation coefficlent significantly greater than 0.9 but, for the ring coating wear, there appeared to be a reasonable correlation between fresh oll $\left(200^{\circ} \mathrm{C}\right)$ and fresh oll $\left(350^{\circ} \mathrm{C}\right)$ data, and also between fresh oll $\left(200^{\circ} \mathrm{C}\right)$ and high-soot oll $\left(200^{\circ} \mathrm{C}\right)$ results. There was little correlation between lubricated and unlubricated wear data, although the best fit was with the fresh oll $\left(350^{\circ} \mathrm{C}\right)$ vs unlubricated $\left(200^{\circ} \mathrm{C}\right)$ tests. For oylinder liner wear, correlation coefficients were very low for all combinations of test conditions (Table 31).

An attempt was made to correlate ring wear with liner wear for the four different test conditions (Table 32). The best correlation was for fresh oll $\left(200^{\circ} \mathrm{C}\right)$ tsets, for which the correlation coefficient was 0.728 . Ring wear was found to increase with increasing liner wear (or vice versa). Under all other test conditions, the liner wear was found to be independent of ring wear. This conclusion is drawn for a set of data using coating material as the variable, for fixed test conditions. However, for a particular ring coating . liner wear couple and varying the temperature, there was found to be a correlation between ring and liner wear, as discussed in section 4.2.

No correlation was fourd between coating wear coe filcients and microhardness values for any test condition (Table 33). This is shown graphically for $200^{\circ} \mathrm{C}$ fresh oll wear data in Figure 3, section 1.2.

An example of one of the correlations identified, coating wear at $350^{\circ} \mathrm{C}$ vs coating wear at $200^{\circ} \mathrm{C}$, is shown in Figure 123. Plotting the data on a logarithmic scale showed relatively low scatter. Coating wear data for the 200 and $350^{\circ} \mathrm{C}$ tests with fresh oll are shown on the same graph in Figure 124. The materials are listed in order of decreasing wear coefficient, using the $200^{\circ} \mathrm{C}$ values. If the $35^{\circ} \mathrm{C}$ results were to correlate with the $200^{\circ} \mathrm{C}$ results, the graph should show the same trend of decreasing wear on both sldes. Figure 124 shows that there was a failly good correlation between 200 and $350^{\circ} \mathrm{C}$ wear coefficients, although there were some exceptions. For example, the Ferro-Tio coatings showed very low wear at $200^{\circ} \mathrm{C}$ compared with other materials, but comparatively high wear at $350^{\circ} \mathrm{C}$.

Comparison of results for fresh and high-soot, engine-tested lubricants at $200^{\circ} \mathrm{C}$ are shown in Figures 125 and 126, using the same format. In this case, although there was a broad correlation, there were many significant exceptions, giving rise to a greater amount of scatter. Ceramic and cermet coatings were found to perform well compared to metallic coatings in high-scot tests, which distorts the correlation.

A comparison between fresh oil lubricated and unlubricated test results (at $200^{\circ} \mathrm{C}$ ) is shown in Figures 127 and 128. In this case, there was very little correlation. In particular, the alumina-zirconia and chromium oxide coatings performed much better in dry tests than would be expected from $200^{\circ} \mathrm{C}$ lubricated tests, and the Ferro-Tic coatings performed much worse.

In summary, it is evident that the performance of a particular coating and iner couple relative to other combinations depends on the test conditions used, at least within the range of variables evaluated here. Tribological testing of materials for dlesel engine environments must include the key varlables of temperature and lubricant soot loading/oll degradation and should evaluate lubricated and unlubricated performance. Without this information, attempts to predict the behavior in engine tests would be potentially very inaccurate. 
Table 30. Correlation coefficients $\left(r^{2}\right)$ for ring coating wear under the four different test conditions.

\begin{tabular}{|c|c|c|c|c|}
\hline \multirow[t]{2}{*}{ Coating Wear } & \multicolumn{4}{|c|}{ Coating Wear } \\
\hline & $\begin{array}{l}\text { Fresh Oll } \\
200^{\circ} \mathrm{C}\end{array}$ & $\begin{array}{l}\text { Fresh On } \\
350^{\circ} \mathrm{C}\end{array}$ & $\begin{array}{l}3.3 \% \text { Soot } \\
200^{\circ} \mathrm{C}\end{array}$ & $\begin{array}{l}\text { Dry } \\
200^{\circ} \mathrm{C}\end{array}$ \\
\hline Fresh Oll $200^{\circ} \mathrm{C}$ & - & 0.802 & 0.898 & 0.365 \\
\hline Fresh Oll $350^{\circ} \mathrm{C}$ & 0.902 & - & 0.809 & 0.761 \\
\hline $3.3 \%$ Soot $200^{\circ} \mathrm{C}$ & 0.898 & 0.809 & - & 0.017 \\
\hline Dry $200^{\circ} \mathrm{C}$ & 0.365 & 0.761 & 0.017 & - \\
\hline
\end{tabular}

Table 31. Correlation coefficients $\left(r^{2}\right)$ for cylinder liner wear under the four different test conditions.

\begin{tabular}{|l|c|c|c|c|}
\hline \multirow{2}{*}{ Liner Wear } & \multicolumn{4}{|c|}{ Liner Wear } \\
\cline { 2 - 5 } & $\begin{array}{c}\text { Fresh Oll } \\
200^{\circ} \mathrm{C}\end{array}$ & $\begin{array}{c}\text { Fresh OHI } \\
350^{\circ} \mathrm{C}\end{array}$ & $\begin{array}{c}3.3 \% \text { Soot } \\
200^{\circ} \mathrm{C}\end{array}$ & $\begin{array}{c}\text { Dry } \\
200^{\circ} \mathrm{C}\end{array}$ \\
\hline Fresh Oll $200^{\circ} \mathrm{C}$ & - & 0.013 & 0.239 & 0.023 \\
\hline Fresh Oll $350^{\circ} \mathrm{C}$ & 0.043 & - & 0.007 & 0.138 \\
\hline $3.3 \%$ Soot $200^{\circ} \mathrm{C}$ & 0.239 & 0.007 & - & 0.035 \\
\hline Dry $200^{\circ} \mathrm{C}$ & 0.023 & 0.138 & 0.035 & - \\
\hline
\end{tabular}

Table 32. Liner wear vs ring costing wear regression: correlation coefficients $\left(r^{2}\right)$.

\begin{tabular}{|l|c|}
\hline Test Condition & Liner vs Coating Wear \\
\hline Fresh ON $200^{\circ} \mathrm{C}$ & 0.728 \\
\hline Fresh ON $350^{\circ} \mathrm{C}$ & 0.011 \\
\hline $3.3 \%$ Soot $200^{\circ} \mathrm{C}$ & 0.092 \\
\hline Dry $200^{\circ} \mathrm{C}$ & 0.160 \\
\hline
\end{tabular}

Table 33. Ring wear vs coating microhardness regression: correlation coefficients $\left(r^{2}\right)$.

\begin{tabular}{|l|c|}
\hline Test Condition & $\begin{array}{c}\text { Ring Woar vs } \\
\text { Microhardness }\end{array}$ \\
\hline Fresh Oll $200^{\circ} \mathrm{C}$ & 0.032 \\
\hline Fresh Oll $350^{\circ} \mathrm{C}$ & 0.052 \\
\hline $3.3 \%$ Soot $200^{\circ} \mathrm{C}$ & 0.012 \\
\hline Dry $200^{\circ} \mathrm{C}$ & 0.075 \\
\hline
\end{tabular}




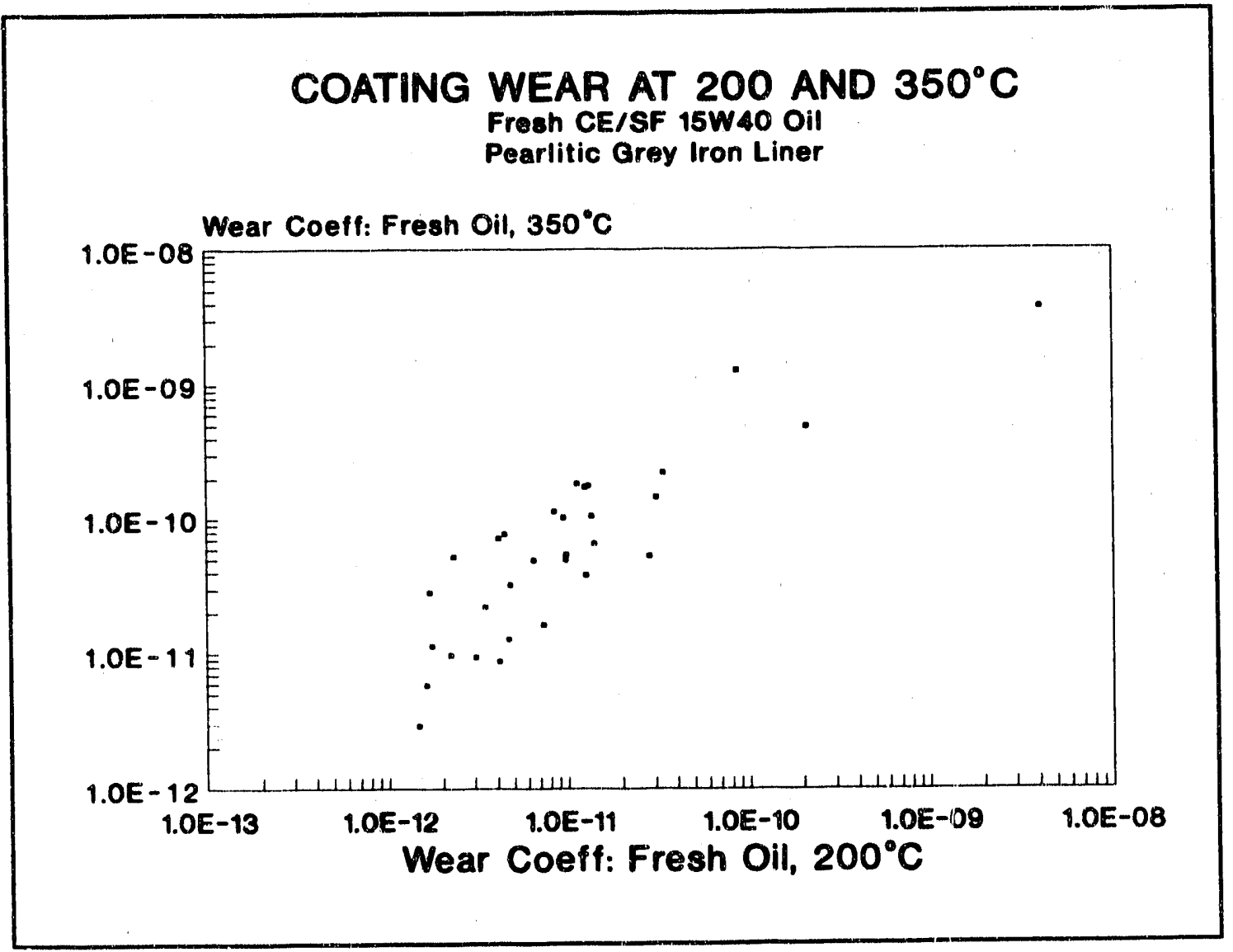

Figure 123. Coating wear at $350^{\circ} \mathrm{C}$ plotted against coating wear at $200^{\circ} \mathrm{C}$ with fresh oil. 


\section{COATING WEAR AT 200 AND $350^{\circ} \mathrm{C}$ Fresh CE/SF 15 WAO OII \\ Pearlitic Grey Iron Liner}

\section{Ring Coating}

$$
\begin{array}{r}
\text { Boride Diffusion } \\
\text { APS ZTY } \\
\text { LTAVD Ta2N } \\
\text { HVOF NiCrBSi } \\
\text { APS Armacor M } \\
\text { APS MO-MOO2 } \\
\text { APS Cr }
\end{array}
$$
APS A1203-26\% ZrO2 APS Cr203-50\%A1203 APS Tribolite APS MO-Ni APS Armacor $T$ APS Cr203-33\%stell APS Al2O3-41\% ZrO2 APS $\mathrm{Cr} 203$ (BIRL) HVOF WC-Co (TMT) LPPS Ferrotic CS40 HVOF Cr3C2-20\% NiCr LTAVD CrN

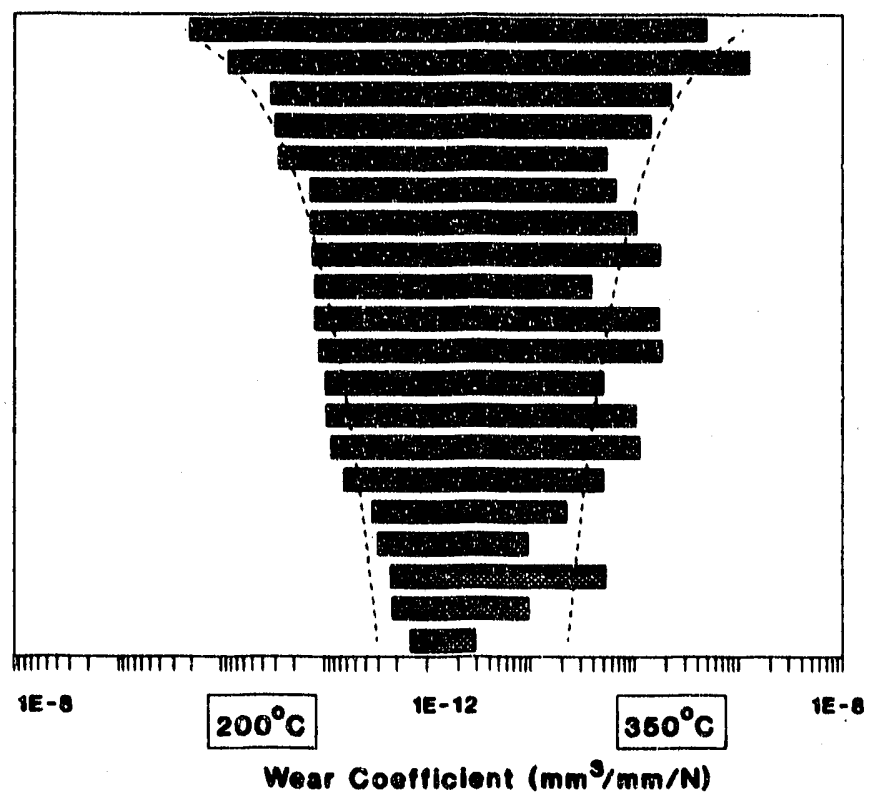

Figure 124. Coating wear coefficients measured at 200 and $350^{\circ} \mathrm{C}$ with fresh oil. 


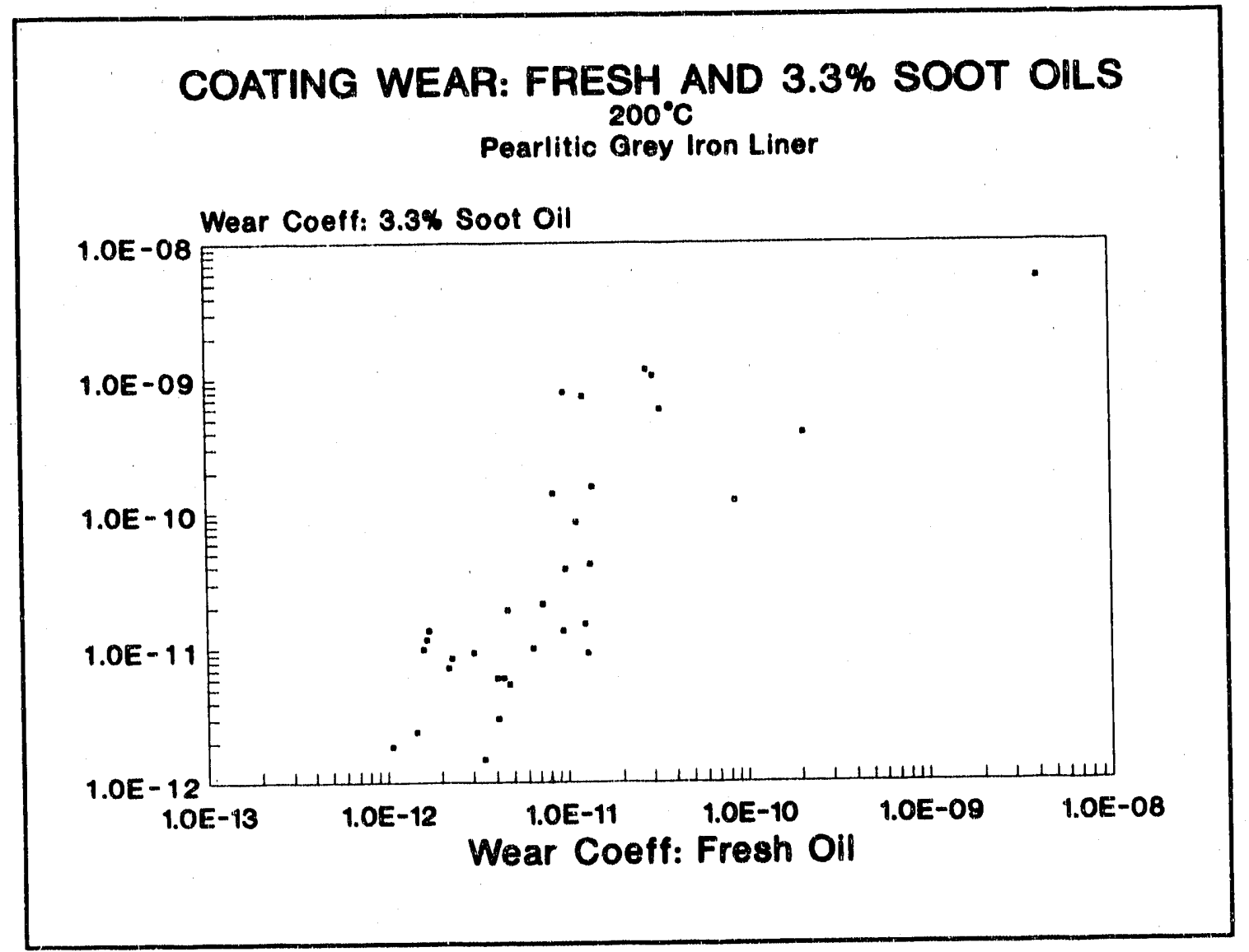

Figure 125 . Coating wear with $3.3 \%$ soot oil plotted against coating wear with fresh oll at $2000 \mathrm{C}$. 


\section{COATING WEAR - FRESH AND 3.3\% SOOT OILS CE/SF 15 W40 Lubricants, $200^{\circ} \mathrm{C}$ \\ Pearlitic Grey Iron Liner}

Ring Coating Boride Diffusion HVOF NICrBsi APS Armacor $M$ APS MO-MOO2 APS Cr APS A1203-26\%ZRO2 APS Cr2O3-50\%A1203 APS Tribolite APS Mo-Ni APS Armacor T APS Cr203-33\%stoll APS A1203-41\%ZrOZ APS Cr2O3 (BIRL) HVOF WC-Co (TMT) LPPS Ferrotic CS40 HVOF Cr3C2-20\%NiCr LTAVD CrN

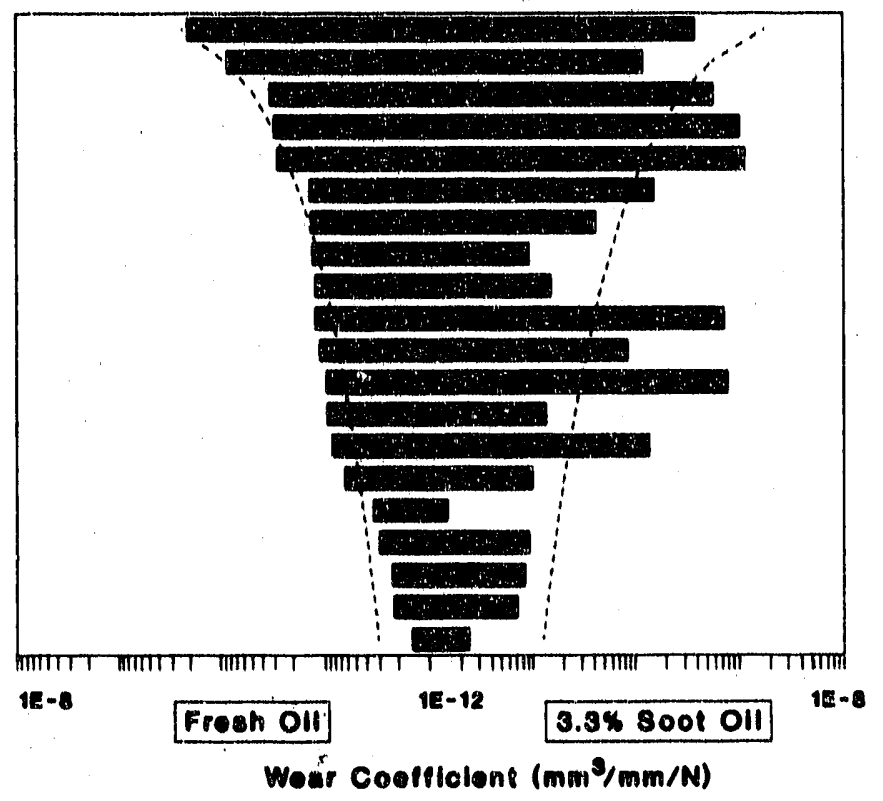

Figure 126. Coating wear coefficients measured for fresh and $3.3 \%$ soot engine-tested oll at $200^{\circ} \mathrm{C}$. 


\section{COATING WEAR: LUBRICATED AND DRY $200^{\circ} \mathrm{C}$ \\ Pearlitio Grey Iron LIner}

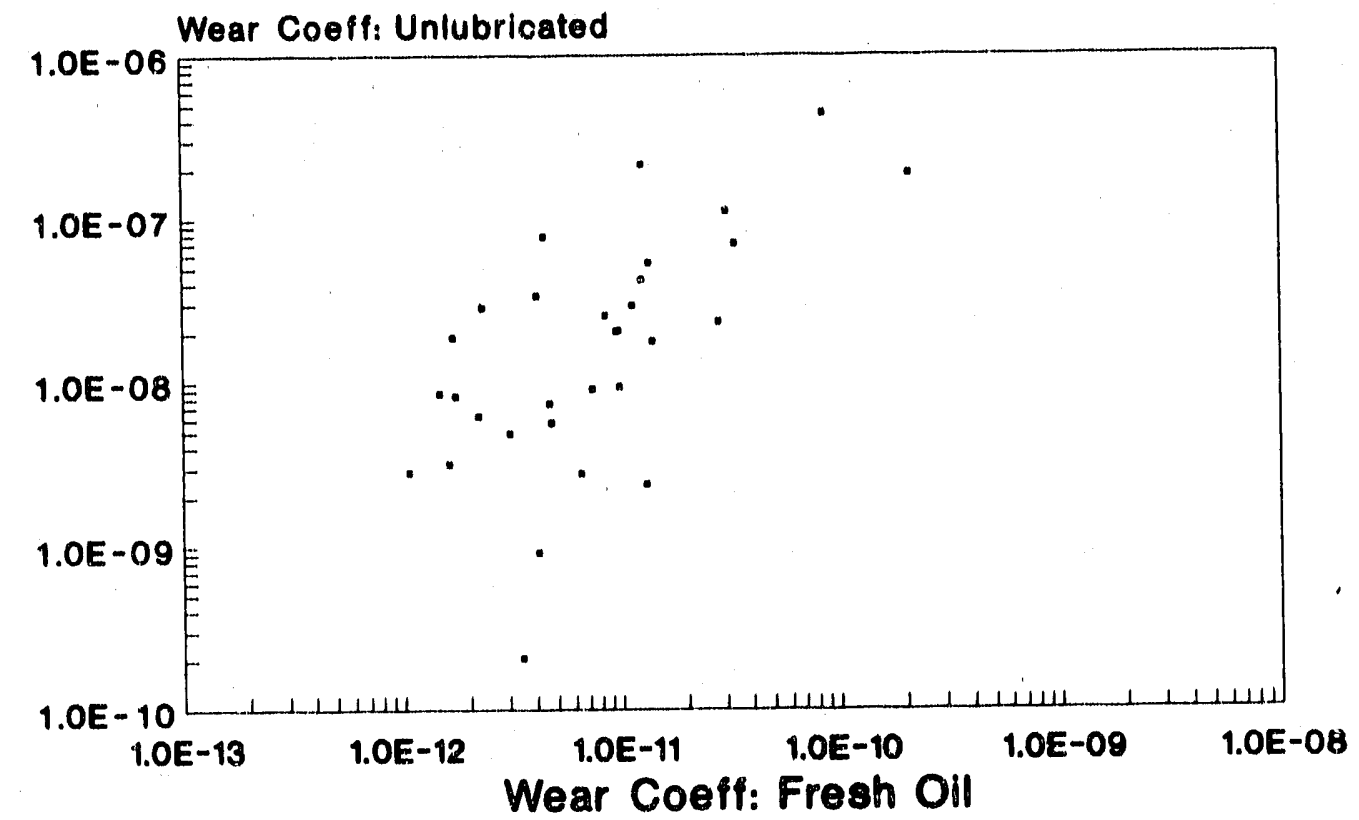

Figure 127. Coating wear without lubricant plotted against coating wear with fresh oll at $200^{\circ} \mathrm{C}$. 


\section{COATING WEAR - LUBRICATED AND DRY $200^{\circ} \mathrm{C}$ \\ Pearlitic Grey Iron Liner}

\section{Ring Coating}

Boride Diffusion

APS ZTY

LTAVD Ta2N

HVOF NICrBSI

APS Armacor $M$

APS MO-MOO2 APS $\mathrm{Cr}$

APS A1203-26\% ZrO2 APS Cr203-50\%Al2O3

APS Tribolite APS MO-Ni APS Armacor T APS Cr203-33\%Stell APS Al2O3-41\% ZrOP APS $\mathrm{Cr} 203$ (BIRL) HVOF WC-CO (TMT) LPPS Ferrotic CS40 HVOF $\mathrm{Cr} 3 \mathrm{C} 2-20 \% \mathrm{NiCr}$ LTAVD CrN

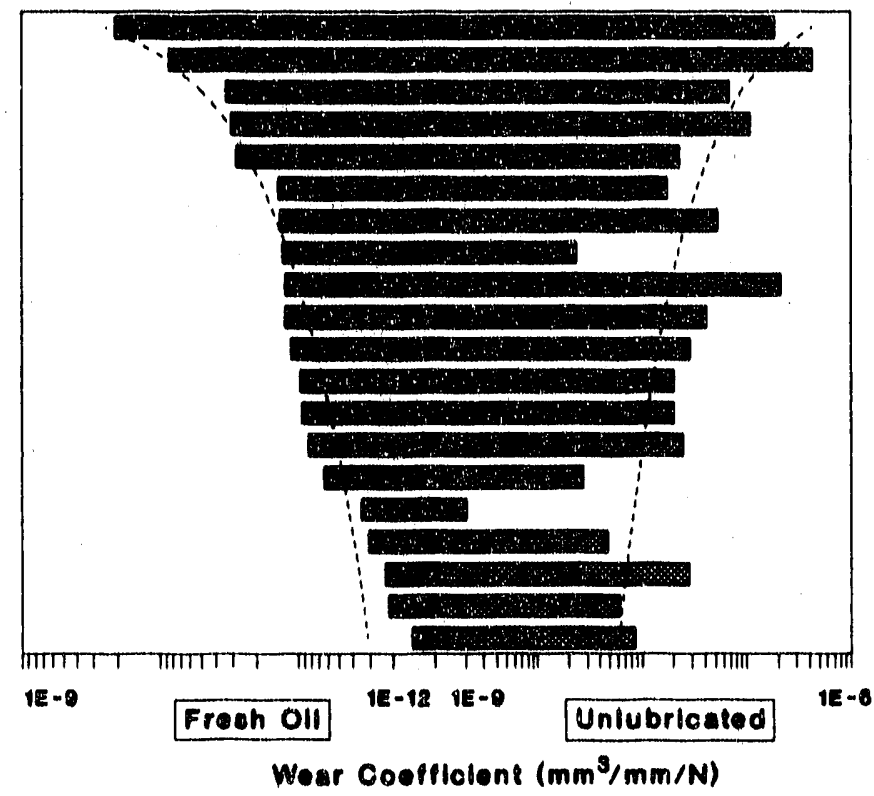

Figure 128. Coating wear coefficients measured for lubricated and unlubricated wear tests at $200{ }^{\circ} \mathrm{C}$. 


\section{CONCLUSIONS}

The tribological properties of a variety of advanced coating materlals have been evaluated under conditions which simulate the piston ring - cylinder liner environment near top ring reversal in a heavy duty diesel engine. Coated "ring" samples were tested against a conventlonal pearlitic grey cast Iron liner material using a high temperature reclprocating wear iest rig.

Emphasis was placed on the variables of greatest interest for diesel engine piston ring coatings: lubricated wear rates as a function of temperature, the effects of lubricant contamination and degradation in diesel environments and scuff resistance. For each coating, tests were conducted at 200 and $350^{\circ} \mathrm{C}$ with a fresh CE/SF 15 W40 lubricant, and at $200^{\circ} \mathrm{C}$ with a high-s0ot, engine-tested oll. Materials were also evaluated with no lubrication (at $200^{\circ} \mathrm{C}$ ), in order to rank the silding wear properties of different materials under "scuffing" conditions. A material with good scuff resistance is desirable in case of temporary loss of oil film in the engine (on start-up or under short duration conditions of extreme hot running, for example).

In this program, advanced plston ring coating - cylinder liner tribological systems have been developed. The best materials combination identfiled (HVOF $\mathrm{Cr}_{3} \mathrm{C}_{2}-20 \% \mathrm{NiCr}$ sliding against $\mathrm{H} 13$ tool steel) showed lower boundary lubricated ring and liner wear coefficients at $350^{\circ} \mathrm{C}$ than the conventional electroplated hard chromium - pearitic grey cast iron system gave at $200^{\circ} \mathrm{C}$. In addition, many ceramic and cermet coatings displayed greater tolerance to lubricant soot loading and oll degradation than the conventional materials, and also provided improved anti-scuff (unlubricated) propertles. Thus, a significant improvement in wear control technology for future, advanced diesel engines has been demonstrated.

For lowest coating wear under boundary lubricated conditions, the most promising candidates were high velocity oxy-fuel (HVOF) $\mathrm{Cr}_{3} \mathrm{C}_{2}-20 \% \mathrm{NICr}$ and WC - $12 \%$ Co cermets, low temperature arc vapor deposited (LTAVD) CrN and plasma sprayed chromlum oxides and $\mathrm{Al}_{2} \mathrm{O}_{3}-\mathrm{ZrO}_{2}$ materials. These materials generally showed lower wear than electroplated hard chromium or thermally sprayed metallic coatings. the latter two materials were also found to give excellent wear resistance in unlubricated tests and at extremely high temperatures $\left(450^{\circ} \mathrm{C}\right)$ with a synthetic oil. The LTAVD CrN coating provided the lowest lubricated wear rates of all the materials evaluated, but may be too thin $(4 \mu \mathrm{m})$ for use as a top ring facing

The effects of microstructure on wear were investigated for several systems, including plasma sprayed chromium oxides and tungsten carbide - cobalt coatings. For chromium oxides, wear rates increased with increasing porosity and inter-splat microcracking, with a factor of approximately four difference between the best and worst materials in fresh oll lubricated tests. For WC - 12\% Co materials, wear rates appeared to increase with increasing degree of carbide solutionizing, varying by a factor of nine from best to worst materials with fresh oil. Thus, it is important to optimize the powder and spray process in order to obtain the lowest possible coating wear.

For lubricated tests against pearlitic grey cast iron, ring coating and cylinder liner wear rates were a strong function of temperature, typically increasing by almost an order of magnitude between 200 and $350^{\circ} \mathrm{C}$. The relative ranking of coating materials was broadly similar at both temperatures. In contrast to the behaviour with cast iron liners, a chromium oxide ring vs silica-chromia-alumina liner wear couple was found to display almost no temperature sensittity. From examination of wear surfaces, it is speculated that cast iron cylinder liner materials may undergo corrosive wear (etching and pitting), giving rise to abrasive surface films and wear debris which in turn cause wear of the coating. In a series of liner optimization tests, the use of an $\mathrm{H} 13$ tool steel liner resulted in decreased wear of a $\mathrm{HVOF} \mathrm{Cr}_{3} \mathrm{C}_{2}-20 \%$ $\mathrm{NiCr}$ ring counterface compared to wear with cast iron liners.

Most of the coatings evaluated showed higher wear rates with high-soot, engine-tested oll than with fresh oil, with increases of more than a factor of ten in some cases. Wide variations in the sensitivity to soot loading, oll degradation and contamination were observed, and so it is important to take these effects into account when evaluating materials. Generally, metallic materials were found to be much more sensitive to soot/oil degradation than ceramic and cermet coatings. Thus, decreased "soot sensittvity" is a significant driving force for utilizing ceramic or cermet coatings in diesel engine wear applications.

A HVOF $\mathrm{Cr}_{3} \mathrm{C}_{2}-20 \% \mathrm{NiCr}$ coating showed the best combination of low ring and liner wear. WC - Co materials, although very wear resistant, tended to produce high liner wear. Several alternative cylinder liner materials were evaluated as counterfaces for the HVOF $\mathrm{Cr}_{3} \mathrm{C}_{2}-20 \% \mathrm{NICr}$ ring coating, in order to optimize the tribological system. Overall, the best wear performance was obtained with a hardened $\mathrm{H} 13$ tool steel liner, which gave lower wear than several cast irons, and even produced lower wear of the ring coating. A silica-chromla-alumina liner coating gave very low wear, but at the expense of higher ring wear. 


\section{ACKNOWLEDGEMENTS}

This project was sponsored by the U.S. Department of Energy through the Ceramic Technology for Advanced Heat Engines (CTAHE) Project, contract No. 86X-SA581C (Project Management: Oak Ridge National Laboratory).

Coating materials were developed at several subcontractors identified in the text of the report. In addition, slurry-sprayed sillca-chromla-alumina samples were prepared at Cummins Engine Company under license from Kaman Sclences, Inc. (Boulder, CO). Several of the subcontractors are commerclal coatings vendors and, for these companies, it should be understood that all of the materials prepared for this program were produced by experimental processes, and are not necessarly representative of commerclal coatings. Nothing in this report is to be construed as an endorsement or comparison of one vendor versus another.

The contributions of the following personnel to this project are gratefully acknowiedged:

APS Materials lnc

$\begin{array}{ll}\text { Garroll Tackett } & \text { Materials Engineer } \\ \text { Doug Harris } & \text { President }\end{array}$

Northwestern University Basic Ind ustrial Besearch Laboratony (B/RL)

Andrzej Adamski

Jerome Oleksy

Boyd Machine \& Repair Company Inc.

Larry Boyd

Cummins Engine Company lnc.

Mark Fear

Tom Robinson

Roger England

Terry Underwood

Harry Miller

Duane Riggs

Tom Yonushonis

Jim Patten

Implant Sciences Corporation

Keith Hensley

Oak Ridoe National Laboratory

David Stinton

Ernie Long

Ray Johnson
President

Research Scientist

Research Scientist

Materials Technician (tribological testing)

Salaried Associate (scanning electron microscopy)

Materials Technician (X-ray diffraction)

Materials Techniclan

Chemical Technician (Kaman Science process)

Chemical Technician (Kaman Science process)

Director, Ceramics \& Tribology

Executive Director, Materials Research \& Development

Appllcations Engineer

Technical Monitor

Management Staff Member, CTAHE Project

Manager, CTAHE Project 
Turbine Metal Technology, lne
Rajan Bamola
Vice President, Research \& Development
Eugene Clark
Vice President, Technology

United Technologies Besearch Center. Engineered Coatings Group

Tom Slavin

Research Engineer

Alan Scharman

Research Engineer

Alfred Matarese

Chief, Processing Development

Richard Novak

Manager, Materlals Process Development

Vapor Technologies, Inc.

Thomas Mullan

Manager, Technical Sales

Michagl Walsh

President

Research sponsored by the U.S. Department of Energy, Assistant Secretary for Conservation and Renewable Energy, Office of Transportation Technologies, as part of the Ceramic Technology Project, Materials Development Program, under contract DE-AC05-84OA21400 with Martin Marietta Energy Systems, Inc., Work Breakdown Subelement 1.3.3.2. 


\section{REFERENOES}

1. "Goetze Piston Ring Manual", publ. Goetze AG, D.5093 Burscheid, West Germany, 1991.

2. K.G. Budinskl, "Surface Engineering for Wear Resistance", Prentice Hall, 1988.

3. H. Beyer and H.J. Neuhauser, "SEM Studies of Craoking in Thermally Sprayed Piston Ring Coatings", Technical Report K20 of Goetze AG, 5093 Bursoheid, W. Germany.

4. U. Buran, H.C. Mader and M. Morsbach, "Plasma-Sprayed Coatings for Piston Rings: State of Development and Application Potential", Technical Peport K35 of Goetze AG, 5093 Burscheld, W. Germany.

5. R. Messier, K.E. Spear, A.R. Badzlan and R. Roy, "The Quest for Dlamond Coatings", J. Metals, September 1887, 8 - 11.

6. K.E. Spear, "Dlamond - Ceramlc Coating of the Future", J. Am. Ceram. Soc. 72 [2], 171 - 191, 1989.

7. J.C. Angus, P. Koidl and S. Domitz, "Carbon Thin Films", in "Plasma Deposited Thin Films", od. J. Mort and F. Jansen, CRC Press, Boca Raton, FL, 1986, Chapter 4, pp. $89-127$.

8. H.F. Prasse, H.E. McCormlck and R.D. Anderson, "Now Developments in Piston Rings for High BMEP Engines", Proc. National Powerplant Meeting, Cleveland, $\mathrm{OH}$, Ootober 27 - 29, 1969. Society for Automotive Engineers, Warrendale, FA, 1969, Paper No. 690753.

9. H. Yoshida, K. Kusama and J. Sagawa, "Effects of Surface Treatments on PIston Ring Friction Force and Wear", Proc. SAE International Congress and Exhibition, Detroit, Mlchigan, Feb. 26 - Mar, 2, 1990. Soclety for Automotive Engineers, Warrendale, PA, 1990, Paper No. 900589.

10. D.J. Patierson, K.M. Morrison and G.B. Schwartz, "Piston and Ring Assembly Friction Studies in Cummins 903 Engine", U.S. Army Tank - Automolive Command Contract DAAE07-84-C-R134. Publ. TACOM Research, Development \& Engineering Center Technical Report No. 13475, Warren, MI, June 1989.

11. A.C. MCDonald Jr. and M.G.S. Naylor, "Wear Characteristics of Selected Oxide and Non-Oxide Ceramics", presented at the 93rd Annual Meeting of the American Ceramic Soclety, Cincinnati, $\mathrm{OH}_{1}$ April 28 - May 2, 1991.

12. D.L. Houck and W. Whisenant, "Properties of Several Molybrdenum-Bearing Thermally Sprayed Coatings", presented at the International Conference on Matallurgical Coatings, San blego, CA, April 18, 1989.

13. E.M. Levin and H.F. McMurdle, "Phase Diagrams for Ceramists, 1975 Supplement", Am. Ceram. Soc., Westerville, $\mathrm{OH}, 1975$. Figures 4377 and 4388, pp. 135 - 136.

14. Y.S. Wang, S.M. Hisu and R.G. Munro, "Ceramic Wear Maps: Alumina", Lub. Eng. 47 (1), 63 - 69.

15. K.F. Dufrane and P.A. Gaydos, "Dynamic Contact of Ceramics in Ring-Cylinder Applications", Proceedings of the U.S. Department of Energy 26th Annual Automottve Technology Development Contractor's Coordination Meeting, Dearborn, MI, October 24 - 27, 1988. Publ. SÄE P-219, pp. $145-148$.

16. F.G. Rounds, "Carbon: Cause of Diesel Engine Wear?", Proc. Automotive Engineering Congr., Detroit, Mi, Sept. 26 - 30, 1977. Society for Automotive Engineers, Warrendale, PA, 1977, Paper No. 770829.

17. P.R. Ryason, I.Y. Chan and J.T. Gllmore, "Pollshing Wear by Soot", Wear 137 (1990), 15 - 24.

18. M. Kawamura, T. Ishiguro, K. Fujita and H. Morimoto, "Deterioration of Antiwear Properties of Diesel Engine Oils During Use", Wear 123 (1988), $269-280$.

19. I. Berbezier and J.M. Martin, "The Adverse Effect of Carbon in Mill Wear with ZDDP Lubricant Additive", Tribology International 21 (2), April 1988, 80 - 96.

20. S. Corso and R. Adamo, "The Effect of Diesel Soot on Reactivity of Oll Additives and Valve Train Materla/s", Soclety for Automotive Engineer8, Warrendale, PA, 1984, Paper No. 841369.

21. M.G.S. Nayior, unpublished research, Cummins Engine Company, Inc. 


\section{BIBLLIOGAAPHY}

1. M.G.S. Naylor, "Wear Resistant Ceramlo Coatings", presented at the U.8. Department of Energy Annual Automotive Technology Development Contraotor's Coordination Meeting, Dearborn, M., Ootober 28-31, 1991.

2. M.G.S, Naylor, "Development of Wear-Res/stant Ceramic Coatings for In-Cylinder Dlesel Engine Components", presented at the 93rd Annual Meeting of the American Ceramio Soclety, Clncinnati, $\mathrm{OH}$, April 28 - May 2, 1991.

3. M.G.S. Naylor, "Wear Res/stant Ceramlo Coatings", proceedings of the U.S. Department of Energy Annual Automothe Technology Development Contractor's Coordinatlon Meeting, Dearborn, MI, October 22-25, 1990. Publ, SAE P.243, pp, 273 - 281.

4. M.G.S. Naylor, T.M. Yonushonis, T.P. Slavin and A.P. Matarese, Wear Properties of High Velocity Oxy-Fuel (HVOF) Thermal Spray Coatings for Dlesel Engine Applications", presented at ASM Materials Week'90, Detroit, MI, Ootober 8-11, 1990.

5. M.G.S. Nayler and M.P. Fear, "Dovelopment of Wear-Pesistant Ceramic Coatings for In. Cylinder Diesel Engine Components", proceedings of the U.S. Department of Energy Coatings for Advanced Heat Engines Workshop, Castine, ME, August 6-9, 1990 (in press).

6. M.G.S. Naylor and M.P. Fear, "Development of Wear-Aesistant Ceramic Coatings for Diesel Engine Components", proceedings of the U.S. Department of Energy 27th Annual Automotive Technology Development Contractor's Coordination Meeting, Dearborn, MI, October 23-26, 1989. Publ, SAE P-230, pp. 131 - 141.

7. M.G.S. Naylor and M.P. Fear, "Development of Wear-Resistant Ceramio Coatings for Advanced Diesel Engines", proceedings of the U.S. Department of Energy 26th Annual Automotlve Technology Development Contractor's Coordination Meeting, Dearborn, MI, October 24-27, 1988. Publ. SAE P-219, pp. 111 - 118.

8. M.G.S. Naytor, "Development of Advanced Dlesel Wear Coatings", proceedings of the U.S.

Department of Energy Coatings for Advanced Heat Engines Workshop, Castine, ME, July 27-30, 1987, NTIS CONF-870762, pp. IV-19 to IV-24. 


\section{INTERNAL DISTRIBUTION}

1-2. Central Research Library

3. Document Reference Section

4-5. Laboratory Records Department

6. Laboratory Records, ORNL RC

7. ORNL Patent Section

8-10. MAC Records Office

11. L.. F. Allard, Jr.

12. L. D. Armstrong

13. P. F. Becher

14. R. F. Bernal

15. T. M. Besmann

16. P. J. Blau

17. A. Bleter

18. E. E. Bloom

19. K. W. Boling

20. R. A. Bradley

21. C. R. Brinkman

22. V. R. Bullington

23. R. S. Carlsmith

24. P. T. Carison

25. G. M. Caton

26. S. J. Chang

27. R. H. Cooper, Jr.

28. S. A. David

29. J. H. DeVan

30. J. L. Ding

31. M. K. Ferber

32. F. M. Foust

33. F. Fulkerson

34. R. L. Graves

35. D. L. Greene

36. E. E. Hoffiman

37. C. R. Hubbard

38. M. A. Janney

39. M. G. Jenkins
40-44. D. R. Johnson

45. W. F. Jones

46. D. Josi in

47. R. R. Judkins

48. M. A. Karnitz

49. M. R. Kass

50. B. L. Keyes

51. H. D. Kimrey, Jr.

52. T. G. Kolltie

53. K. C. LiU

54. E. L. Long, Jr.

55. W. D. Maniy

56. R. W. McClung

57. D. J. McGuire

58. J. R. Merriman

59. B. J. Moses

60. T. A. Nolan

61. J. L. Rich

62. C. R. Richmond

63. J Robbins

64. M. L. Santella

65. A. C. Schaffhauser

66. S. Scott

67. G. M. Slaughter

68. E. J. Soderstrom

69. D. P. Stinton

70. R. W. Swindeman

71. V. J. Tennery

72. T. N. Tiegs

73. J. R. Weir, Jr.

74. B. H. West

75. F. W. Wiffen

76. S. G. Winslow

77. J. M. Wyrick

78. C. S. Yust 


\section{EXTERNAL DISTRIBUTION}

83. James H. Adair

University of Florida

Materials Science and

Engineering

317 MAE Bldg.

Gainesville, FL 32611-2066

84. Donald F. Adams

Univ'arsity of Wyoming

Mechanical Engineering Department

P. 0. Box 3295

Laramte, WY 82071

85. Jalees Ahmad

AdTech Systems Research, Inc.

1342 North Fairfield Road

Dayton, OH 45432-2698

86. Yoshio Akimune

NISSAN Motor Co. . Ltd.

Materials Research Laboratory

1 Natsushima-Cho

Yokosuka 237

JAPAN AIR MAIL

87. Mufit Akinc

Iowa State University

322 Spedding Hall

AmEs, IA 50011

88. Ilhan A. Aksay

University of Washington

Materials Science and Engineering Department, FB-10

Seattle, WA 98195

89. R. G. Alexander

BASE

26 Malvern Close

Kettering Northants NN16 AJP

UNITED KINGDON AIR MAIL

90. Richard L. Allor

Ford Motor Company

Material Systems

Reliability Department

20000 Rotunda Drive

P.0. Box 2053, Room S-2031

Dearborn, MI 48121-2053
91. Richard T. Alpaugh

U.S. Department of Energy

Advanced Propulston Division

CE-322, Forrestal Building

Washington, DC 20585

92. Joseph E. Amaral

Instron Corporation

Corporate Engineering office

100 Royale street

Canton, MA 02021

93. Edward M. Anderson

Aluminum Company of America North American Industrial Chemicals Division

P.0. Box 300

Bauxite, AR 72011

94. Norman C. Anderson

Ceradyne, Inc.

Ceramic-to-Metal Division

3169 Redh111 Avenue

Costa Mesa, CA 92626

95. Don Anson

Battelle Columbus Laboratortes

Thermal Power Systems

$505 \mathrm{King}$ Avenue

Columbus, OH 43201-2693

96. Thomas Arbanas

G.B.C. Materials Corporation

580 Monastery Drive

Latrobe, PA 15650-2698

97. Frank Armat 1s

3M Company

3M Center

Building 60-1N-01

St. Paut, MN 55144-1000

98. Everett B. Arnold

Detrott Diesel Corporation

Mechanical Systems Technology

13400 Outer Drive, West

Detrolt, MI 48239-4001

99. Rtchard M. Arons

PA Consulting Group

279 Princetorn Road

Hightstown, NJ 08550 
100. Berti1 Aronsson

Sandvik $A B$

S- 12680

Stockholm Lerkrogsvagen 19

SWEDEN AIR MAIL

101. Dennis Assanis

University of IIIInois

Department of Mechanical Engineering

1206 W. Green Street

Urbana, IL 61801

102. Will lam H. Atwell

Dow Corning Corporation

3901 South Saginaw Road

MS: 540

Midland, MI 48686-0995

103. V. S. Avva

North Carolina A\&T State University

Department of Mechanical Engineering

Greensboro, NC 27411

104. Patrick Badgley

Adiabatics, Inc.

3385 Commerce Drive

Columbus, IN 47201

105. Sunggi Baik

Pohang Institute of Science \& Technology

Department of Materials Science and Engineering

P.0. Box 125

Pohang 790-600

KOREA AIR MAIL

106. John M. Bailey

Caterpillar, Inc.

Technical Center

Building $L$

P.0. Box 1875

Peorta, IL 61656-1875

107. Bob Baker

Ceradyne, Inc.

3169 Redhill Avenue

Costa Mesa, CA 92626
108. Frank Baker

Aluminum Company of America

Alcoa Technical Center

Alcoa Center, PA 15069

109. J. G. Baldoni

GTE Laboratories Inc.

40 Sylvan Road

Waltham, MA 02254

110. Clifford P. Ballard

Allied-Signal, Inc.

Ceramics Program

P.0. Box 1021

Morristown, NJ 07962-1021

111. M. Balu

Amoco Performance Products Inc. 4500 McGinnis Ferry Road

Alpharetta, GA 30202

112. B. P. Bandyopadhyay

Toyohashi University of Technolngy

School of Production Systems

Engineering

Tempaku-Cho Toyohasht 440

JAPAN AIR MAIL

113. P. M. Barnard

Ruston Gas Turbines Limitod

Metallurgical Laboratory

P. 0. Box 1

Lincoln LN2 5DJ

ENGLAND AIR MAIL

114. Harold N. Barr

Hittman Corporation

9190 Red Branch Road

Columbia, MD 21045

115. Renald D. Bartoe

Vesuvius McDanel

510 Ninth Avenue

Box 560

Beaver Falls, PA 15010-0560

116. Donald M. Bartos

Dow Corning Corporation

Advanced Ceramics Program

Midland, MI 48686-0995 
117. David L. Baty

Babcock \& Wilcox-LRC

P.0. Box 11165

Lynchburg, VA 24506-1165

118. Donald F. Baxter, Jr. ASM International Advanced Materials and Processes Materials Park, OH 44073-0002

119. M. Brad Beardsley Caterpillar, Inc. Advanced Materials Technology Technical Center BTdg. E P.0. Box 1875

Peoria, IL 61656-1875

120. Robert Beck

Teledyne CAE

Materials Engineering/Programs

1330 Laskey Road

P.0. Box 6971

Toledo, OH 43612

121. John C. Bell

Shel1 Research Limited

Thornton Research Centre

P.0. Box 1

Chester, Chl 3SH

ENGLAND AIR MAIL

122. Albert H. Bell, III General Motors Technical Center 30200 Mound Road

Engineering Building/W3 Turbine Warren, MI 48090-9010

123. M. Bentele

Xamag, Inc.

259 Melville Avenue

Fairfield, CT 06430

124. Larry D. Bentsen

BF Goodrich Company

R\&D Center

9921 Brecksville Road

Brecksville, OH 44141

125. Joseph C. Bentz

ENTEERATEC

2525 Sandcrest Drive

Columbus, IN 47203
12:6. Louis Beregszazi

Defiance Precision Products

P.0. Drawer 428

Defiance, $\mathrm{OH} 43512$

127. Tolm Bernecki

Northwestern University

BIRL

1801 Maple Avenue

Evanston, IL 60201-3135

128. Charles F. Bersch

Institute for Defense Analyses

1801 North Beauregard Street

Alexandria, VA 22311

129. Ram Bhatt

NASA Lewis Research Center

2 '1000 Brookpark Road

Clevel and, $\mathrm{OH} 44135$

130. Deane I. Biehler

Caterpillar, Inc.

Engineering and Research Materials

Technical Center, Building E

P.O. Box 1875

Peoria, IL 61656-1875

131. John. H. Bjerklie

Consolidated Natural Gas Service Co., Inc.

Research Department

CNG Tower

Pittsburgh, PA 15222-3199

132. William D. Bjorndaht

TRW, Inc.

One Space Park

Building 01, Room 2040

Redondo Beach, CA 90278

133. Keith A. Blakely

Advanced Refractory

Technologies, Inc.

699 Hertel Avenue

Buffalo, NY 14207

134. Edward G. B1 anchard

Netzsch Inc.

112 Pickering ay

Exton, PA 19341 
135. Keith Blandford

Boride Products, Inc.

2879 Aero Park Drive

Traverse City, MI 49684

136. Bruce Boardman

Deere and Company Technical

Center

3300 River Drive

Moline, IL 61265

137. Russell Bockstedt Hoechst Celanese Corporation 150 JFK Parkway

Short Hills, NJ 07078

138. M. Boehmer

DLR German Aerospace Research Establ ishment

Postfach 906058

D-5000 Koln 90

GERMANY AIR MAIL

139. Lawrence P. Boesch

EER Systems Corp.

1593 Spring Hill Road

Vienna, VA 22182-2239

140. Donald H. Boone

Boone \& Associates

2412 Cascade Drive

Walnut Creek, CA 94598-4313

141. Tom Booth

Allied-Signal Aerospace Company

AiResearch Los Angeles

Division

2525 West 190th Street

Torrance, CA 90509-2960

142. Tibor Bornemisza

Sundstrand Power Systems

4400 Ruffin Road

San Diego, CA 92186-5757

143. J.A.M. Boulet

University of Tennessee

Department of Engineering

Science and Mechanics

310 Perkins Hall

Knoxyi??e, TH 37996=2030
144. H. Kent Bowen

Massachusetts Institute of Technology

77 Massachusetts Avenue

Room E40-434

Cambridge, MA 02139

145. Leslie J. Bowen

Materials Systems

53 Hillcrest Road

Concord, MA 01742

146. Steven C. Boyce

Air Force Office of

Scientific Research

AFOSR/NA B1dg. 410

Bolling AFB DC 20332-6448

147. Gary L. Boyd

CEC

400 Howell Avenue, No. 4

Warl and, WY 82401

148. Steve Bradley

UOP Research Center

50 East Algonquin Road

Des Plaines, IL 60017-6187

149. Michael C. Brands

Cummins Engine Company, Inc.

P.0. Box 3005

Mail Code 50179

Columbus, IN 47201

150. Raymond J. Bratton

Westinghouse Science and

Technology Center

1310 Beutah Road

Pittsburgh, PA 15235

151. John J. Brennan

United Technologies Corporation

Research Center

Silver Lane, MS: 24

East Hartford, CT 06108

152. Jeff D. Bright

Ceramatec, Inc.

2425 South 900 West

Salt Lake City, UT 84108 
153. Terrence K. Brog

Coors Ceramics Company

Corporate Development and

Technology

4545 McIntyre Street

Golden, CO 80403

154. Gunnar Broman

317 Fairlane Drive

Spartanburg, SC 29302

155. Al Brown

High-Tech Materials Alert

P.0. Box 882

Dayton, NJ 08810

156. Jesse Brown

Virginia Polytechnic Institute and State University

Center for Advanced Ceramic Materials

B1 acksburg, VA 24061-0256

157. Sherman D. Brown

University of 117 inois

Materials Science and

Engineering Department

105 South Goodwin Avenue

204 Ceramics Building

Urbana, IL 61801

158. S. L. Bruner

Ceramatec, Inc.

2425 South 900 West

Salt Lake City, UT 84119

159. Adolfo Brusaferro

Keramont Corporation

4231 South Fremont Avenue

Tucson, AZ 85714

160. W. Bryzik

U.S. Army Tank Automotive Command

R\&D Center

Propulsion Systems Division

Warren, MI 48397-5000

161. S. T. Buljan

GTE Laboratories, Inc.

40 Sylvan Road

Waltham, MA 02254
162. S. J. Burden

GTE Valenite

1711 Thunderbird

Troy, MI 48084

163. Curt V. Burkland

AMERCOM, Inc.

8928 Fullbright Avenue

Chatsworth, CA 91311

164. Bill Bustamante

AMERCOM, Inc.

8928 Fullbright Street

Chatsworth, CA 91311

165. Oral Buyukozturk

Massachusetts Institute of Technology

77 Massachusetts Avenue

Room 1-280

Cambridge, MA 02139

166. David A. Caillet

Ethyi Corporation

251 Florida Street

Baton Rouge, LA 70801

167. Frederick J. Calnan

Heany Industries, Inc.

249 Briarwood Lane

P.0. Box 38

Scottsville, NY 14546

168. Roger Cannon

Rutgers University

Ceramics Department

P.0. Box 909

Piscataway, NJ 08855-0909

169. Scott Cannon

P.0. Box 567254

Atlanta, GA 30356

170. Harry W. Carpenter

19945 Acre Street

Northridge, CA 91324

171. David Carruthers

Kyocera Industrial Ceramics Company

P.0. Box 2279

Vancouver, WA 98668-2279 
172. Calvin H. Carter, Jr. Cree Research, Inc. 2810 Meridian Parkway Durham, NC 27713

173. J. David Casey 35 Atlant is Street West Roxbury, MA 02132

174. Jere G. Castor J. C. Enterprise 5078 North 83rd Street Scottsdale, AZ 85250

175. James D. Cawley Case Western Reserve University Materials Science and Engineering Department Clevel and, $\mathrm{OH} 44106$

176. Thomas C. Chadwick Den-Mat Corporation P.O. Box 1729

Santa Maria, CA 93456

177. Ronald H. Chand Chand Kare Technical Ceramics 2 Coppage Drive Worcester, MA 01603

178. Robert E. Chaney EG\&G Idaho, Inc.

Idaho National Engineering Laboratory

P.0. Box 1625

Idaho Falls, ID 83415-3525

179. Frank C. Chang

U.S. Army Materials Technology Laboratory AMTL-EMM

405 Arsenal Street Watertown, MA 02172

180. Robert M. Chapman

Allied-Signal Aerospace Company

1530 Wilson Boulevard, 10th Floor

Arlington, VA 22209
181. William Chapman

Williams International Corporation 2280 West Maple Road Walled Lake, MI 48390-0200

182. Charlie Chen LECO Corporation P.0. BoX 211688 Augusta, GA 30917

183. Albert A. Chesnes U.S. Department of Energy Transportation Technologies CE-30, Forrestal Building, 6B-094 Washington, DC 20585

184. Kaiyin Chia Carborundum Company P.0. Box 832 Niagara Falls, NY 14302

185. Frank Childs EG\&G Idaho, Inc. Idaho National Engineering Laboratory

P.0. Box 1625

Idaho Falls, ID 83415-3527

186. William J. Chmura Torrington Company 59 Field Street Torrington, CT 06790-4942

187. Tsu-Hei Chou University of Delaware Center for Composite Materials 201 Spencer Laboratory Newark, DE 19716

188. R. J. Christopher Ricardo Consulting Engineers Bridge Works Shoreham-By-Sea Hest Sussex BN43 5FG ENGLAND AIR MAIL

189. Joel P. Clark Massachusetts Institute of Technology Room 8-409

Cambridge, MA 02139 
190. Giorgio Clarotti

Commission of the European Communities

DGXII-C3, MO75, 1-53;

200 Rue de la Loi

B-1049 Brussels

BELGIUM AIR MAIL

191. H. J. Clegg

ICI Advanced Materials

P.0. Box 11

The Heath, Runcorn Cheshire

WA7 4QE

ENGLAND

AIR MAIL

192. Joseph Clevel and

GTE Products Corporation

Hawes Street

Towanda, PA 18848-0504

193. Gloria M. Collins

ASTM

1916 Race Street

Philadelphia, PA 19103

194. William C. Connors

Sundstrand Aviation Operations

Materials Science and

Engineering Department

4747 Harrison Avenue

P.0. Box 7002

Rockford, IL 61125-7002

195. John A. Coppola

Carborundum Company

P.0. Box 156

Niagara Falls, NY 14302

196. Normand D. Corbin

Norton Compan's

Advanced Ceramics

Goddard Road

Northboro, MA 01532-1545

197. Douglas Corey

Allied-Signal Aerospace

Company

2525 West 190th Street

MS:T52

Torrance, CA 90504-6099
198. Keith P. Costello

Chand/Kare Technical Ceramics

2 Coppage Drive

Worcester, MA 01603-1252

199. Ed L. Courtright

Pacific Northwest

Laboratory

MS : K3-59

Richland, WA 99352

200. Anna Cox

Mitchell Market Reports

P.0. Box 23

Monmouth Gwent NP5 4YG

UNITED KINGDOM AIR MAIL

201. Thomas Coyle

Unocal Corporation

Unocal Science \&echnology Division

376 South Valencia Avenue

Brea, CA 92621

202. Art Cozens

Instron Corporation

3414 Snowden Avenue

Long Beach, CA 90808

203. Robert C. Craft

American Ceramic Society, Inc.

757 Brooksedge Plaza Drive Hesterville, $\mathrm{OH} 43081$

204. Mark Crawford

New Technology Week

4604 Monterey Drive

Annandale, VA 22003

205. Richard A. Cree

Markets Products, Inc.

P.0. Box 14328

Columbus, OH 43214-0328

206. Les Crittenden

Yesuvius McDane 1

Box 560

Beaver Falls, PA 15010 
207. William J. Croft

U.S. Army Materials

Technology Laboratory

405 Arsenal Street

Watertown, MA 02172

208. M. J. Cronin

Mechanical Technology, Inc.

968 Albany-Shaker Road

Latham, NY 12110

209. Gary M. Crosbie

Ford Motor Company

1430 Culver Avenue

S-2079, SRL Building

Dearborn, MI 48121-4036

210. Floyd W. Crouse, Jr.

U.S. Department of Energy

Morgantown Energy

Technology Center

Collins Ferry Road

P.0. Box 880

Morgantown, WV 26505

211. John Cuccio

Allied-Signal Aerospace Company

Garrett Auxilliary Power Division

P.0. Box 5227, MS: 130? ?Q

Phoenix, AZ 85010

212. Raymond Cutler

Ceramatec, Inc.

2425 South 900 West

Salt Lake City, UT 84119

213. Charles D'Angelo

GTE Laboratories, Inc.

40 Sylvan Road

Waltham, MA 02154

214. Stephen C. Danforth

Rutgers University

Ceramic Engineering Department

P.0. Box 909

Piscataway, NJ 08855-0909
215. Sankar Das Gupta

Electrofuel Manufacturing Co., Ltd.

9 Hanna Avenue

Toronto Ontario MGK-1W8

CANADA AIR MAIL

216. Charles Davis

Sverdrup Technology, Inc., MSFC

620 Discovery Drive

Huntsville, AL 35806

217. Frank Davis

Allied Signal Aerospace Co.

7550 Lucerne Dr., \# 203

Middleburg Heights, $\mathrm{OH} 44130$

218. Robert F. Davis

North Carolina State University

Materials Engineering Department

229 Riddick Laboratory

P.0. Box 7907

Raleigh, NC 27695

219. Thomas DeAngelis

Carborundum Company

Niagara Falls R\&D Center

P.0. Box 832

Niagara Falls, NY 14302

220. George DeBell

Ford Motor Company

Material Systems Reliability

Department

20000 Rotunda Drive

P.0. Box 2053, Room S-2023

Dearborn, MI 48121-2053

221. Michael Deluca

AMP-AKZO

West Lane

Aquebogue, NY 11931

222. Gerald L. DePoorter

Colorado School of Mines

Metallurgical and Materials

Engineering Department

Golden, CO 80401 
223. J. F. DeRidder

Omni Electro Motive, Inc., 12 Seely Hill Road

Newfield, NY 14867

224. Nick C. Dellow

Materials Technology

Publications

40 Sotheron Road

Watford Herts WD1 2QA

UNITED KINGDOM AIR MAIL

225. L. R. Dharani

University of Missouri-Rolla

224 M.E.

Rolla, MO 65401

226. Douglas A. Dickerson

Union Carbide Specialty

Powders

1555 Main Street

Indianapol is, IN 46224

227. John Dodsworth

Vesuvius Research \&

Development

Technical Ceramics Group

Box 560

Beaver Falls, PA 15010

228. B. Dogan

Institut fur Werkstofforschung

GKSS-Forschungszentrum

Geesthacht GmbH

Max-Planck-Strasse

D-2054 Geesthacht

GERMANY AIR MAIL

229. Jean-Marie Drapier

FN Moteurs S.A.

Material and Processing

B-4041 Milmort (Herstal)

BELGIUM AIR MAIL

230. Kenneth C. Dreitlein

United Technologies

Research Center

Silver Lane

East Hartford, CT 06108
231. Robin A.L. Drew

McGill University

Department of Mining and Metallurgical Engineering 3450 University Street Montreal Quebec H3A 2A7 CANADA AIR MAIL

232. Hinston H. Duckworth

BCL

Columbus Division

505 King Avenue

Columbus, OH 43201-2693

233. Edmund M. Dunn

Texel Company

6 Third Street

Lexington, MA 02173

234. Bill Durako

Sundstrand Aviation Operations

Department 789-6

4747 Harrison Avenue

P.0. Box 7002

Rockford, IL 61125-7002

235. Ernest J. Duwell

212 Elm Street

Hudson, WI 54016

236. Chuck J. Dziedzic

Coors Ceramics Company

Structural Products Group

17750 West 32nd Avenue

Golden, CO 80401

237. Robert J. Eagan

Sandia Mational Laboratories

Engineered Materials \& Processes Center

Org 1700

P.0. Box 5800

Albuquerque, NM 87185-5800

238. Jeffrey Eagleson

Lanxide Corporation

1001 Connect icut Avenue, N.W. Washington, DC 20036 
239. Harry E. Eaton

United Technologies Corporation

Research Center

Silver Lane

East Hartford, CT 06108

240. Harvil1 C. Eaton

Louistana State

University

nffice of Research and Economic Development

240 Thomas Boyd Hall

Baton Rouge, LA 70803

241. Christopher A. Ebel

Carborundum Company

Technology Division

P.0. Box 337

Niagara Falls, NY 14302

242. J. J. Eberhardt

U.S. Department of Energy

Office of Transportation

Materials

CE-34, Forrestal Building

Washington, DC 20585

243. Jim Edler

Eaton Corporation

26201 Northwestern

Highway

P.0. Box 766

Southfield, MI 48037

244. William A. Ellingson

Argonne National Laboratory

Materials Science \& Technology

Division

9700 South Cass Avenue

Argonne, IL 60439

245. William S. Ellis

Machined Ceramics

629 N. Graham St.

N. Industrial Park

Bowling Green, KY 42101

246. Glen B. Engle

Nuclear \& Aerospace Materials

Corporation

16716 Martincoit Road

Poway, CA 92064
247. Jeff Epstein

Ceramic Technologies, Inc.

2107 Jamara Lane

Houston, TX 77077

248. Kenneth A. Epstein

Dow Chemical U.S.A.

Ceramics and Advanced

Materials

800 Butlding

Midland, MI 48667

249. Art Erdemir

Argonne National Laboratory

Materials and Components

Technology Division

9700 South Cass Avenue

Argonne, IL 60439

250. E. M. Erwin

Lubrizol Corporation

1819 East 225th Street

Euclid, $\mathrm{OH} 44117$

251. Kenji Esaki

Toyota Technical Center

U.S.A., Inc.

2000 Town Center, Suite 500

Southfield, MI 48075

252. Jose L. Escalante

Anglo-Mex-Tech. Inc.

3923 N.W. 24th Street

Miami, FL 33142

253. John N. Eust is

U.S. Department of Energy

Industrial Energy Efficiency

Division

CE-221, Forrestal Building

Washington, DC 20585

254. Robert C. Evans

NASA Lewis Research Center

Terrestrial Propulsion Office

21000 Brookpark Road, MS : 86-6

Clevel and, $\mathrm{OH} 44135$

255. W. L. Everitt

Kyocera International, Inc.

8611 Balboa Avenue

San Diego, CA 92123 
256. Gordon Q. Evison 332 South Michigan Avenue Suite 1730 Chicago, IL 60604

257. John W. Fairbanks U.S. Department of Energy Advanced Propulsion Division CE-322, Forrestal Building Washington, DC 20585

258. Tim Fawcett

Dow Chemical Company

Central Research, Advanced Ceramics Laboratory 1776 Butlding

Midland, MI 48674

259. Robert W. Fawley Sundstrand Power Systems Division of Sundstrand Corparation 4400 Ruffin Road P.0. Box 85757

San Diego, CA 92186-5757

260. John J. Fedorchak GTE Products Corporation Hawes Street Towanda, PA 18848-0504

261. Jeff T. Fenton Vista Chemical Company 900 Threadneedle Houston, TX 77079

262. Larry Ferre11

Babcock \& Wilcox

0ld Forest Road Lynchburg, VA 24505

263. Raymond R. Fessler BIRL Industrial Research Lab 1801 Maple Avenue Evanston, IL 60201

264. Michelle Finch

E. I. DuPont de Nemours \& Company, Inc. Experimental Station Information Center E302/301 Wilmington, DE 19898
265. Arthur D. Fine

United Technologies Corporation Pratt \& Whitney Aircraft 400 Main Street

MS: $163-10$

East Hartford, CT 06108

266. Ross F. Firestone

Ross Firestone Company

188 Mary Street

Winnetka, IL 60093-1520

267. Sharon L. Fletcher

Arthur D. Little, Inc.

15 Acorn Park

Cambridge, MA 02140-2390

268. Thomas F. Foltz

Textron Specialty Materials

2 Industrial Avenue

Lowe11, MA 01851

269. Renee G. Ford

Materials and Processing Report

P.0. Box 72

Harrison, NY 10528

270. John Formica

Supermaterials

2020 Lakeside Avenue

Cleveland, $\mathrm{OH} 44114$

271. Jennifer M. Fox

Dyson Refractories Limited

RED Laboratory

Owler Bar

Sheffield S17 3BJ

UNITED KINGDOM AIR MAIL

272. Edwin Frame

Southwest Research Institute

Division 2

P.0. Drawer 28510

San Antonio, TX 78284

273. Armanet Francois

French Scientific Mission 4101 Reservoir Road, N.W. Washington DC 20007-2176

274. R. G. Frank

Technology Assessment Group 10793 Bentley Pass Lane Lovel and, $\mathrm{OH} 45140$ 
275. David J. Franus

Forecast International

22 Commerce Road

Newtown, CT 06470

276. Marc R. Freedman

NASA Lewis Research Center

21000 Brookpark Road

MS : 49-3

Clevel and, $\mathrm{OH} 44135$

277. Douglas Freitag

LTV Missiles Division

P.0. Box 650003

MS:WT - 21

Dallas, TX 75265

278. Brian R.T. Frost

Argonne National Laboratory

9700 South Cass Avenue

Building 900

Argonne, IL 60439

279. Lawrence R. Frost

Instron Corporation

100 Royall Street

Canton, MA 02021

280. George A. Fryburg

Norton/TRW Ceramics

7A.4 Raymond Avenue

Salem, NH 03079

281. Xiren Fu

Shanghai Institute of Ceramics

Chinese Academy of Sciences

1295 Ding-xi Road

Shanghai 200050

CHINA AIR MAIL

282. John Gahimer

P.0. Box 1302

Dublin, $\mathrm{OH} 43017$

283. J. P. Gallagher

University of Dayton Research Institute

300 College Park, JPC-250

Dayton, $\mathrm{OH}$ 45469-0120
284. Tom Garritano

University of Tennessee

Science Alliance

101 South College

Knoxville, TN 37996-1328

285. Joy A. Garwood

Norton Company

Advanced Ceramics

Goddard Road

Northboro, MA 01532-1545

286. H. Maury Gatewood

Reynolds Metals Company Corporate R\&D

Fourth and Canal streets

P.0. Box 27003

Richmond, VA 23261

287. L. J. Gauckler

ETH-Zurich

Sonneggstrasse 5

CH-8092 Zurich 8092

SWITZERLAND

AIR MAIL

288. Peter A. Gaydos

Battelle Columbus Laboratories

505 King Avenue

Columbus, OH 43201

289. George E. Gazza

U.S. Army Materials Technology Laboratory Ceramics Research Division 405 Arsenal Street Watertown, MA 02172-0001

290. D. Gerster

CEA-DCON

33 Rue De La Federation Paris 75015

FRANCE AIR MAIL

291. John Ghinazzi

Coors Technical Ceramics Company

1100 Commerce Park Drive

Oak Ridge, TN 37830 
292. Robert Giddings

General Electric Company

Research Laboratory

P.0. Box 8

Schenectady, NY 12301

293. A. M. Glaeser

University of Californta

Materials Science and Mineral

Engineering

Lawrence Berkeley Laboratory

Hearst Mining Building

Berkeley, CA 94720

294. Paul Glance

Concept Analysis

R\&D

950 Stephenson Highway

Dupont Automotive Development Butlding

Troy, MI 48007-7013

295. Joseph W. Glatz

$N=y a l$ Air Propulsion Center

Systems Engineering Division

P.0. Box 7176, PE24

Trenton, NJ 08528

296. W. M. Goldberger

Superior Graphite Company

R\&D

2175 East Broad Street

Columbus, $\mathrm{OH} 43209$

297. Allan E. Goldman

U.S. Graphite, Inc.

907 West Outer Drive

Oak Ridge, TN 37830

298. Stephen T. Gonczy

Allied Signal Research

P.0. Box 5016

Des Plaines, IL 60017

299. Jeffrey M. Gonzales

GTE Products Corporation

Hawes Street

Towanda, PA 18848-0504

300. Robert J. Gottschall

U.S. Department of Energy

ER-131, MS:G-236

Washington, DC 20545
301. Earl Graham

Cleveland State University

Department of Chemical Engineering

Euclid Avenue at East 24th Street

Cleveland, $\mathrm{OH} \$ 4115$

302. William A. Graham Lanxide Corporation

P.0. Box 6077

Newark, DE 19714-6077

303. Robert E. Green, Jr. Johns Hopkins University

Matertals Science and Engineering Department Baltimore, MD 21218

304. Lance Groseclose

General Motors Corporation

Allison Gas Turbine Division

P.0. Box 420, MS:W-5

Indianapolis, IN 46206

305. Mark F. Gruninger

Union Carbide Corporation

Specialty Powder Business

1555 Main Street

Ind tanapolis, IN 46224

306. Ernst Gugel

Cremer Forschunysinstitut GmbH\&CO.KG

Oeslauer Strasse 35

D-8633 Roedental 8633

GERMANY

AIR MAIL

307. Donald L. Guile

Corning Glass Works

SP-DV-1-9

Corning, NY 14831

308. Bimleshwar P. Gupta

Solar Energy Research Institute

Mechanical and Industrial Technology Division

1617 Cole Boulevard

Golden, CO 80401 
309. John P. Gyekenyesi

NASA Lewis Research Center 21000 Brookpark Road, MS:6-1

Cleveland, $\mathrm{OH} 44135$

310. Nabil S. Hakim

Detroft Diesel Corporation

13400 West Outer Drive

Detroit, MI 48239

311. Philip J. Haley

General Motors Corporation

Vehicular Engineering

P.0. Box 420, MS:T12A

Indianapolis, IN 46236

312. Judith Hall

Fiber Materials, Inc.

Biddeford Industrial Park

5 Morin Street

Biddeford, ME 04005

313. Y. Harada

IIT Research Institute

Nometallic Materials and Composites

10 West 35th Street

Chicago, IL 60616

314. R. A. Harmon

25 Schalren Drive

Latham, NY 12110

315. Amy Harmon-Barrett

Mart in Marietta Laboratories

1450 South Rolling Road

Baltimore, MD 21227

316. Norman H. Harris

Hughes Aircraft Company

P.0. Box 800520

Saugus, CA 91380-0520

317. Alan Hart

Dow Chemical Company

Advanced Ceramics Laboratory

1776 Building

Midl and, MI 48674
318. Pat E. Hart

Battelle Pacific Northwest Laboratortes

Ceramics and Polymers Development Section

P.O. Box 999

Richland, WA 99352

319. Stephen D. Hartline

Norton Company

Advanced Ceramics

Goddard Road

Northboro, MA 01532-1545

320. Michael H. Haselkorn

Caterpillar, Inc.

Engineering Research Materials

Technical Center, Butlding $E$

P.0. Box 1875

Peoria, IL 61656-1875

321. N. B. Havewala

Corning, Inc.

SP..PR-11

Corning, NY 14831

322. John Haygarth

Teledyne WAA Chang Albany

P.0. Box 460

Albany, OR 97321

323. Norman L. Hecht

University of Dayton Research Institute

300 College Park

Dayton, OH 45469-0172

324. Peter W. Heitman

General Motors Corporation

Allison Gas Turbine Division

P.O. Box 420, MS:W-5

Indianapolis, IN 46206-0420

325. Robert W. Hendricks

Virginia Polytechnic Institute and State University

Materials Engineering Department

210 Holden Hall

B1 acksburg, VA 24061-0237 
326. Wynne Henley Hertel Cutting Technologies, Inc. 1000 Cilearview Court

Oak Ridge, TN 37830

327. Thomas L. Henson

GTE Products Corporation

Chemical \& Metallurgical

Division

Hawes Street

Towanda, PA 18848

328. Thomas P. Herbell

NASA Lewis Research Center

21000 Brookpark Road

MS : 49 - 3

Cleveland, $\mathrm{OH} 44135$

329. Marlene Heroux

Rolls-Royce, Inc.

2849 Paces Ferry Road

Suite 450

Atlanta, GA 30339-3769

330. Robert L. Hershey

Science Management Corporation

1255 New Hampshire Ave., N.W.

Suite 1033

Washington, DC 20036

331. Hendrik Heystek

Bureau of Mines

Tuscaloosa Research Center

P.0. Box L

University, AL 35486

332. Wallace C. Higgins

Norwal Uni imited

P.0. Box 1258

Alfred, NY 14802

333. Robert V. Hillery

GE Aircraft Engtnes

One Neumann Way, M.D. H85

Cincinnati, $\mathrm{OH} 45215$

334. Arthur Hindman

Instron Corporation

100 Royall Street

Canton, MA 02021

335. Jon Hines

757 Brooksedge Plaza Drive

Westerville, OH 43081-6136

336. Hans Erich Hintermann

CSEM

Matertals and Micromechanics Diviston

Rue Breguet 2

Neuchatel 2000

SWITZERLAND

AIR MAIL

337. Shinichi Hirano

Mazda R\&D of North America, Inc.

1203 Woodridge Avenue

Ann Arbor, MI 48105

338. Tommy Hiraoka

NGK Locke, Inc.

1000 Town Center

Southfield, MI 48075

339. John M. Hobday

U.S. Department of Energy

Morgantown Energy Technology Center

Collins Ferry Road

P.0. Box 880

Morgantown, WV 26507

340. Greg Hoenes

Vista Chemical Company

900 Threadneedle

P.O. Box 19029

Houston, TX 77079-2990

341. Clarence Hoenig

Lawrence Livermore National Laboratory

P.0. Box 808, Matl Code L-369

Livermore, CA 94550

342. Thomas Hollstein

Fraunhofer-Inst itut fur Werkst of fmechan ik IWM Wohlerstrabe 11 D-7800 Freiburg GERMANY AIR MAIL 
343. Richard Holt

National Research Council of Canada

Structures and Materials Laboratory

Ottawa Ontario KIA OR6

CANADA AIR MAIL

344. Joseph Homeny

University of Illinais

Department of Materials Science and Engineering

105 South Goodwin Avenue

Ceramics Building

Urbana, IL 61801

345. A. T. Hopper

Battelle Columbus Laboratories

Metals and Ceramics Department 505 King Avenue

Columbus, $\mathrm{OH}$ 43201-2693

346. Michael Horgan

Materials Engineering Magazine 1100 Superior Avenue

Cleveland, OH 44114

347. Woodie Howe

Coors Technical Ceramics Company

1100 Commerce Park Drive

Oak Ridge, TN 37830

348. Stephen M. Hsu

National Institute of

Standards and Technology

Gaithersburg, MD 20899

349. Hann S. Huang

Argonne National Laboratory

9700 South Cass Avenue

Argonne, IL 60439-4815

350. Gene Huber

Precision Ferrites \& Ceramics

5576 Corporate Drive

Cypress, CA 90630

351. M. L. Huckabee

GTE Laboratories, Inc.

40 Sylvan Road

Wal tham, MA 02254
352. Harold A. Huckins

Princeton Advanced Technology, Inc.

56 Finley Road

Princeton, NJ 08540

353. Fred R. Huettic

Advanced Magnetics, Inc.

45 Corey Lane

Mendham, NJ 07945

354. Bi11 Huffman

Zircar

110 North Main Street

Florida, NY 10921

355. Brian K. Humphrey

Lubrizol Petroleum

Chemicals Co.

3000 Town Center, Suite 1340

Southfield, MI 48075-1201

356. Robert M. Humrick

Dylon Ceramic Technologies

3100 Edgehil1 Road

Clevel and Heights, $\mathrm{OH} 44118$

357. Lorretta Inglehart

National Science Foundation

Division of Materials Research

1800 "G" Street, N.W.,

Room 408

Washington, DC 20550

358. Michael S. Inoue

Kyocera International, Inc.

KII Library

8611 Balboa Avenue

San Diego, CA 92123-1580

359. Osama Jadaan

University of WisconsinPlattevilie

General Engineering Division

1 University Plaza

Platteville, WI 53818

360. Curtis A. Johnson

General Electric Company

Corporate R\&D

Room MB-187

P.0. Box 8

Schenectady, NY 12301 
361. Sylvia Johnson

SRI International

333 Ravenswood Avenue

Menlo Park, CA 94025

362. Thomas A. Johnson Lanxide Corporation

1300 Marrows Road

P.0. Box 6077

Newark, DE 19714-6077

363. W. S. Johnson

Indiana University

One City Centre, Suite 200

Bloomington, IN 47405

364. Jill E. Jonkouski

U.S. Department of Energy

9800 South Cass Avenue

Argonne, IL 60439-4899

365. L. A. Joo

Great Lakes Research Corporation

P.0. Box 1031

Elizabethton, TN 37643

366. A. D. Joseph

SPX Corporation

700 Terrace Point

Muskegon, MI 49443

367. Adam Jostsons

Australian Nuclear Science \& Technology Organization

Lucas Heigh is Research Laboratories

New Illawarra Road

Lucas Heights New South Wales

AUSTRALIA AIR MAIL

368. Matthew K. 'dneau

Ethyl Corporation

451 Florida Street

Baton Rouge, LA 70801

369. Hartmut Kainer

Didier-Herke AG

Anlagentechnik Wiesbaden

Abraham-Lincoln-Str. 16

D-62 Wiesbaden

GERMANY AIR MAIL
370. Tom Kalamasz

Norton/TRW Ceramics

7A-4 Raymond Avenue

Salem, NH 03079

371. Lyle R. Kal ienbach

Phillips Petroleum Company

RED

Mai1 Drop:123AL

Bartlesville, OK 74004

372. Nick Kamiya

Kyocera Industrial Ceramics Corporation

2700 River Road

Des Plaines, IL 60018

373. Roy Kamo

Adiabatics, Inc.

3385 Commerce Park Drive

Columbus, IN 47201

374. S. Kang

GTE Laboratories, Inc.

40 Sylvan Road

Waltham, MA 02254

375. Chih-Chun Kao

Industrial Technology Research Institute

Mat:erials Research Laboratories

195 Chung-Hsing Road, Sec. 4 Chuttung Hsinchu 31015 R.O.C.

TAIWAN AIR MAIL

376. Keith R. Karasek

Allifed-Signal, Inc.

Engineered Materials Research Center

50 East Algonquin Road

P.0. B. 5016

Des: Plaines, IL 60017-5016

377. Robert E. Kasse1

Ceradyne, Inc.

3169 Redhill Avenue

Costa Mesa, CA 92626

378. All Ian Katz

Mright Laboratory

Meta's and Ceramics Division

WL/MLLM

Wright-Patterson AFB, OH 45433 
379. R. Nathan Katz

Worcester Polytechnic Institute

Dept. of Mechanical

Engineering

100 Institute Road

Worcester, MA 01609

380. Ted Kawaguchi

Tokai Carbon America, Inc.

375 Park Avenue, Suite 3802

New York, NY 10152

381. Noritsugu Kawashima

TOSHIBA Corporation

Mechanical Engineering Laboratory

4-1 Ukishima-Cho

Kawasaki-Ku Kawasaki 210

JAPAN AIR MAIL

382. Lisa Kempfer

Penton Publishing

Materials Engineering

1100 Superior Avenuse

Clevel and, $\mathrm{OH}$ 44114-2543

383. Frederick L. Kennard, III

General Motors Corporation

AC Rochester

Department 32-24, EB

1300 North Dort Highway

Flint, MI 48556

384. David 0. Kennedy

Lester B. Knight Cast

Metals Inc.

549 West Randolph Street

Chicago, IL 60661

385. George Keros

Photon Physics

3175 Penobscot Building

Detroit, MI 48225

386. Pramod K. Khandelwal

General Motors Corporation

Allison Gas Turbine Division

P.0. Box 420, MS: W05

Indianapolis, IN 46206
387. Jim R. Krokite11

Allied-S Ingien 1 Aerospace Company

Garrett Auxiliary Power Division

P.0. Box 5227

Phoenix, AZ 85010

388. Han J. Kim

GTE Laboratories, Inc.

40 Sylvan Road

Waltham, MA 02254

389. Shin Kim

Korea Institute of Machinery

\& Metals

66 Sangnam-dong, Changwon

Kyungnam 641-010

KOREA AIR MAIL

390. W. C. King

Mack Truck, Z-41

1999 Pennsylvania Avenue

Hagerstown, MD 21740

391. Carol Kirkpatrick

MSE, Inc.

CDIF Technical Library

P.0. Box 3767

Butte, MT 59702

392. Tony Kirn

Caterpillar, Inc.

Defense Products Department, JB7

Peoria, IL 61629

393. James D. Kiser

MASA Lewis Research Center

21000 Brookpark Road, MS:49-3

Clevel and, $\mathrm{OH} 44135$

394. Max Klein

Gas Research Institute

Thermodynamics

8600 West Bryn Mawr Avenue

Chicago, IL 60631

395. Richard N. Kleiner

Coors Ceramics Company

4545 McIntyre Street

Golden, Co 80403 
396. Stanley J. Klima

NASA Lewis Research Center

21000 Brookpark Road

MS:6-1

Cleveland, OH 44135

397. Chris E. Knapp

Norton Advanced Ceramics of Canada Ltd.

8001 Daly Street

Niagara Falls, Ontario L2G 6S2

CANADA AIR MAIL

398. Albert S. Kobayashi

University of Washington

Mechanical Engineering

Department

MS:FU10

Seattle, WA 98195

399. Shigeki Kobayashi

Toyota Central Research Labs, Inc.

Nagakute Aichi 480-11

JAPAN AIR MAIL

400. Richard A. Kole

Z-Tech Corporation

8 Dow Road

Bow, NH 03304

401. E. Kostiner

University of Connecticut

Chemistry Department, U-60

Storrs, CT 06269-3060

402. Kenneth A. Kovaly

Technical Insights, Inc.

P. 0. Box 1304

Fort Lee, NJ 07024-9967

403. Ralph G. Kraft

Spraying Systems Company

North Avenue at Schmale Road

Wheaton, IL 60189-7900

404. Saunders B. Kramer

U.S. Department of Energy

Advanced Propulsion Division

CE-322, Forrestal Building

Washington, DC 20585
405. Arthur Kranish

Trends Publishing, Inc.

1079 National Press Building

Washington, DC 20045

406. A. S. Krieger

Radiation Science, Inc.

P.0. Box 293

Belmont, MA 02178

407. Pieter Krijgsman

Ceramic Design International Holding B.V.

P.0. Box 68

Hattem 8050-AB

THE NETHERLANDS

AIR MAIL

408. Waltraud M. Kriven

University of Illinois

Materials Science and

Engineering Department

105 South Goodwin Avenue

Urbana, IL 61801

409. Edward J. Kubel, Jr.

ASM International Advanced Materials \& Processes

Materials Park, OH 44073

410. Dave Kupperman

Argonne National Laboratory

9700 South Cass Avenue

Argonne, IL 60439

411. Oh-Hun Kwon

Norton Company

Advanced Ceramics

Goddard Road

Northboro, 01532-1545

412. W. J. Lackey

Georgia Institute of Technology

Materials Science and

Technology

Atlanta, GA 30332

413. Jai Lala

Tenmat Ltd.

40 Somers Road

Rugby Warwickshire CV22 7DH

ENGLAND AIR MAIL 
414. Hari S. Lamba

General Motors Corporation

Electro-Motive Division

9301 West 55th Street

LaGrange, IL 60525

415. Richard L. Landingham

Lawrence Livermore National Laboratory

Ceramics, Corrosion, and Thermochemistry

P.0. Box 808, L-369

Livermore, CA 94550

416. Charles J. Landry

Chand Kare Technical Ceramics

712 Flat Hill Road

Lumenburg, MA 01462

417. Manfred W. Langer

Volkswagen AG

Material Technology

3180 Wolfsburg 1

GERMANY AIR MAIL

418. James Lankford

Southwest Research Institute

Department of Materials

Sciences

6220 Culebra Road

San Antonio, TX 78228-0510

419. Stantey B. Lasday

Business News Publishing Co.

Manor Oak One

1910 Cochran Road, Suite 630

Pittsburgh, PA 15220

420. Mark S. Laser

Solar Turbines, Inc.

2211 Erie Street

San Diego, CA 92110

421. S. K. Lau

Carborundum Company

Technology Division

P.0. Box 832, B-100

Niagara Falls, NY 14302

422. Edward A. Lauder

Advanced Composite Materials Cornoration

1525 South Buncombe Road

Greer, SC 29651-9208
423. J. Lawrence Lauderdale

Babcock \& Wilcox

Contract Research Division

1850 "K" Street, Suite 950

Washington, DC 20006

424. Harry A. Lawler

Carborundum Company

Technology Division

P.0. Box 832

Niagara Falls, NY 14302

425. Jean F. LeCostaouec

Textron Speciality Materials

2 Industrial Avenue

Lowe 11, MA 01851

426. Benson P. Lee

Interscience, Inc.

9718 Lake Shore Boulevard

Clevel and, $\mathrm{OH} 44108$

427. Burtrand I. Lee

Clemson University

Department of Ceranic Engineering

01 in $\mathrm{Hall}$

Clemson, SC 29634-0907

428. June-Gunn Lee

KIST

Structural Ceramic Lab

P.0. Box 131, Cheong-Ryang

Seout 130-650

KOREA AIR MAIL

429. Ran-Rong Lee

Ceramics Process Systems

Corporation

155 Fortune Boulevard

Milford, MA 01757

430. Stan Levine

NASA Lewis Research Center

21000 Brookpark Road

MS: 49-3

Cleveland, $\mathrm{OH} 44135$

431. Alan V. Levy

Lawrence Berkeley Laboratory

One Cyclotron Road, MS:62-203

Berke? Ey. CA 94720 
432. Ai-Kang $L i$

Materials Research

Laboratories, ITRI

195-5 Chung-Hsing Road, Sec. 4

Chutung Hsinchu 31015 R.O.C.

TAIWAN AIR MAIL

433. Winston W. Liang

Hong Kong Industrial

Technology Centre Co. Ltd.

78 Tat Chee Avenue

4/F, HKPC Building

Howloon

HONG KONG AIR MAIL

434. Robert Licht

Norton Company

Advanced Ceramics

Goddard Road

Northboro, MA 01532-1545

435. E. Lilley

Norton Company

Advanced Ceramics

Goddard Road

Northboro, MA 01532-1545

436. Laura J. Lindberg

Allied-Signal Aerospace Company

Garrett Fluid Systems Division 1300 West Warner

MS: 93-901-1207-4TT

P.0. Box 22200

Tempe, AZ 85284-2200

437. Leonard C. Lindgren

General Motors Corporation

Allison Gas Turbine Division

P.0. Box 420, Speed Code:T-20A

Indianapolis, IN 46206-0420

438. Hans A. Lindner

Cremer Forschungsinstitut GmbH\&CO.KG

Oeslaver Strasse 35

D-8633 Rodenta1 8866

GERMANY AIR MAIL
439. Ronald E. Loehman

Sandia National Laboratories Chemistry \& Ceramics

Department 1840

P.0. Box 5800

Albuquerque, NM 87185

440. Jeffrey C. Logas

Winona State University

Composite Materials Engineering

115 Pasteur Hall

Winona, MN 55987

441. Bill Long

Babcock \& Wilcox

P.0. Box 11165

Lynchburg, VA 24506

442. William D. Long

Wacker Chemicals (USA), Inc.

ESK Engineered Ceramics

50 Locust Avenue

New Canaan, CT 06840

443. L. A. Lott

EG\&G Idaho, Inc.

Idaho National Engineering Laboratory

P.0. Box 1625

Idaho Falls, ID 83415-2209

444. Raouf 0 . Loutfy

MER Corporation

7960 South Kolb Road

Tucson, AZ 85706

445. Gordon R. Love

Aluminum Company of America

Alcoa Technical Center

Alcoa Center, PA 15069

446. Lydia Luckevich

Ortech International

2395 Speakman Drive

Mississauga Ontario L5K $1 B 3$

CANADA

AIR MAIL 
447. James W. MacBeth

Carborundum Company

Structural Ceramics Division

P.0. Box 1054

Niagdaralls, NY 14302

448. H. Macharen

General Electric Company

Thomson Laboratory, Materials

Engineering 36807

1000 Western Avenue

Lynn, MA 01910

449. George Maczura

Aluminum Company of America

Industrial Chemicals Division

670 One Allegheny Square

Pittsburgh, PA 15212

450. David Maginnis

Tinker AFB

OC-ALC/LIIRE

Tinker AFB OK 73145-5989

451. Frank Maginnis

Aspen Research, Inc.

220 Industrial Boulevard

Moore, OK 73160

452. Tai-il Mah

Universal Energy Systems, Inc.

Ceramics and Composites

Research

4401 Dayton-Xenia Road

Dayton, OH 45432

453. Kenneth M. Maillar

Barbour Stockwell Company

83 Linskey Way

Cambridge, MA 02142

454. Lorenzo Majno

Instron Corporation

100 Royall Street

Canton, MA 02021

455. S. G. Malghan

National Institute of Standards and Technology

I-270 \& Clopper Road

Gaithersburg, MD 20899
456. Lars Malmrup

United Turbine AB

Box 13027

Malmo S-200 44

SWEDEN AIR MAIL

457. John Mangels

Ceradyne, Inc.

3169 Redhill Avenue

Costa Mesa, CA 92626

458. Russe11 V. Mann

Matec Appilied Sciences, Inc.

75 South Street

Hopkinton, MA 01748

459. William R. Manning

Champion Aviation Products

Division

01d Norris Road

P.0. Box 686

Liberty, SC 29657

460. Ken Marnoch

Amercom, Inc.

8928 Fullbright Avenue

Chatsworth, CA 91311

461. Robert A. Marra

Aluminum Company of America

Alcoa Technical Center

Advanced Ceramics Center - E

Alcoa Center, PA 15069

462. Chauncey L. Martin

3 Company

3M Center, Building 60-1N-01

St. Paul, MN 55144

463. Stevan C. Martin

Advanced Refractory

Technologies, Inc.

699 Hertel Avenue

Buffa10, NY 14207

464. Kelly J. Mather

Williams International

Corporation

2280 West Maple Road

P.0. Box 200

Walled Lake, MI 48088 
465. James $P$. Mathers

3M Company

$3 M$ Center

Building 201-3N-06

St. Paul, MN 55144

466. Marshall Mayer

Instron Corporation

3815 Presidential Parkway, Suite 100

Atlanta, GA 30340

467. Ron Mayville

Arthur D. Little, Inc.

15-163 Acorn Park

Cambridge, MA 02140

468. F. N. Mazadarany

General Electric Company

Research Laboratory

Building K-1, Room MB-159

P.0. Box 8

Schenectady, NY 12301

469. James W. McCauley

Al fred University

NYS College of Ceramics

Binns-Merrill Hall

Alfred, NY 14802

470. Carolyn McCorinick

Allied-Signal Aerospace

Company

Garrett Auxiliary Power

Division

B1dg. 1303-206

P.0. Box 5227, MS:9317-2

Phoenix, AZ 85010

471. Louis R. Mccreight

2763 San Ramon Drive

Rancho Palos Verdes, CA 90274

472. Col in F. McDonald

McDonald Thermal Engineering

1730 Castellana Road

La Jolla, CA 92037

473. B. J. McEntire Norton Company, TRW Ceramics Goddard Road

Northboro, MA 01532-1545
474. Chuck McFadden

Coors Ceramics Company

600 9th Street

Golden, CO 80401

475. Henry McFadden

Magnetic Bearings, Inc.

Engineering Library

609 Rock Road

Radford, VA 24141

47i. Thomas D. McGee

Iowa State University

Materials Science and

Engineering Department 110 Engineering Annex

Ames, IA 50011

4/7. Carol McGill

Corning Inc.

Sullivan Park, FR-02-08

Corning, NY 14831

478. T. C. McLaren

Cameron Forged Products Company

P.O. Box 1212

Houston, TX 77251-1212

479. James McLaughl in

Sundstrand Power Systems

4400 Ruffin Road

P.0. Box 85757

San Diego, CA 92186-5757

480. Arthur F. McLean

6225 North Camino Almonte

Tucson, AZ 85718

481. Matt McMonigle

U.S. Department of Energy

Improved Energy Productivity Division

Forrestal Buflding, CE-231

Washington, DC 20585

482. Dennis McMurtry

EG\&G Idaho, Inc.

Idaho National Engineering Laboratory

P.0. Box 1625

Idaho Falls, ID 83415 
483. D. B. Meadowcroft National Power Technology and Environmental Centre Kelvin Avenue Leatherhead Surrey KT22 7SE ENGLAND

AIR MAIL

484. Jo Meglen

11004 Birdfoot Court Reston, VA 22091

485. Pankaj K. Mehrotra Kennametal, Inc. P.0. Box 639 Greensburg, PA 15601

486. Joseph J. Meindl Reynolds International, Inc. 6603 West Broad Street

P.0. Box 27002

Richmond, VA 23261-7003

487. Michael D. Meiser

Allied-Signal Aerospace Company Garrett Ceramic Components Division 19800 South Van Ness Avenue Torrance, CA 90509

488. George Messenger National Research Council of Canada

Engine Laboratory

Building M-7

Ottawa Ontario KIA OR6

CANADA AIR MAIL

489. D. Messier

U.S. Army Materials Technology Laboratory

SLCMT-EMC

405 Arsenal Street

Watertown, MA 02172-0001

490. Gary L. Messing

Pennsylvania State University

Ceramic Science and Engineering Department

119 Steidle Building

University Park, PA 16802
491. Arthur G. Metcalfe

Arthur G. Metcalfe and

Associates, Inc.

2108 East 24th Street

National City, CA 91950

492. R. Metselaar

Eindhoven University

Centre for Technical Ceramics

P.0. Box 513

Eindhoven $5600 \mathrm{MB}$

THE NETHERLANDS

AIR MAIL

493. Nancy S. Meyers

U.S. Department of Energy

Transportation Technologies

CE-30, Forrestal Building 6B-094

Washington, DC 20585

494. David J. Michael

Harbison-Walker Refractories Company

P.0. Box 98037

Pittsburgh, PA 15227

495. Ken Michaels

Chrysler Motors Corporation

Ceramtcs Development Metallurgical Processes

P.0. Box 1118, CIMS:418-17-09

Detroit, MI 48288

496. Bernd Michel

Institute of Mechanics

Fracture and Micromechanics

Department

P.0. Box 408

D-9010 Chemnitz

GERMANY AIR MAIL

497. David E. Miles

Conmission of the European Communities

rue de la Loi, 200

B-1049 Brusseis

BELGIUM AIR MAIL

498. John V. Milewski

Superkinetics, Inc.

P.0. Box 8029

Santa Fe, NM 87504 
499. Carl E. Miller

AC Rochester

1300 North Dort Highway, MS: $32-31$

Engineering Building $B$

Flint, MI 48556

500. Mike Miller

McGraw-Hill Aviation Week

Performance Materials

1156 15th Street, N.W.

Washington, DC 20005

501. Charles W. Miller, Jr.

Centorr Furnaces/Vacuum Industries

542 Amherst Street

Nashua, NH 03063

502. R. Mininni

Enichem America

2000 Cornwall Road

Monmouth Junction, NJ 08852

503. Michele V. Mitchell

Allied-Signal Aerospace Company

Garrett Ceramic Components

Division

19800 South Van Ness Avenue

Torrance, CA 90501-1149

504. Howard Mizuhara

GTE - WESGO

477 Harbor Boulevard

Belmont, CA 94002

505. Helen Moeller

Babcock \& Wilcox

P.0. Box 11165

Lynchburg, VA 24506-1165

506. Francois R. Mollard

Metalwork'ng Technology, Inc.

1450 Scalp Avenue

Johnstown, PA 15904

507. Phil Mooney

Panametrics

NDE Division

221 Crescent Street

Waltham, MA 02254
508. Thomas Morel

Ricardo North America

645 Blackhawk Drive

Westmont, IL 60559

509. Geoffrey P. Morris

3M Company

3M Traffic Control Materials Division

B1dg. 209-BW-10, 3M Center

St. Paul. MN 55144-1000

510. Jay A vorrison

Rolls-Royce, Inc.

Engineering and Information Center, Overlook 1

2849 Paces Ferry Road, Suite 450

Atlanta, GA 30339-3769

511. Joel P. Moskowitz

Ceradyne, Inc.

3169 Redhill Avenue

Costa Mesa, CA 92626

512. Brij Moudgil

University of Florida

Material Science and Engineering

Gainesville, FL 32611

513. Christoph J. Mueller

Sprechsaal Publishing Group

P.0. Box 2962, Mauer 2

D-8630 Coburg

GERMANY AIR MAIL

514. Thomas W. Mullan

Vapor Technologies Inc.

345 Route 17 South

Upper Saddle River, NJ 07458

515. M. K. Murthy

MKM Consultants International

10 Avoca Avenue, Unit 1906

Toronto Ontario M4T 2B7

CANADA AIR MAIL.

516. Solomon Musikant

TransCon Technologies, Inc.

Materials Science \& Engineering 1508 Waynesboro Road

Paoli, PA 19301 
517. David L. Mustoe

Custom Technical Ceramics

8041 West I-70 Service Road, Unit 6

Arvada, CO 80002

518. Curtis V. Nakaishi

U.S. Department of Energy

Morgantown Energy Technology Center

Collins Ferry Road

P.0. Box 880

Morgantown, WV 26507-0880

519. Yoshio Nakamura

Faicera Research Institute 2-5-8 Hiyakunin-cho Shinjuku-Ko Tokyo

JAPAN AIR MAIL

520. K. S. Narasimhan

Hoeganaes Corporation

River Road

Riverton, NJ 08077

521. Samue1 Natansohn

GTE Laboratories, Inc.

40 Sylvan Road

Wal tham, MA 02254

522. Robert Naum

Applied Resources, Inc.

P.0. Box 241

Pittsford, NY 14534

523. Malcolm Naylor

Cummins Engine Company, Inc.

P.0. Box 3005, Mail Code 50183

Columbus, IN 47202-3005

524. Jeffrey Neil

GTE Laboratories, Inc.

40 Sylvan Road

Waltham, MA 02254

525. Fred A. Nichols

Argonne National Laboratory

9700 South Cass Avenue

MCT - Butlding 212

Argonne, IL 60439
526. H. Nickel

Furschungszentrum Jüelich (KFA)

P. 0. Box 1913

Jüelich 1-5170 BRD NRW

GERMANY AIR MAIL

527. Dale E. Niesz

Rutgers University

Center for Ceramic Research

P.0. Box 909

Piscataway, NJ 08855-0909

528. David M. Nissley

United Technologies Corporation

Pratt \& Whitney Aircraft

400 Main Street, MS: 163-10

East Hartford, CT 06108

529. Richard D. Nixdorf

ReMaxCo Technologies, Inc.

11317 Snyder Road

Knoxville, TN 37932

530. Bernard North

Kennametal, Inc.

P.0. Box 639

Greensburg, PA 15601

531. Bruce E. Novich

Ceramics Process Systems Corporation

155 Fortune Boulevard

Milford, MA 01757

532. Daniel Oblas

GTE Laboratories, Inc.

40 Sylvan Road

Waltham, MA 02254

533. Don Ohanehi

Magnetic Bearings, Inc.

1908 Sussex Road

Blacksburg, VA 24060

534. Robert Orenstein

General Electric Company

55-112, River Road

Schenectady, NY 12345 
535. Norb Osborn

Aerodyne Dallas

151 Regal Row,

Suite 120

Dallas, TX 75247

536. A. M. Paddick

BP International Limited

BP Research Centre, Main Library

Chertsey Road

Sunbury-on-Thames

Middlesex TW16 7LN

UNITED KINGDON AIR MAIL

537. Russell J. Page

Kanthal-Artcor

3001 Redhill Avenue, II-109

Costa Mesa, CA 92705

538. Richard Palicka

Cercom, Inc.

1960 Watson Way

Vista, CA 92083

539. Muktesh Pal iwal

GTE Products Corporation

Hawes Street

Towanda, PA 18848

540. Joseph E. Palko

General Electric Company

55-113, River Road

Schenectady, NY 12345

541. Hayne Palmour, III

North Carolina State University

Materials Science and Engineering Dept.

Raleigh, NC 27605-7905

542. Joseph N. Panzarino

Norton Company

Advanced Ceramics

Goddard Road

Northboro, MA 01532-1545

543. Pellegrino Papa

Corning Inc.

MP-WX-02-1

Corning, NY 14831
544. E. Beth Pardue

Technology for Energy

Corporation

One Energy Center

P.0. Box 22996

Knoxvilie, TN 37933-0996

545. Soon C. Park

3M Company

3M Center

Building 142-4N-02

P.O. Box 2963

St. Paul, MN 55144

546. Hartmut Paschke

Schott Glaswerke

Christoph-Dorner-Strasse 29

D-8300 Landshut

GERMANY AIR MAIL

547. Marina R. Pascucci

GTE Laboratories, Inc.

40 Sylvan Road

Waltham, MA 02254

548. James W. Patten

Cummins Engine Company, Inc.

Materials Engineering

P.0. Box 3005, Mail Code 50183

Columbus, IN 47202-3005

549. Robert A. Penty

Eastman Kodak Company

KAD/D73 - 35612

901 Elmgrove Road

Rochester, NY 14653

550. Robert W. Pepper

Textron Specialty Materials

2 Industrial Avenue

Lowe 17, MA 01851

551. Peter Perdue

Detroit Diesel Corporation

Research Advanced Development Group

13400 West Outer Drive, Speed Code A-07

Detroit, MI 48239-4001 
552. Bruce Peters

Dow Chemical Company

Butlding 52

Midland, MI 48667

553. John J. Petrovic

Los Alamos National Laboratory

Group MST-4, MS:6771

Los Alamos, NM 87545

554. Frederick S. Pettit

University of Pittsburgh

Pittsburgh, PA 15261

555. Ben A. Phillips

Phillips Engineering Company

721 Pleasant Street

St. Joseph, MI 49085

556. Richard C. Phoenix

Ohmtek, Inc.

2160 Liberty Drive

Niagara Falls, NY 14302

557. B uce J. Pletka

Michigan Technological University

Metallurgical and Materials

Engineering Department

Houghton, MI 49931

558. John P. Pollinger

Garrett Ceramic Components

19800 Van Ness Avenue

Torrance, CA 90501

559. P. Popper

High Technology Ceramics International Journal

22 Pembroke Drive

Westl ands Newcastle-under-Lyme

Staffs ST5 2JN

ENGLAND AIR MAIL

560. F. Porz

Universitat Karlsruhe

Institut fur Keramik Im

Maschinendau

Postfach 6980

D-750i Karlsruhe

GERMANY AIR MAIL
561. Harry L. Potma

Royal Netherlands Embassy

Science and Technology

4200 Linnean Avenue, N.W.

Washington, DC 20008

562. Bob R. Powe 11

General Motors Research Laboratories

Metallurgy Department

30500 Mound Road

Box 9055

Warren, MI 48090-9055

563. Stephen C. Pred

ICD Group, Inc.

1100 Valley Brook Avenue

Lyndhurst, NJ 07071

564. Karl M. Prewo

United Technologies Research Center

All Silver Lane

MS: 24

East Hartford, CT 06108

565. Peter E. Price

Industrial Materials Technology, Inc.

P.0. Box 9565

Andover, MA 01810

566. Joseph M. Proud GTE Laboratories, Inc.

Materials Science Laboratory

40 Sylvan Road

Waltham, MA 02254

567. Vimal K. Pujari

Norton Company

Advanced Ceramics

Goddard Road

Northboro, MA 0]532-1545

568. George Quinn

National Institute of

Standards and Technology

Ceramics Division, B1dg. 223

Gaithersburg, MD 20899 
569. Ramas V. Raman

Ceracon, Inc.

1101 North Market Boulevard, Sulte 9

Sacramento, CA 95834

570. Charles F. Rapp

Owens Corning Fiberglass

2790 Columbus Road

Granville, $\mathrm{OH}$ 43023-1200

571. Dennis W. Readey

Colorado School of Mines

Department of Metallurgy and Materials Engineering Golden, CO 80401

572. Wilfred J. Reballo PAR Enterprises, Inc. 12601 Clifton Hunt Lane Clifton, VA 22024

573. Harold Rechter

Chicago Fire Brick Company R\&D

7531 South Ashland Avenue

Chicago, IL 60620

574. Robert R. Reeber

U.S. Army Research Office

P.0. Box 12211

Research Triangle Park, NC 27709

575. K. L. Reifsnider

Virginia Polytechnic institute and State University

Department of Engineering Science and Mechanics

Bl acksburg, VA 24061

576. Paul E. Rempes

McDonnel1 Douglass Missle Systems Company

P.0. Box 516, Mail Code: 1066086

St. Louis, MO 63166-0516

577. Gopal S. Revankar

John Deere Company

Metals Research

3300 River Drive

Moline, IL 61265
578. K. T. Rhee

Rutgers University

Mechanical Engineering

P.0. Box 909

Piscataway, NJ 08854

579. James Rhodes

Advanced Composite Materials Corporation

1525 South Buncombe Road

Greer, SC 29651

580. Roy W. Rice

W. R. Grace and Company

7379 Route 32

Columbia, MD 21044

581. David W. Richerson

2093 East Delmont Drive

Salt Lake City, UT 84117

582. Tomas Richter

J. H. France Refractories

$1944 \mathrm{Clarence}$ Road

Snow Shoe, PA 16874

583. Michel Rigaud

Ecole Polytechnique

Campus Universite De Montreal

P.0. Box 6079, Station A

Montrea7, P.Q quebec H3C $3 A 7$

CANADA AIR MAIL

584. R. E. Riman

Rutgers University

Ceramics Engineering Department

P.0. Box 909

Piscataway, NJ 08855-0909

585. Barry Ringstrom

Superior Graphite Company

P.0. Box 2373

Smyrna, GA 30081

586. John E. Ritter

University of Massachusetts

Mechantcal Engineering Department Amherst, MA 01003 
587. Frank L. Roberge

Allied-Signal Aerospace Company

Garrett Auxiliary Power Division

P.0. Box 5227

Phoenix, AZ 85010

588. W. Eric Roberts Advanced Ceramic Technology: Inc. 990 "F" Enterprise Street Orange, CA 92667

589. Martha Rohr U.S. Department of Energy DOE Oak Ridge Field Office Building 4500N

P.0. Box 2008, MS:6269

Oak Ridge, TN 37831-6269

590. Y. G. Roman

TNO TPD Keramick

P.O. Box 595

Einhoven 5600 AN HOLLAND AIR MAIL

591. Mark D. Roos

Carborundum Company

P.0. Box 156

Niagara Falls, NY 14302

592. Michael Rossetti

Arthur D. Little, Inc.

15 Acorn Park

Cambridge, MA 01240

593. Barry R. Rossing

Lanxide Corporation

1300 Marrows Road

Newark, DE 19714-6077

594. Steven L. Rotz Lubrizol Corporation

29400 Lakel and Boulevard

Wickliffe, OH 44092

595. Bruce Rubinger

Global Competitiveness, Inc.

One Devonshire Place,

Suite 1011

Boston, MA 02109
596. Robert Ruh

Wright Laboratory

WL/MLLM

Wright-Pattersan AFB, OH 45433

597. Robert J. Russel1

17 Highgate Road

Framingham, MA 01701

598. L. Will tam Sahley

Supermaterials Company

$24400 \mathrm{High}$ and Road

Richmond Heights, $\mathrm{OH} 44143$

599. Jon Salem

NASA Lewis Research Center

21000 Brookpark Center

Cleveland, $\mathrm{OH} 44135$

600. W. A. Sanders

NASA Lewis Research Center 21000 Brookpark Road,

MS: 49-3

Cleveland, OH 44135

601. J. Sankar

North Carolina A\&T State University

Department of Mechanical Engineering

Greensboro, NC 27411

602. Yasushi Sato

NGK Spark PIugs (U.S.A.), Inc. 1200 Business Center Drive, Suite 300

Mt. Prospect, IL 60056

603. Maxine L. Savitz

All ied-Signal Aerospace Company

Garrett Ceramic Components Division

19800 Souti, Van Ness Avenue

Torrance, CA 90501

604. Ashok Saxena

Georgia Institute of Technology

Materials Engineering

Atlanta, GA 30332-0245 
605. David W. Scanlon

Instron Corporation

100 Royall Street

Canton, MA 02021

606. Charles A. Schacht

Schacht Consulting Services

12 Holl and Road

Pittsburgh, PA 15235

607. James Schienle

Allied-Signal Aerospace Company

Garrett Auxiliary Power

Division

2739 East Washington Street

P.0. Box 5227, MS: 1302-2P

Phoenix, AZ 85010

608. John C. Schneider

San Juan Technologies

P.0. Box 49326

Colorado Springs, CO 80949-9326.

609. Gary Schnittgrund

Rocketdyne, BA05

6633 Canoga Avenue

Canoga Park, CA 91303

610. Mark Schomp

Lonza, Inc.

Corporate Headquarters

17-17 Route 208

Fair Lann, NJ 07410

611. Joop Schoonman

Delft University of Technology

Laboratory for Inorganic Chemistry

P.0. Box 5045

2600 GA Delft.

THE NETHERLANDS

AIR MAIL

612. John Schuldies

Industrial Ceramic Technology, Inc.

37 Enterprise Drive

Ann Arbor, MI 48103
613. Robert B. Schulz

U.S. Department of Energy office of Transportation Materials CE-34, Forrestal Building Washington, DC 20585

614. Murray A. Schwartz Materials Technology Consulting, Inc.

30 Orchard Way, North

Potomac, MD 20854

615. Peter Schwarzkopf

SRI International

333 Ravenswood Avenue

Menlo Park, CA 94025

616. Thomas C. Schweizer

Princeton Economic Research, Inc. 12300 Twinbrook Pkwy., Suite 650

Rockville, MD 20852

617. William T. Schwessinger

Multi-Arc Scientific Coatings

1064 Chicago Road

Troy, MI 48083-4297

618. W. D. Scott

University of Washington

Materials Science Department

Mail Stop:FB10

Seattle, WA 98195

619. Nancy Scoville

Thermo Electron Technologies

74 West Street

P.0. Box 9046

Wal tham, MA 02254-9046

620. Brian Seegmiller

Coors Ceramics Company

600 9th Street

Golden, CO 80401 
621. T. B. Selover AICRE/DIPPR 3575 Traver Road

Shaker Heights, $\mathrm{OH} 44122$

622. J. H. Selverian

GTE Laboratories, Inc. 40 Sylvan Road Waltham, MA 02254

623. Charles E. Semler Semler Materials Services 4160 Mumford Court Columbus, $\mathrm{OH} \mathbf{4 3 2 2 0}$

624. Thomas Service Service Engineering Laboratory 324 Wells Street Greenfield, MA 01301

625. Kish Seth

Ethyl Corporation

R\&D Laboratories

P.0. Box 341

Baton Rouge, LA 70821

626. Karleen Seybold

Allied-Signal Aerospace Company

Garrett Auxiliary Power Division

P.0. Box 5227

Phoenix, AZ 85010

627. William J. Shack Argonne National Laboratory 9700 South Cass Avenue Building 212

Argonne, IL 60439

628. Peter T. B. Shaffer

Technical Ceramics. Laboratories, Inc. 4045 Nine/McFarl and Drive Alpharetta, GA 30201

629. Richard K. Shaltens NASA Lewis Research Center 21000 Brookpark Road, MS: $301-2$

Clevel and, $\mathrm{OH} 44135$
630. Robert S. Shane

238 Hemlock Road

Wynnewood, PA 19096

631. Daniel Shanefield

Rutgers University

Ceramics Engineering Department

P.0. Box 909

Piscataway, NJ 08855-0909

632. Ravi Shankar

Chromalloy

Research and Technology Division

Blaisdell Road

Orangeburg, NY 10962

633. Terence Sheehan

Alpex Wheel Company

727 Berkley Street

New Milford, NJ 07646

634. Dinesh K. Shetty

University of Utah

304 EMRO, Dept. of Materials

Science and Engineering

Salt Lake City, UT $\mathbf{8 4 1 1 2}$

635. Masahide Shimizu

Ceramic Society of Jlapan

2-2-503 Takiyama 6-chome

Higashikurume-Shi Tokyo 203

JAPAN AIR MAIL

636. John Shipinski

Toyota Technical Center U.S.A., Inc.

Technical Research Department

2000 Town Center, Suite 500

Southfield, MI 48075

637. Thomas Shreves

American Ceramic Society, Inc. Library

757 Brooksedge Plaza Drive

Westerville, OH 43081-2821

638. Jack D. Sibold

Coors Ceramics Company

Contracts for Corporate Technology

4545 McIntyre Street

Golden, $\mathrm{CO} 80403$ 
639. George H. Siege1

Point North Associates, Inc.

P.0. Box 907

Madison, NJ 07940

640. Richard Silberglitt

Technology Assessment and Transfer, Inc.

133 Defense Highway, \#212

Annapolis, MD 21401

641. Mary Silverberg

Norton Company

Advanced Ceramics Library

Goddard Road

Northboro, MA 01532-1545

642. Gurpreet Singh

Department of the Navy Internal Combustion \& Gas Turbine Engine Division Code $56 \times 31$

Washington, OC 20362-5101

643. Maurice J. Sinnott

University of Michigan

Chemical and Metallurgical Engineering

5106 IST Building

Ann Arbor, MI 48109-2099

644. John Skildum

3M Company

3M Center

Building 224-2S-25

St. Paul, MN 55144

645. David P. Smith

Hoskins, Rees \& Smith

1910 Cochran Road

Manor Oak II, Suite 658

Pittsburgh, PA 15220

646. Richard H. Smoak

Smoak \& Associates

3554 Hollyslope Road

Altadena, CA $91001-3923$
647. Jay R. Smyth

Allied-Signal Aerospace

Company

Garrett Auxiliary Power

Division

2739 East Washington Street

P.0. Box 5227

MS: $93-173 / 1303-207$

Phoenix, AZ 85010

648. Edward A. Snajdr

Premier Refractories and Chemicals, Inc.

P.0. Box 392

Findlay, $\mathrm{OH} 44815$

649. Rafal A. Sobotowski

British Petroleum Company

Technical Center, Broadway

3092 Broadway Avenue

Cleveland, $\mathrm{OH} 44115$

650. A. G. Solomah

SAC International Ltd.

1445 Bonhill Road, \#13

Mississauga Ontario L5T IV3

CANADA AIR MAIL

651. S. Somiya

Nishi Tokyo University

3-7-19 Seijo, Setagaya

Tokyo 157

JAPAN AIR MAIL.

652. Boyd W. Sorenson

DuPont Lanxide Composites

1300 Marrows Road

P.0. Box 6077

Neward, DE 19707

653. Charles A. Sorrell

U.S. Department of Energy

Advanced Industrial

Concepts Division

CE-232, Forrestal

Building

Washington, DC 20585 
654. C. Spencer

EA Technology

Capenhurst Chester CH1 6ES

UNITED KINGDOM AIR MAIL

655. Allen Spizzo

Hercules, Inc.

Hercules Plaza

Wilmington, DE 19894

656. Richard M. Spriggs

Alfred University

Center for Advanced Ceramic Technology

Alfred, NY 14802

657. Charles Spuckler

NASA Lewis Research Center

21000 Brookpark Road

MS: $5-11$

Cleveland, $\mathrm{OH}$ 44135-3191

658. M. Srinivasan

Material Solutions

P.0. Box 663

Grand Island, NY 14702-0663

659. Gordon L. Starr

Cummins Engine Company, Inc.

Design \& Technology

P.0. Box 3005

Mail Code 50182

Columbus, IN 47202-3005

660. Jim Stevenson

Windrock, Incorporated

154 Fairbanks Plaza

Oak Ridge, TN 37830

661. Tom Stillwagon

Allied-Signal Aerospace Company

Garrett Ceramic Components Division

19800 South Van Ness Avenue

Torrance, CA 90501

662. Harold L. Stocker

General Motors Corporation

Allison Gas Turbine Division P.0. Box 420

Indianapolis, IN 46206
663. Paul D. Stone

Dow Chemical USA

1776 "Eye" Street, N.W., Suite 575

Washington, DC 20006

664. Roger S. Storm

Carborundum Company

Technology Division

P.0. Box 337

Niagara Falls, NY 14302-0337

665. Peter A. Stranges

4 Chittenden Lane

Owings Mills, MD 21117

666. F. W. Stringer

Aero \& Industrial

Technology Ltd.

P.0. Box 46, Wood Top

Burnley Lancashire BB11 4BX

UNITED KINGDOM AIR MAIL

667. Thomas N. Strom

NASA Lewis Research Center

21000 Brookpark Road

MS: 86- 6

Clevel and, $\mathrm{OH} 44135$

668. M. F. Stroosnijder

Institute for Advanced

Materials

Joint Research Centre

21020 Ispra (VA)

ITALY AIR MAIL

669. Karsten Styhr

30604 Ganado Drive

Rancho Palos Verdes, CA 90274

670. T. S. Sudarshan

Materials Modification, Inc.

2929-Pl Eskridge Center

Fairfax, VA 22031

671. M. J. Sundaresan

University of Miami

Mechanical Engineering

Department

P.0. Box 248294

Coral Gables, FL 33124 
672. Patrick L. Sutton

U.S. Department of Energy

Advanced Propulsion Division

CE-322, Forrestal Building

Washington, DC 20585

673. Will ard H. Sutton

United Technologies

Corporation

Research Center, MS:24

Silver Lane

East Hartford, CT 06108

674. Ron Sviben

100 Indel Avenue

Rancocas, NJ 08073

675. J. J. Swab

U.S. Army Materials Technology Laboratory

Ceramics Research Division

SLCMT - EMC

405 Arsenal Street

Watertown, MA 02172

676. Robert E. Swanson

Metalworking Technology, Inc.

1450 Scalp Avenue

Johnstown, PA 15904

677. Scott L. Swartz

Battelle Columbus

Laboratories

Metals and Ceramics

505 King Avenue

Columbus, $\mathrm{OH} 43201$

678. Steve Szaruga

Air Force Wright Aeronautical Laboratory

Materials Directorate

WL/MLBC

Wright-Patterson

$A F B, O H$ 45433-6533

679. Yo Tajima

NGK Spark Plug Company, Ltd.

NTK Technical Ceramic Division

2808 Iwasaki

Komaki-shi Aichi-ken 485

JAPAN AIR MAIL
680. Fred Teeter

5 Tralee Terrace

East Amherst, NY 14051

681. Monika 0. Ten Eyck

Carborundum Company

Technology Division

P.0. Box 832

Niagara Falls, NY 14302

682. David F. Thompson

Corning Glass Works

SP-DV-02-1

Corning, NY 14831

683. Merle L. Thorpe

Hobart Tafa Technologies, Inc.

146 Pembroke Road

Concord, NH 03301

684. Eberhard Tiefenbacher

Daimler-Benz AG Abt. FIS

Mercedes-Strabe 136

Stuttgart 60

GERMANY AIR MAIL

685. T. Y. Tien

University of Michigan

Materials Science and

Engineering Department

Dow Bullding

Ann Arbor, MI 48103

686. Julian M. Tishkoff

Air Force Office of Scientific Research

AFOSR/NA

Bolling AFB, DC 20332-6448

687. D. M. Tracey

Norton Company

Advanced Ceramics

Goddard Road

Northboro, MA 01532-1545

688. Dick Trippett

General Motors Corporation

Allison Gas Turbine Division

P.O. Box 420, MS:W-16

Indianapol is, IN 46206-0420 
689. L. J. Troste1, Jr.

Box 199

Princeton, MA 01541

690. W. T. Tucker

General Electric Company

Corporate R\&D

Building K1-4C35

P.0. Box 8

Schenectady, NY 12301

691. Masanori Ueki

Nippon Steel Corporation

Central R\&D Bureau

1618 Ida

Nakahara-Ku Kawasaki 211

JAPAN AIR MAIL

692. Filippo M. Ugolini

ATA Studio

Via Degli Scipioni, 268A

ROMA 00192

ITALY AIR MAIL

693. Donald L. Vaccari

Allison Gas Turbines

P.0. Box 420

Speed Code 549

Indianapol is, IN 46206-0420

694. Carl F. Van Conant

Boride Products, Inc.

2879 Aero Park Drive

Traverse City, MI 49684

695. Marcel H. Van De Voorde

Commission of the European Communities

Institute for Advanced Materials

Joint Research Centre

P.0. Box 2

1755 ZG Petten

THE NETHERLANDS AIR MAIL

696. 0. Van Der Biest

Katholieke Universiteit Leuven

Departement Metaalkunde en Toegepaste

de Croylaan 2

B-3030 Leuven

BELGIUM

AIR MAIL
697. Michael Vannier

Washington University, St. Louis

Mallinckrodt Institute of Radiology

510 South Kings Highway

St. Louis, MO 63110

698. Stan Venkatesan

Southern Coke \& Coal

Corporation

P.0. Box 52383

Knoxville, TN 37950

699. V. Venkateswaran

Carborundum Company

Niagara Falls R\&D Center

P.0. Box 832

Niagara Falls, NY 14302

700. Dennis Viechnicki

U.S. Army Materials Technology Laboratory

405 Arsenal Street

Watertown, MA 02172-0001

701. Ted Vojnovich

U.S. Department of Energy

Office of Energy Research, ER-42

Washington, DC 20585

702. John D. Volt

E. I. Dupont de Nemours \& Company, Inc.

P.0. Box 80262

Wilmington, DE 19880

703. John B. Wachtman

Rutgers University

Ceramics Department

P.0. Box 909

Piscataway, NJ 08855

704. Shigetaka Wada

Toyota Central Research Labs, Inc.

Nagakute Aichi 480-11

JAPAN AIR MAIL. 
705. Janet Wade

Allied-Signal Aerospace Company

Garrett Auxiliary Power Division, Department 93-772

P.O. Box 5227, MS:1303-2

Phoenix, AZ 85010

706. Richard L. Wagner

Ceramic Technologies, Inc.

537 Turt le Creek South Drive, Suite 240

Indianapolis, IN 46227

707. J. Bruce Wagner, Jr.

Arizona State University

Center for Solid State Science

Tempe, AZ 85287-1704

708. Daniel J. Wahlen

Kohler, Co.

$444 \mathrm{Highl}$ and Drive

Kohler, WI 53044

709. Ingrid Wahlgren

Royal Institute of Technology

Studsvik Library

S-611 82 Nykoping

SWEDEN AIR MAIL

710. Ron H. Walecki

Allied-Signal Aerospace Company

Garrett Ceramic Components

Division

19800 South Van Ness Avenue

Torrance, CA 90501

711. Michael S. Walsh

Vapor Technologies Inc.

2100 Central Avenue

Boulder, CO 80301

712. Chien-Min Wang

Industrial Technology Research Institute

Materials Research Laboratories

195 Chung-Hsing Road, Sec. 4 Chutung Hs inchu 31015 R.0.C.

TAIWAN

AIR MAIL
713. Robert M. Washburn

ASMT

11203 Col ima Road

Whittier, CA 90604

714. Gerald Q. Weaver

Carborundum Specialty Products

42 Linus Allain Avenue

Gardner, MA 01440-2478

715. Karen E. Weber

Detroit Diesel Corporation

Technology and Planning

13400 West Outer Drive

Detroit, MI 48239-4001

716. R. W. Weeks

Argonne National Laboratory

MCT-212

9700 South Cass Avenue

Argonne, IL 60439

717. Ludwig Weiler

ASEA Brown Boveri AG

Corporate Research

EppeTheimer Str. 82

D-6900 Heidelberg

GERMANY AIR MAIL

718. James Wessel

Dow Corning Corporation

1800 "M" Street, N.W., Suite 325 South

Washington, DC 20036

719. Robert D. West

Therm Advanced Ceramics

P.0. Box 220

Ithaca, NY 14851

720. Thomas J. Whalen

Ford Motor Company

26362 Harriet

Dearborn Heights, MI 48127

721. Ian A. White

Hoeganaes Corporation

River Road

Riverton, N.J 08077 
722. Alan Whitehead

General Electric Company

1 River Road, 55-111

Schenectady, NY 12345

723. Sheidon M. Wiederhorn National Institute of

Standards and Technology

Building 223, Room A329

Gaithersburg, MD 20899

724. John F. Wight

Alfred University

McMahon Building

Alfred, NY 14802

725. D. S. Wilkinson

McMaster University

Materials Science and

Engineering Department

1280 Main Street, West

Hamilton Ontario L8S 4L7

CANADA AIR MAIL

726. James C. Williams

General Electric Company

Engineering Materials Technology Labs

One Neumann Way

Mail Drop: $\mathrm{H85}$

Cincinnati, OH 45215-6301

727. Janette R. Williams

Kollmorgen Corporation

PCK Technology Division

150 Motor Parkway, \#262

Hauppauge, NY 11788-5108

728. Steve J. Williams

RCG Hagler Bailly, Inc.

1530 Wilson Boulevard,

Suite 900

Arlington, VA 22209-2406

729. Craig A. Willikens

Norton Company

Advanced Ceramics

Goddard Road

Northboro, MA 01532-1545
730. Roger R. Wills

TRW, Inc.

Valve Division

1455 East 185th Street

Cleveland, $\mathrm{OH} 44110$

731. David Gordon Wilson

Massachusetts Institute of Technology

Mechanical Engineering Department

77 Massachusetts Avenue, Room 3-455

Cambridge, MA 02139

732. Matthew F. Winkler

Seaworthy Systems, Inc.

P.0. Box 965

Essex, C? 06426

733. Gerhard Winter

Hermann C. Starck Berlin GmbH, Werk Goslar

P.0. Box 2540

D-3380 Goslar 3380

GERMANY AIR MAIL

734. W. L. Winterbottom

Ford Motor Company

Material Systems Reliability

Department

20000 Rotunda Drive

SRL, Room E-3182

P.0. Box 2053

Dearborn, MI 48121

735. David G. Wirth

Coors Ceramics Company

600 9th Street

Golden, CO 80401

736. Thomas J. Wissing

Eaton Corporation

Engineering \& Research Center

P.0. Box 766

Southfield, MI 48037

737. James C. Withers

MER Corporation

7960 South Kolb Road

Building $F$

Tucson, AZ 85706 
738. Dale E. Wittmer

Southern III inois University

Mechanical Engineering Department

Carbondale, IL 62901

739. Warren W. Wolf

Owens Corning Fiberglass

2790 Columbus Road, Route 16

Granville, OH 43023

740. George W. Wolter

Howmet Turhine Components

Corporation

Technical Center

699 Benston Road

Whitehal1, MI 49461

741. James C. Wood

NASA Lewis Research Center

21000 Brookpark Road

MS: 86-6

Clevel and, $\mathrm{OH} 44135$

742. Marrill Wnod

LECO Corporation

Augusta Division

P.0. Box 211688

Augusta, GA 30917-1688

743. Wayne L. Worrell

University of Pennsylvania

Department of Materials

Science and Engineering

3231 Walnut Street

Philadelphia, PA 19104

744. John F. Wosinski

Corning Inc.

ME-2 E-5 H8

Corning, NY 14830

745. Ian G. Wright

Battelle Columbus Laboratories

505 King Avenue

Columbus, $\mathrm{OH} 43201$

746. Ruth Wroe

ERDC

Metals \& Materials Industries

Division

Capenhurst Chester $\mathrm{CHI}$ 6ES

ENGLAND AIR MAIL
747. Bernard J. Wrona

Advanced Composite Materials Corporation

1525 South Buncombe Road

Greer, SC 29651

748. Carl C. M. Wu

Naval Research Laboratory

Ceramic Branch, Code 6373

Washington, DC 20375

749. John C. Wurst

University of Dayton Research Institute

300 College Park

Dayton, OH 45469-0101

750. Neil Wyant

ARCH Development Corp.

9700 South Cass Avenue

Building 202

Argonne, IL 60439

751. Roy Yamamoto

Texaco Inc.

P.0. Box 509

Beacon, NY 12508-0509

752. John Yamanis

Allied-Signal, Inc.

Ceramics Program

P.0. Box 1021

Morristown, NJ 07962-1021

753. Harry C. Yeh

Allied-Signal Aerospace Company

Garrett Ceramic Components Division

19800 South Van Ness Avenue

Torrance, CA 90509

754. Hiroshi Yokoyama

Hitachi Research Lab

$4026 \mathrm{Kuji}$-Cho

Hitachi-shi Ibaraki 319-12

JAPAN AIR MAIL

755. Thomas M. Yonushonis

Cummins Engine Company, Inc.

P.0. Box 3005

Matl Code 50183

Columbus, IN 47202-3005 
756. Thomas J. Yost Corning, Inc.

Technical Products Division, Main Plant 21-1-2

Corning, Nir 14831

757. Jong Yung

Sunds trand Aviation Operations

Department 789-6

4747 Harrison Avenue

Rockford, IL 61125

758. A. L. Zadoks Caterpillar Inc. Technical Center, Building L P.0. Box 1875

Peoria, IL 61656-1875

759. Avi Zangvil

University of Illinois

Materials Research Laboratory

104 South Goodwin Avenue

Urbana, IL 51801

760. Charles H. Zenuk

Transtech

6529 East Calle Cavalier

Tucson, AZ 85715

761. Anne Marie Zerega

U.S. Department of Energy

Office of Energy Research, ER-42

Washington, DC 20585

76\%. Ken Zillimer

Applied Test Systems, Inc.

$2571 \mathrm{Mt}$. Gallant Road

Rock Hill, SC 29730

763. Carl Zweben

General Electric Company

P.O. Box 8555, VFSC/V4019

Philadelphia, PA 19101

764. Klaus M. Zwilsky

National Research Council

National Materials

Advisory Board

2101 Constitution Avenue

Washington, DC 20418
765. Department of Energy

DOE Field Office, Oak Ridge

Assistant Manager for Energy

Research and Development

P.0. Box 2001

Oak Ridge, TN 37831-8501

766-775. Department of Energy

Office of Scientific and

Technical Information

Office of Information

Services

P.0. Box 62

Oak Ridge, TN 37831

For distribution by microfiche as shown in DOE/OSTI-4500, Distribution Category UC-332 (Ceramics/Advanced Materials). 

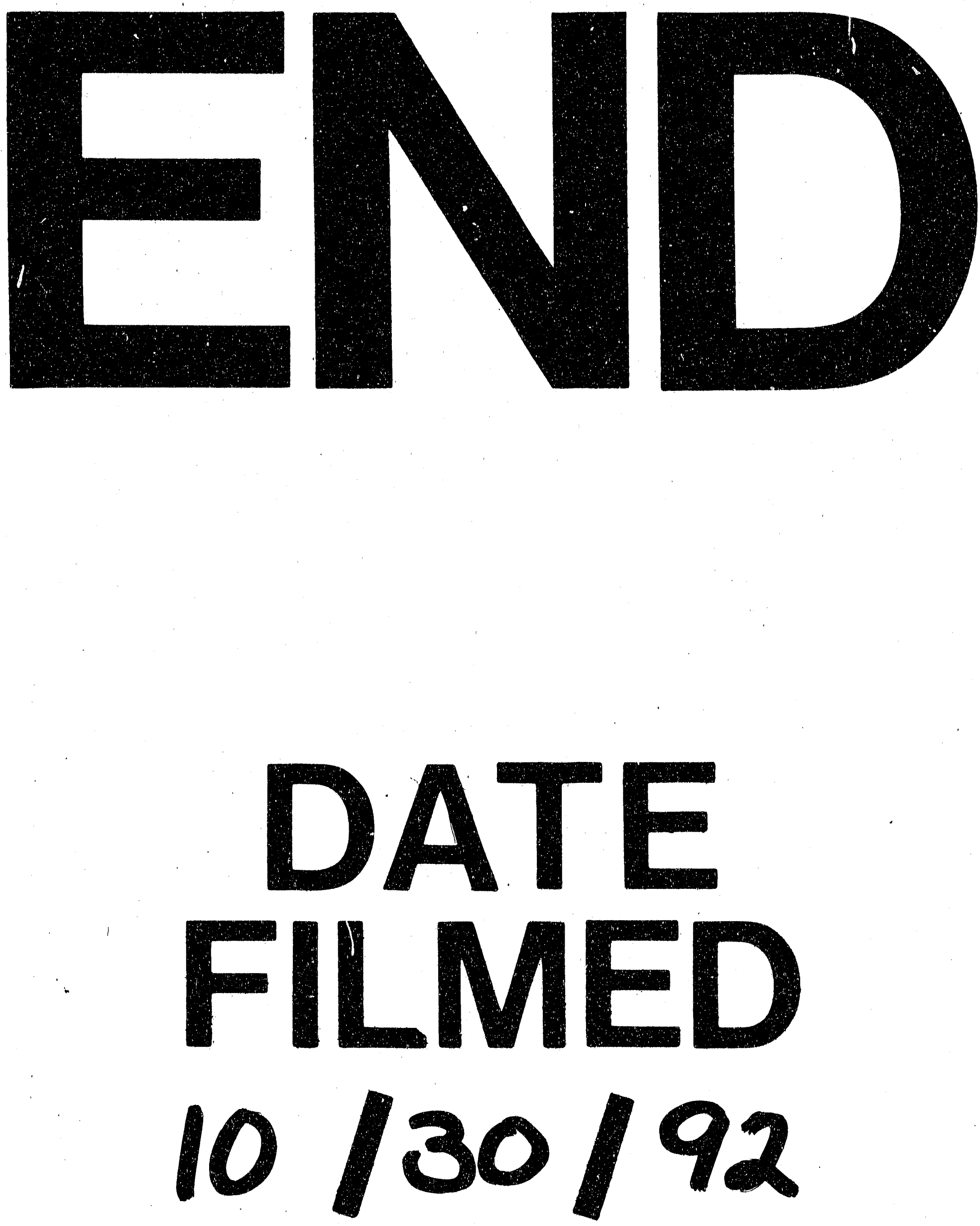


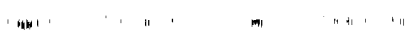

